\title{
WestVirginiaUniversity
}

THE RESEARCH REPOSITORY @ WVU

Graduate Theses, Dissertations, and Problem Reports

2007

\section{Development of a separation riser with flow pulsations for small coal particles}

Jordan M. H. Musser

West Virginia University

Follow this and additional works at: https://researchrepository.wvu.edu/etd

\section{Recommended Citation}

Musser, Jordan M. H., "Development of a separation riser with flow pulsations for small coal particles" (2007). Graduate Theses, Dissertations, and Problem Reports. 4321.

https://researchrepository.wvu.edu/etd/4321

This Thesis is protected by copyright and/or related rights. It has been brought to you by the The Research Repository @ WVU with permission from the rights-holder(s). You are free to use this Thesis in any way that is permitted by the copyright and related rights legislation that applies to your use. For other uses you must obtain permission from the rights-holder(s) directly, unless additional rights are indicated by a Creative Commons license in the record and/ or on the work itself. This Thesis has been accepted for inclusion in WVU Graduate Theses, Dissertations, and Problem Reports collection by an authorized administrator of The Research Repository @ WVU. For more information, please contact researchrepository@mail.wvu.edu. 


\title{
DEVELOPMENT OF A SEPARATION RISER WITH FLOW PULSATIONS FOR SMALL COAL PARTICLES
}

\author{
by \\ Jordan M. H. Musser \\ Thesis submitted to the College of Engineering and Mineral Resources \\ at West Virginia University \\ in partial fulfillment of the requirements \\ for the degree of \\ Master of Science \\ in \\ Mechanical Engineering
}

Approved by

Eric Johnson, PhD, Committee Chairperson

Bruce Kang, PhD

Alfred Stiller, PhD

Mechanical and Aerospace Engineering

Morgantown, West Virginia

2007

Keywords: Coal Perpetration, Fluidization, Separation Technology 


\title{
$\underline{\text { ABSTRACT }}$ \\ DEVELOPMENT OF A SEPARATION RISER WITH FLOW PULSATIONS FOR SMALL COAL PARTICLES
}

\begin{abstract}
by Jordan M. H. Musser
Removing sulfur before combustion is essential to lower the sulfur dioxide produced during combustion. Common separation processes have large obstacles including usage of large quantities of water, the need to dry the coal after separation, and additional environmental hazards created during the separation process. The current exploratory research concentrates on coal particles in the size range of $105<\mathrm{d}_{\mathrm{p}}<210$ microns. A small scale circulating fluidized bed was constructed with the addition of a gas pulsation generator. Various superficial gas velocities, $\mathrm{u}_{0}$, were used in conjunction with various rates of pulsations. The system was able to segregate dirtier coal from cleaner coal with various efficiencies for different flow conditions. The most favorable flow conditions were found to be: $1 \mathrm{~Hz}$ flow pulsations and a superficial gas velocity of $0.8581 \mathrm{~ms}^{-1}$ which reduced the mass percent sulfur of the initial sample of coal from $1.66 \%$ to $1.37 \%$.
\end{abstract}




\section{ACKNOWLEDGMENTS}

I would like to thank my committee members for all of their help in the construction of this document; Dr. Johnson, Dr. Kang and Dr. Stiller. Special thanks to Dr. Johnson for all the support and redirecting I needed along the way. Thanks to Dr. Kang for calling attention to items of interest that I would have never thought of looking into on my own. Thanks to Dr. Al Stiller for really keeping the committee on task during the oral defense and the 'story time' before my defense that loosened me up a bit.

Thanks are also in order for Dr. Frank Saus for being there with a credit card when a trip to Lowes was needed. Without Dr. Saus (and his credit card), none of the research would have been possible. Thanks to the CAST program for supplying Dr. Saus with the credit card and living stipend, for without those, I would never have accomplished as much.

I would like to thank the staff of the National Research Center for Coal and Energy (NRCCE) Analytical Chemistry Laboratory for processing what seemed like a million little bags of coal. Special thanks to Ms. Tiffany Bittle for dealing with all of my samples and questions, and still finding the time to show me how the ICP-OES works (even though I still don't understand it).

Thanks to Mr. Bryan Wimer and The Femi. Femi, you are always a good for a story, even if it has nothing to do with what is going on at the moment. Femi, don't forget that if you ever need to raise funds for your research, you can host the 'whack-a-car fund raiser' for 5 bucks and hit, and I will be first in line. Bryan, you were a great research partner to be paired with during the past two years. However, I don't think I'll ever miss pushing around carts of sand to be sifted. Thanks for all of the idea sharing and support. 
Thanks to Dr. Mary Ann Clarke for letting me run off to finish my thesis. I look forward to the research that you and I will accomplish together.

Last, but not least, I would like to thank my friends and family for all of the support that you have given me over the past two years. Without your support I would not have been able achieve anything. 


\section{TABLE OF CONTENTS}

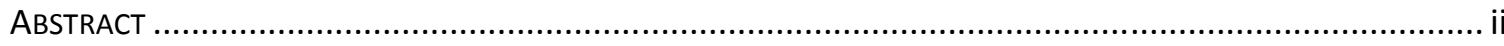

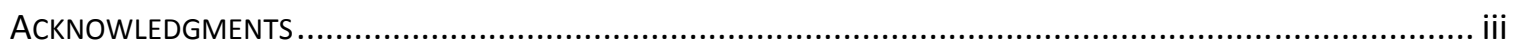

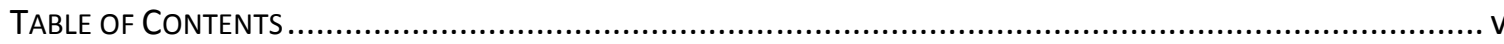

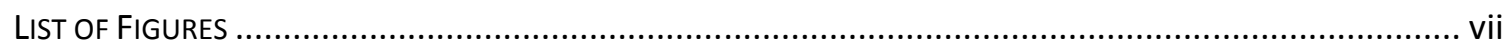

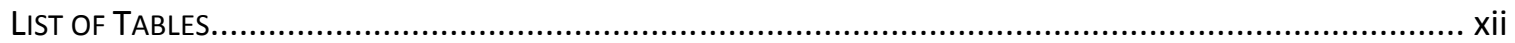

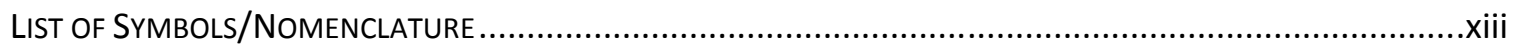

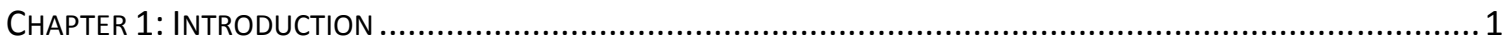

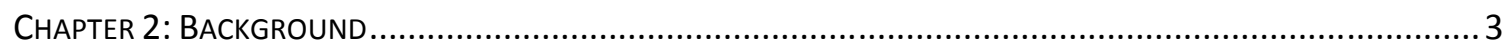

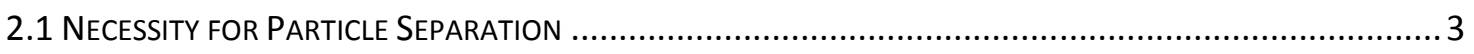

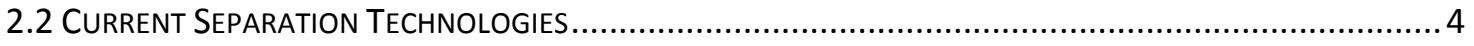

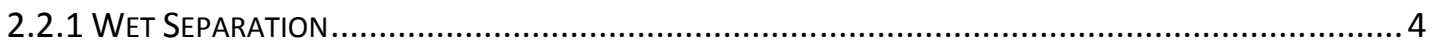

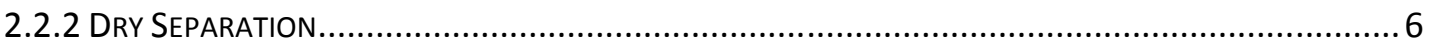

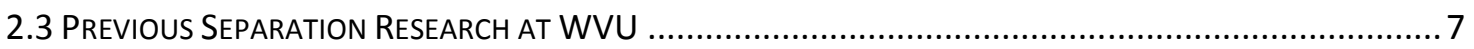

2.3.1 Separation of SMall Particles Due to Density Differences (Regester, 2004) .................... 7

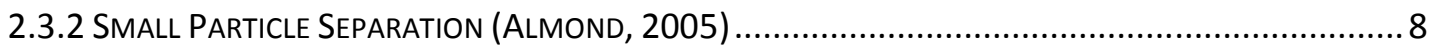

2.3.3 SePARATION Of Fine Coal Particles (AKHTAR, 2006) ..................................................... 9

2.4 DESCRIPTION OF SEPARATION IN THE RISER SYSTEM .............................................................. 9

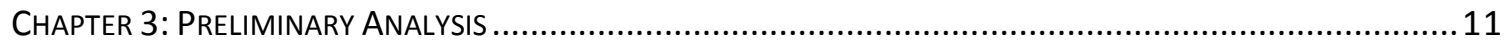

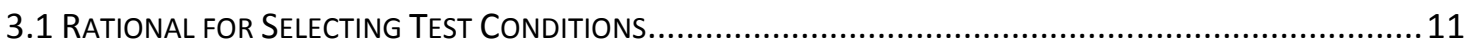

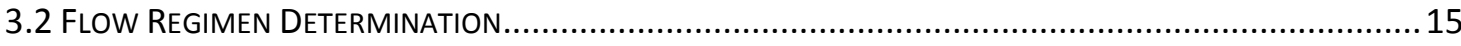

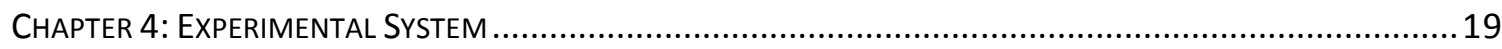

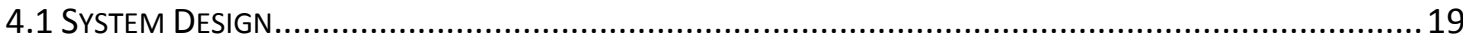

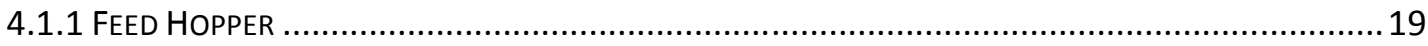

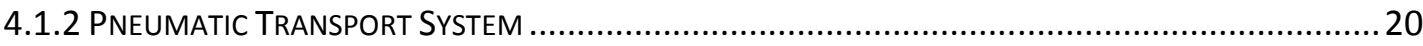

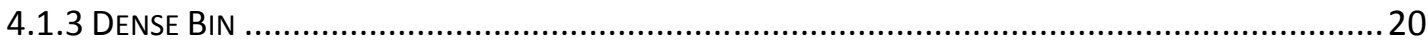

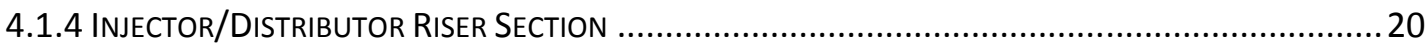

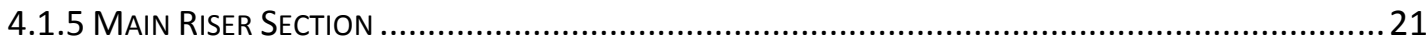

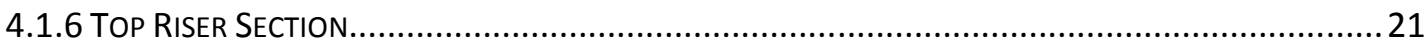

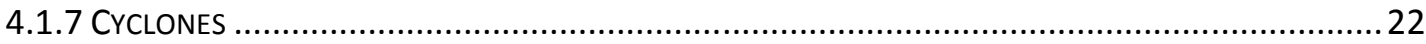

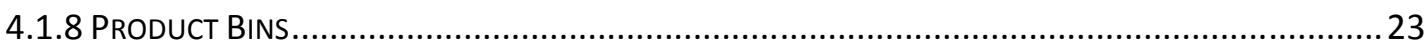

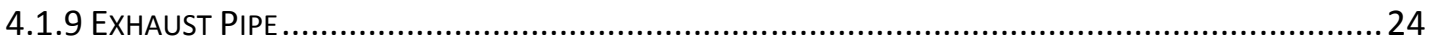

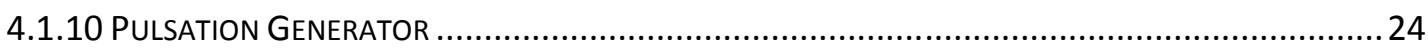

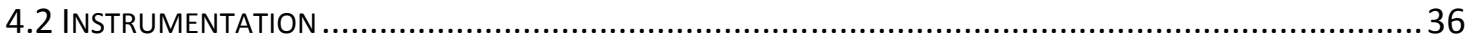

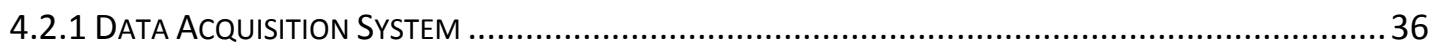

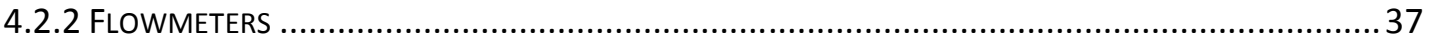

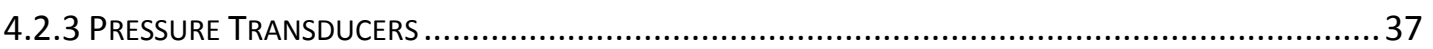

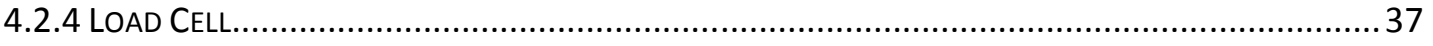

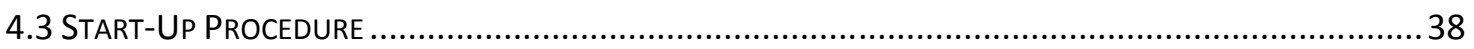

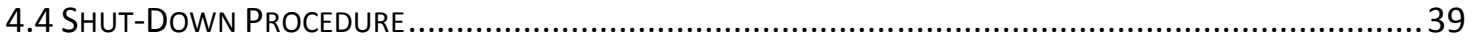

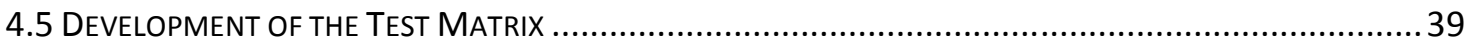




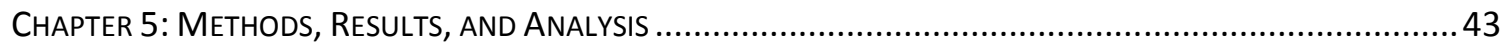

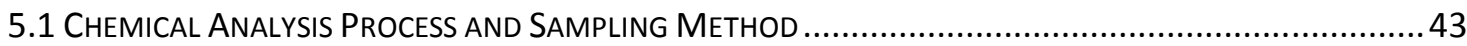

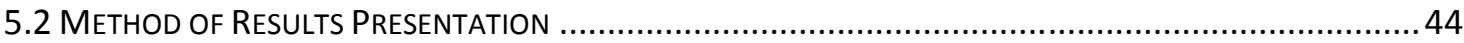

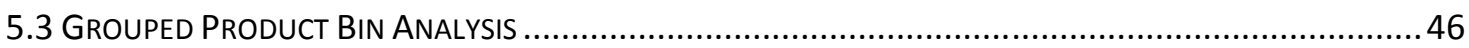

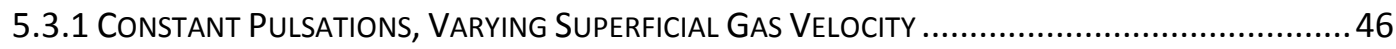

5.3.2 Constant SuPERficial Gas Velocity, Varying PulSation RATE......................................5

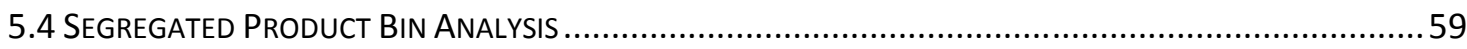

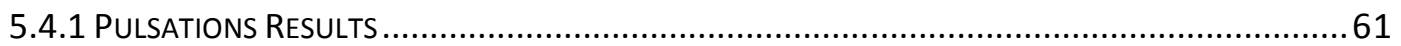

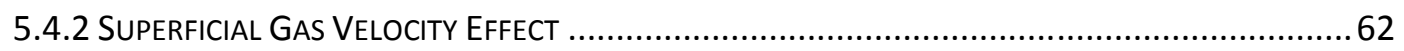

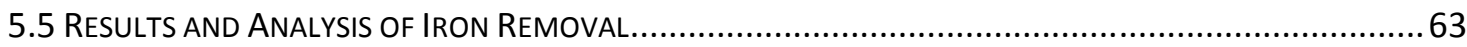

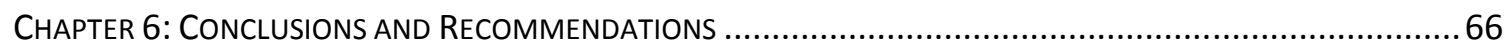

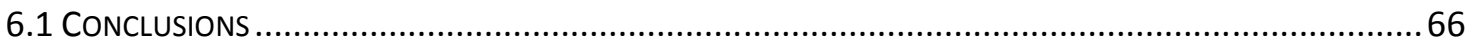

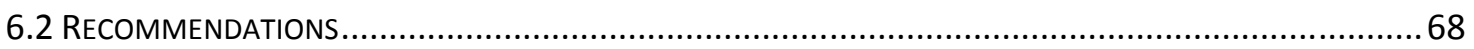

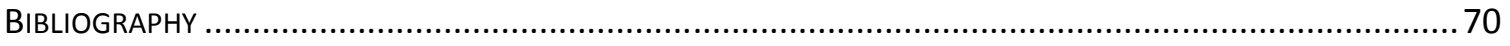

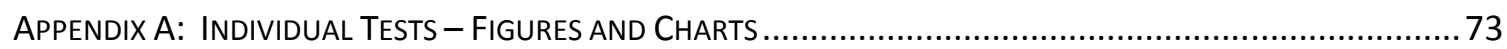

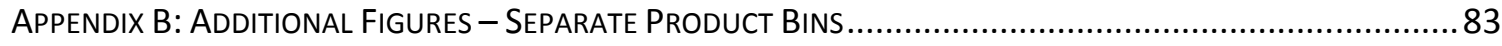

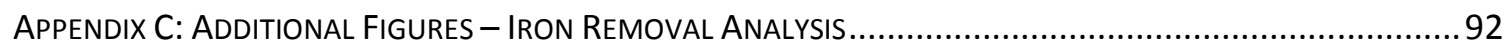

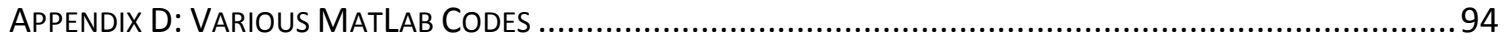

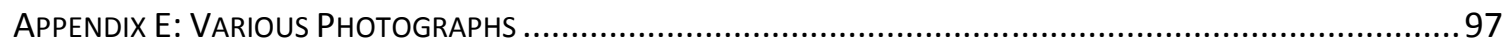




\section{LIST OF FIGURES}

Figure 3-1: Superficial gas velocity and particle diameter selection method.

Figure 3-2: Effect of pyrite percentage on particle terminal velocity The percentage of ranges from $0 \%$ (pure coal) to $100 \%$ (pure pyrite) with $10 \%$ increments

Figure 3-3: Modification of the test matrix's superficial gas velocity due to particles with varying pyrite. Shown are particles with $10 \%$ increments in percent pyrite, ranging from $0 \%$ to $100 \%$ (pure) pyrite. 14

Figure 3-4: Flow regime map for coal particles, $d_{p}=210$ microns, $D=0.05 m(B i$, et al., 1995) ......17

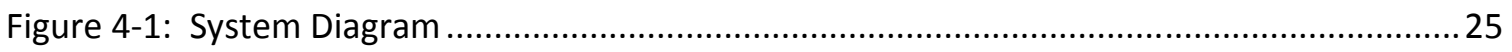

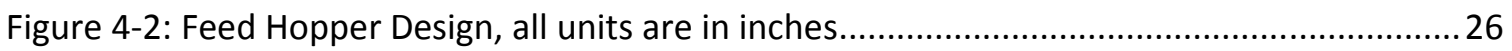

Figure 4-3: Pneumatic Transport System Design, all units are in inches .....................................2

Figure 4-4: Dense Bin Riser Section Design, all units are in inches............................................. 28

Figure 4-5: Injector/Distributor Section of Riser Design, all units are in inches ...........................29

Figure 4-6: Main Riser Section Design, all units are in inches ................................................... 30

Figure 4-7: Top Riser Section Design, all units are in inches.................................................... 31

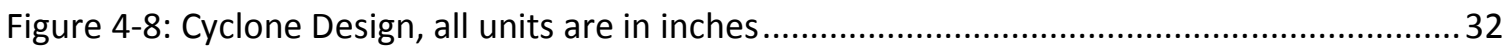

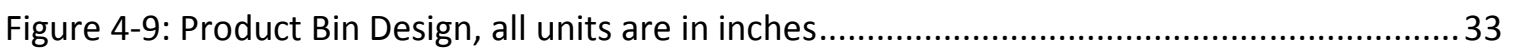

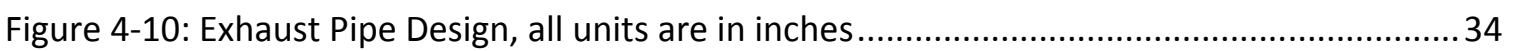

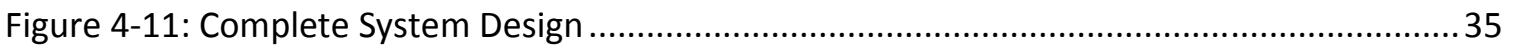

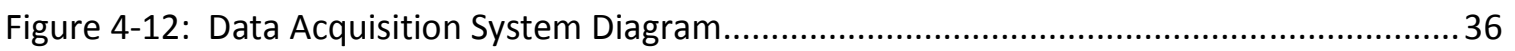

Figure 4-13: Graphical representation of the volumetric flow rate as a function of time for a superficial gas velocity of $0.9621 \mathrm{~ms}^{-1}$ and flow pulsations of $\mathrm{OHz}, 1 \mathrm{~Hz}$ and $2 \mathrm{~Hz} \ldots \ldots \ldots \ldots \ldots \ldots \ldots . . . . . . . . . .11$

Figure 5-1: Results from tests without pulsations, coal particles $\left(105<d_{p}<210\right) \mu m$, and decreasing superficial gas velocity with grouped Product Bins................................................ 47

Figure 5-2: Riser Pressure $\left(\mathrm{inH}_{2} \mathrm{O}\right)$ for $1 \mathrm{~Hz}$ pulsation test. Test conditions included $\left(\mathrm{u}_{0}=0.9101 \mathrm{~ms}^{-}\right.$

, $\left.\dot{m}=3.53 \mathrm{~kg}-\mathrm{hr}^{-1}\right)$ for coal particles $\left(105<\mathrm{d}_{\mathrm{p}}<210\right) \mu \mathrm{m}$ .49 
Figure 5-3: Results from tests with $1 \mathrm{~Hz}$ pulsations, coal particles $\left(105<\mathrm{d}_{\mathrm{p}}<210\right) \mu \mathrm{m}$, and decreasing superficial gas velocity with grouped Product Bins. 50

Figure 5-4: Riser Pressure $\left(\mathrm{inH}_{2} \mathrm{O}\right)$ for $2 \mathrm{~Hz}$ pulsation test. Test conditions included $\left(\mathrm{u}_{0}=0.9101 \mathrm{~ms}^{-}\right.$ $\left.{ }^{1}, \dot{m}=3.46 \mathrm{~kg}^{-} \mathrm{hr}^{-1}\right)$ for coal particles $\left(105<\mathrm{d}_{\mathrm{p}}<210\right) \mu \mathrm{m}$

Figure 5-5: Results from tests with $2 \mathrm{~Hz}$ pulsations, coal particles $\left(105<\mathrm{d}_{\mathrm{p}}<210\right) \mu \mathrm{m}$, and decreasing superficial gas velocity with grouped Product Bins. 52

Figure 5-6: Results from tests with superficial gas velocity $\mathrm{u}_{0}=0.9621 \mathrm{~ms}^{-1}$, coal particles $\left(105<\mathrm{d}_{\mathrm{p}}<210\right) \mu \mathrm{m}$, varying pulsation rates $(0 \mathrm{~Hz}, 1 \mathrm{~Hz}$, and $2 \mathrm{~Hz})$, and grouped Product Bins. .54

Figure 5-7: Results from tests with superficial gas velocity $\mathrm{u}_{0}=0.9101 \mathrm{~ms}^{-1}$, coal particles $\left(105<\mathrm{d}_{\mathrm{p}}<210\right) \mu \mathrm{m}$, varying pulsation rates $(0 \mathrm{~Hz}, 1 \mathrm{~Hz}$, and $2 \mathrm{~Hz})$, and grouped Product Bins. 55

Figure 5-8: Results from tests with superficial gas velocity $\mathrm{u}_{0}=0.8581 \mathrm{~ms}^{-1}$, coal particles $\left(105<\mathrm{d}_{\mathrm{p}}<210\right) \mu \mathrm{m}$, varying pulsation rates $(0 \mathrm{~Hz}, 1 \mathrm{~Hz}$, and $2 \mathrm{~Hz})$, and grouped Product Bins........56

Figure 5-9: Results from tests with superficial gas velocity $u_{0}=0.8061 \mathrm{~ms}^{-1}$, coal particles $\left(105<d_{p}<210\right) \mu m$, varying pulsation rates $(0 \mathrm{~Hz}, 1 \mathrm{~Hz}$, and $2 \mathrm{~Hz})$, and grouped Product Bins. 57

Figure 5-10 Results from tests with $\mathrm{OHz}$ pulsations, coal particles $\left(105<\mathrm{d}_{\mathrm{p}}<210\right) \mu \mathrm{m}$, decreasing superficial gas velocity with separated Product Bins.

Figure 5-11 Results from tests with superficial gas velocity $u_{0}=0.9621 \mathrm{~ms}^{-1}$, coal particles $\left(105<\mathrm{d}_{\mathrm{p}}<210\right) \mu \mathrm{m}$, varying pulsation rates $(0 \mathrm{~Hz}, 1 \mathrm{~Hz}$, and $2 \mathrm{~Hz})$, and separated Product Bins......62

Figure 5-12: Results from tests with $1 \mathrm{~Hz}$ pulsations, coal particles $\left(105<\mathrm{d}_{\mathrm{p}}<210\right) \mu \mathrm{m}$, and decreasing superficial gas velocity with grouped Product Bins. This figure compares the percent change of mass percent sulfur to the percent change of mass percent iron for tests with the given flow conditions. 63

Figure 5-13: Results from tests with superficial gas velocity $\mathrm{u}_{0}=0.9621 \mathrm{~ms}^{-1}$, coal particles $\left(105<\mathrm{d}_{\mathrm{p}}<210\right) \mu \mathrm{m}$, varying pulsation rates $(1 \mathrm{~Hz}$ and $2 \mathrm{~Hz})$, and grouped Product Bins. This figure compares the percent change of mass percent sulfur to the percent change of mass percent iron for tests with the given flow conditions.

Figure A-1: Test Results for superficial gas velocity $\mathrm{u}_{0}=0.9621 \mathrm{~ms}^{-1}$, No pulsations $-0 \mathrm{~Hz}, \dot{m}=$ $(4.62,3.71,1.72) \mathrm{kg}^{*} \mathrm{hr}^{-1},\left(105<\mathrm{d}_{\mathrm{p}}<210\right) \mu \mathrm{m}$ coal particles, and grouped Product Bin results. ...... 73

Figure A-2: Test Results for superficial gas velocity $\mathrm{u}_{0}=0.9101 \mathrm{~ms}^{-1}$, No pulsations $-0 \mathrm{~Hz}, \dot{m}=$ $(4.68,2.42,3.64) \mathrm{kg}^{*} \mathrm{hr}^{-1},\left(105<\mathrm{d}_{\mathrm{p}}<210\right) \mu \mathrm{m}$ coal particles, and grouped Product Bin results. ...... 73

Figure A-3: Test Results for superficial gas velocity $\mathrm{u}_{0}=0.8581 \mathrm{~ms}^{-1}$, No pulsations $-0 \mathrm{~Hz}, \dot{m}=$ $(1.19,2.62,1.64) \mathrm{kg}^{*} \mathrm{hr}^{-1},\left(105<\mathrm{d}_{\mathrm{p}}<210\right) \mu \mathrm{m}$ coal particles, and grouped Product Bin results. ...... 74 
Figure A-4: Test Results for superficial gas velocity $\mathrm{u}_{0}=0.8061 \mathrm{~ms}^{-1}$, No pulsations $-0 \mathrm{~Hz}, \dot{m}=$ $(2.92,3.28,2.91) \mathrm{kg}^{*} \mathrm{hr}^{-1},\left(105<\mathrm{d}_{\mathrm{p}}<210\right) \mu \mathrm{m}$ coal particles, and grouped Product Bin results. ...... 74

Figure A-5: Test Results for superficial gas velocity $\mathrm{u}_{0}=0.9621 \mathrm{~ms}^{-1}$, Pulsations $-1 \mathrm{~Hz}, \dot{m}=(3.14$, $2.57,3.61) \mathrm{kg}^{*} \mathrm{hr}^{-1},\left(105<\mathrm{d}_{\mathrm{p}}<210\right) \mu \mathrm{m}$ coal particles, and grouped Product Bin results. 75

Figure A-6: Test Results for superficial gas velocity $\mathrm{u}_{0}=0.9101 \mathrm{~ms}^{-1}$, Pulsations $-1 \mathrm{~Hz}, \dot{m}=(4.17$, $3.53,4.31) \mathrm{kg}^{*} \mathrm{hr}^{-1},\left(105<\mathrm{d}_{\mathrm{p}}<210\right) \mu \mathrm{m}$ coal particles, and grouped Product Bin results. .75

Figure A-7: Test Results for superficial gas velocity $\mathrm{u}_{0}=0.8581 \mathrm{~ms}^{-1}$, Pulsations $-1 \mathrm{~Hz}, \dot{m}=(4.17$, $4.04,2.94) \mathrm{kg}^{*} \mathrm{hr}^{-1},\left(105<\mathrm{d}_{\mathrm{p}}<210\right) \mu \mathrm{m}$ coal particles, and grouped Product Bin results. .76

Figure A-8: Test Results for superficial gas velocity $\mathrm{u}_{0}=0.8061 \mathrm{~ms}^{-1}$, Pulsations $-1 \mathrm{~Hz}, \dot{m}=(4.69$, $3.43,2.61) \mathrm{kg}^{*} \mathrm{hr}^{-1},\left(105<\mathrm{d}_{\mathrm{p}}<210\right) \mu \mathrm{m}$ coal particles, and grouped Product Bin results. .76

Figure A-9: Test Results for superficial gas velocity $\mathrm{u}_{0}=0.9621 \mathrm{~ms}^{-1}$, Pulsations $-2 \mathrm{~Hz}, \dot{m}=(4.51$, $4.38,4.62) \mathrm{kg}^{*} \mathrm{hr}^{-1},\left(105<\mathrm{d}_{\mathrm{p}}<210\right) \mu \mathrm{m}$ coal particles, and grouped Product Bin results. .77

Figure A-10: Test Results for superficial gas velocity $\mathrm{u}_{0}=0.9101 \mathrm{~ms}^{-1}$, Pulsations $-2 \mathrm{~Hz}, \dot{m}=(4.56$, $4.85,3.46) \mathrm{kg}^{*} \mathrm{hr}^{-1},\left(105<\mathrm{d}_{\mathrm{p}}<210\right) \mu \mathrm{m}$ coal particles, and grouped Product Bin results. .77

Figure A-11: Test Results for superficial gas velocity $\mathrm{u}_{0}=0.8581 \mathrm{~ms}^{-1}$, Pulsations $-2 \mathrm{~Hz}, \dot{m}=(4.51$, $4.03,3.91) \mathrm{kg}^{*} \mathrm{hr}^{-1},\left(105<\mathrm{d}_{\mathrm{p}}<210\right) \mu \mathrm{m}$ coal particles, and grouped Product Bin results. 78

Figure A-12: Test Results for superficial gas velocity $\mathrm{u}_{0}=0.8061 \mathrm{~ms}^{-1}$, Pulsations $-2 \mathrm{~Hz}, \dot{m}=(3.07$, $2.41,3.67) \mathrm{kg}^{*} \mathrm{hr}^{-1},\left(105<\mathrm{d}_{\mathrm{p}}<210\right) \mu \mathrm{m}$ coal particles, and grouped Product Bin results. 78

Figure B-1: Results from tests with $1 \mathrm{~Hz}$ pulsations, coal particles $\left(105<\mathrm{d}_{\mathrm{p}}<210\right) \mu \mathrm{m}$, decreasing superficial gas velocity with separated Product Bins.

Figure B-2: Test Results from tests with $2 \mathrm{~Hz}$ pulsations, coal particles $\left(105<\mathrm{d}_{\mathrm{p}}<210\right) \mu \mathrm{m}$, decreasing superficial gas velocity with separated Product Bins. 83

Figure B-3: Test Results for superficial gas velocity $\mathrm{u}_{0}=0.9101 \mathrm{~ms}^{-1}$, coal particles $\left(105<d_{p}<210\right) \mu m$, varying pulsation rates $(0 \mathrm{~Hz}, 1 \mathrm{~Hz}$, and $2 \mathrm{~Hz})$, and separated Product Bins...... 84

Figure B-4: Test Results for superficial gas velocity $\mathrm{u}_{0}=0.8581 \mathrm{~ms}^{-1}$, coal particles $\left(105<d_{p}<210\right) \mu m$, varying pulsation rates $(0 \mathrm{~Hz}, 1 \mathrm{~Hz}$, and $2 \mathrm{~Hz})$, and separated Product Bins...... 84

Figure B-5: Test Results for superficial gas velocity $\mathrm{u}_{0}=0.8061 \mathrm{~ms}^{-1}$, coal particles $\left(105<\mathrm{d}_{\mathrm{p}}<210\right) \mu \mathrm{m}$, varying pulsation rates $(0 \mathrm{~Hz}, 1 \mathrm{~Hz}$, and $2 \mathrm{~Hz})$, and separated Product Bins...... 85

Figure B-6: Test Results for superficial gas velocity $\mathrm{u}_{0}=0.9621 \mathrm{~ms}^{-1}$, No pulsations $-0 \mathrm{~Hz}, \dot{m}=$ $(4.62,3.71,1.72) \mathrm{kg}^{*} \mathrm{hr}^{-1},\left(105<\mathrm{d}_{\mathrm{p}}<210\right) \mu \mathrm{m}$ coal particles, and separated Product Bin results..... 85

Figure B-7: Test Results for superficial gas velocity $\mathrm{u}_{0}=0.9101 \mathrm{~ms}^{-1}$, No pulsations $-0 \mathrm{~Hz}, \dot{m}=$ $(4.68,2.42,3.64) \mathrm{kg}^{*} \mathrm{hr}^{-1},\left(105<\mathrm{d}_{\mathrm{p}}<210\right) \mu \mathrm{m}$ coal particles, and separated Product Bin results..... 86 
Figure B-8: Test Results for superficial gas velocity $\mathrm{u}_{0}=0.8581 \mathrm{~ms}^{-1}$, No pulsations $-0 \mathrm{~Hz}, \dot{m}=$ $(1.19,2.62,1.64) \mathrm{kg}^{*} \mathrm{hr}^{-1},\left(105<\mathrm{d}_{\mathrm{p}}<210\right) \mu \mathrm{m}$ coal particles, and grouped Product Bin results. ...... 86

Figure B-9: Test Results for superficial gas velocity $\mathrm{u}_{0}=0.8061 \mathrm{~ms}^{-1}$, No pulsations $-0 \mathrm{~Hz}, \dot{m}=$ $(2.92,3.28,2.91) \mathrm{kg}^{*} \mathrm{hr}^{-1},\left(105<\mathrm{d}_{\mathrm{p}}<210\right) \mu \mathrm{m}$ coal particles, and separated Product Bin results..... 87

Figure B-10: Test Results for superficial gas velocity $\mathrm{u}_{0}=0.9621 \mathrm{~ms}^{-1}$, Pulsations $-1 \mathrm{~Hz}, \dot{m}=(3.14$, $2.57,3.61) \mathrm{kg}^{*} \mathrm{hr}^{-1},\left(105<\mathrm{d}_{\mathrm{p}}<210\right) \mu \mathrm{m}$ coal particles, and separated Product Bin results. 87

Figure B-11: Test Results for superficial gas velocity $\mathrm{u}_{0}=0.9101 \mathrm{~ms}^{-1}$, Pulsations $-1 \mathrm{~Hz}, \dot{m}=(4.17$, $3.53,4.31) \mathrm{kg}^{*} \mathrm{hr}^{-1},\left(105<\mathrm{d}_{\mathrm{p}}<210\right) \mu \mathrm{m}$ coal particles, and separated Product Bin results. .88

Figure B-12: Test Results for superficial gas velocity $\mathrm{u}_{0}=0.8581 \mathrm{~ms}^{-1}$, Pulsations $-1 \mathrm{~Hz}, \dot{m}=(4.17$, $4.04,2.94) \mathrm{kg}^{*} \mathrm{hr}^{-1},\left(105<\mathrm{d}_{\mathrm{p}}<210\right) \mu \mathrm{m}$ coal particles, and separated Product Bin results. .88

Figure B-13: Test Results for superficial gas velocity $\mathrm{u}_{0}=0.8061 \mathrm{~ms}^{-1}$, Pulsations $-1 \mathrm{~Hz}, \dot{m}=(4.69$, $3.43,2.61) \mathrm{kg}^{*} \mathrm{hr}^{-1},\left(105<\mathrm{d}_{\mathrm{p}}<210\right) \mu \mathrm{m}$ coal particles, and separated Product Bin results. .89

Figure B-14: Test Results for superficial gas velocity $\mathrm{u}_{0}=0.9621 \mathrm{~ms}^{-1}$, Pulsations $-2 \mathrm{~Hz}, \dot{m}=(4.51$, $4.38,4.62) \mathrm{kg}^{*} \mathrm{hr}^{-1},\left(105<\mathrm{d}_{\mathrm{p}}<210\right) \mu \mathrm{m}$ coal particles, and separated Product Bin results. .89

Figure B-15: Test Results for superficial gas velocity $\mathrm{u}_{0}=0.9101 \mathrm{~ms}^{-1}$, Pulsations $-2 \mathrm{~Hz}, \dot{m}=(4.56$, $4.85,3.46) \mathrm{kg}^{*} \mathrm{hr}^{-1},\left(105<\mathrm{d}_{\mathrm{p}}<210\right) \mu \mathrm{m}$ coal particles, and separated Product Bin results. 90

Figure B-16: Test Results for superficial gas velocity $\mathrm{u}_{0}=0.8581 \mathrm{~ms}^{-1}$, Pulsations $-2 \mathrm{~Hz}, \dot{m}=(4.51$, $4.03,3.91) \mathrm{kg}^{*} \mathrm{hr}^{-1},\left(105<\mathrm{d}_{\mathrm{p}}<210\right) \mu \mathrm{m}$ coal particles, and separated Product Bin results. 90

Figure B-17: Test Results for superficial gas velocity $\mathrm{u}_{0}=0.8061 \mathrm{~ms}^{-1}$, Pulsations $-2 \mathrm{~Hz}, \dot{m}=(3.07$, $2.41,3.67) \mathrm{kg}^{*} \mathrm{hr}^{-1},\left(105<\mathrm{d}_{\mathrm{p}}<210\right) \mu \mathrm{m}$ coal particles, and separated Product Bin results. 91

Figure C-1: Results from tests with $2 \mathrm{~Hz}$ pulsations, coal particles $\left(105<\mathrm{d}_{\mathrm{p}}<210\right) \mu \mathrm{m}$, and decreasing superficial gas velocity with grouped Product Bins. This figure compares the percent change of mass percent sulfur to the percent change of mass percent iron for tests with the given flow conditions.

Figure C-2: Results from tests with superficial gas velocity $u_{0}=0.9101 \mathrm{~ms}^{-1}$, coal particles $\left(105<d_{p}<210\right) \mu m$, varying pulsation rates $(1 \mathrm{~Hz}$ and $2 \mathrm{~Hz})$, and grouped Product Bins. This figure compares the percent change of mass percent sulfur to the percent change of mass percent iron for tests with the given flow conditions. 92

Figure C-3: Results from tests with superficial gas velocity $\mathrm{u}_{0}=0.8581 \mathrm{~ms}^{-1}$, coal particles $\left(105<\mathrm{d}_{\mathrm{p}}<210\right) \mu \mathrm{m}$, varying pulsation rates $(1 \mathrm{~Hz}$ and $2 \mathrm{~Hz})$, and grouped Product Bins. This figure compares the percent change of mass percent sulfur to the percent change of mass percent iron for tests with the given flow conditions. 
Figure C-4: Results from tests with superficial gas velocity $\mathrm{u}_{0}=0.8061 \mathrm{~ms}^{-1}$, coal particles $\left(105<\mathrm{d}_{\mathrm{p}}<210\right) \mu \mathrm{m}$, varying pulsation rates $(1 \mathrm{~Hz}$ and $2 \mathrm{~Hz})$, and grouped Product Bins. This figure compares the percent change of mass percent sulfur to the percent change of mass percent iron for tests with the given flow conditions.

Figure E-1: Experimental system

Figure E-2: Initial mixture sample (200x) Particle diameter $(105<\mathrm{dp}<210) \mu \mathrm{m}$......

Figure E-3: Dense bin sample $(200 \mathrm{x}) \mathrm{OHz}$ pulsations, $\mathrm{u}_{0}=0.9621 \mathrm{~ms}^{-1}$, Particle diameter $(105<\mathrm{dp}<210) \mu \mathrm{m}$

Figure E-4: Product bin 1 sample $(200 x) \mathrm{OHz}$ pulsations, $\mathrm{u}_{0}=0.9621 \mathrm{~ms}^{-1}$, Particle diameter $(105<\mathrm{dp}<210) \mu \mathrm{m}$ 99

Figure E-5: Product bin 2 sample $(200 x) \mathrm{OHz}$ pulsations, $\mathrm{u}_{0}=0.9621 \mathrm{~ms}^{-1}$, Particle diameter $(105<\mathrm{dp}<210) \mu \mathrm{m}$ 99 


\section{LIST OF TABLES}

Table 2-1: Various wet separations methods (Budge, et al., 2000)............................................. 5

Table 2-2: Various dry separations methods (Lockhart, 1984) ................................................. 6

Table 3-1: Maximum particle diameter in microns to be collected with superficial gas velocity compensation for particle of varying pyrite percentage for an initial sample size rage $100<d_{p}<210$ 15

Table 4-1: Cyclone Flow conditions and cut diameter. .23

Table 4-2: Flow velocities and volumetric flow rates for $\mathrm{OHz}, 1 \mathrm{~Hz}$, and $2 \mathrm{~Hz}$ pulsation tests .40

Table 5-1: Tabulated results from tests with constant superficial gas velocity and constant gas pulsations 53

Table 5-2: Tabulated results from tests with constant superficial gas velocity and constant gas pulsations 58

Table 5-3: Percentage of material collected in the Product Bins and Dense Bin for all tests. .......59

Table 5-4: Measured Product Bin 1 and Product Bin 2 weights for all tests and flow conditions 60 Table A-1: Results for tests with $\mathrm{OHz}$ pulsations, $\mathrm{u}_{0}=0.9621 \mathrm{~ms}^{-1}$, and grouped Product Bins.......79

Table A-2: Results for tests with $\mathrm{OHz}$ pulsations, $\mathrm{u}_{0}=0.9101 \mathrm{~ms}^{-1}$, and grouped Product Bins....... 79

Table A-3: Results for tests with $\mathrm{OHz}$ pulsations, $\mathrm{u}_{0}=0.8581 \mathrm{~ms}^{-1}$, and grouped Product Bins....... 79

Table A-4: Results for tests with $\mathrm{OHz}$ pulsations, $\mathrm{u}_{0}=0.8061 \mathrm{~ms}^{-1}$, and grouped Product Bins....... 80

Table A-5: Results for tests with $1 \mathrm{~Hz}$ pulsations, $\mathrm{u}_{0}=0.9621 \mathrm{~ms}^{-1}$, and grouped Product Bins....... 80

Table A-6: Results for tests with $1 \mathrm{~Hz}$ pulsations, $\mathrm{u}_{0}=0.9101 \mathrm{~ms}^{-1}$, and grouped Product Bins....... 80

Table A-7: Results for tests with $1 \mathrm{~Hz}$ pulsations, $\mathrm{u}_{0}=0.8581 \mathrm{~ms}^{-1}$, and grouped Product Bins....... 81

Table A-8: Results for tests with $1 \mathrm{~Hz}$ pulsations, $\mathrm{u}_{0}=0.8061 \mathrm{~ms}^{-1}$, and grouped Product Bins.......81

Table A-9: Results for tests with $2 \mathrm{~Hz}$ pulsations, $\mathrm{u}_{0}=0.9621 \mathrm{~ms}^{-1}$, and grouped Product Bins....... 81

Table A-10: Results for tests with $2 \mathrm{~Hz}$ pulsations, $\mathrm{u}_{0}=0.9101 \mathrm{~ms}^{-1}$, and grouped Product Bins..... 82

Table A-11: Results for tests with $2 \mathrm{~Hz}$ pulsations, $\mathrm{u}_{0}=0.8581 \mathrm{~ms}^{-1}$, and grouped Product Bins..... 82

Table A-12: Results for tests with $2 \mathrm{~Hz}$ pulsations, $\mathrm{u}_{0}=0.8061 \mathrm{~ms}^{-1}$, and grouped Product Bins..... 82 


\section{$\underline{\text { LiST OF SYMBOLS/NOMENCLATURE }}$}

\begin{tabular}{|c|c|c|c|}
\hline Symbol & Meaning & Symbol & Meaning \\
\hline Ar & Archimedes number & $\mathrm{V}_{\mathrm{CA}}$ & Type A chocking velocity \\
\hline $\mathrm{B}_{\mathrm{c}}$ & Cyclone gas inlet width & $V_{i}$ & $\begin{array}{l}\text { Gas velocity at cyclone } \\
\text { inlet }\end{array}$ \\
\hline$d_{p}$ & Particle diameter & $\forall$ & Volumetric flow rate of gas \\
\hline $\mathrm{D}_{\mathrm{c}}$ & $\begin{array}{l}\text { Cyclone major cylinder } \\
\text { diameter }\end{array}$ & $\forall_{\mathrm{L}}$ & $\begin{array}{l}\text { Lower volumetric flow rate } \\
\text { of gas between flow } \\
\text { pulsations }\end{array}$ \\
\hline $\mathrm{D}_{\mathrm{e}}$ & $\begin{array}{l}\text { Cyclone gas outlet } \\
\text { diameter }\end{array}$ & $\mathrm{V}_{\mathrm{mp}}$ & $\begin{array}{l}\text { Transition velocity from } \\
\text { core-annular to dilute flow }\end{array}$ \\
\hline $\mathrm{g}$ & Gravity & $\mathrm{V}_{\mathrm{p}}$ & Particle velocity \\
\hline $\mathrm{G}_{\mathrm{s}}$ & Mass flux & $\forall_{U}$ & $\begin{array}{l}\text { Upper volumetric flow rate } \\
\text { of gas during pulsations }\end{array}$ \\
\hline $\mathrm{h}$ & Height of the riser & $\mathrm{x}$ & Distance from Injector \\
\hline $\mathrm{H}_{\mathrm{c}}$ & Cyclone gas inlet height & $\mathrm{Z}_{\mathrm{c}}$ & Cyclone cone length \\
\hline$J_{c}$ & $\begin{array}{l}\text { Cyclone dust outlet } \\
\text { diameter }\end{array}$ & & \\
\hline $\mathrm{L}_{\mathrm{c}}$ & Major cyclone length & & \\
\hline$\dot{m}$ & Mass flow rate & & \\
\hline $\mathrm{N}$ & Number of particle turns & & \\
\hline $\mathrm{P}_{\mathrm{py}}$ & Percentage of pyrite & & \\
\hline PCMPI & $\begin{array}{l}\text { Percent change of mass } \\
\text { percent iron }\end{array}$ & & \\
\hline PCMPS & $\begin{array}{l}\text { Percent change of mass } \\
\text { percent sulfur }\end{array}$ & & \\
\hline $\mathrm{Re}_{\mathrm{t}}$ & $\begin{array}{l}\text { Particle Reynolds number } \\
\text { at terminal velocity }\end{array}$ & $\begin{array}{l}\text { Greek } \\
\text { Symbol }\end{array}$ & Meaning \\
\hline $\mathrm{u}$ & Superficial gas velocity & $\varrho_{g}$ & Gas density \\
\hline $\mathrm{u}_{\mathrm{L}}$ & $\begin{array}{l}\text { Lower superficial gas } \\
\text { velocity between flow } \\
\text { pulsations }\end{array}$ & $\varrho_{p}$ & Particle density \\
\hline $\mathrm{u}_{\mathrm{U}}$ & $\begin{array}{l}\text { Upper superficial gas } \\
\text { velocity during flow } \\
\text { pulsations }\end{array}$ & $\varrho_{c}$ & Density of coal \\
\hline $\mathrm{u}_{\mathrm{t}}$ & Terminal velocity & $Q_{\text {py }}$ & Density of pyrite \\
\hline $\mathrm{V}_{\mathrm{CC}}$ & Classic choking velocity & $\mu$ & Gas viscosity \\
\hline
\end{tabular}




\section{CHAPTER 1: \\ INTRODUCTION}

The Air Quality Act of 1963 was the first in a series of efforts made to control the amount of pollutants being emitted from various sources. Combustion of coal containing sulfur, as in a coal fired power plant, is a major source of sulfur dioxide generated in the United States. In order to reduce the amount of sulfur dioxide produced, removing sulfur before combustion is essential.

There are several methods to reduce the amount of sulfur in coal, which typically involves extracting as much pyrite, an iron and sulfur mineral, as possible. Common separation processes have large obstacles including usage of large quantities of water, the need to dry the coal after separation, and additional environmental hazards created during the separation process. Also, as ideal mining sites reduce in number, the need for a separation process that can be operated in an unfavorable environment is necessary. Dry separation eliminates the need for water, making this process ideal for arid and/or cold environment. Unlike wet separation processes, there is no need to dry particles after separation, no slurry byproducts are produced, and there is no additional cost for treating wastewater. Therefore, the use of a dry separation process, such as a circulating fluidized bed system (CFB), would be ideal for the beneficiation of coal.

Previous work on CFB systems at West Virginia University (WVU) demonstrated that particles can be separated by density differences (Regester, 2004). In this system, a flow phenomena known as fast fluidization is employed. This flow has two distinct regions, the core and the annulus. The core flow is comprised of a dilute solid/air mixture moving up the center of the riser, whereas the annulus is made up of dense solids moving 
down the riser wall. The lower density particles become entrained in the core flow and are removed from the top of the riser, passing through a series of cyclones, and deposited in a collection bin. Denser particles migrate towards the walls, enter into the annulus flow, and exit the bottom of the riser into a second collection bin. The large density differences between coal and pyrite make them ideal for this separation process.

The current exploratory research concentrates on coal particles in the size range of $105<\mathrm{d}_{\mathrm{p}}<210$ microns. A small scale CFB was reconstructed from the remains of previous research with a few modifications and the addition of a gas pulsation generator. Various superficial gas velocities were used in conjunction with various rates of pulsations to determine what conditions, if any, lead to segregation of dirtier coal, coal with a higher mass percent sulfur, from cleaner coal, coal with a lower mass percent sulfur.

The percent change in mass percent sulfur (PCMPS) is the main focus for analyzing the results of the system. Various forms of data presentation were established to show all of the flow conditions for each test. The percent change in mass percent iron (PCMPI) has also been given attention to relate changes in the mass percent sulfur to changes in the mass percent of pyrite. 


\section{CHAPTER 2:}

\section{BACKGROUND}

\subsection{NeCEssity for Particle Separation}

The burning of coal containing high levels of sulfur is directly related to various environmental hazards including air pollution and acid rain. Coal fired power plants in the United States are under strict regulations from the Environmental Protection Agency (EPA) to monitor and control the amount of sulfur dioxide produced. The Clean Air Act as amended in 1990 specifies that sulfur dioxide emissions must be below 1.2 pounds/million BTU after January 1, 2000 (Phase II sulfur dioxide requirements, 1990).

Sulfur occurs in coal in three different forms: pyrite, inorganic sulfates, and organicallybound structures (Richardson, et al., 1979). When discussing the process of physical coal cleaning, the emphasis is typically on pyritic sulfur. The sulfur content in coal varies greatly from $0.5 \%$ to $11 \%$ sulfur by mass (Monticello, et al., 1985). The size of pyrite particles in a coal seam can range from microscopic to boulder size with various locations and orientations (Ergun, 1981). For adequate liberation of the pyrite from coal, coal needs to be micronized; however a crush size has not been defined for maximum pyrite liberation (McCartney, et al., 1969) (Richardson, et al., 1979) (Cavallaro, et al., 1976).

In order to reduce the amount of emissions, coal can either be cleaned before use or the exhaust gas may be passes through gas scrubbers. The advantages to cleaning coal before burning are: 1) being able to sell coal to customers regardless of their ability to clean the coal, 2) reducing the costs on fuel gas scrubbers, and 3) reducing the amount of scrubber sludge which must be land-filled (Kawatra, et al., 2001). 


\subsection{Current Separation Technologies}

Wet and dry separation processes are used to describe the two general methods for cleaning coal. There has been a general trend in coal preparation to move away from the use of jig based systems in favor of dense media separators. Froth floatation is also becoming a standard technique for particle separation, especially with regards to small particles (Budge, et al., 2000).

Dry separation methods peaked in the United States in 1965 with 25 million tons of coal cleaned using pneumatic tables and jigs. Since then, the number of dry separation plants have been in a steady decline worldwide. The reduction in dry separation is attributed to the increased moisture content of mined coal, and a sharper separation can be achieved with wet separation techniques (Lockhart, 1984).

\subsubsection{Wet Separation}

There are several advantages in using wet separation techniques. Dense media separation is favored for its ability to: 1) make sharp separations, 2) strictly control specific gravity of the separation fluid, and 3) handle a wide variety of feed sizes and qualities. The disadvantage to using dense media separation is that the capital, operating, and maintenance costs can be relatively high (Leonard, 1991)

Jigging methods are known for their ability to achieve both high quality and high recovery rates. However, jigging methods cannot make as distinct of a separation as dense media methods where the feed coal has a large percent of 'near-gravity' material (Leonard, 1991). Near-gravity material is material whose specific gravity is close to the specific gravity of the separation fluid. Another downfall of jigging methods is the consumption of a large amount of water. As much as 5 tons of water is needed for jigging one ton of coal, with fresh 
water being added continuously (Chen, et al., 2003). The large water consumption makes jigging methods impractical in arid or cold climates where drought or freezing is possible (Donnelly, 1999) A short summary of wet separation techniques is shown in Table 2-1.

TABLE 2-1: Various wet separations methods (BUDGE, ET AL., 2000)

\begin{tabular}{|c|c|c|}
\hline Apparatus & Particle Size Range & Application \\
\hline $\begin{array}{l}\text { Run-of-Mine Jig } \\
\text { (ROM Jig) }\end{array}$ & $>100 \mathrm{~mm}$ & Removal of large discard stone \\
\hline Baum Jig & $150-0.5 \mathrm{~mm}$ & Removal of impurities with large density differences \\
\hline $\begin{array}{l}\text { Fine-Grain Improved } \\
\text { Jigs }\end{array}$ & $10-0.1 \mathrm{~mm}$ & Removal of various coal impurities \\
\hline $\begin{array}{l}\text { Coarse-Grain } \\
\text { Improved Jigs }\end{array}$ & $100-10 \mathrm{~mm}$ & Removal of various coal impurities \\
\hline $\begin{array}{l}\text { LArge COal Dense } \\
\text { Medium Separator } \\
\text { (Larcodems) }\end{array}$ & $\begin{array}{l}100-1 \mathrm{~mm} \\
\text { Or } \\
120-1 \mathrm{~mm}\end{array}$ & Removal of shale and preparation of power plant coals \\
\hline $\begin{array}{l}\text { Dense Media Baths } \\
\text { (DM Baths) }\end{array}$ & $250-6 \mathrm{~mm}$ & Removal of various coal impurities \\
\hline $\begin{array}{l}\text { Dense Media } \\
\text { Cyclones } \\
\text { (DM Cyclones) }\end{array}$ & $\begin{array}{c}13-0.5 \mathrm{~mm} \\
\text { large systems up to } \\
75 \mathrm{~mm}\end{array}$ & $\begin{array}{l}\text { Removal of impurities where the feed contains a large } \\
\text { percentage of small density difference particles }\end{array}$ \\
\hline $\begin{array}{l}\text { Fine Coal DM } \\
\text { Cyclone }\end{array}$ & $>0.5 \mathrm{~mm}$ & Removal of various coal impurities, mainly pyrite \\
\hline Teeter-bed Separator & $\begin{array}{l}\text { Discards Material 4- } \\
0.1 \mathrm{~mm}\end{array}$ & $\begin{array}{c}\text { Removal of various impurities with large relative } \\
\text { density differences in feed }\end{array}$ \\
\hline Spiral Concentrators & $2-0.1 \mathrm{~mm}$ & Removal of various coal impurities \\
\hline Water Only Cyclones & $2-0.1 \mathrm{~m}$ & Removal of various coal impurities \\
\hline Barrel Washer & $\begin{array}{l}250-100 \mathrm{~mm} \\
\text { Raw Feed }\end{array}$ & Recover of previously discarded waste tips \\
\hline Froth Floatation & $<0.6 \mathrm{~mm}$ & Removal of low carbonaceous inert minerals \\
\hline
\end{tabular}

Wet separation is largely established throughout the world due to the high separation efficiencies and simplicity. Rather common disadvantages to the wet separation processes are: 1) the need to manage large quantities of wastewater and slurry produced, 2) the need to dry the treated particles after separation, and 3) the additional costs of thickener, flotation reagents, flocculants, etc. (Leonard, 1991). 


\subsubsection{DRY SEPARATION}

Like wet separation techniques, dry separation has both advantages and disadvantages. Due to increasing safety regulations to reduce the amount of respirable dust created during the mining process, the mined coal face must be wetted. The increased moisture content must be removed before processing by dry separation techniques; however, it is more economical to dry the coal before processing than to dry the cleaned coal after wet processing (Leonard, 1991). Dry processes are also known to have inferior separation. More drawbacks to dry separation are that most processes have a high sensitivity to feed rates, sizes, and moisture content, as well as the need be to screened into narrow size ranges for adequate separation to take place (Lockhart, 1984). A short summary of dry separation techniques is shown in Table $2-2$.

TABLE 2-2: Various dry separations methods (LOCKHART, 1984)

\begin{tabular}{|c|c|}
\hline Apparatus & Method \\
\hline Air Table/Jig & $\begin{array}{c}\text { Uses differentials in the settling velocities in air to induce } \\
\text { separation (Same theory as wet jigging) }\end{array}$ \\
\hline Air Fluidized Particle Beds & $\begin{array}{c}\text { The apparent fluid density reflects the density of the solid } \\
\text { particles and voidage causing the particles to float or sink } \\
\text { according to their density and size }\end{array}$ \\
\hline Counter-Current Fluidized Cascade & $\begin{array}{c}\text { The particles are fluidized slightly above the minimum } \\
\text { fluidization velocity causing separation according to } \\
\text { density in the bed }\end{array}$ \\
\hline High-Gradient Magnetic Separation \\
(HGMS) & $\begin{array}{c}\text { Uses high magnetic gradients to attract weakly } \\
\text { paramagnetic or very fine ferromagnetic particles }\end{array}$ \\
\hline Open Gradient Magnetic Separation & $\begin{array}{c}\text { Segregates falling particles in a falling stream according to } \\
\text { their magnetic characteristics }\end{array}$ \\
\hline Electrodynamic Separation & $\begin{array}{c}\text { Feed particles become charges from an ion bombardment } \\
\text { and are pinned to a rotating drum. Particles with higher } \\
\text { conductivity lose their charge faster while the more } \\
\text { insulated particles stay attached }\end{array}$ \\
\hline Triboelectric Separation & $\begin{array}{c}\text { Charges particles by means of friction, then the particles } \\
\text { are pass through a electric field, deflecting them according } \\
\text { to the magnitude and sign of their charge }\end{array}$ \\
\hline
\end{tabular}


Aside from the many disadvantages, dry separation has many applications in which it would be better suited for use than wet separation. As mentioned before, wet techniques require the use of large quantities of water and the wastewater must be treated after use. Dry separation methods alleviate these problems. Since there is no water needed during the processing, there is no strain on the local water supply. The fear of contaminating ground water supplies is also unnecessary because there is no waste water produced. Dry separation techniques are also applicable in environments where freezing or drought may arise.

\subsection{Previous Separation Research at WVU}

There have been three investigations into using circulating fluidized beds for particle separation conducted previously at West Virginia University. Two circulating bed systems, one moderate and one small in scale, have been constructed to investigate the phenomenon of separation. The moderate scale system has shown that particle separation by density and by size is applicable for particles of varying density, size, and composition; however, none of the previous research has been able to obtain adequate results on separating cleaner coal from dirtier coal.

\subsubsection{Separation of Small Particles Due to Density Differences (Regester, 2004)}

The first investigation was to determine if particles of varying density, namely sand and steel shot, could be separated using a CFB riser system. The investigation also measured the effects of varying riser geometry on separation efficiency. The height of the riser, the exit of the riser, and the collection gap were the riser geometries of major interest.

The riser height was varied from 8 feet $(2.44 \mathrm{~m})$ to 14 feet $(4.27 \mathrm{~m})$, the exit of the riser tested the effects of a side outlet in comparison to a 90 degree swept outlet, and the collection gap ratio was varied from 0.8 to 0.9 . All of the geometries were tested at various mass fluxes. 
It was found that a riser height of 14 feet and a 90 degrees swept riser exit outlet allowed for the best separation characteristics with the highest mass fluxes though the size of the collection gap was determined to have a negligible effect on separation. The given geometries allowed for a collection efficiency of heavy particles of over $80 \%$ and a mass fraction of collected particles of over 0.70 .

\subsubsection{Small Particle Separation (Almond, 2005)}

The second investigation was to determine if the previously described system could separate particles solely based on particle size or particle density. The system was also used to determine the feasibility of separating cleaner coal from dirtier coal.

The separation of particles based on size showed great success. Tests were conducted with superficial gas velocities of 2.0 and $2.4 \mathrm{~ms}^{-1}$. Both superficial gas velocities resulted in the majority of large particles being collected in the dense/large particle bin and the majority of small particles being collected in the product bin. The bag filter collected only a negligible amount of particles.

The separation of particles based on density also showed great success. Tests were conducted with superficial gas velocities of $3.5,4.3$, and $4.8 \mathrm{~ms}^{-1}$. The mass fraction of the heavy particles varied with the superficial gas velocities, ranging from $96.6 \%$ when a superficial gas velocity of $3.5 \mathrm{~ms}^{-1}$ was employed to $86 \%$ when a $4.8 \mathrm{~ms}^{-1}$ superficial gas velocity was employed.

Unlike like the two previous investigations, the separation of cleaner coal from dirtier coal did not provide favorable results. Chemical analysis of the products of separation showed that only minor separation of material occurred. Also, higher concentrations of sulfur were detected in the product bin than that reported in the dense bin, contradicting the hypothesis. 
Finally, the chemical analysis process yielded a wide range of results for all the test samples, making any form of definite conclusions difficult.

\subsubsection{Separation of Fine Coal Particles (Akhtar, 2006)}

A small scale circulating fluidized bed system was constructed for the investigation of the separation of fine coal particles. The sole purpose of this investigation was again to attempt to separate cleaner coal fines from dirtier coal fines. The general system, excluding small modifications to the riser, is the same as that used in this investigation. Due to inadequate flow control devices, proper flow conditions were never achieved, thus no valuable data was obtained from this project.

\subsection{Description of Separation in the Riser System}

The separation process within the riser is highly dependent upon the flow conditions. From visual inspection the flow regime was determined to be core-annular flow. This flow regime is denoted by a particle movement upward in the center of the riser and particle movement downward along the riser walls.

The pattern of core-annular flow is necessary for separation to occur. The particles are initially injected axially at high speeds along the center of the riser. The initial momentum of the particles is greater than the drag force and gravity and the particle is able to move up through the riser. As the particles pass through the riser, the particles are ejected from the core into the annulus (Rhodes, et al., 1992). At the walls, were the gas velocity is at its lowest (Moran, et al., 2001), the momentum of the particle is no longer able to overcome the gravitational force and the particles fall. As the particles move downwards along the riser wall, clusters are formed. The aggregation of the particles is due to the deceleration of the particles as they move down the wall. Similarly, as the clusters grow and the cluster's voidage becomes low, the effective drag force again becomes large enough to overcome the gravitational force, 
accelerating the cluster and leading to its disaggregation (Liu, et al., 2006). However, particle clusters that disaggregate near the distributor are expected to contain large or dense particles that should able to overcome the drag and turbulent force due to their high momentum, thus bypassing the distributor to be collected in the dense bin. Particles whose momentum is not great enough to overcome the drag force are swept back into the core of the flow and again transported up through the riser.

When clusters disintegrate too close to the distributor of the riser system, large particles are able to trap smaller particles, forcing them into the dense collection bin. Thus, to prevent clean coal particles from being removed as waste, it is beneficial to have the clusters breakup at a distance above the distributor.

Rhodes, et al. (1992) reported that small pulsations near the wall are partially responsible for the disaggregation of clusters. Thus, in the experimental system, gentle pulsations have been added to the flow to aid in cluster disaggregation further away from the riser distributor. The gentle pulsations in the flow field are also used, theoretically, to modify the gas velocity profile without changing the overall properties of the flow.

The flow pulsations are intended to increase the effects of the Saffman lift force, also known as the shear lift force. The Saffman lift force can be calculated using Equation (2-1) (Saffman, 1965) where $\mathrm{C}_{\mathrm{LS}}$ is the Saffman lift coefficient and is shown in Equation (2-2) (Mei, 1992). However, at this time there is not enough information known about the flow to calculate the force.

$$
\begin{aligned}
& F_{\text {SLF }}=1.615\left(\mathbf{u}-\mathbf{v}_{\mathbf{p}}\right)(\rho \mu)^{0.5} C_{L S} \sqrt{\left|\frac{\partial u}{\partial n}\right|} * \operatorname{sign}\left(\frac{\partial u}{\partial n}\right), \text { for }(n=\chi, y, z) \\
& C_{L S}=\left\{\begin{array}{cc}
\left(1-0.3314 \gamma^{0.5}\right) \exp \left(-0.1 \operatorname{Re}_{p}\right)+0.3314 \gamma^{0.5} \operatorname{Re}_{p}^{0.5} & \text { for }\left(\operatorname{Re}_{p} \leq 40\right) \\
0.0524 \gamma^{0.5} \operatorname{Re}_{p}^{0.5} & \text { for }\left(\operatorname{Re}_{p}>40\right)
\end{array} \text { where } \gamma=\frac{0.5 d_{p}\left|\frac{\partial u}{\left|u-v_{p}\right|}\right| \frac{\partial n}{\partial n} \mid}{}\right.
\end{aligned}
$$




\section{CHAPTER 3: \\ PRELIMINARY ANALYSIS}

\subsection{Rational for Selecting Test Conditions}

The phenomenon of separation is directly related to the superficial gas velocity, particle density, and particle diameter. For separation by density to occur, particles of two distinct densities need to be sieved into a specific size range. For a more general discussion, the two particle densities will be referred to as low density and high density. Also, the superficial gas velocities discussed are in general. Specific gas velocities and the difference between tests with gas pulsations and tests without gas pulsations are reserved for Chapter 4 Section 4.5.

To determine the size range, first a maximum particle diameter, $\mathrm{d}_{\mathrm{p}, \max }$, is selected. To establish the minimum particle diameter, $\mathrm{d}_{\mathrm{p}, \text { min }}$, the terminal velocity, $\mathrm{u}_{\mathrm{t}}$, of the maximum particle size of low density material is calculated using Equation 3-1 (Fan, et al., 1998). Selecting the superficial gas velocity in this manner ensures that the largest particle of low density material will be entrained in the flow. To verify that the criterion of the equation is met, the corresponding Reynolds Number, $\mathrm{Re}_{\mathrm{t}}$, is calculated using Equation 3-2.

$$
\begin{aligned}
& u_{t}=\left(0.072 \frac{d_{p}^{1.6}\left(\rho_{p}-\rho_{g}\right) g}{\rho_{g}^{0.4} \mu^{0.6}}\right)^{1 / 1.4} \text { for } 2<\operatorname{Re}_{t}<50 \\
& \operatorname{Re}_{t}=\frac{\rho_{g} d_{p} u_{t}}{\mu} \\
& \mu \text { - gas viscosity } \\
& \varrho_{\mathrm{g}}-\text { gas density } \\
& \varrho_{\mathrm{P}}-\text { particle density } \\
& \mathrm{d}_{\mathrm{p}}-\text { particle diameter } \\
& \mathrm{g} \text { - gravity } \\
& \mathrm{u}_{\mathrm{t}}-\text { terminal velocity }
\end{aligned}
$$


The minimum particle size is back-calculated using the same equation. Rearranging Equation 3-1 in terms of particle diameter yields Equation 3-3. Solving Equation 3.3 using the previously calculated terminal velocity and exchanging the low particle density for the high particle density defines the minimum particle diameter. The minimum particle diameter is such that the minimum particle diameter of high density material will not become entrained in the flow. The selection process is shown in Figure 3-1.

$$
d_{p, \min }=\left(\frac{u_{t}^{1.4} \rho_{g}^{0.4} \mu^{0.6}}{0.7072\left(\rho_{p}-\rho_{g}\right) g}\right)^{1 / 1.6}
$$

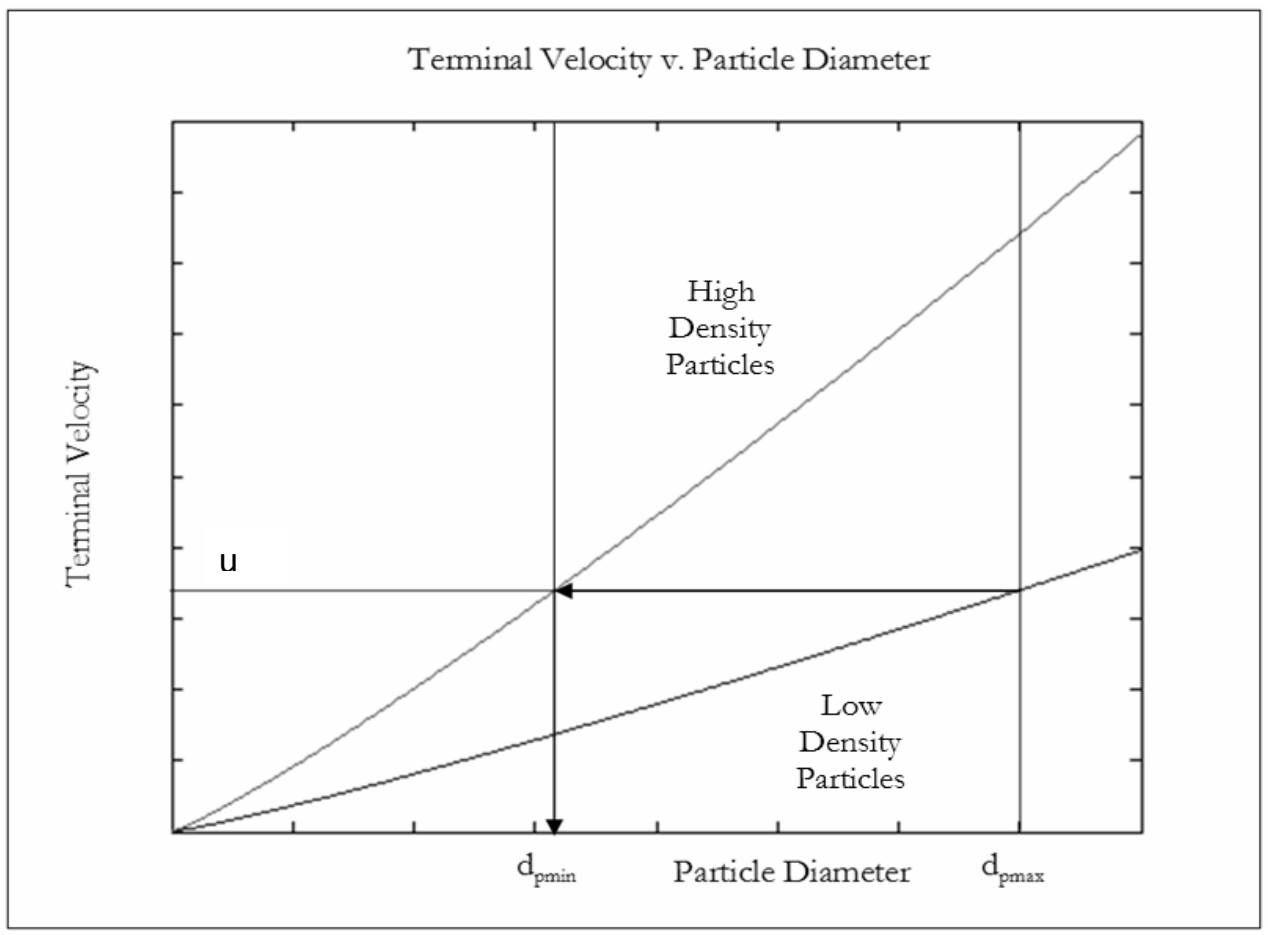

FIGURE 3-1: Superficial gas velocity and particle diameter selection method

The calculated terminal velocity used in the selection of the particle size range is set as the superficial gas velocity. As Equation 3-1 implies, there is a strong dependency on the density of the particles for the determination of the superficial gas velocity. Previous research at West Virginia University involving separation of small particles due to density differences 
(Regester, 2004) concentrated on the separation of two distinct substances of different densities (i.e. sand and steel shot). However, there is no distinction between pure coal and the contaminates; since the main objective is to reduce the total sulfur of the initial coal sample and since pyrite is the obvious contaminate to be removed to reduce the total sulfur, the remaining discussion will be directly relate to pyrite removal.

A portion of the pyrite matter may be liberated from the coal via crushing, but there may still be a large portion of particles containing pyrite of varying percentages. The assumption of two distinct terminal velocity curves, as in Figure 3-1, is not reasonable for particles of varying composition.

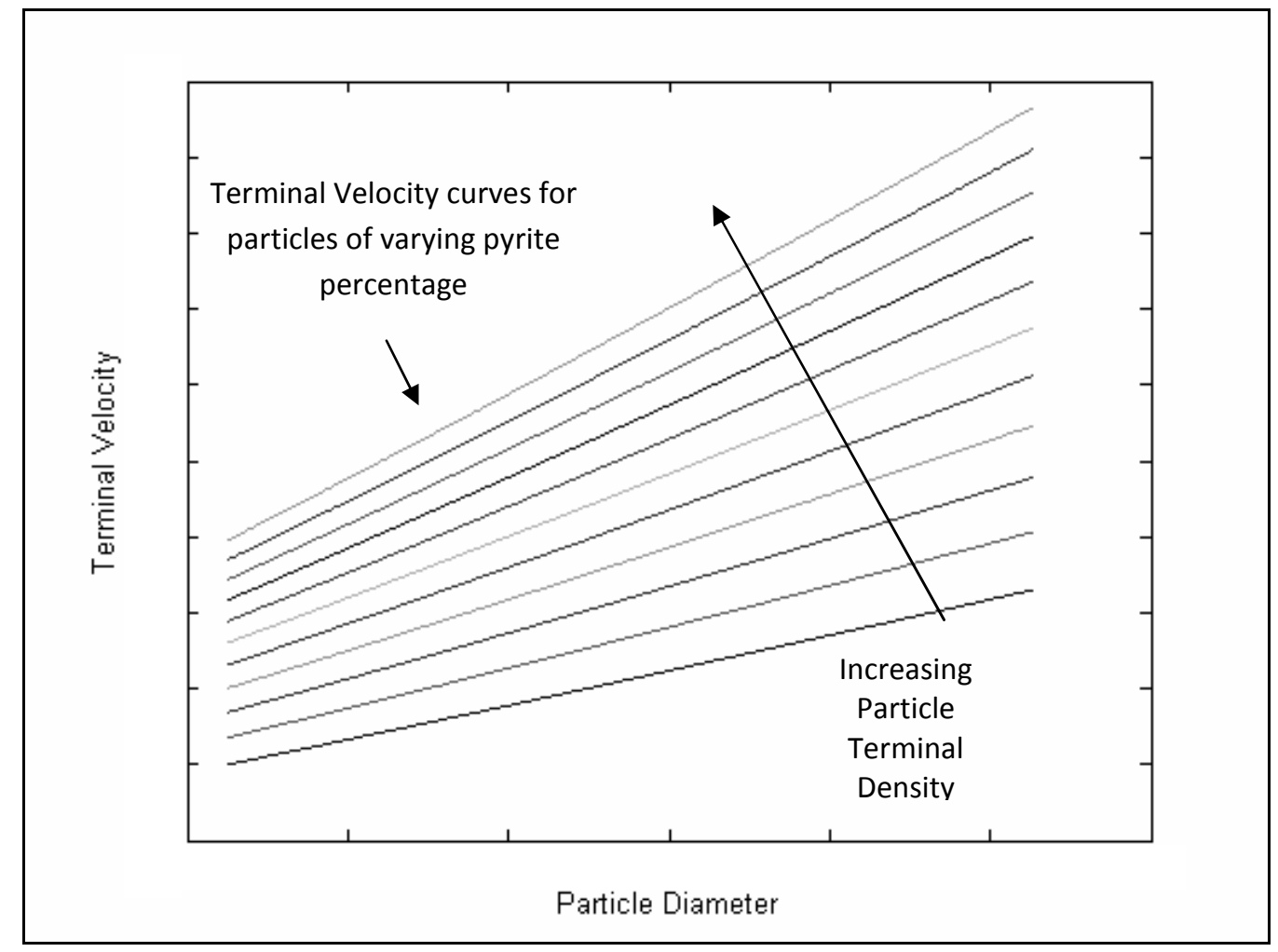

FIGURE 3-2: Effect of pyrite percentage on particle terminal velocity The percentage of ranges from $0 \%$ (pure coal) to $100 \%$ (pure pyrite) with $10 \%$ increments

$$
\rho_{p}=P_{p y} \rho_{p y}+\rho_{c}\left(1-P_{p y}\right)
$$


In order to account for the different particle densities, the terminal velocities for particles containing various percentages of pyrite were calculated. Equation 3-4 was developed to replicate various percentages of pyrite. The percentage of pyrite varied from zero to one hundred in increments of ten; the result is shown in Figure 3-2. With the effect of the percentage of pyrite known, the test matrix was then modified to account for particles of varying pyrite content, shown in Figure 3-3.

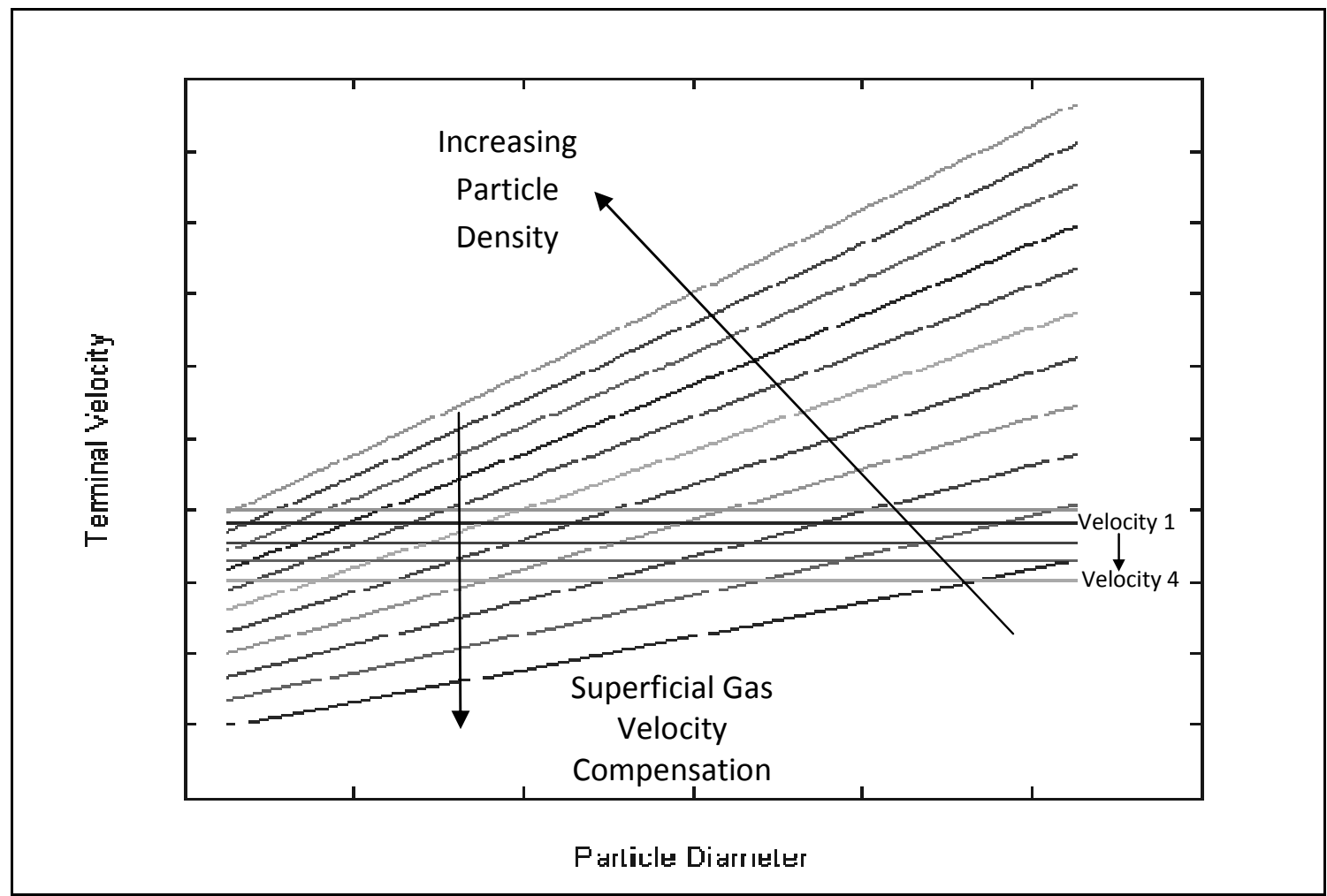

FIGURE 3-3: Modification of the test matrix's superficial gas velocity due to particles with varying pyrite. Shown are particles with $10 \%$ increments in percent pyrite, ranging from $0 \%$ to $100 \%$ (pure) pyrite.

Table 3-1 shows the maximum particle size that is expected to be captured with the superficial gas velocity compensation. The flow conditions set for Velocity 1 are for an ideal case of a mixture of pure coal mixed with pure pyrite; thus, all pure coal particles are collected and all pure pyrite particles are rejected. As the flow conditions are modified to account for particles comprised of both coal and pyrite, the maximum pure coal particle diameter decreases with the decrease of pyrite percentage. 
Table 3-1: Maximum particle diameter in microns to be collected with superficial gas velocity compensation for particle of varying pyrite percentage for an initial sample size rage $100<d_{p}<210$

\begin{tabular}{|c|c|c|c|c|}
\hline $\begin{array}{c}\text { Percent } \\
\text { Pyrite }\end{array}$ & Velocity 1 & Velocity 2 & Velocity 3 & Velocity 4 \\
\hline $0 \%$ & 210 & 210 & 205 & 194 \\
\hline $10 \%$ & 196 & 187 & 178 & 168 \\
\hline $20 \%$ & 175 & 167 & 158 & 150 \\
\hline $30 \%$ & 159 & 151 & 144 & 136 \\
\hline $40 \%$ & 146 & 139 & 132 & 125 \\
\hline $50 \%$ & 135 & 129 & 122 & 116 \\
\hline $60 \%$ & 127 & 121 & 115 & 109 \\
\hline $70 \%$ & 119 & 114 & 108 & - \\
\hline $80 \%$ & 113 & 108 & - & - \\
\hline $90 \%$ & 107 & - & - & - \\
\hline $100 \%$ & - & - & - & - \\
\hline
\end{tabular}

\subsection{Flow Regimen Determination}

Two methods were used in attempting to identify to flow regimen of the system; however, neither of the methods accurately identify the flow regime in accordance to their standards. From visual inspection compared to literature, it was determined that the system most likely operates in the core-annular dilute-phase flow and homogeneous dilute-phase flow regimes.

Monazam et. al. (2005) describe a method of determining the flow regime of a CFB by denoting the time required to empty the solids from the riser under given flow conditions. Using this method requires a great deal of information concerning the experimental system which was beyond the scope of this research. Due to the inability of the pressure sensors to measure a difference between the two measurement ports, an accurate estimate of emptying 
time could not be obtained. Also, numerous tests would need to be conducted solely for the purpose of determining the flow regime. The time required to acquire the needed information was not available; thus, this method could not be applied.

The next method for determining the flow regime suggests using flow regime mapping (Bi, et al., 1995). This method uses various flow conditions to estimate transition points between the various regimes. $\mathrm{Bi}$ and Grace use the Classical choking velocity $\left(\mathrm{V}_{\mathrm{cc}}\right)$, Type $\mathrm{A}$ choking velocity $\left(\mathrm{V}_{\mathrm{ca}}\right)$, and the velocity where a minimum pressure drop indicates transition from homogeneous dilute flow to core annular dilute flow $\left(\mathrm{V}_{\mathrm{mp}}\right)$ to create the flow regime map. The equations for estimating these velocities are listed below.

$$
\begin{aligned}
& V_{C C}=\left(32 \operatorname{Re}_{t}^{-0.06}\left(\frac{G_{s}}{\rho_{g}}\right)^{0.28} \sqrt{g d_{p}}\right)^{1 / 1.28} \quad \text { (Yousfi, et al., 1974) (3-5) } \\
& V_{C A}=\left(21.6 A r^{0.105}\left(\frac{G_{s}}{\rho_{g}}\right)^{0.542} \sqrt{g d_{p}}\right)^{1 / 1.542} \quad \text { (Bi, et al., 1991) (3-6) } \\
& V_{m p}=10.1\left(d_{p} g\right)^{0.347}\left(\frac{G_{s}}{\rho_{g}}\right)^{0.31}\left(\frac{d_{p}}{D}\right)^{-0.139} A r^{-0.021} \quad(B i, \text { et al., 1991) (3-7) } \\
& \text { Ar - Archimedes number } \quad \operatorname{Re}-\text { Reynolds Number } \quad G_{\mathrm{s}}-\text { solids mass flux } \\
& \varrho_{g}-\text { gas density } \quad \mathrm{d}_{\mathrm{p}}-\text { particle diameter } \quad \mathrm{D}-\text { riser diameter }
\end{aligned}
$$

The three equations suggested by Bi and Grace are plotted in Figure 3-4. For the flow conditions used during the tests, it can be seen that this method does not adequately verify the flow regime. Due to the extremely low mass fluxes and low superficial gas velocities employed, this method cannot be applied. 
Without an empirical method for determining the flow regime, it is presumed from observations that the flow regime in the riser is core-annular dilute phase transport. The coreannulus flow structure is described by dilute suspension of particles in the center of the riser with net movement upwards encompassed by a dense suspension of particles near the wall with net movement downward (Kim, et al., 2004). This regime was selected by visually inspecting the riser during testing due to the inability to correlate measurable parameters to any current methods mentioned in the literature.

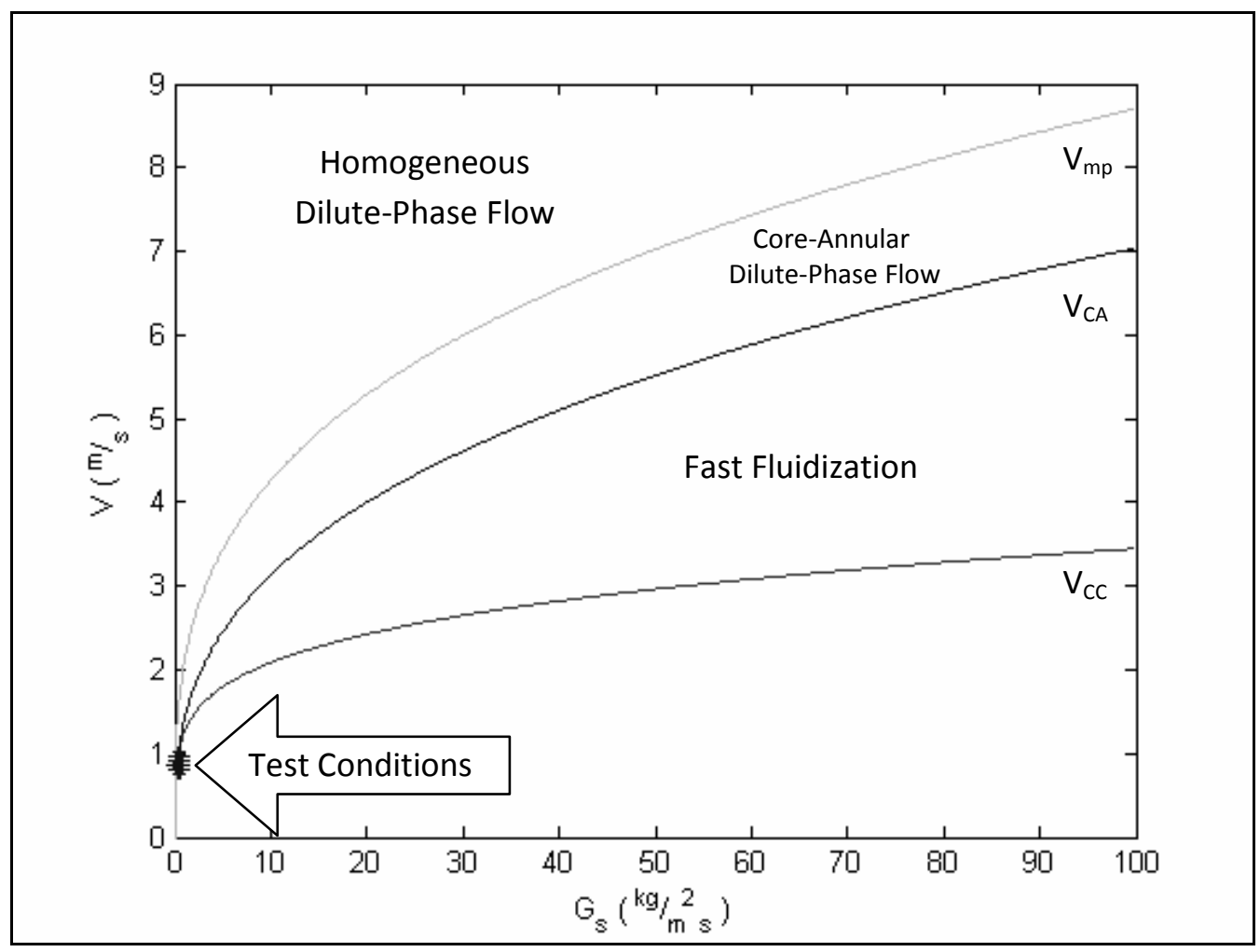

FIGURE 3-4: Flow regime map for coal particles, $d_{p}=210$ microns, $D=0.05 m$ (BI, ET AL., 1995)

A major design parameter also limits the ability to relate the experimental system to systems described in literature. The experimental system does not have the ability to maintain a bottom bed of particles during operation. Where as, most CFB systems have a gas distributor plate that occupies the bottom of the riser. This allows particles to form a bed at 
the bottom of the riser. The particles can eventually become re-entrained into the flow, rather than being removed into a secondary collection bin as waste. 


\section{CHAPTER 4: \\ EXPERIMENTAL SYSTEM}

\subsection{SYSTEM DESIGN}

The experimental system consists of six sections; the feed hopper, riser, dense bin, cyclones, product bins, and pulsation generator. The instrumentation that accompanies the system includes eight flow meters, a load cell, and two pressure transducers. The following is a brief discussion of the components that make up the complete system. Figure 4.1 is a general system diagram showing the flow patterns and measurement points in the system.

\subsubsection{FeEd Hopper}

The feed hopper, sketched in Figure 4.2, is where the initial mixture is added to the system. The hopper has a five inch inner diameter and is constructed of $1 / 2$ inch thick clear acrylic tubing. The top of the hopper has a $1 / 2$ inch thick flange and solid cap. The flange is secured with $1 /{ }_{32}$ inch steel pins and acrylic adhesive. The flange has six bolt holds placed 60 degrees apart for securing. The flanged sections are separated by a paper filter gasket to prevent leaking. All flanges mentioned from this point forward are attached in the same manner and will not be directly specified. The cap also contains a $3 / 4$ inch tapped hole for loading of solids. During tests, the tapped hole is sealed with a steel plug to prevent reversal of flow. The front of the hopper contains a pressure gauge for monitoring the internal pressure of the hopper. At the bottom of the hopper a PVC 4x2 inch reducing coupling schedule (SCH) 40 is attached via a $4 \times 4$ inch clay-to-plastic pipe rubber boot. The reducing coupling uses a $2 x^{1 / 2}$ inch straight to threaded bushing to connect to the pneumatic transport system. 


\subsubsection{PNEUMATIC TRANSPORT SyStem}

The pneumatic transport system, PTS, shown in Figure 4.3, connects the feed hopper to the riser assembly. The PTS is coupled to the feed hopper via a $1 / 2 \times 1 / 2$ in. straight female to threaded male PVC adapter. The adapter is joined to a $1 / 2$ inch PVC ball valve with a short length of $1 / 2$ inch SCH 40 PVC piping. The valve is used to control the amount of solids flow out of the feed hopper. To prevent the coal particles from clogging the outlet of the feed hopper or the solids control valve, two $1 / 4$ inch male quick-disconnects were installed. The quick-disconnects allow for small amounts of air to be injected into the transport system to aid in solids flow. Another section of $1 / 2$ inch SCH 40 PVC piping is used to connect the valve to a $3 / 4 \times 1 / 2$ inch PVC reducing tee. The right end of the reducing tee was connected to a $1 / 4$ inch quick-disconnect for the injection of the main transport gas. The left end of the reducing tee is attached to the riser injector.

\subsubsection{DENSE BIN}

The dense bin, located at the bottom of the riser system and shown in Figure 4.4, is constructed of $1 / 4$ inch acrylic tubing with a two inch inner diameter. The top of the dense bin has an acrylic flange for securing it to the injector/distributor section of the riser. The bottom of the dense bin is sealed with $1 / 4$ inch acrylic disk, secured by acrylic adhesive.

\subsubsection{INJECTOR/DISTRIBUTOR RISER SECTION}

The riser section, shown in Figure 4.5, is constructed of $1 / 4$ inch thick acrylic tubing with a two inch inner diameter. The total length of the section is 12 inches with half inch flanges on each end. The distributor is located three and a half inches from the bottom. The distributor was machined from a one and three quarter inch stainless steel solid rod six inches in length. The top of the distributor was milled at a 60 degree concave angle. A half inch hole 
was drilled down the center from the top of the distributor to the air injection cavity. The cavity was created by drilling parallel to the bottom of the distributor and tapping the ends for $\mathrm{a}^{3} / 8$ inch threaded pipe. $\mathrm{A} /{ }_{8}$ inch threaded pipe was inserted to each end, one connected to the main distributor gas flow, while the other was connected to the pulsation generator. The dimensions of the distributor allow for a $1 / 8$ inch clearance between the distributor and the riser wall. The distributor is secured in place with two $1 /{ }_{32}$ stainless steel pins through the riser wall sealed with acrylic adhesive.

The injector was created by inserting a $3 / 4 \times 1 / 2$ inch PVC female reducing elbow through the side of the riser with approximately a $1 / 4$ inch clearance below the top flange. The injector is secured to the riser wall with clear acrylic adhesive. The outlet of the injector is $1 / 2$ inch SCH 40 PVC and is centered within the riser section. The inlet of the injector is a short length of $3 / 4$ inch SCH 40 PVC piping that is push fitted to the pneumatic transport system.

\subsubsection{MAIN RISER SECTION}

The main riser section, shown in Figure 4.6, is constructed of $1 / 4$ inch acrylic tubing with a two inch inner diameter and 60 inches in length. The top and bottom of the main riser section have acrylic flanges for securing it to the injector/distributor section of the riser and the top riser section. Approximately 27 inches from the bottom of the section is a $1 / 4$ inch tapped hole that allows for pressure measurements within the riser.

\subsubsection{TOP RISER SECTION}

The top riser section, shown in Figure 4.7, is constructed of $1 / 4$ inch acrylic tubing with a two inch inner diameter. The top and bottom of the section have acrylic flanges for securing it to the main riser section and securing the riser cap. The cap was constructed of $1 / 4$ inch acrylic bolted to the top flange. An inch below the top flange is the riser exit. The exit was 
created by drilling a one inch hole through the side wall and inserting a short length of $3 / 4$ inch SCH 40 PVC tubing. The tubing is secured with clear acrylic adhesive. Approximately $3 \frac{3}{4}$ inch from the bottom of the top riser section is another $1 / 4$ hole to allow for pressure measurements.

\subsubsection{CYCLONES}

A two stage cyclone system was selected to remove the product particles from the riser exhaust gas. Figure 4.8 shows the design parameters for both cyclones. The design parameters were selected using the typical dimensions and ratios for cyclone design, shown in Equations 4-1 through 4-7 (Danielson, 1967) where $\mathrm{D}_{\mathrm{c}}$ is the major cylinder diameter.

$$
\begin{array}{ll}
\text { Major cylinder length } & L_{c}=2 D_{c} \\
\text { Cone length } & Z_{c}=2 D_{c} \\
\text { Gas outlet diameter } & D_{e}=\frac{D_{c}}{2} \\
\text { Gas inlet length } & H_{c}+S_{c}=\frac{5}{8} D_{c} \\
\text { Gas inlet height } & H_{c}=\frac{D_{c}}{2} \\
\text { Gas inlet width } & B_{c}=\frac{D_{c}}{4} \\
& J_{c}=\frac{D_{c}}{4}
\end{array}
$$

The velocity though the cyclone is estimated from the test matrix. The maximum and minimum volumetric flow rates for the system are 248 and 208 cubic feet per hour. $(7.0$ and 
$5.9 \mathrm{~m}^{3} \mathrm{hr}^{-1}$ ) The gas inlet velocity, $\mathrm{V}_{\mathrm{i}}$, was calculated by dividing the volumetric flow rate by the cyclone inlet area.

The calculation for the cut size, the particle size were the cyclone will have a $50 \%$ collection efficiency, is shown in Equation 4-8. Here $\mathrm{N}$, the number of turns the particles make inside the riser, is estimated by the dividing the total length of the cyclone by the inlet height. Also, all values are in English units. Table 4-1 shows the cut size and number of turns for the cyclones at the maximum and minimum flow conditions.

$$
D_{p c}=\sqrt{\frac{9 \mu D_{c}}{2 N V_{i}\left(\rho_{p}-\rho_{g}\right) \pi}}
$$

TABLE 4-1: CYCLONE FLOW CONDITIONS AND CUT DIAMETER

\begin{tabular}{|c|c|c|}
\cline { 2 - 3 } \multicolumn{1}{c|}{} & Lower Bound & Upper Bound \\
\hline Flow rate $(\mathrm{SCFH})$ & 208 & 248 \\
\hline Area $\left(\mathrm{ft}^{2}\right)$ & 0.005 & 0.005 \\
\hline Inlet Velocity $\left(\mathrm{fts}^{-1}\right)$ & 10.60 & 12.63 \\
\hline Number of Turns & 8 & 8 \\
\hline Cut Diameter (microns) & 6.1 & 5.6 \\
\hline
\end{tabular}

\subsubsection{PRODUCT BINS}

The product bins, shown in Figure 4.9, are constructed with $3 / 4$ inch SCH 40 PVC piping. The top of the product bins have $a \frac{3 / 4}{4}$ inch straight female to threaded male adapter connected to $\mathrm{a}^{3} / 8 \mathrm{x} 3 / 4$ female adapters; this allows for a direct connection to the cyclones. The bottoms of the product bins have a $3 / 4$ inch PVC ball valve to prevent solids and gas flow during tests and easy solids removal at the end of tests. 


\subsubsection{EXHAUST PIPE}

The exhaust pipe, shown in Figure 4-10, is constructed from $3 / 4$ inch SCH 40 PVC piping. The outlet has $24,1 / 4$ inch holes drilled to prevent excess pressure buildup. A filter bag is used to remove coal fines from the exhaust air. The filter is created by removing the top of a upright vacuum cleaner bag, pulling the bag around the exhaust pipe, and securing the bag with zip-ties. This system is used do the inexpensiveness of vacuum bags and zip-ties. This system also allows for the collection of the exhaust fines for analysis.

\subsubsection{PuLSATION GENERATOR}

Three pieces of equipment were used to construct the pulsation generator; a two-way general purpose solenoid valve (Omega Engineering SV-3306), a programmable/arbitrary function generator (AFG 5101), and an amplifier (MB Dynamics SS250VCS). The desired frequency for the pulsations was programmed into the function generator whose signal was amplified before being sent to the solenoid valve. The fluid entrance of the solenoid valve was connected to a flow meter via pressure hose tubing so that the airflow through the valve could be controlled. The exit of the valve was connected to distributor of the riser using pressure hose tubing and quick-disconnect couplings so that the pulsation generator could be disconnected from the system when not in use.

The average opening time for the valve is $15 \mathrm{msec}$ with an average closing time of 25msec. With such short times for opening and closing of the valve, and the low rate of pulsations $(1 \mathrm{~Hz}$ and $2 \mathrm{~Hz})$ the valve is considered to operate as an on/off valve. Therefore, the valve is considered to be fully open or fully closed during operation. 


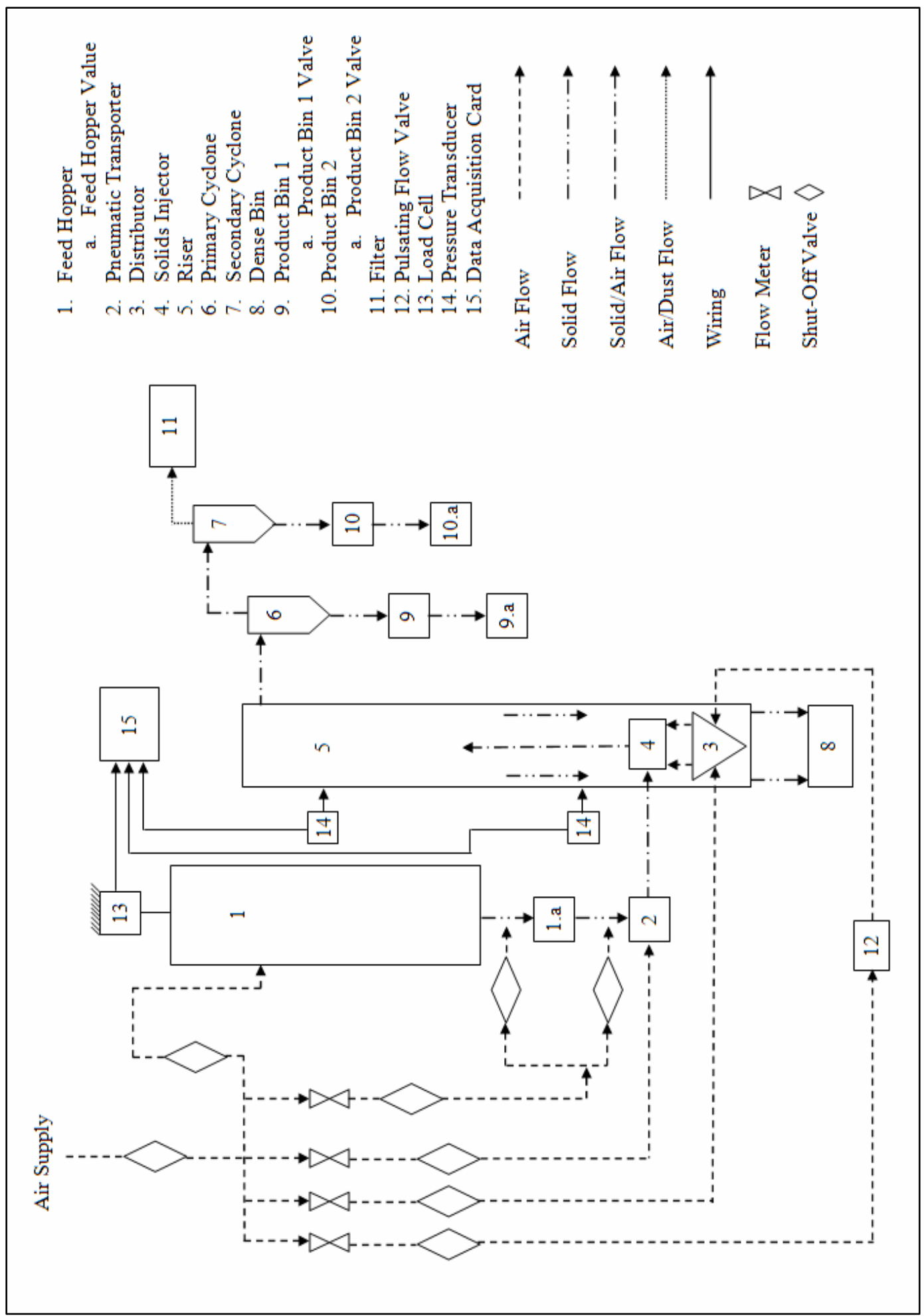

FIGURE 4-1: System Diagram 


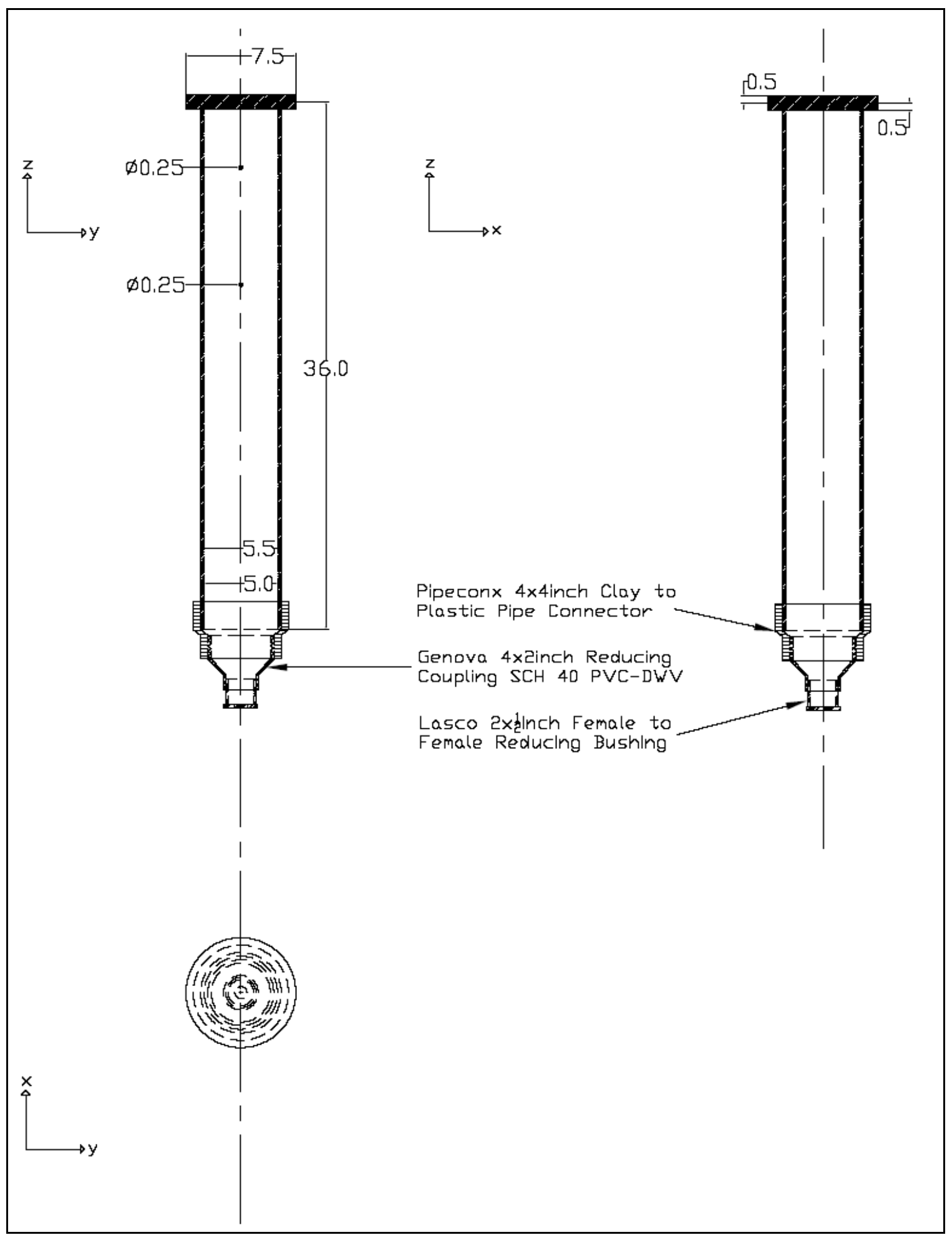

FIGURE 4-2: Feed Hopper Design, all units are in inches 


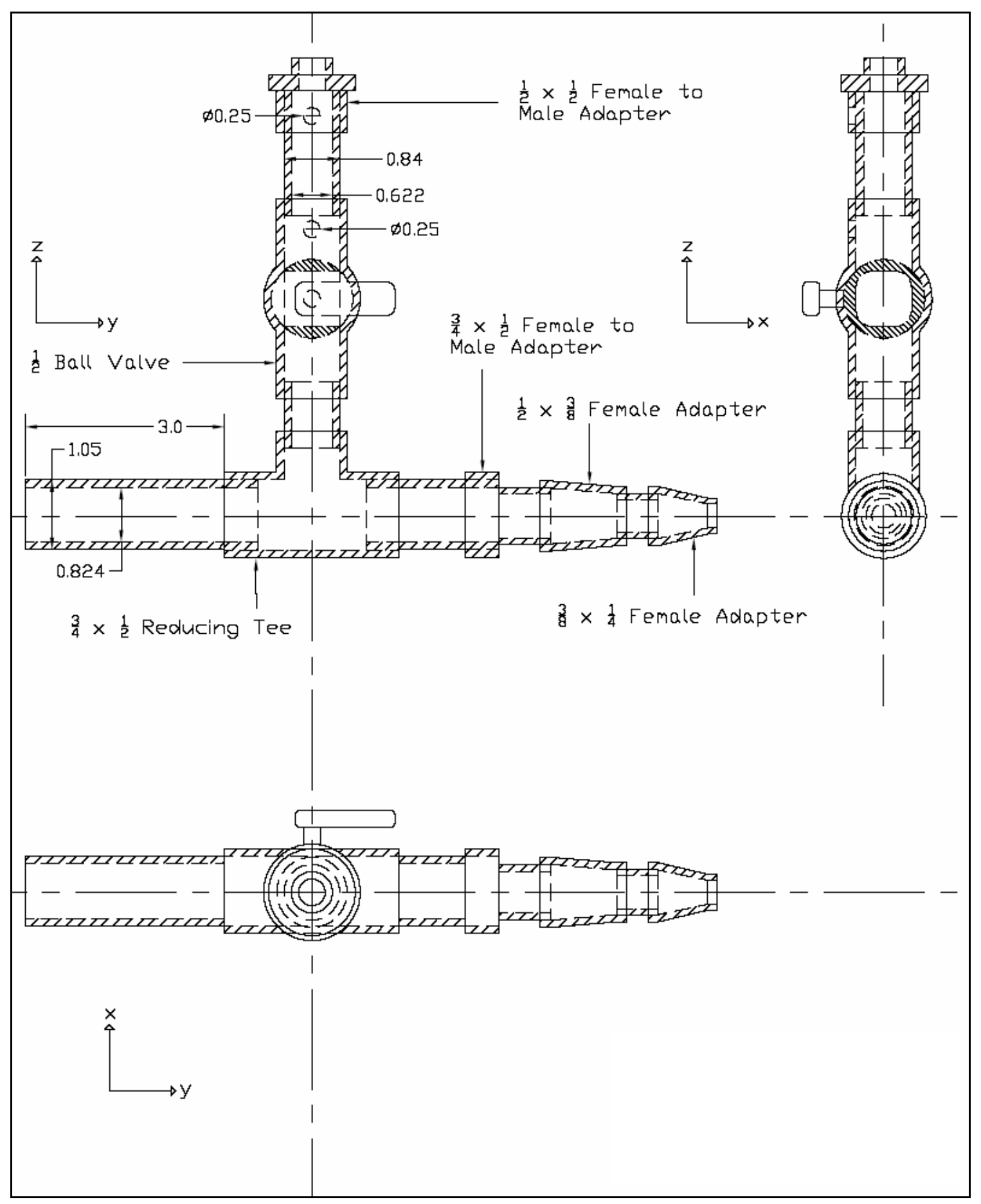

FIGURE 4-3: Pneumatic Transport System Design, all units are in inches 


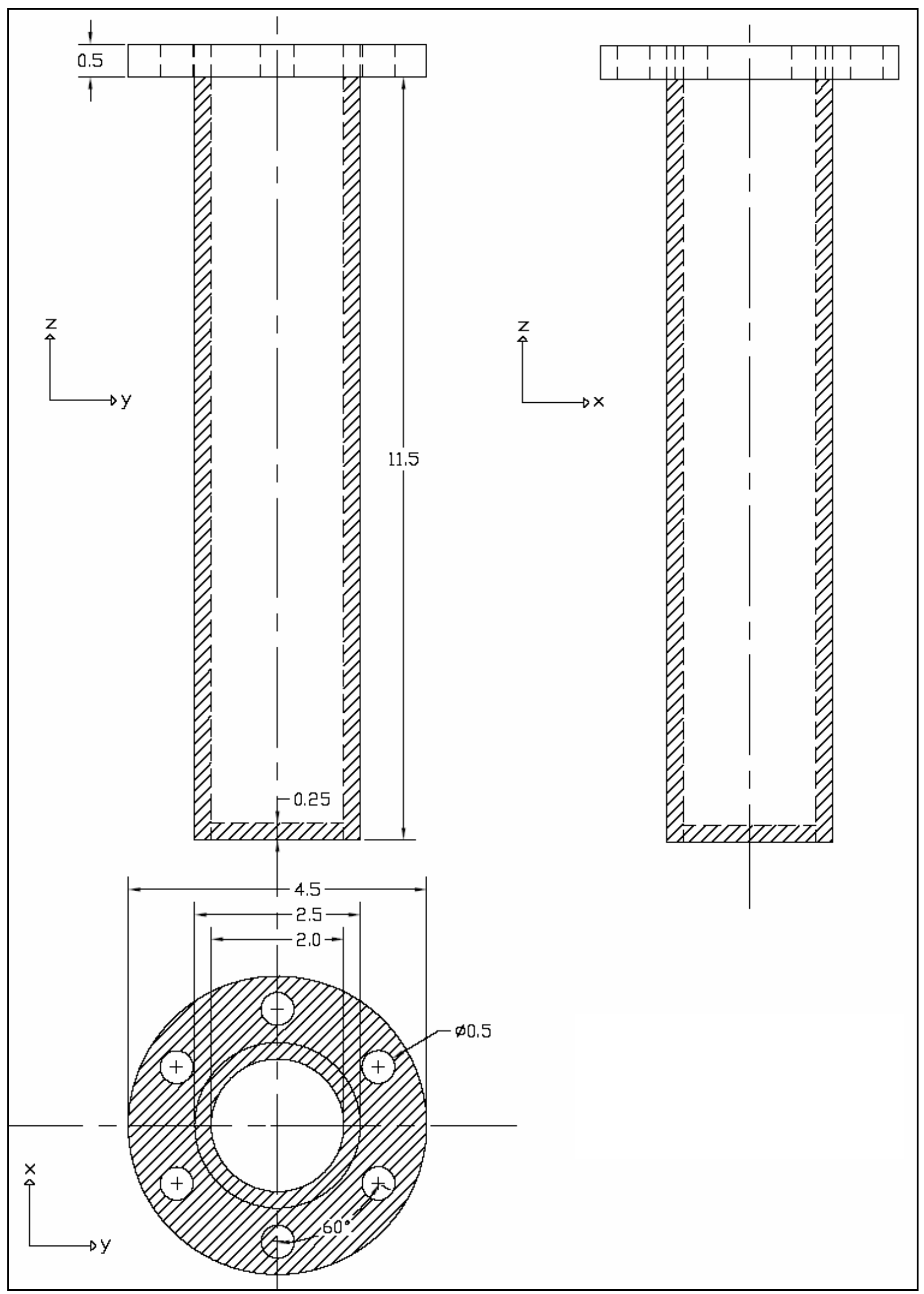

FIGURE 4-4: Dense Bin Riser Section Design, all units are in inches 


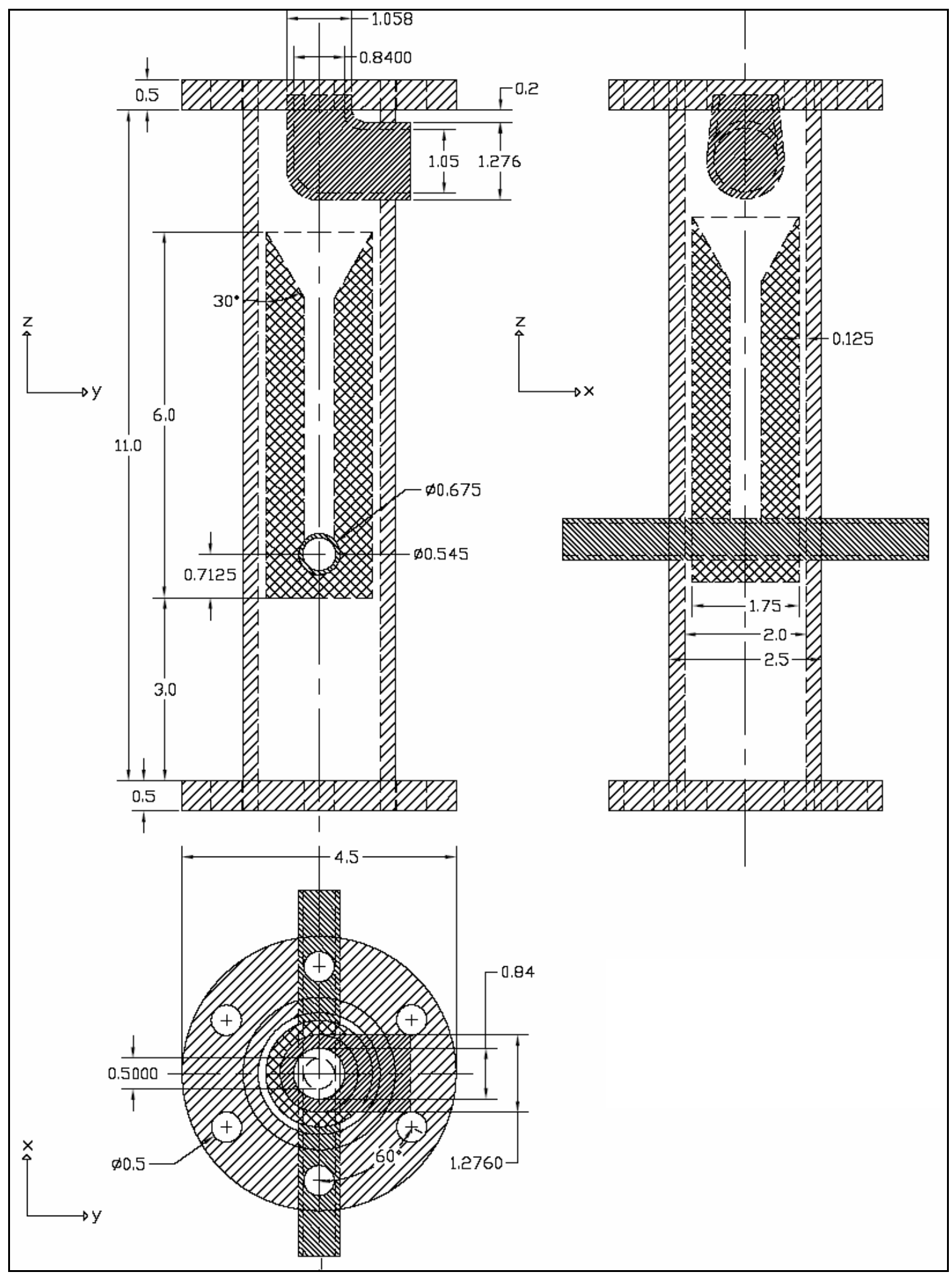

FIGURE 4-5: Injector/Distributor Section of Riser Design, all units are in inches 


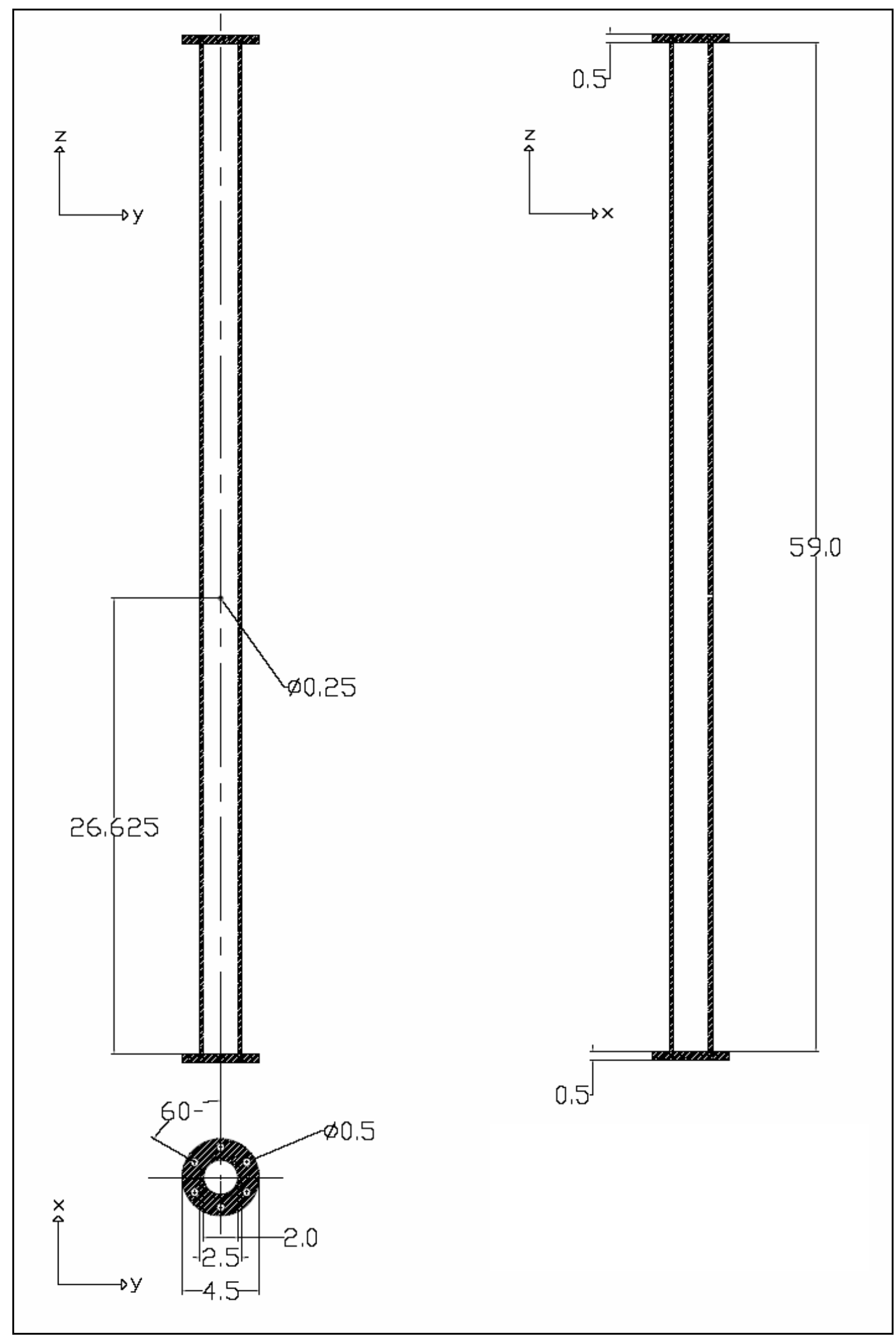

FIGURE 4-6: Main Riser Section Design, all units are in inches 


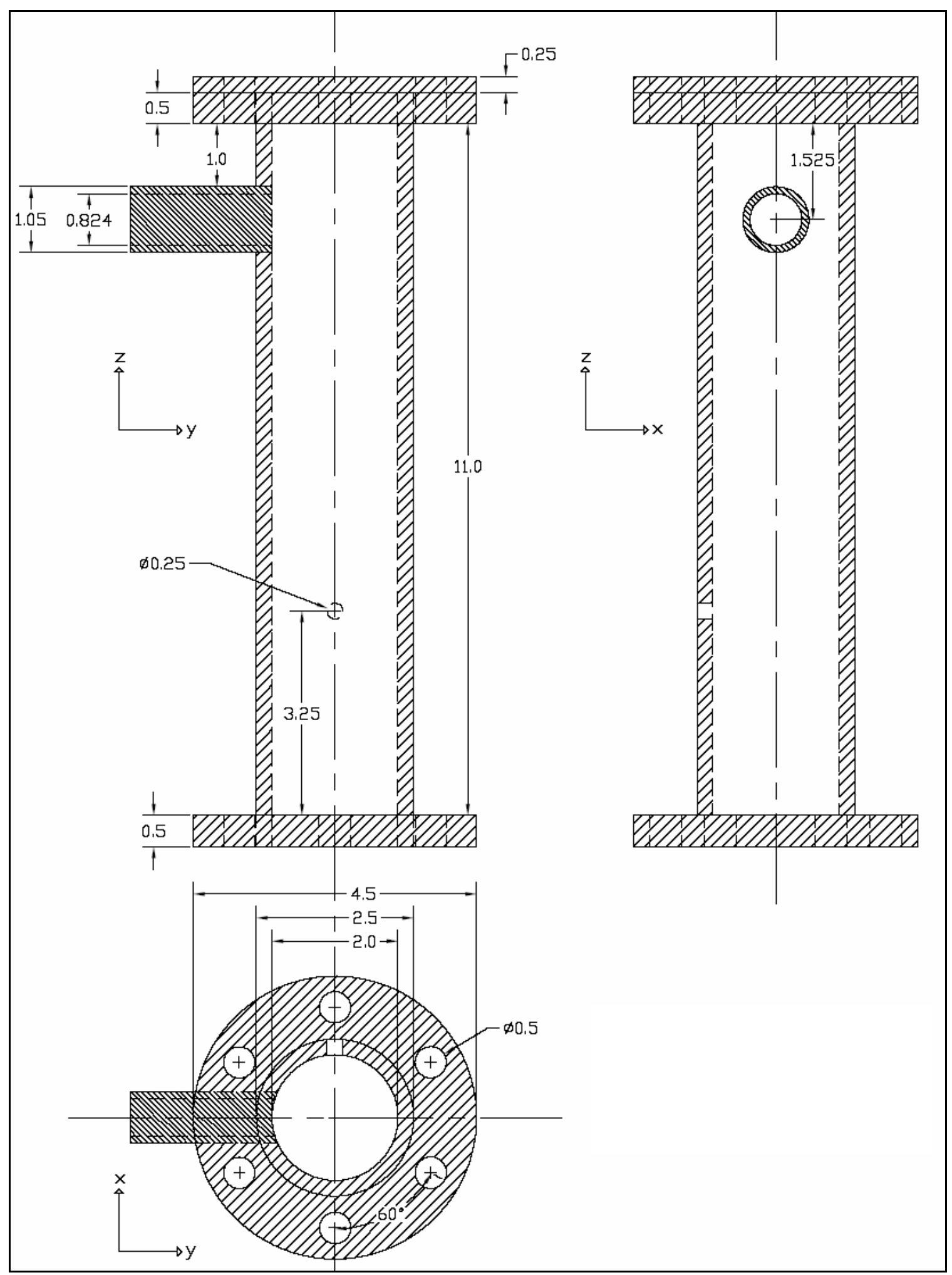

FIGURE 4-7: Top Riser Section Design, all units are in inches 


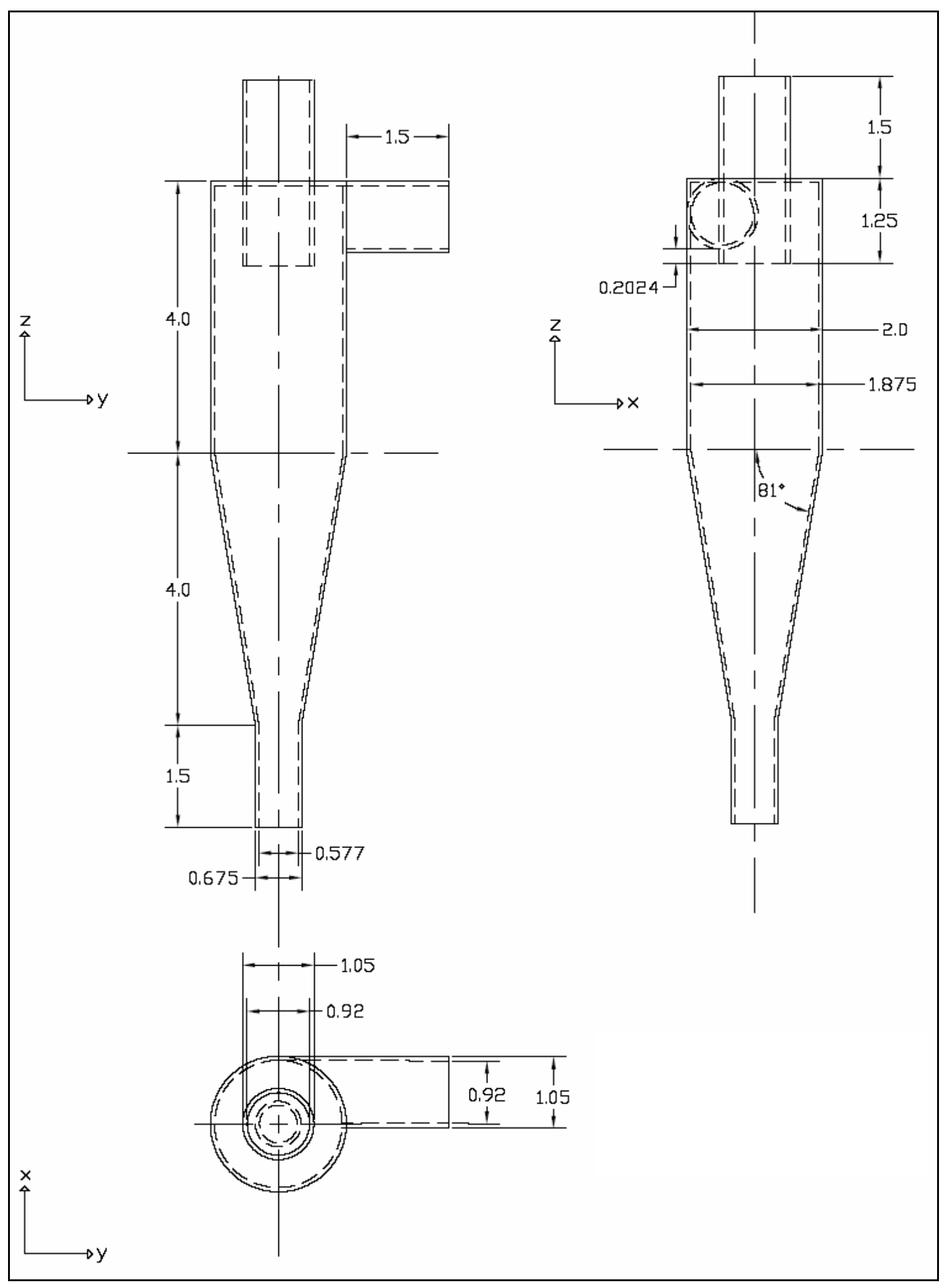

FIGURE 4-8: Cyclone Design, all units are in inches 


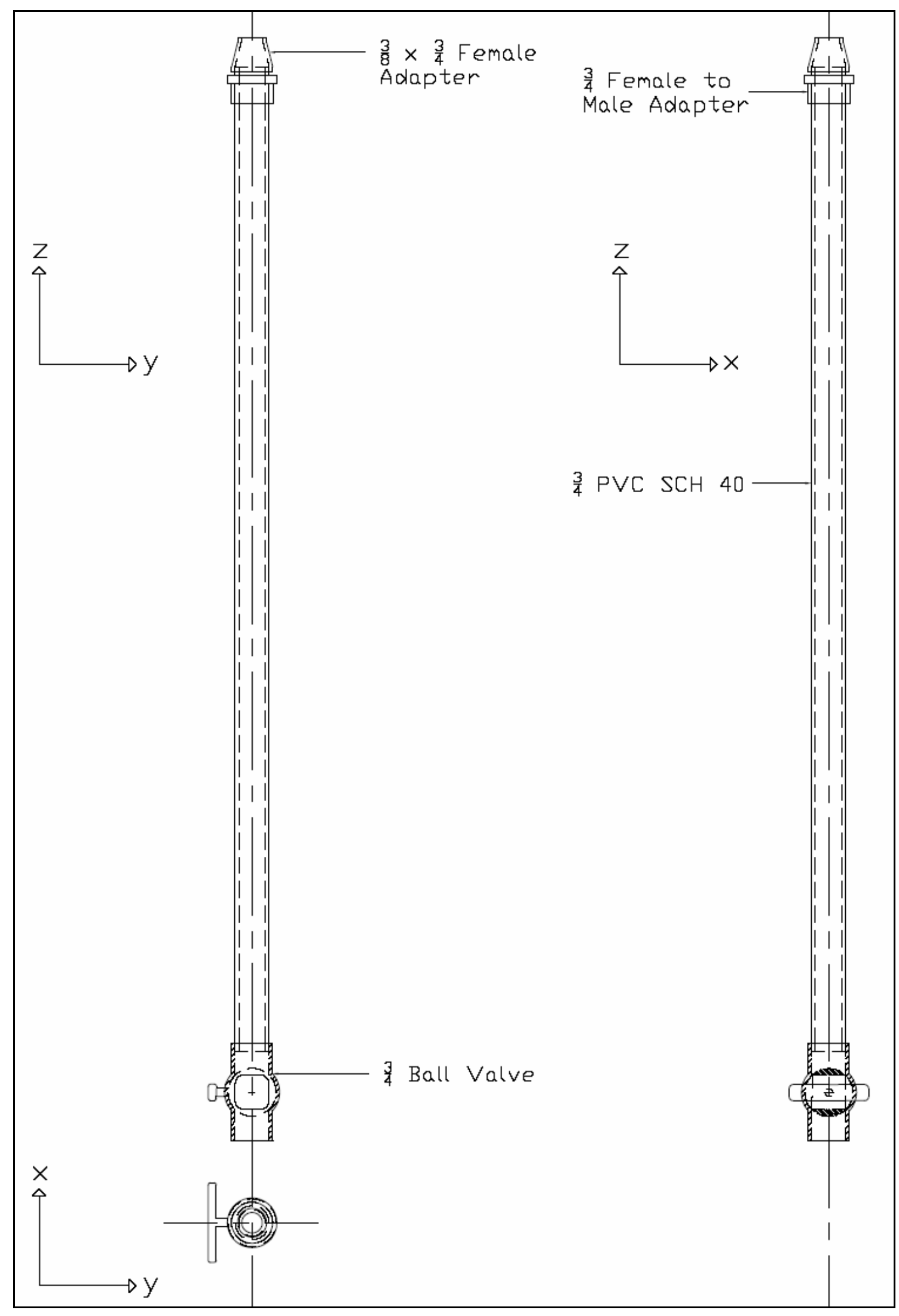

FIGURE 4-9: Product Bin Design, all units are in inches 


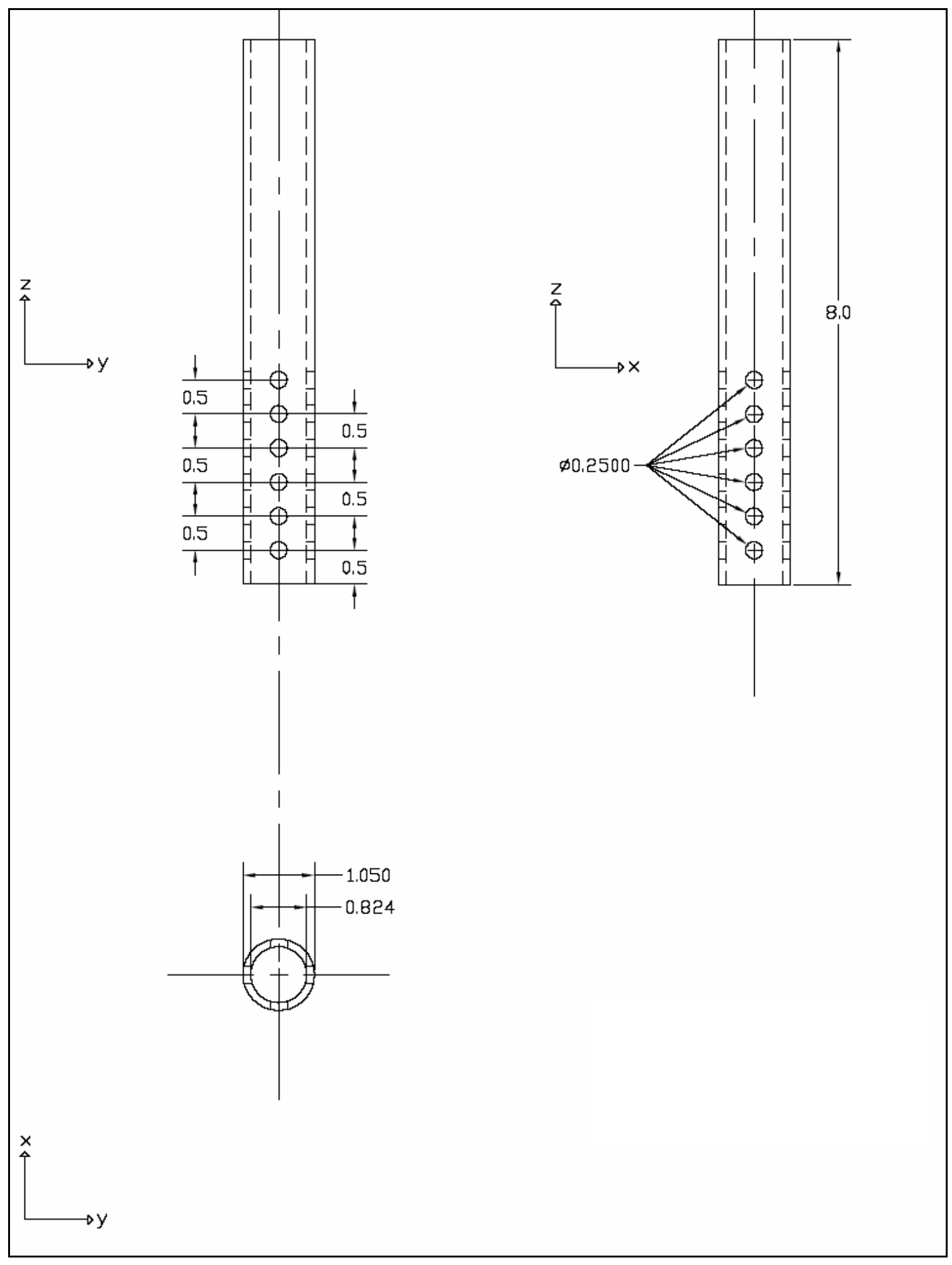

FIGURE 4-10: Exhaust Pipe Design, all units are in inches 


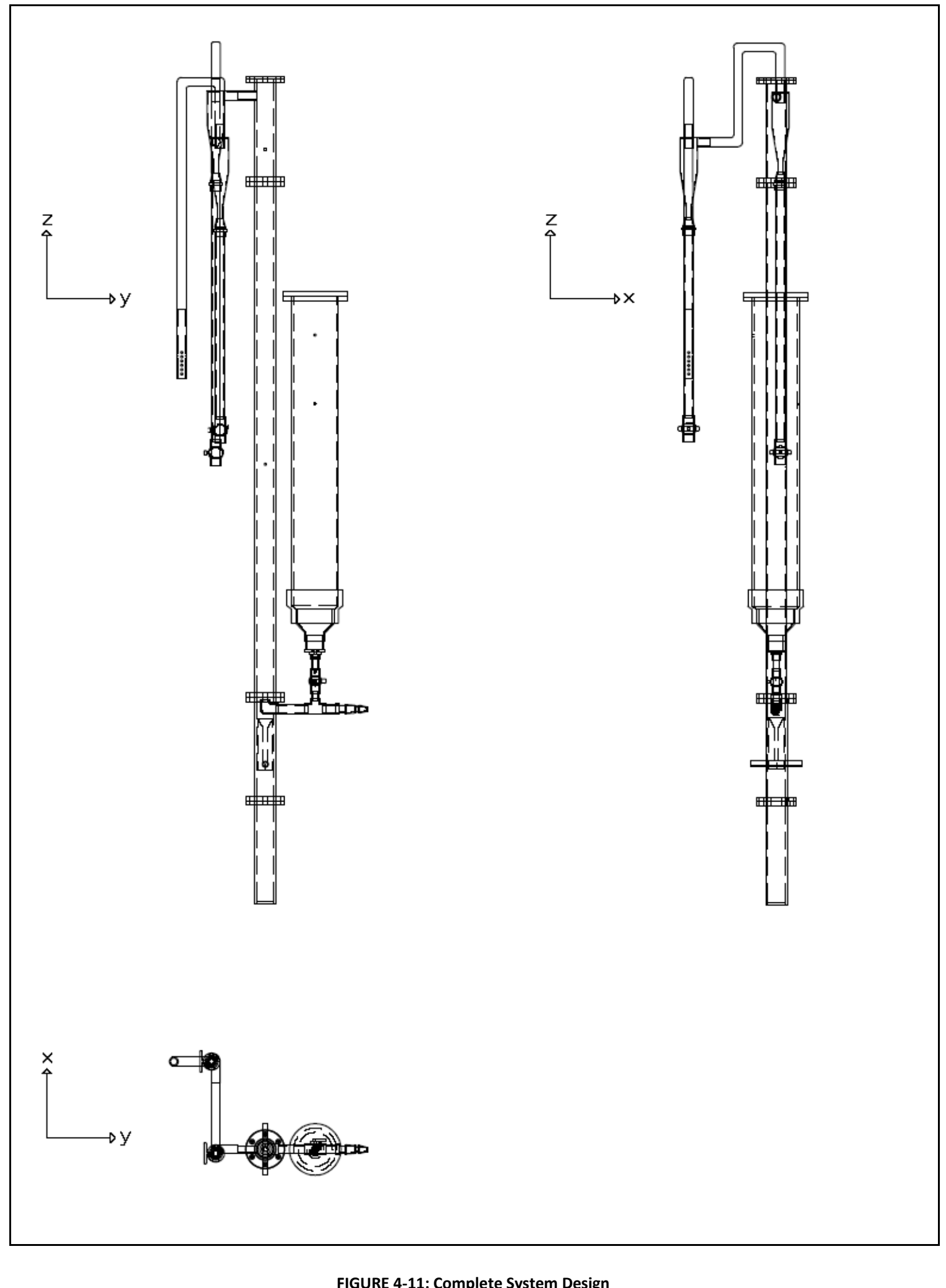




\subsection{INSTRUMENTATION}

The system uses two pressure transducers to measure the pressure inside the riser, a load cell to measure the weight of the feed hopper, and eight flow meters to measure various feeds of air. The load cell and two pressure transducers are connected to a data acquisition card in a computer where the measurements are continuously monitored and recorded.

\subsubsection{DATA ACQUISITION SYSTEM}

Several components make up the data acquisition system. The Analog Devices 5B4003 signal conditioner is used to amplify the signal from the load cell and relay the signal to the Analog Devices 5B-08 backplane. The load cell signal from the backplane along with the signals from the pressure transducers are sent to the MSTB 009-09 analog termination board. The termination board compiled the signals and transmits them to a Microstar Laboratories DAP 5200a/526 data acquisition board. The data acquisition board is connected directly to a computer and controlled by Microstar Laboratories DAPView. The program plotted the results continuously on a computer monitor while recording the values in comma separated value text files for future analysis. A diagram of the data acquisition system is shown in Figure

\subsection{2.}

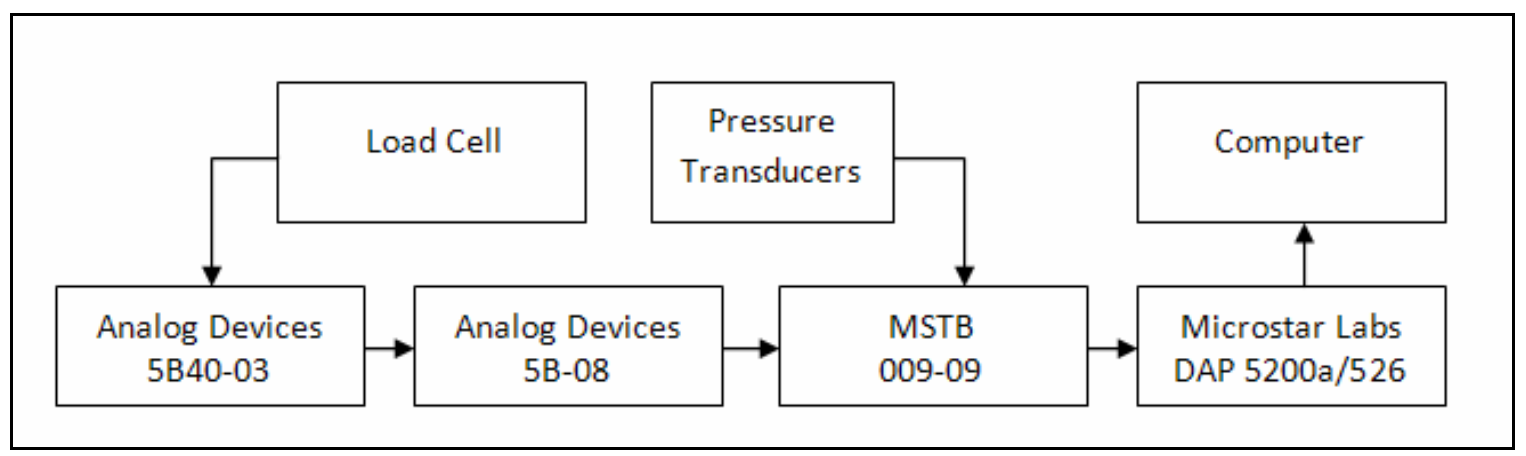

FIGURE 4-12: Data Acquisition System Diagram 


\subsubsection{FLOWMETERS}

Two different ranged flowmeters are used to control the gas flow into the system. The large flowmeter has a measurement range from 20 to 200 SCFH (0.566 to $\left.5.663 \mathrm{~m}^{3} \mathrm{hr}^{-1}\right)$ (Omega Engineering FL-2009). This flowmeter size was used to control the gas flow into the riser's distributor and on occasion also used to control the flow into the pneumatic transport tube connecting the feed hopper to the riser injector. To control lower gas flows, flowmeters with an operating range of 4 to $50 \mathrm{SCFH}\left(0.113\right.$ to $\left.1.416 \mathrm{~m}^{3} \mathrm{hr}^{-1}\right)$ (Omega Engineering FL2007) are used. Lower gas flows are needed for the pulsation system and the pneumatic transport system. All flowmeters are fitted with quick-disconnect fittings to allow easy transitioning between low and high flowmeters.

\subsubsection{PRESSURE TRANSDUCERS}

Two differential pressure transducers (Omega Engineering PX-277-01D5V) were used to measure the pressure within the riser. The transducers are rated at a full scale of 0 to 1 in $_{2} \mathrm{O}(249 \mathrm{~Pa})$ adjustable to a full scale of 0 to 0.5 inH $_{2} \mathrm{O}(124.5 \mathrm{~Pa})$ and 0 to 0.25 in $_{2} \mathrm{O}$ $(62.3 \mathrm{~Pa})$. The accuracy of the transducers is one percent of the selected full scale and the field output is adjustable from 0 to $5 \mathrm{~V}$ or 0 to $10 \mathrm{~V}$. The selected operating ranges are set at a field output of 0 to $5 \mathrm{~V}$ and a full scale rating of 0 to $0.5 \mathrm{inH}_{2} \mathrm{O}$ giving them an accuracy of $0.005 \mathrm{inH}_{2} \mathrm{O}(1.25 \mathrm{~Pa})$. The two drilled and tapped holes $(1 / 8$ in NPT), one located on the main riser section the other located on the top riser section, are fitted with barbed hose connectors. Rubber tubing connects the two measurement ports to the pressure transducers.

\subsubsection{LOAD CELL}

A load cell (Omega Engineering LC101-200), that supports a maximum load of 200lbs $(90.72 \mathrm{~kg})$, is used to suspend the feed hopper from the framing. The load cell monitors the 
weight in the feed hopper in conjunction with the data acquisition system. This allows for the calculation of the mass flux into the riser (out of the feed hopper) as well as the total mass of solids used for testing.

\subsection{StART-UP PROCEDURE}

The start-up procedure is given below with reference numbers shown in Figure 4-1.

1. Turn on power supply for riser lighting system, function generator and amplifier

2. Verify that the feed hopper valve (1.a) is closed

3. Verify product bin 1 valve (9.a) and Product Bin 2 valve (10.a) are close and that the dense bin (8) is attached and secured

4. Record weight of a new filter bag and secure on filter (11) with zip-ties

5. Take samples of initial mixture

6. Pour initial mixture into feed (1)

7. Turn on power supply to computer, load cell readouts, and pressure transducers

8. Turn on computer and launch DAPView

a. Load workspace: CFB Mini

b. Select location for load cell and pressure transducer data file storage

9. Verify that all flowmeters are closed

10. Open main air supply valve

11. Set distributor flowmeter to desired setting

12. Set pneumatic transport flowmeter to desired setting

13. Set pulsation flowmeter to desired setting

14. Turn on function generator and specify desired setting

15. Turn on amplifier

16. Set feed hopper gas flowmeter to desired setting

17. Start data acquisition software

18. Open feed hopper valve (1.a) 


\subsection{SHUt-DOWN ProceduRE}

The shut-down procedure is given below, again with references to Figure 4-1.

1. Close the feed hopper valve (1.a)

2. Shutoff feed hopper gas flowmeter

3. Visually, verify that the riser is empty if not, wait until so to continue

4. Stop data acquisition software

5. Shutoff pulsation flowmeter

6. Turn off function generator

7. Turn off amplifier

8. Shutoff pneumatic transport flowmeter

9. Shutoff distributor flowmeter

10. Remove dense bin (8) and record weight

11. Open Product Bin 1 valve (9.a) to collect solids and record weight

12. Open Product Bin 2 valve (10.a) to collect solids and record weight

13. Remove filter bag and record weight

14. Reconnect dense bin, and close Product Bin valves

15. Take samples of Product Bin 1 material, Product Bin 2 material, and dense bin

16. Pour, if any, solids from filter bag and take samples

17. Turn off computer followed turning off all other power supply units

18. Fill out proper lab documentation and submit samples for analysis

\subsection{DeVelopment of the Test Matrix}

To determine the effect of flow pulsations on separation, three different flow pulsations were considered. The first tests were conducted without flow pulsations. This was done to provide a base for comparison for tests with flow pulsations. Four different superficial gas velocities are used for this section: $0.9621 \mathrm{~ms}^{-1}, 0.9101 \mathrm{~ms}^{-1}, 0.8581 \mathrm{~ms}^{-1}$, and $0.8061 \mathrm{~ms}^{-1}$, respectively. Three tests were conducted at each superficial gas velocity for a total of twelve tests without flow pulsations. 
The superficial gas velocity was initially set equal to the terminal velocity of a spherical coal particle with a diameter of 210 microns. The following tests were conducted at reduced superficial gas velocities at graduated intervals of approximately $0.05 \mathrm{~ms}^{-1}$. This was done in order to compensate for particles with a varying percentage of pyrite as described in Chapter 3, Section 3.1.

The next group of tests considered was tests with $1 \mathrm{~Hz}$ flow pulsations. These tests differ from those of tests without flow pulsations because of the varying superficial gas velocity. These tests have a lower superficial gas velocity, $\mathrm{u}_{\mathrm{L}}$, and an upper superficial gas velocity, $\mathrm{u}_{\mathrm{U}}$, as a result of the flow pulsations. The lower superficial gas velocity accounts for the time when the solenoid valve is closed. The upper superficial gas velocity accounts for with the solenoid valve is open and additional gas is injected into the system.

The upper superficial gas velocity is selected to be the same superficial gas velocity as that used in tests without flow pulsations. This was done so that the upper superficial gas velocity would not exceed the terminal velocity of spherical pyrite particles with a diameter of 105 microns. The lower superficial gas velocity is $0.04 \mathrm{~ms}^{-1}$ below the upper superficial gas velocity (i.e. $\mathrm{u}_{\mathrm{L}}=\mathrm{u}_{\mathrm{U}}-0.04 \mathrm{~ms}^{-1}$ ). This accounts for a decrease of $10 \mathrm{SCFH}$ of the total volumetric flow rate of gas into the system. The flow velocities used for the four sets of tests with $1 \mathrm{~Hz}$ pulsations is shown in Table 4-2.

TABLE 4-2: Flow velocities and volumetric flow rates for $\mathrm{OHz}, \mathbf{1 H z}$, and $2 \mathrm{~Hz}$ pulsation tests

\begin{tabular}{|c|c|c|c|c|c|c|}
\hline & \multicolumn{2}{|c|}{ OHz Tests } & \multicolumn{4}{c|}{$1 \mathrm{~Hz}$ and 2Hz Tests } \\
\hline & $\mathrm{u}$ & $\nabla$ & $\mathrm{u}_{\mathrm{U}}$ & $\mathrm{u}_{\mathrm{L}}$ & $\mathrm{V}_{\mathrm{U}}$ & $\nabla_{\mathrm{L}}$ \\
\hline & $\mathrm{ms}^{-1}$ & $\mathrm{SCFH}$ & $\mathrm{ms}^{-1}$ & $\mathrm{~ms}^{-1}$ & $\mathrm{SCFH}$ & $\mathrm{SCFH}$ \\
\hline Set 1 & 0.9621 & 248 & 0.9621 & 0.9221 & 248 & 238 \\
\hline Set 2 & 0.9101 & 234 & 0.9101 & 0.8691 & 234 & 224 \\
\hline Set 3 & 0.8581 & 221 & 0.8581 & 0.8181 & 221 & 211 \\
\hline Set 4 & 0.8061 & 208 & 0.8061 & 0.7661 & 208 & 198 \\
\hline
\end{tabular}




$$
\begin{array}{ll}
\text { u - superficial gas velocity } & \forall-\text { volumetric flow rate } \\
\text { subscript ' } U \text { ' - upper } & \text { subscript 'L' - lower }
\end{array}
$$

Tests with $2 \mathrm{~Hz}$ pulsations were the same as tests with $1 \mathrm{~Hz}$ pulsations, the flow velocities are shown in Table 4-2. Again, the upper superficial gas velocity used was the same as tests without flow pulsations. The lower superficial gas velocity was equivalent to reducing the volumetric flow rate of gas into the riser by 10SCFH. A graphical representation of the three different flow conditions $(0 \mathrm{~Hz}, 1 \mathrm{~Hz}$, and $2 \mathrm{~Hz}$ flow pulsations) for a superficial gas velocity of $0.9521 \mathrm{~ms}^{-1}$ is shown in Figure 4-13.

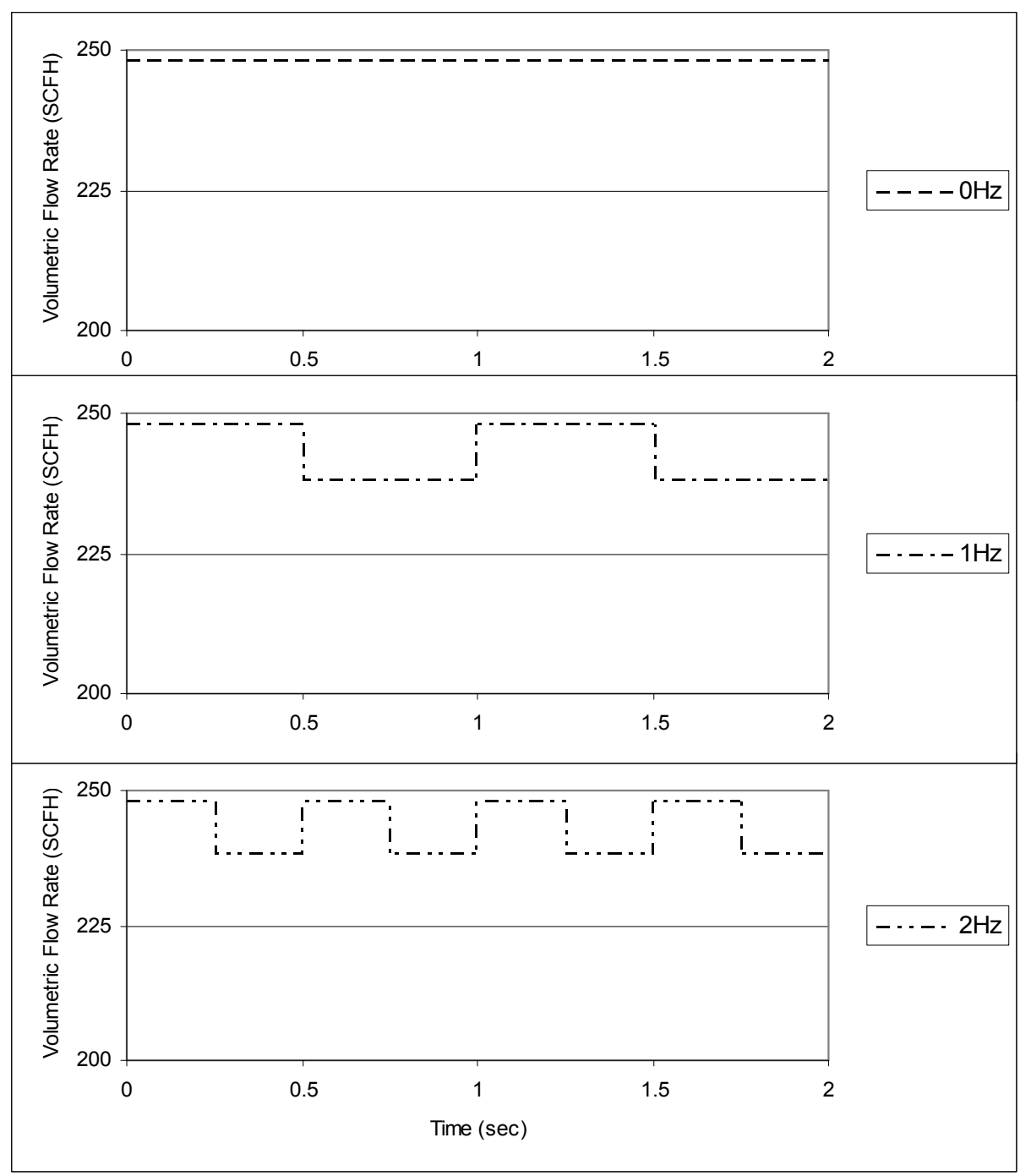

FIGURE 4-13: Graphical representation of the volumetric flow rate as a function of time for a superficial gas velocity of $0.9621 \mathrm{~ms}^{-1}$ and flow pulsations of $0 \mathrm{~Hz}, 1 \mathrm{~Hz}$ and $2 \mathrm{~Hz}$ 
Due to the limited scope of this research, the mass flow rate of solids into the system was to be held constant for all tests. The target mass flow rate into the system was set at $2.5 \mathrm{kghr}^{-1}$. This mass flow rate was selected to prevent excess solids from crowding the system and reducing separation efficiencies. 


\section{CHAPTER 5: \\ METHODS, RESULTS, AND ANALYSIS}

The results from the experimental system are presented and discussed in this chapter. Due to the large amount of data this section has been divided into several sections to present the results in the clearest manner possible. The method for sample collection and chemical analysis is also given a brief discussion.

\subsection{Chemical Analysis Process and Sampling Method}

Before the implementation of separation tests, the number of samples that needed to be taken to acquire an adequate representation of the material had to be determined. A generic test was run, and three groups of samples, all taken from the same collection bin, were submitted for chemical analysis. The first group contained three samples, the second contained six samples, and the third contained nine samples. The standard deviation and average total sulfur percentage was determined, and the analysis showed that three samples are adequate for determining the sulfur content of the coal, with only minor deviations in comparison to groups with six and nine samples. This information allowed for the minimal amount of sampling to reduce the time and total cost of the chemical analysis.

An inductively coupled plasma - optical emission spectrometer (ICP-OES) was used to analyze the total sulfur of the coal. All tests were performed by the National Research Center for Coal and Energy (NRCCE) Analytical Laboratory under the direction of Kenneth Stewart Laboratory Director. To analyze the samples, 0.5 grams of material was initially mixed with 10 milliliters of nitric acid, 5 milliliters hydrochloric acid, and 35 milliliters of deionized water. The mixture was then heated until all of the coal was digested and the total volume reduced 
from 50 milliliters to 10 milliliters. The mixture was then diluted by adding deionized water, bring the volume back again to 50 milliliters. Once the mixture had been fully prepared, it was passed through the ICP-MS where the amount of total sulfur and iron in the mixture $(\mathrm{mg} / \mathrm{L})$ was recorded. The recorded data was then converted to parts per million (ppm) in the sample using Equation 5-1. This value can then be divided by 10,000 to obtain the total percent mass of the element of interest; for the performed tests, iron and sulfur were the elements of interest.

$$
\mathrm{ppm}=\left(\mathrm{ICP}-\mathrm{MS} \text { Output } \frac{\mathrm{mg}}{\mathrm{L}}\right)\left(\frac{V_{\text {liquid }}}{m_{\text {sample }}} \frac{m L}{\mathrm{~g}}\right)\left(\frac{1 L}{1000 m L}\right)\left(\frac{1000 \mathrm{~g}}{1 \mathrm{~kg}}\right)
$$

\subsection{Method of Results Presentation}

In order to have an initial value of mass percent sulfur to compare to the final product for evaluation, a sulfur mass balance was conducted. This method assumes that the total amount of sulfur present in the final samples is equivalent to the starting value of sulfur in the initial sample. The method of determining the initial mass percent sulfur is shown below in Equation (5-2). The shown equation does not include information from the filter; however, when a sufficient amount of material was collected in the filter bag, the resulting chemical analysis and weight were also used in the analysis process. Here, mps represents mass percent sulfur, IS represents initial sample, PB1 represents Product Bin 1, PB2 represents Product Bin 2, and DB represents Dense Bin. The same method was used to calculate the iron content of the samples.

$$
\text { mps of IS }=\frac{(\mathrm{mps} P B 1 * \text { PB } 1 \text { Mass })+(\text { mps PB } 2 * \text { PB } 2 \text { Mass })+(\text { mps DB } * \text { DB Mass })}{(\text { IS Mass })}
$$


Due to the varying composition of the initial sample, a standardized form needed to be developed in order to present all of the data in a uniform manner. This was done by subtracting the mass percent sulfur of the initial sample from the mass percent sulfur from the Product Bins and Dense Bin, then dividing by the initial mass percent sulfur. This resulted in a value referred to as the percent change of mass percent sulfur. This approach also yields a negative value when the mass percent sulfur was reduced and a positive value when the mass percent sulfur increased; again, the same method was used for iron analysis. Equations 5-3A and $5-3 \mathrm{~B}$ shows this calculation.

Percent Change of MPS of Product Bin $=\frac{\text { MPS of Product Bin }- \text { MPS of Initial Sample }}{\text { MPS of Initial Sample }}$

Percent Change of MPS of Dense Bin $=\frac{\text { MPS of Dense Bin }- \text { MPS of Initial Sample }}{\text { MPS of Initial Sample }}$

The results and analysis section has been separated into two divisions to allow for the presentation of the data in two different forms. The first approach combines the two product stream results. This is done because the low volume of product collected by the secondary product bin. By combining the two product bins in the results, a more applicable volume of product can be discussed. The second approach shows the data from the two product bins independent from the other.

As previously stated, it is hypothesized that the material collected in the Product Bin will be cleaner coal, and conversely, the material collected in the Dense Bin will be dirtier coal. In the results section, the discussion will be based on the material in the Dense and Product Bins and will not specify if the coal is expected to be cleaner or dirtier. This provides a method of results presentation allows more information about the system's operation to by known. 
Finally, to prevent cluttering the results and analysis section with the presentation and discussion of individual tests, the following sections will be reserved to discuss only the results as groups. The group discussions will correspond to either the tests with the same pulsation rate or the same superficial gas velocity. However, the results from the individual tests are presented in Appendix A.

\subsection{Grouped Product Bin Analysis}

In this section all of the results will presented twice; once discussing the effects of the pulsations and again discussing the effects of the superficial gas velocity. Each subsection will discuss the results of the individual test parameters, and at the end, there is a final section that combines all of the results for a general discussion.

\subsubsection{Constant Pulsations, Varying Superficial Gas Velocity}

The first group of results to be considered are tests without pulsations and varying superficial gas velocity. These tests are used as control tests for all of the following results because they give an initial value of separation without flow pulsations. Control tests had to be conducted since the previous investigation involving separation of coal fines with the crude original experimental system did not provide any usable data (Akhtar, 2006).

There are a total of twelve tests that create the control group; four superficial gas velocities were used, each with three different tests. The highest volumetric flow rate of air used corresponds to the terminal velocity of a pure coal particle with a diameter of 210 microns. The superficial gas velocity then decreases by $\sim 0.05 \mathrm{~ms}^{-1}$ between each of the three following superficial gas velocities. This was done to account for particles with a varying pyrite percentage as discussed in Section 3.1 Determination of the Text Matrix. 
The results for tests without pulsations are shown in Figure 5-1. It should be noted that not all tests have results for the filter. This is due to the lack of sufficient material in the filter bag for chemical analysis. Linear trend lines have been added to Figure 5-1 only for the purpose of optical analysis. It should be noted that the trend lines can not be used to extrapolate data due to the independence to the horizontal axis. For this reason the equations used to generate the trend lines have not been included in the text or figure.

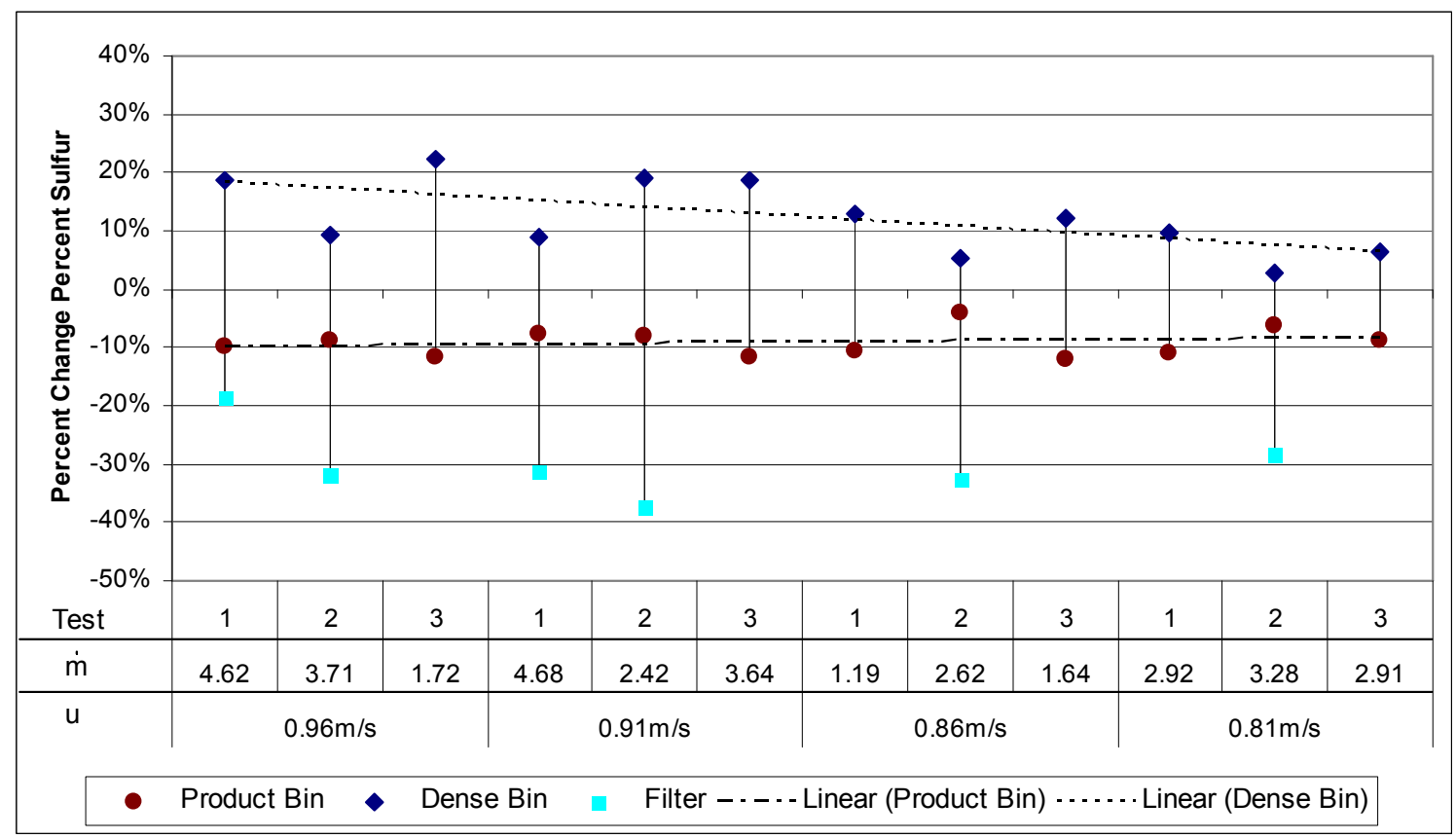

Figure 5-1: Results from tests without pulsations, coal particles $\left(105<d_{p}<210\right) \mu m$, and decreasing superficial gas velocity with grouped Product Bins.

As hypothesized, the percent change of mass percent of sulfur (PCMPS) was reduced in the Product Bin and filter with an increase seen in the Dense Bin. As the superficial gas velocity is decreased, the PCMPS decreased for both the product and dense bins. The reduction of the PCMPS in the Dense Bin may be contributed to the inability of the superficial gas velocity to adequately entrain large particles coal in the riser. Since the larger particles can not become entrained, the large particles ultimately become deposited in the Dense Bin. As explained in Chapter 3 Section 3.1, a superficial gas velocity of $0.8161 \mathrm{~ms}^{-1}$ can entrain pure 
coal particles with a maximum diameter of 194 microns, respectively. Thus, any particle larger than 194 microns, regardless of the percentage of pyrite, should be collected as waste material in the Dense Bin. The reduction of the superficial gas velocity has a minor effect on the PCMPS of the Product Bin, slightly reducing the PCMPS as the superficial gas velocity is decreased.

The control tests, tests with $\mathrm{OHz}$ pulsations, had an average PCMPS in the Product Bin of $-9.2 \%$ with a standard deviation of $2.5 \%$; the Dense Bin has an average PCMPS of $12.2 \%$ with a standard deviation of $6.3 \%$. The average mass percent sulfur of the initial sample is 1.91 with a standard deviation of $0.21 \%$; the average mass percent sulfur of the Product Bin is 1.73 with a standard deviation of $0.18 \%$; and the average mass percent sulfur of the Dense Bin is 2.15 with a standard deviation of $0.33 \%$.

The second group of tests to be discussed is tests with $1 \mathrm{~Hz}$ gas pulsations. The pulsations for the $1 \mathrm{~Hz}$ tests were created using $10 \mathrm{SCFH}$ of air, pressurized at approximately 105psig that passed through a solenoid valve. A full description of the equipment used to create the flow pulsations is discussed in detail in Section 4.1.10 Pulsation Generator. The effect of the $1 \mathrm{~Hz}$ flow pulsations on the riser pressure is shown in Figure 5-2 with the relative status of the valve; open or closed. Due to the length of time required to determine the percent sulfur in the products after a test, only the pre-described pulsation setting could be investigated.

Figure 5-2 shows a two second sample of the riser pressure as a function of time for a test with $1 \mathrm{~Hz}$ pulsations, $\mathrm{u}_{0}=0.9101 \mathrm{~ms}^{-1}$ and a mass flow rate of $3.53 \mathrm{ks}-\mathrm{hr}^{-1}$. At time zero, the valve is in the process of opening. The sharp rise in the riser pressure can be attributed to the opening of the valve with the release of the high pressure air. When the valve's back pressure 
is relieved, the riser pressure drops to a pseudo-constant value. At time $\sim 0.5$ seconds, the valve has closed and the riser pressure is returns to the pressure of normal operation without flow pulsations. At time $\sim 1.0$ second, the valve reopens and the pressure fluctuations repeat.

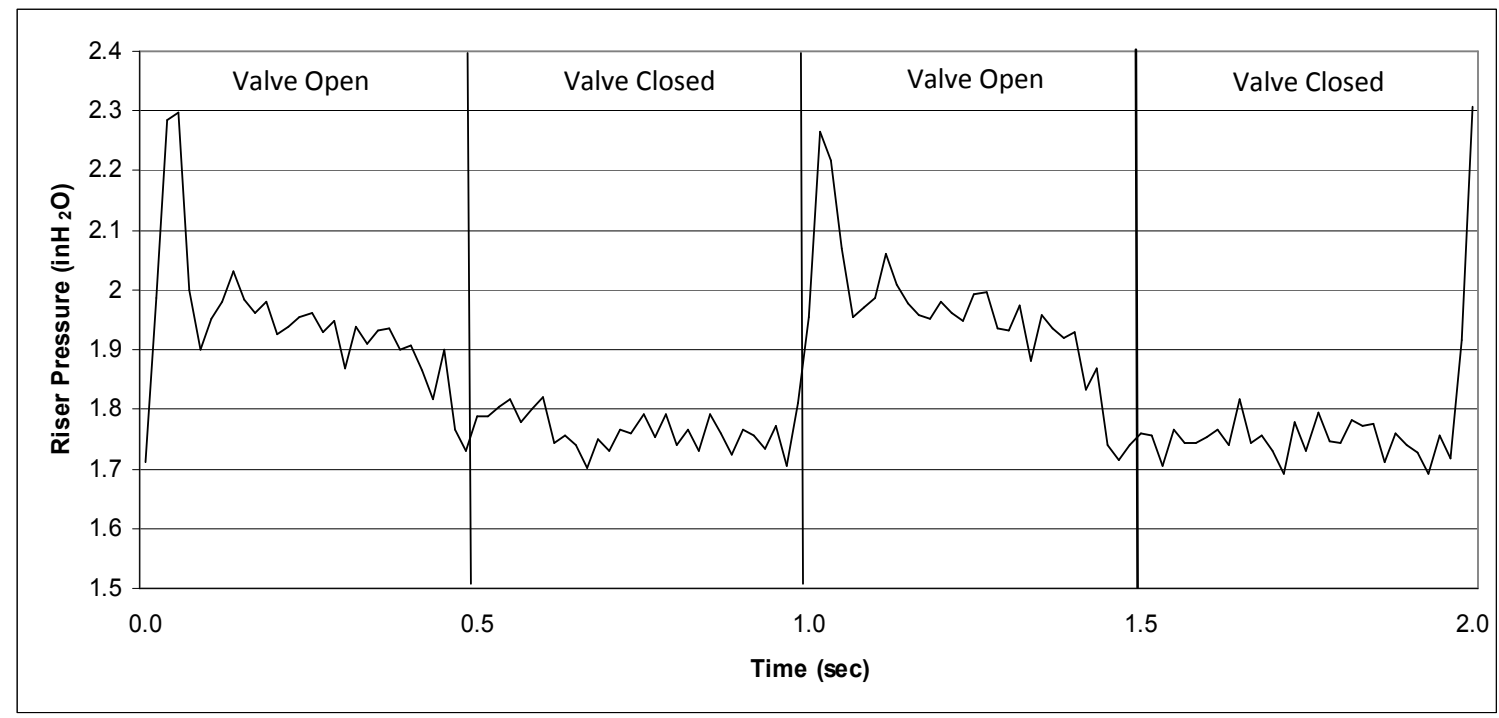

FIGURE 5-2: Riser Pressure $\left(\mathrm{inH}_{2} \mathrm{O}\right)$ for $1 \mathrm{~Hz}$ pulsation test. Test conditions included $\left(\mathrm{u}_{0}=0.9101 \mathrm{~ms}^{-1}, \dot{m}=3.53 \mathrm{~kg}^{-\mathrm{hr}^{-1}}\right)$ for coal particles $\left(105<d_{p}<210\right) \mu m$

To determine the effect of separation as a function of $1 \mathrm{~Hz}$ pulsations, a total of twelve tests were preformed; four superficial gas velocities were used, each with three different tests. The results for tests with $1 \mathrm{~Hz}$ pulsations are shown in Figure 5-3. Unlike the tests with $\mathrm{OHz}$ pulsations, the tests with $1 \mathrm{~Hz}$ pulsations show an increase of the PCMPS with the reduction of the superficial gas velocity; however, like the tests with $\mathrm{OHz}$ pulsations, there is also a decrease in the PCMPS of the Dense Bin with the decrease in the superficial gas velocity. This, again, may be attributed to the dilution of the dirtier coal with relative clan coal particles that were too large to be properly entrained in the flow. The figure shows that tests with a superficial gas velocity of $0.8581 \mathrm{~ms}^{-1}$ and $0.8061 \mathrm{~ms}^{-1}$ have the largest PCMPS for the Product Bin than the other superficial gas velocities. 


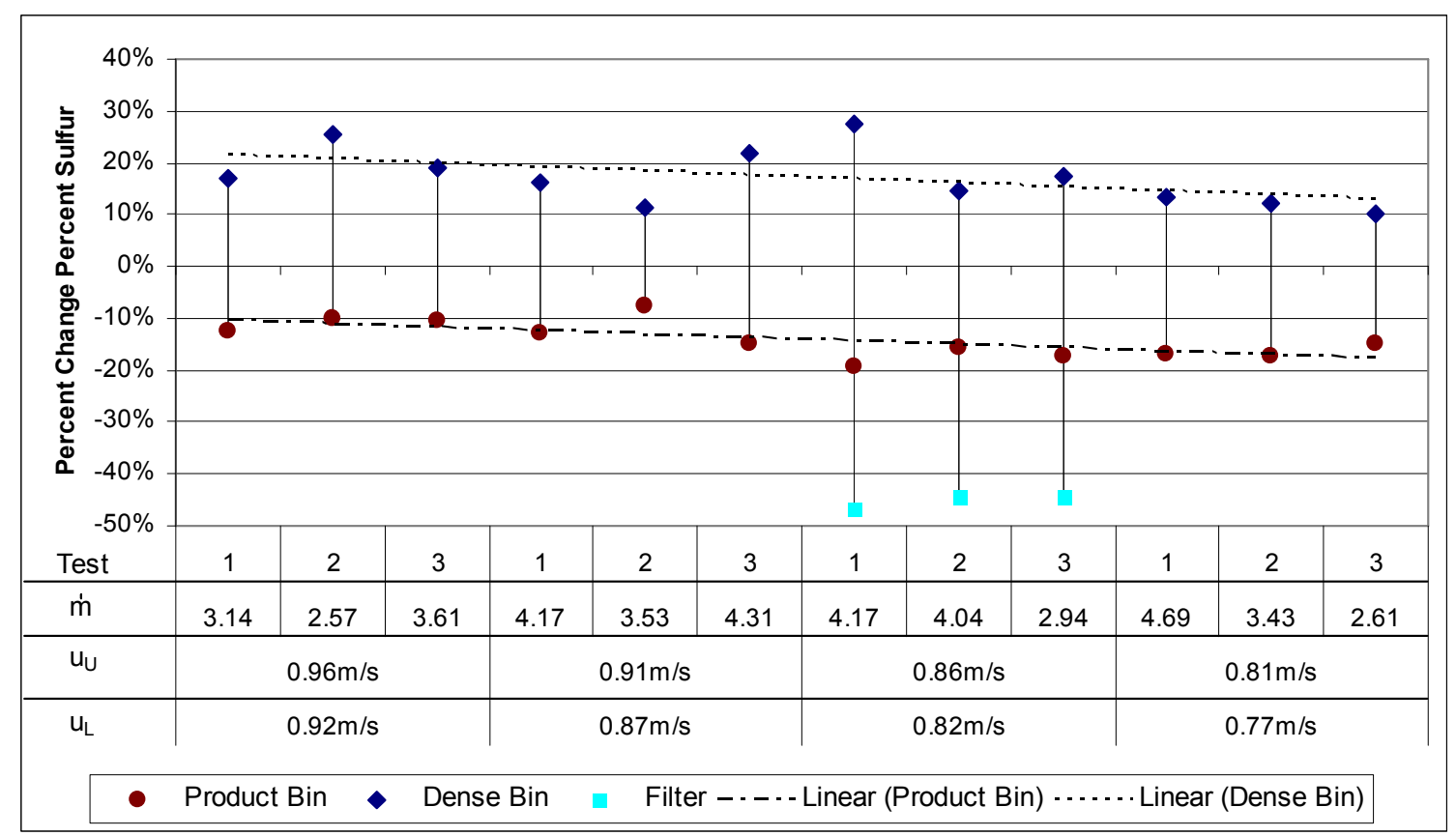

FIGURE 5-3: Results from tests with $1 \mathrm{~Hz}$ pulsations, coal particles $\left(105<\mathrm{d}_{\mathrm{p}}<210\right) \mu \mathrm{m}$, and decreasing superficial gas velocity with grouped Product Bins.

Tests with $1 \mathrm{~Hz}$ pulsations had an average PCMPS in the Product Bin of $-14.12 \%$ with a standard deviation of 3.5\%; the Dense Bin has an average PCMPS of $17.19 \%$ with a standard deviation of $5.53 \%$. The average mass percent sulfur of the initial sample is 1.79 with a standard deviation of $0.32 \%$; the average mass percent sulfur of the Product Bin is 1.55 with a standard deviation of $0.33 \%$; and the average mass percent sulfur of the Dense Bin is 2.11 with a standard deviation of $0.42 \%$.

The final group of this section to be discussed are tests with $2 \mathrm{~Hz}$ gas pulsations. The pulsations for the $2 \mathrm{~Hz}$ tests were created the same way as the $1 \mathrm{~Hz}$ tests, using $10 \mathrm{SCFH}$ of air pressurized at approximately 105psi that passed through a solenoid valve. The valve was programmed to open for a quarter of a second, and then close for a quarter of a second; this action was repeated for the length of the test. The effect of the $2 \mathrm{~Hz}$ flow pulsations on the riser pressure is shown in Figure 5-4 with the relative status of the valve; open or closed. 
Again, due to the length of time required to process the products after a test, only the predescribed pulsation setting could be investigated.

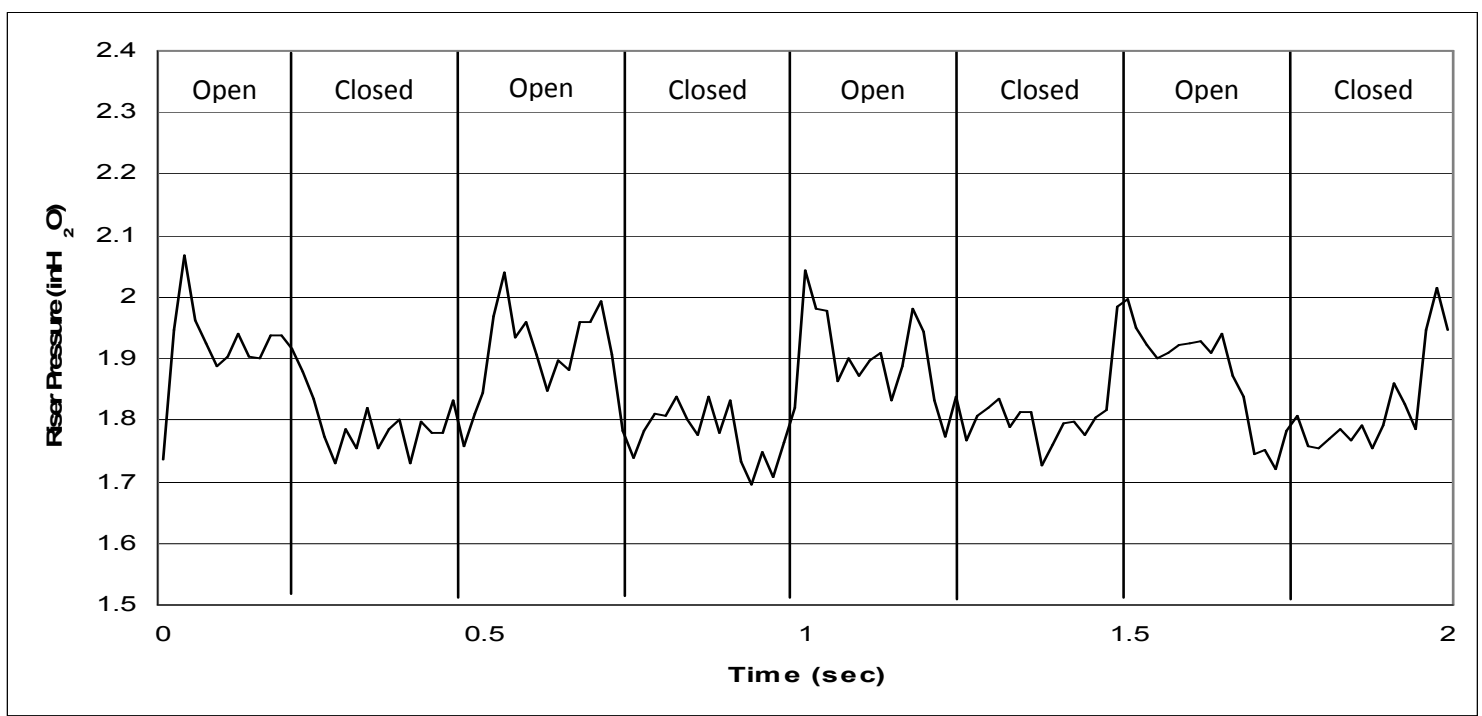

FIGURE 5-4: Riser Pressure $\left(\mathrm{inH}_{2} \mathrm{O}\right)$ for $2 \mathrm{~Hz}$ pulsation test. Test conditions included $\left(\mathrm{u}_{0}=0.9101 \mathrm{~ms}^{-1}, \dot{m}=3.46 \mathrm{~kg}^{-\mathrm{hr}^{-1}}\right)$ for coal particles $\left(105<d_{p}<210\right) \mu m$

Figure 5-4 shows a two second sample of the riser pressure as a function of time for a test with $2 \mathrm{~Hz}$ pulsations, $\mathrm{u}_{0}=0.9101 \mathrm{~ms}^{-1}$, and a mass flow rate of $3.46 \mathrm{ks}-\mathrm{hr}^{-1}$. At time zero, the valve is process of opening; at time $\sim 0.25$ seconds, the valve has closed and the riser pressure returns to the pressure of normal operation without flow pulsations; and at time $\sim 0.5$ second, the valve reopens and the pressure fluctuations repeat.

To determine the effect of separation as a function of $2 \mathrm{~Hz}$ pulsations, a total of twelve tests were preformed; four superficial gas velocities were used, each with three different tests. The results for tests with $2 \mathrm{~Hz}$ pulsations are shown in Figure 5-5. Similar to the tests with $1 \mathrm{~Hz}$ pulsations, the tests with $2 \mathrm{~Hz}$ pulsations show an increase the PCMPS with the reduction of the superficial gas velocity; but not as much as the $1 \mathrm{~Hz}$ pulsation tests. Resembling the tests with $0 \mathrm{~Hz}$ and $1 \mathrm{~Hz}$ pulsations, the PCMPS of the Dense Bin reduces with the decrease in the superficial gas velocity. 


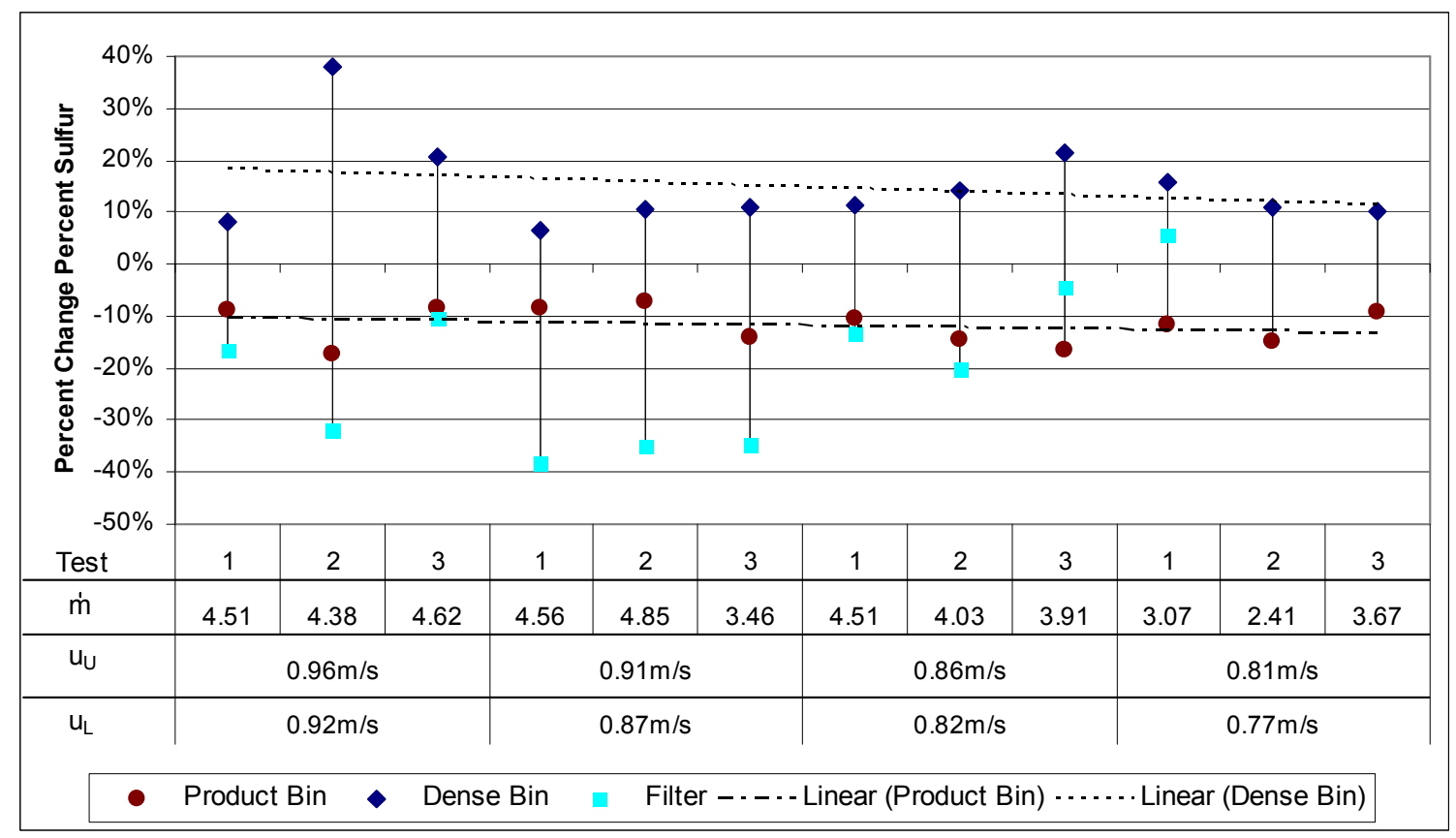

FIGURE 5-5: Results from tests with $2 \mathrm{~Hz}$ pulsations, coal particles $\left(105<\mathrm{d}_{\mathrm{p}}<210\right) \mu \mathrm{m}$, and decreasing superficial gas velocity with grouped Product Bins.

Tests with $2 \mathrm{~Hz}$ pulsations have an average PCMPS in the Product Bin of $-11.82 \%$ with a standard deviation of $3.51 \%$; the Dense Bin has an average PCMPS of $14.86 \%$ with a standard deviation of $8.56 \%$. The average mass percent sulfur of the initial sample is 1.57 with a standard deviation of $0.20 \%$; the average mass percent sulfur of the Product Bin is 1.39 with a standard deviation of $0.21 \%$; and the average mass percent sulfur of the Dense Bin is 1.80 with a standard deviation of $0.22 \%$.

Table 5-1 has all of the results from the tests with constant flow pulsations and varying superficial gas velocity. The table shows that tests with $1 \mathrm{~Hz}$ pulsations have been the most effective in reducing the amount of sulfur from the initial sample; reducing the PCMPS of the Product Bin almost $5 \%$ more than tests with $\mathrm{OHz}$ pulsations and as much as $2.3 \%$ more than tests with $2 \mathrm{~Hz}$ pulsations. 


\begin{tabular}{|c|c|c|c|c|c|c|c|c|c|c|}
\hline & & \multicolumn{3}{|c|}{$\mathrm{OHz}$} & \multicolumn{3}{|c|}{$1 \mathrm{~Hz}$} & \multicolumn{3}{|c|}{$2 \mathrm{~Hz}$} \\
\hline & & 䳮 & 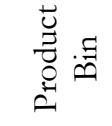 & 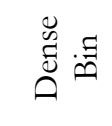 & 㞼 节 & 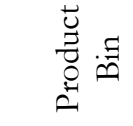 & 岂 & 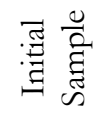 & 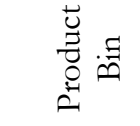 & 峁 \\
\hline \multirow{2}{*}{$\hat{E}$} & Average & $1.91 \%$ & $1.73 \%$ & $2.15 \%$ & $1.79 \%$ & $1.55 \%$ & $2.11 \%$ & $1.57 \%$ & $1.39 \%$ & $1.80 \%$ \\
\hline & $\begin{array}{c}\text { Standard } \\
\text { Deviation } \\
\end{array}$ & $0.21 \%$ & $0.18 \%$ & $0.33 \%$ & $0.32 \%$ & $0.33 \%$ & $0.42 \%$ & $0.20 \%$ & $0.21 \%$ & $0.22 \%$ \\
\hline \multirow{2}{*}{$\sum_{\infty}^{\infty}$} & Average & & $-9.20 \%$ & $12.21 \%$ & & $-14.12 \%$ & $17.19 \%$ & & $-11.82 \%$ & $14.86 \%$ \\
\hline & $\begin{array}{c}\text { Standard } \\
\text { Deviation }\end{array}$ & & $2.45 \%$ & $6.25 \%$ & & $3.50 \%$ & $5.53 \%$ & & $3.51 \%$ & $8.56 \%$ \\
\hline
\end{tabular}

It should be noted that the data presented in Table 5-1 averages the data regardless of the superficial gas velocity; more detailed tables are located in Appendix A. It should also be noted that the MPS of the initial samples of the three different groups varies broadly; for this reason, the results have been described with the percent change of mass percent sulfur as previously described in Section 5.2.

\subsubsection{Constant Superficial Gas Velocity, Varying pulsation Rate}

This section, as well as the three subsequent sections, is dedicated to investigating the effect of varying the pulsation rate while holding the superficial gas velocity constant. This was done to determine the effect of the rate of pulsation for specific superficial gas velocities.

The first velocity investigated is $0.9621 \mathrm{~ms}^{-1}$, whose results are shown in Figure 5-6. This figure shows that the rate of pulsation has little, if any effect on the separation. The trend line shown in the figure does show a slight increase in the PCMPS in the Product Bin and an increase in PCMPS for the Dense Bin; however, both trend lines are strongly influenced by the second $2 \mathrm{~Hz}$ pulsation test that sustained an increase of $37 \%$ in the Dense Bin and a decrease of $17 \%$ in the Product Bin, which were unique to that test. Again, it is imperative to point out 
that the trend lines can not be used to extrapolate data due to the independence to the horizontal axis and for this reason the equations that were used to generate the trend lines have been suppressed.

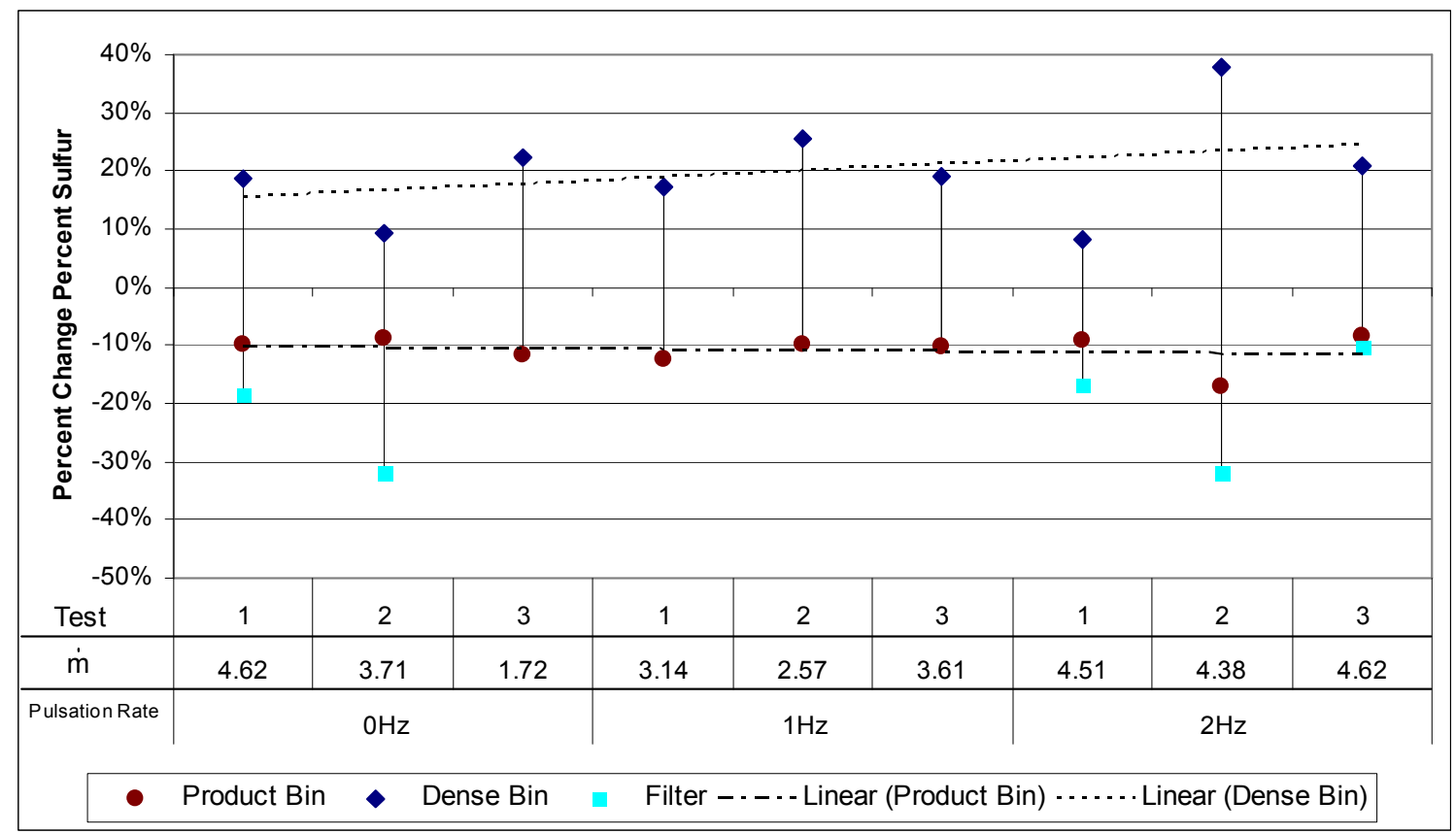

FIGURE 5-6: Results from tests with superficial gas velocity $u_{0}=0.9621 \mathrm{~ms}^{-1}$, coal particles $\left(105<d_{p}<210\right) \mu \mathrm{m}$, varying pulsation rates $(\mathrm{OHz}, 1 \mathrm{~Hz}$, and $2 \mathrm{~Hz})$, and grouped Product Bins.

Tests with a constant superficial gas velocity of $0.9621 \mathrm{~ms}^{-1}$ have an average PCMPS in the Product Bin of $-10.87 \%$ with a standard deviation of $2.73 \%$; the Dense Bin has an average PCMPS of $19.85 \%$ with a standard deviation of $8.82 \%$. The average mass percent sulfur of the initial sample is 1.92 with a standard deviation of $0.22 \%$; the average mass percent sulfur of the Product Bin is 1.72 with a standard deviation of $0.23 \%$; and the average mass percent sulfur of the Dense Bin is 2.30 with a standard deviation of $0.26 \%$.

Figure 5-7 shows the results for tests with a constant superficial gas velocity of $0.9101 \mathrm{~ms}^{-1}$. Again it is shown that the pulsations seem to have little effect on separation with only a slight decrease shown in the PCMPS of the Dense Bin with increasing pulsation rates. 
The PCMPS is seen to be relatively constant for the Product Bin with increasing pulsation rate, with all of the results near a $10 \%$ decrease.

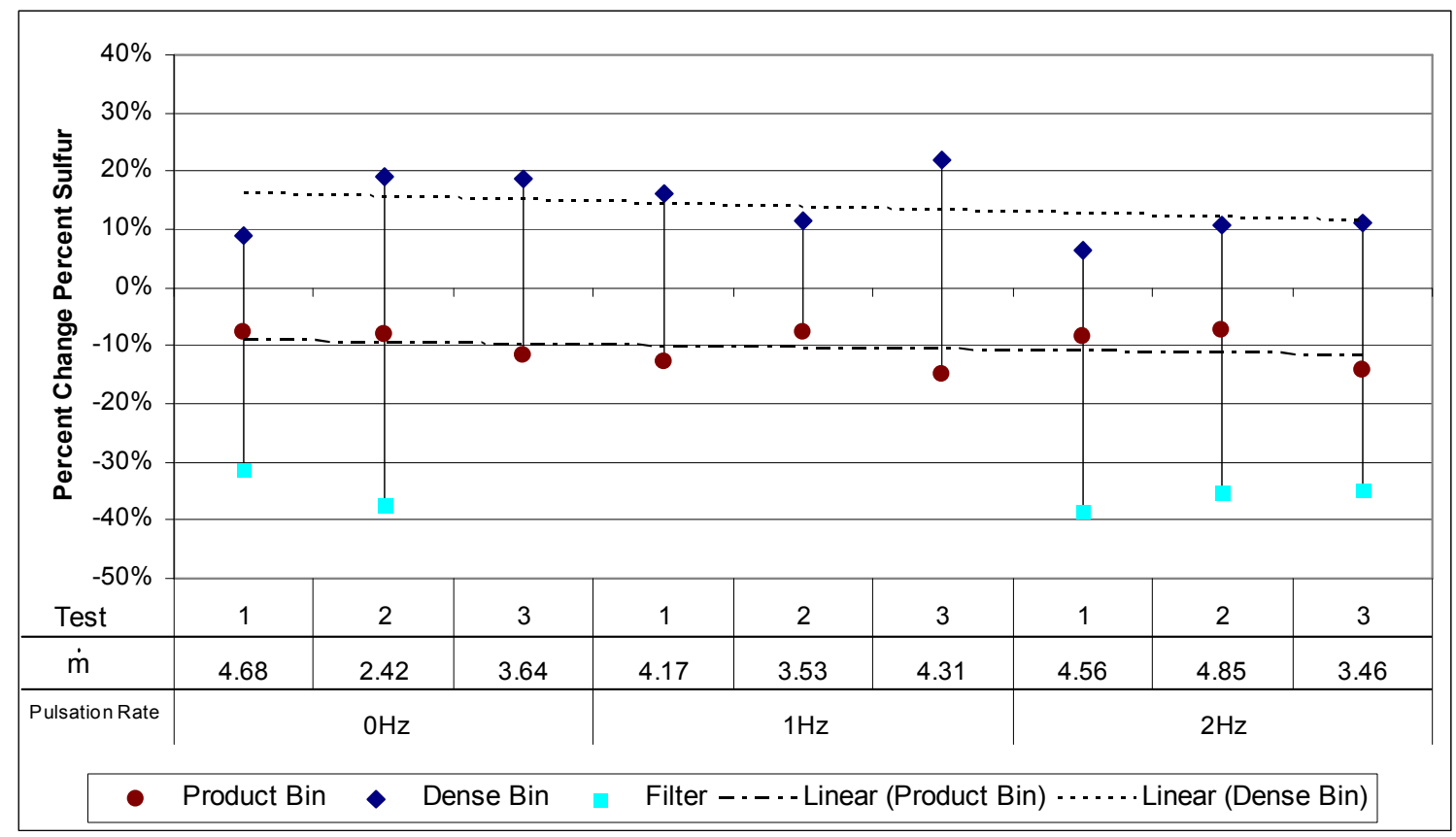

FIGURE 5-7: Results from tests with superficial gas velocity $u_{0}=0.9101 \mathrm{~ms}^{-1}$, coal particles $\left(105<d_{p}<210\right) \mu \mathrm{m}$, varying pulsation rates $(\mathrm{OHz}, 1 \mathrm{~Hz}$, and $2 \mathrm{~Hz})$, and grouped Product Bins.

Tests with a constant superficial gas velocity of $0.9101 \mathrm{~ms}^{-1}$ have an average PCMPS in the Product Bin of $-10.31 \%$ with a standard deviation of $3.15 \%$; the Dense Bin has an average PCMPS of $13.81 \%$ with a standard deviation of $5.33 \%$. The average mass percent sulfur of the initial sample is 1.93 with a standard deviation of $0.22 \%$; the average mass percent sulfur of the Product Bin is 1.73 with a standard deviation of $0.21 \%$; and the average mass percent sulfur of the Dense Bin is 2.20 with a standard deviation of $0.33 \%$.

The next velocity to be investigated is $0.8581 \mathrm{~ms}^{-1}$, whose results are shown in Figure 58. This figure shows that the rate of pulsation does have an effect on the separation. Tests with $1 \mathrm{~Hz}$ pulsations have a larger PCMPS for the Product Bin as well as the Dense Bin. On average, the tests with $1 \mathrm{~Hz}$ pulsation had two times the PCMPS than tests with $2 \mathrm{~Hz}$ pulsations and 4.9 times the PCMPS than that of tests without pulsations. Although the filter data is 
incomplete, the figure also shows that the pulsations also have an advantages effect on the sulfur reduction for the Filter.

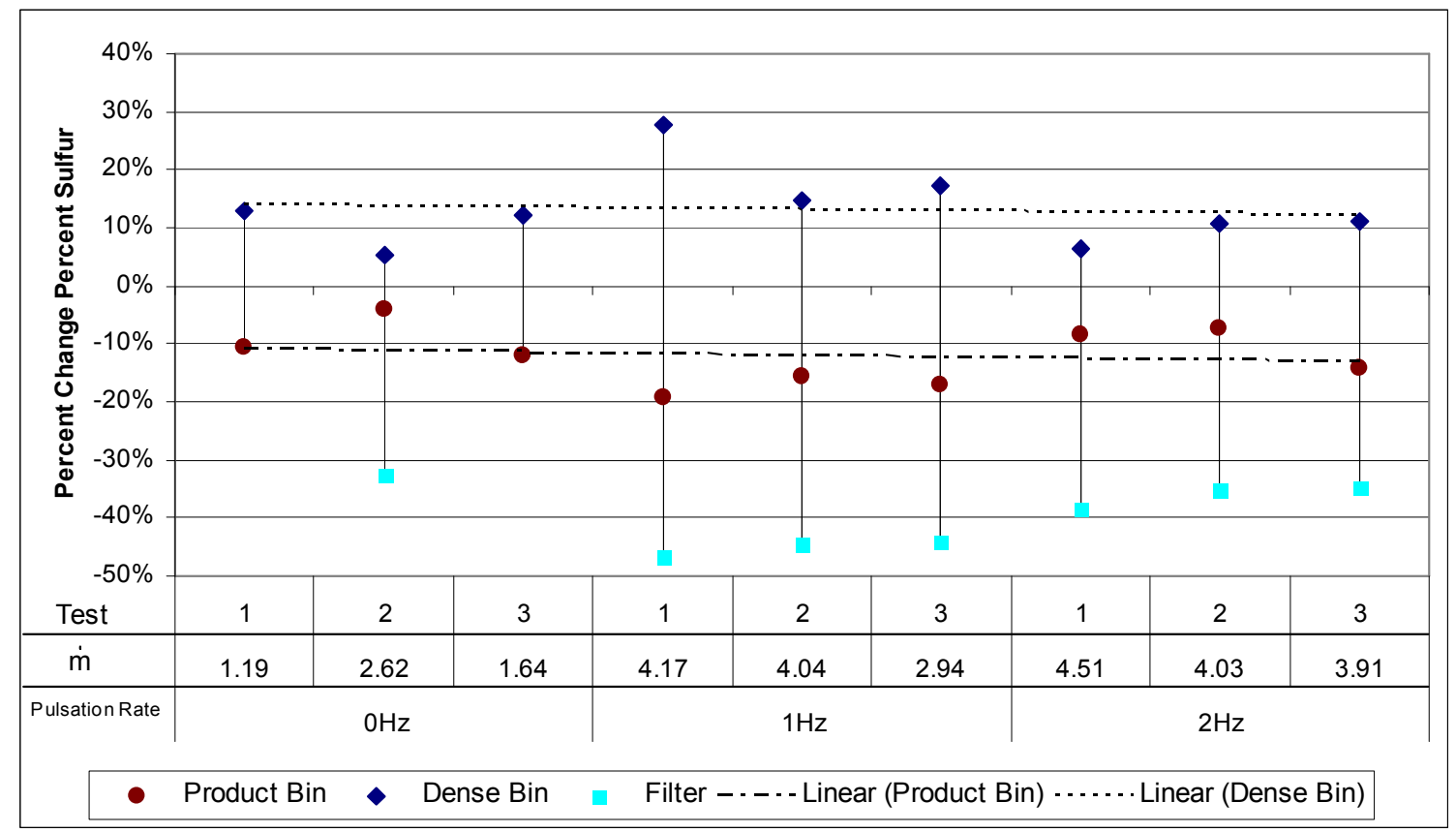

FIGURE 5-8: Results from tests with superficial gas velocity $u_{0}=0.8581 \mathrm{~ms}^{-1}$, coal particles $\left(105<d_{p}<210\right) \mu m$, varying pulsation rates $(\mathrm{OHz}, 1 \mathrm{~Hz}$, and $2 \mathrm{~Hz})$, and grouped Product Bins.

Tests with a constant superficial gas velocity of $0.8581 \mathrm{~ms}^{-1}$ have an average PCMPS in the Product Bin of $-13.34 \%$ with a standard deviation of $4.65 \%$; the Dense Bin has an average PCMPS of $15.22 \%$ with a standard deviation of $6.36 \%$. The average mass percent sulfur of the initial sample is 1.69 with a standard deviation of $0.23 \%$; the average mass percent sulfur of the Product Bin is 1.47 with a standard deviation of $0.23 \%$; and the average mass percent sulfur of the Dense Bin is 1.94 with a standard deviation of $0.24 \%$.

The final velocity to be investigated is $0.8061 \mathrm{~ms}^{-1}$, whose results are shown in Figure 59. This figure shows that the rate of pulsation again has an effect on the separation; however, not as drastic as those seen for the previous superficial gas velocity. Tests with $1 \mathrm{~Hz}$ pulsations have a larger PCMPS for the Product Bin as well as the Dense Bin. On average, the tests with 
$1 \mathrm{~Hz}$ pulsation had 1.4 times the PCMPS than tests with $2 \mathrm{~Hz}$ pulsations and 1.9 times the PCMPS than that of tests without pulsations.

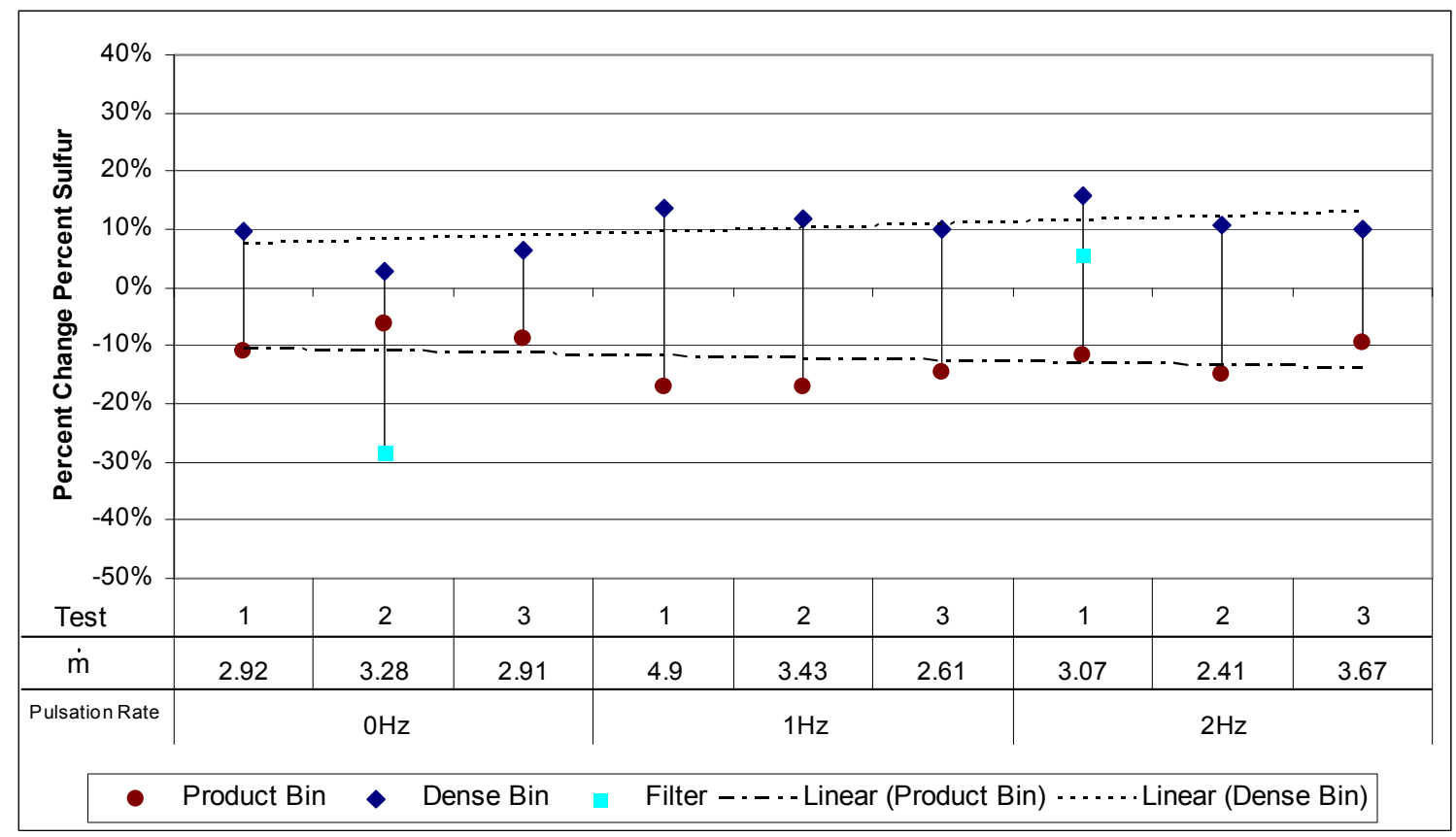

FIGURE 5-9: Results from tests with superficial gas velocity $u_{0}=0.8061 \mathrm{~ms}^{-1}$, coal particles $\left(105<d_{p}<210\right) \mu m$, varying pulsation rates $(\mathrm{OHz}, 1 \mathrm{~Hz}$, and $2 \mathrm{~Hz})$, and grouped Product Bins.

Tests with a constant superficial gas velocity of $0.8061 \mathrm{~ms}^{-1}$ have an average PCMPS in the Product Bin of $-12.33 \%$ with a standard deviation of $3.87 \%$; the Dense Bin has an average PCMPS of $10.13 \%$ with a standard deviation of $3.75 \%$. The average mass percent sulfur of the initial sample is 1.48 with a standard deviation of $0.20 \%$; the average mass percent sulfur of the Product Bin is 1.30 with a standard deviation of $0.21 \%$; and the average mass percent sulfur of the Dense Bin is 1.63 with a standard deviation of $0.18 \%$.

Table 5-2 shows the tabulated results for all the tests for the mentioned superficial gas velocities. Again it is obvious that the tests with superficial gas velocities $0.8581 \mathrm{~ms}^{-1}$ and $0.8061 \mathrm{~ms}^{-1}$ have the greatest effect of the PCMPS. The table also shows the high amount of variance for the average MPS for the initial samples as well as the product and Dense Bin. 
This enforces the method of discussing the PCMPS of the samples, rather than discussing the MPS.

\begin{tabular}{|c|c|c|c|c|c|}
\hline & & \multicolumn{2}{|c|}{ MPS } & \multicolumn{2}{|c|}{ PCMPS } \\
\hline & & Average & $\begin{array}{l}\text { Standard } \\
\text { Deviation }\end{array}$ & Average & $\begin{array}{l}\text { Standard } \\
\text { Deviation }\end{array}$ \\
\hline \multirow{3}{*}{ 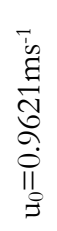 } & Initial Sample & $1.92 \%$ & $0.22 \%$ & & \\
\hline & Product Bin & $1.72 \%$ & $0.23 \%$ & $-10.87 \%$ & $2.73 \%$ \\
\hline & Dense Bin & $2.30 \%$ & $0.26 \%$ & $19.85 \%$ & $8.82 \%$ \\
\hline \multirow{3}{*}{ 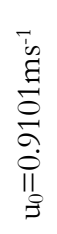 } & Initial Sample & $1.93 \%$ & $0.22 \%$ & & \\
\hline & Product Bin & $1.73 \%$ & $0.21 \%$ & $-10.31 \%$ & $3.15 \%$ \\
\hline & Dense Bin & $2.20 \%$ & $0.33 \%$ & $13.81 \%$ & $5.33 \%$ \\
\hline \multirow{3}{*}{ 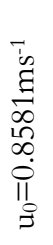 } & Initial Sample & $1.69 \%$ & $0.23 \%$ & & \\
\hline & Product Bin & $1.47 \%$ & $0.23 \%$ & $-13.34 \%$ & $4.65 \%$ \\
\hline & Dense Bin & $1.94 \%$ & $0.24 \%$ & $15.22 \%$ & $3.36 \%$ \\
\hline \multirow{3}{*}{ 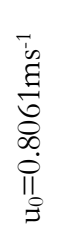 } & Initial Sample & $1.48 \%$ & $0.20 \%$ & & \\
\hline & Product Bin & $1.30 \%$ & $0.21 \%$ & $12.33 \%$ & $3.87 \%$ \\
\hline & Dense Bin & $1.63 \%$ & $0.18 \%$ & $10.13 \%$ & $3.75 \%$ \\
\hline
\end{tabular}

Comparing the results from Table 5-1 and Table 5-2, it shows that $1 \mathrm{~Hz}$ pulsations with a superficial gas velocity of $0.8581 \mathrm{~ms}^{-1}$ yields the best result for separation of clean coal from dirtier coal. These tests had an average PCMPS of 17.35 (reduction) for the Product Bin, far better than any other test conditions. From Table 5-3, it can be seen that the amount of material collected, shown as a percentage of the total initial sample, for these tests averages about 50 percent. Although tests with higher superficial gas velocities tend to have a higher 
amount of material collected as product, none of the tests with higher product material yields have separation results as good as those of $1 \mathrm{~Hz}$ pulsation tests with a superficial gas velocity of $0.8581 \mathrm{~ms}^{-1}$.

TABLE 5-3: Percentage of material collected in the Product Bins and Dense Bin for all tests.

\begin{tabular}{|c|c|c|c|c|c|c|c|}
\hline & \multicolumn{2}{|c|}{$0 \mathrm{~Hz}$} & \multicolumn{2}{|c|}{$1 \mathrm{~Hz}$} & \multicolumn{2}{|c|}{$2 \mathrm{~Hz}$} \\
\hline & & $\begin{array}{l}\text { Product } \\
\text { Bin }\end{array}$ & $\begin{array}{c}\text { Dense } \\
\text { Bin }\end{array}$ & $\begin{array}{c}\text { Product } \\
\text { Bin }\end{array}$ & $\begin{array}{c}\text { Dense } \\
\text { Bin }\end{array}$ & $\begin{array}{c}\text { Product } \\
\text { Bin }\end{array}$ & $\begin{array}{c}\text { Dense } \\
\text { Bin }\end{array}$ \\
\hline \multirow{3}{*}{ 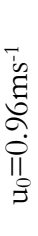 } & 1 & $63.7 \%$ & $35.0 \%$ & $57.3 \%$ & $42.5 \%$ & $47.4 \%$ & $52.4 \%$ \\
\hline & 2 & $50.8 \%$ & $49.0 \%$ & $71.0 \%$ & $28.8 \%$ & $68.5 \%$ & $31.3 \%$ \\
\hline & 3 & $64.8 \%$ & $35.0 \%$ & $63.7 \%$ & $36.0 \%$ & $70.9 \%$ & $29.0 \%$ \\
\hline \multirow{3}{*}{ 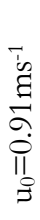 } & 1 & $50.0 \%$ & $48.2 \%$ & $54.9 \%$ & $45.0 \%$ & $42.8 \%$ & $57.0 \%$ \\
\hline & 2 & $65.1 \%$ & $32.6 \%$ & $58.4 \%$ & $41.4 \%$ & $59.2 \%$ & $40.6 \%$ \\
\hline & 3 & $61.1 \%$ & $38.8 \%$ & $58.8 \%$ & $41.0 \%$ & $43.4 \%$ & $56.4 \%$ \\
\hline \multirow{3}{*}{ 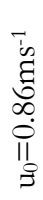 } & 1 & $49.4 \%$ & $49.4 \%$ & $58.6 \%$ & $41.2 \%$ & $52.3 \%$ & $47.5 \%$ \\
\hline & 2 & $51.1 \%$ & $47.3 \%$ & $47.8 \%$ & $52.0 \%$ & $49.1 \%$ & $50.6 \%$ \\
\hline & 3 & $49.3 \%$ & $50.5 \%$ & $49.9 \%$ & $49.9 \%$ & $55.9 \%$ & $43.9 \%$ \\
\hline \multirow{3}{*}{ 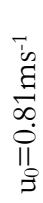 } & 1 & $44.8 \%$ & $54.8 \%$ & $43.0 \%$ & $56.7 \%$ & $57.1 \%$ & $42.8 \%$ \\
\hline & 2 & $30.5 \%$ & $69.1 \%$ & $40.3 \%$ & $59.5 \%$ & $41.1 \%$ & $58.6 \%$ \\
\hline & 3 & $40.1 \%$ & $59.6 \%$ & $39.6 \%$ & $60.1 \%$ & $50.8 \%$ & $49.0 \%$ \\
\hline
\end{tabular}

\subsection{Segregated Product Bin Analysis}

This section will be used to discuss the results for the Product Bin 1 and Product Bin 2 being segregated. Only a small portion of the figures will be displayed in the section as where extra figures are shown in Appendix B. The following sections will not discuss the effect of any of the flow conditions, either superficial gas velocity or flow pulsations, on either the Dense Bin of the Filter; however, all of the figures will contain the results for the Dense Bin and Filter. 
Before the discussion of the results, can proceed, the quantity of material that was recovered from the Product Bins must be explored. Table 5-4 shows the recorded weights of the measured material for each Product Bin. It is shown that the quantity of the material collected from the Product Bins varies greatly from test to test. It also shows that a majority of the material collected from Product Bin 2 is on average seven times less than that collected from Product Bin 1.

TABLE 5-4: Measured Product Bin 1 and Product Bin 2 weights for all tests and flow conditions

\begin{tabular}{|c|c|c|c|c|c|c|c|}
\hline & \multicolumn{2}{|c|}{$0 \mathrm{~Hz}$} & \multicolumn{2}{|c|}{$1 \mathrm{~Hz}$} & \multicolumn{2}{|c|}{$2 \mathrm{~Hz}$} \\
\hline & & \multicolumn{2}{|c|}{ Product Bins Weight (g) } & \multicolumn{2}{|c|}{ Product Bins Weight $(\mathrm{g})$} & \multicolumn{2}{|c|}{ Product Bins Weight (g) } \\
\hline & & 1 & 2 & 1 & 2 & 1 & 2 \\
\hline \multirow{3}{*}{ 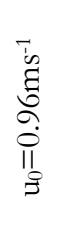 } & 1 & 335 & 275 & 290 & 40 & 270 & 15 \\
\hline & 2 & 265 & 15 & 305 & 90 & 3054 & 45 \\
\hline & 3 & 300 & 15 & 215 & 15 & 310 & 155 \\
\hline \multirow{3}{*}{ 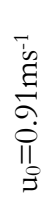 } & 1 & 260 & 25 & 280 & 25 & 185 & 10 \\
\hline & 2 & 290 & 130 & 265 & 10 & 300 & 35 \\
\hline & 3 & 295 & 75 & 300 & 80 & 175 & 25 \\
\hline \multirow{3}{*}{ 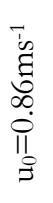 } & 1 & 195 & 10 & 260 & 25 & 260 & 15 \\
\hline & 2 & 265 & 70 & 210 & 15 & 155 & 10 \\
\hline & 3 & 205 & 10 & 205 & 15 & 240 & 15 \\
\hline \multirow{3}{*}{ 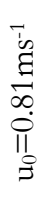 } & 1 & 205 & 20 & 220 & 15 & 305 & 75 \\
\hline & 2 & 140 & 10 & 215 & 15 & 160 & 5 \\
\hline & 3 & 165 & 10 & 145 & 10 & 265 & 15 \\
\hline
\end{tabular}

The average quantity of coal material collected from Product Bin 2 is approximately 33 grams with a standard deviation of 35.4 ; where as the amount of material collected from Product Bin 1 is on average 243 grams with a standard deviation of 54.7. 


\subsubsection{PULSATIONS RESULTS}

Figure 5-10 shows the results from tests without flow pulsations and varying superficial gas velocity. This figure is the same as Figure 5-1 in the previous section with the exception of the Product Bin results. This figure shows the individual results of the Product Bins rather than the combined results in the previous section. It can be seen that the results for the segregated tests are similar to those with the Product Bins combined with the result that Product Bin 1 has a slightly lesser value for the PCMPS and Product Bin 2 has a higher value, respectively.

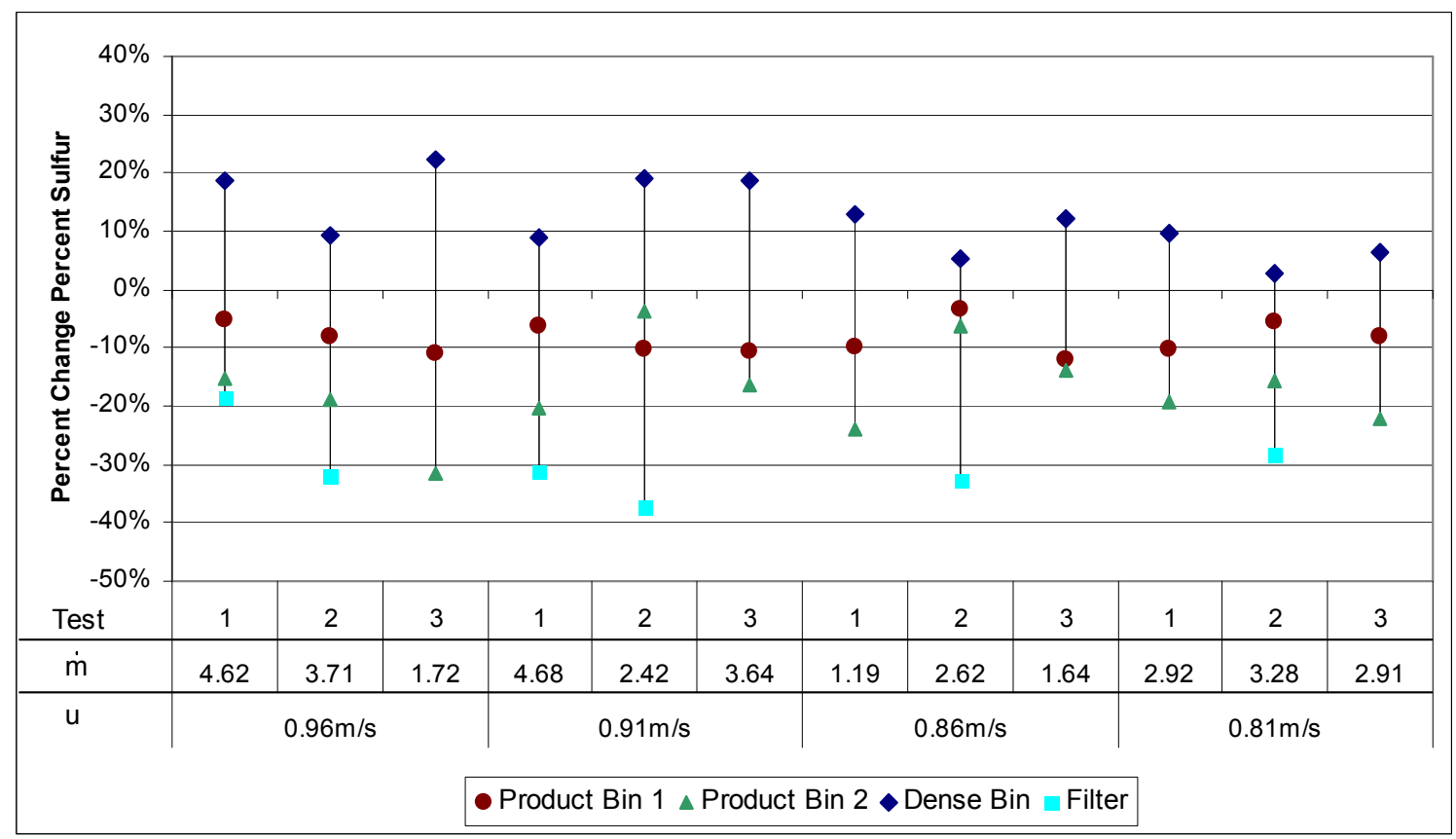

FIGURE 5-10 Results from tests with $0 \mathrm{~Hz}$ pulsations, coal particles $\left(105<\mathrm{d}_{\mathrm{p}}<210\right) \mu \mathrm{m}$, decreasing superficial gas velocity with separated Product Bins.

The results for tests with $1 \mathrm{~Hz}$ pulsations and $2 \mathrm{~Hz}$ pulsations show the same results as those seen with $\mathrm{OHz}$ pulsations with respect to the grouped Product Bins. The figures for these tests have been reserved for Appendix B and will not be directly discussed. Even though the PCMPS for Product Bin 2 are in general better than those of Product Bin 1 or the grouped 
Product Bins, the amount of material collected is so small that there is not an applicable motivation to segregate the bins in future testing.

\subsubsection{Superficial Gas Velocity Effect}

Figure 5-11 shows the results from tests with the same superficial gas velocity of $0.9621 \mathrm{~ms}^{-1}$ pulsations and varying gas pulsations. This figure is the same as Figure 5-6 in the previous section with the exception of the Product Bin results. This figure shows the individual results of the Product Bins rather than the combined results in the previous section.

It can be seen that the results for the segregated tests are similar to those with the Product Bins combined with the result that Product Bin 1 has a slightly lesser value for the PCMPS and Product Bin 2 has a higher value, respectively.

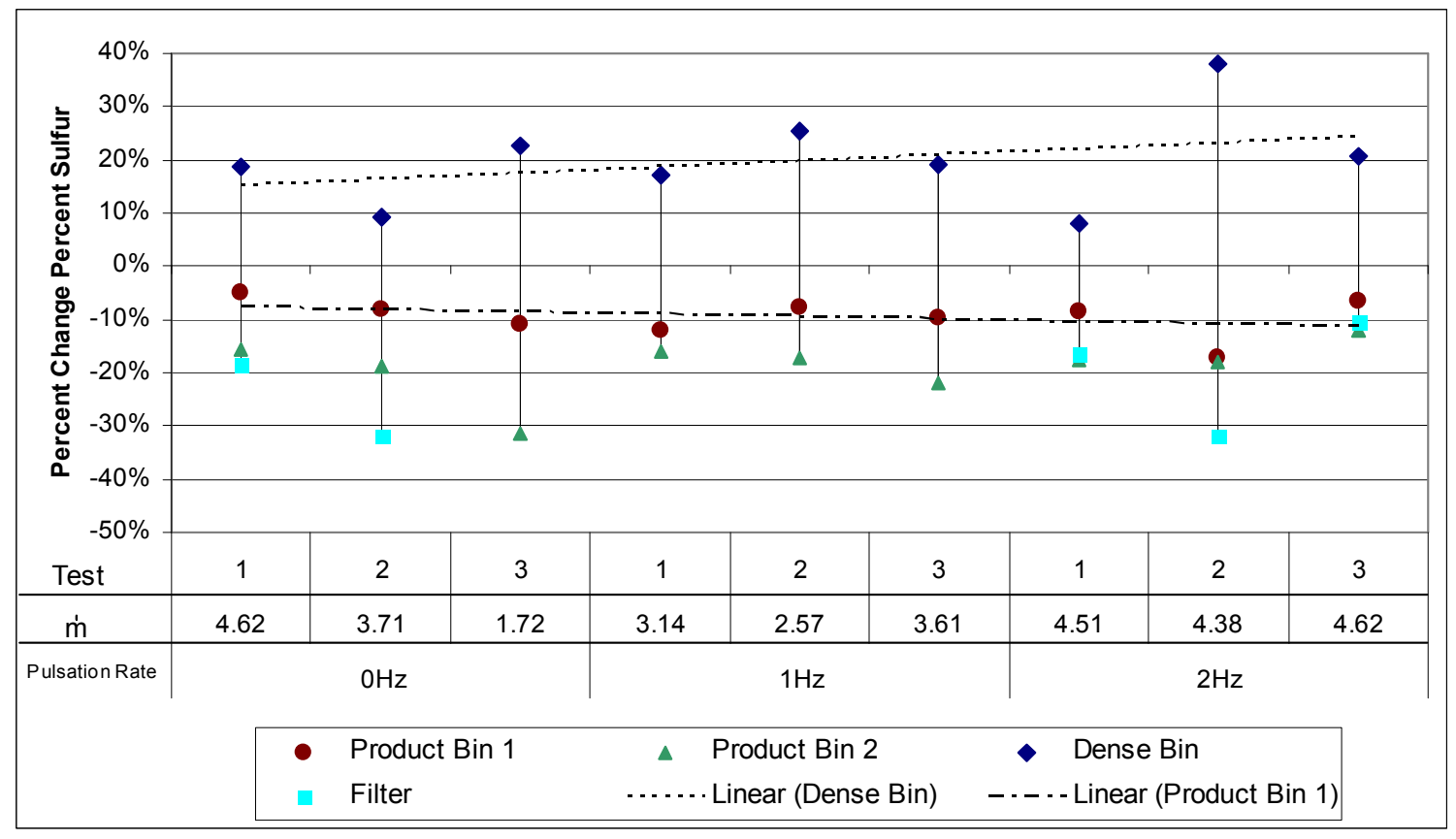

FIGURE 5-11 Results from tests with superficial gas velocity $u_{0}=0.9621 \mathrm{~ms}^{-1}$, coal particles $\left(105<d_{p}<210\right) \mu \mathrm{m}$, varying pulsation rates $(0 \mathrm{~Hz}, 1 \mathrm{~Hz}$, and $2 \mathrm{~Hz})$, and separated Product Bins

The results for tests with superficial gas velocities of $0.9101 \mathrm{~ms}^{-1}, 0.8581 \mathrm{~ms}^{-1}$, and $0.8061 \mathrm{~ms}-1$ show the same results as those seen with a superficial gas velocity of $0.9621 \mathrm{~ms}^{-1}$ 
with respect to the grouped Product Bins. The figures for these tests have been reserved for Appendix B and will not be directly discussed.

\subsection{ResUlts ANd ANALysis of IRON REMOVAL}

Several of the tests were also processed for the mass percent iron (PMI) to determine if the reduction of sulfur corresponded to a reduction in iron as well. This would imply that the percentage of pyrite in the final product had been reduced from the percentage of pyrite of the initial sample. The discussion will be centered on the percent change of mass percent iron (PCMPI) for combined Product Bin results; and the discussion will localized to grouped Product Bin values, thus individual Product Bin analysis will not be discussed for iron results. As in previous sections, only a representative sample of the results will be shown within the text. All other figures can be found in Appendix C.

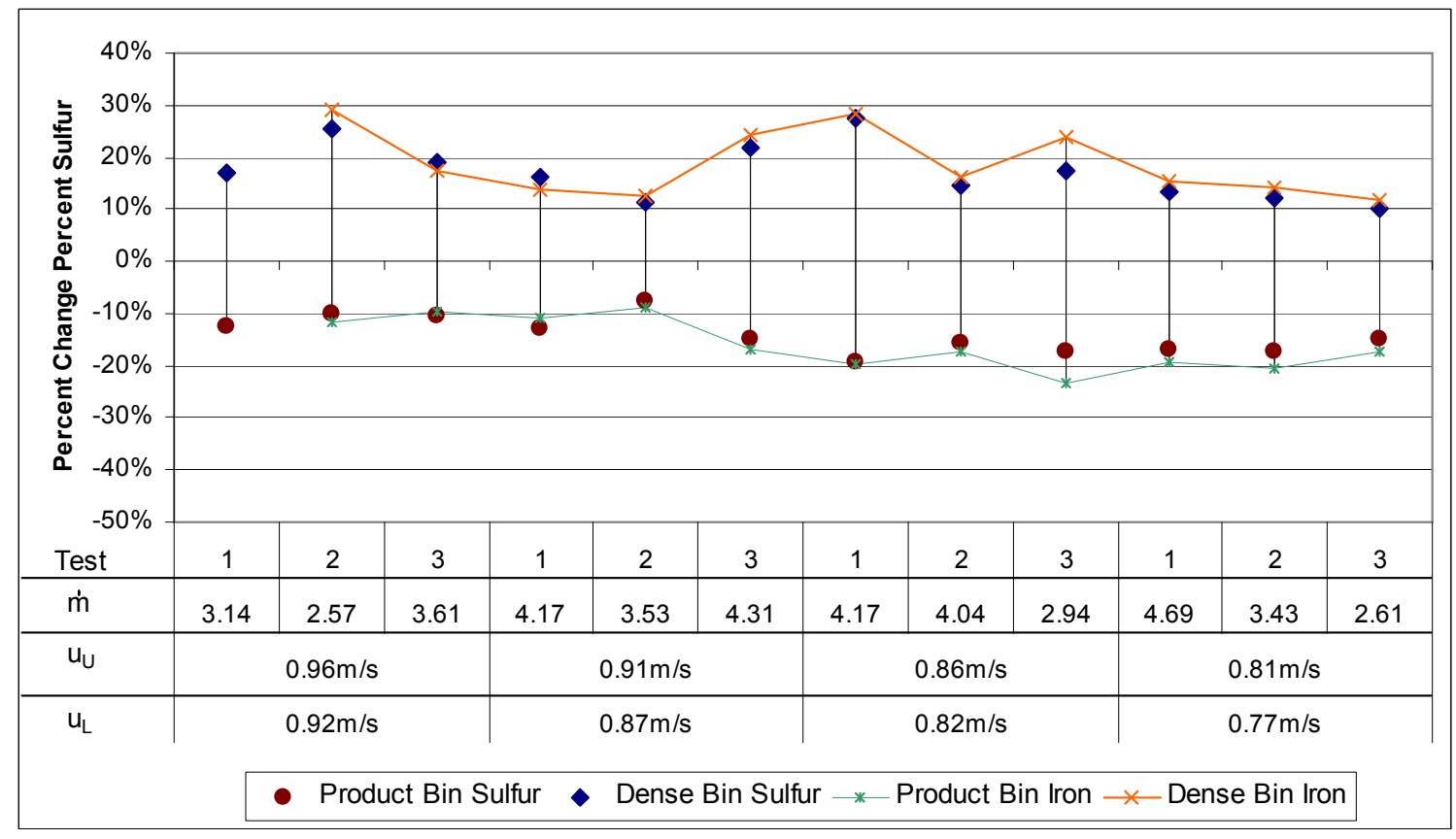

FIGURE 5-12: Results from tests with $1 \mathrm{~Hz}$ pulsations, coal particles $\left(105<\mathrm{d}_{\mathrm{p}}<210\right) \mu \mathrm{m}$, and decreasing superficial gas velocity with grouped Product Bins. This figure compares the percent change of mass percent sulfur to the percent change of mass percent iron for tests with the given flow conditions. 
Figure 5-12 shows the results for $1 \mathrm{~Hz}$ pulsation tests with varying superficial gas velocity. As can be seen, the PCMPI adheres very closely to the PCMPS to for all of the tests. Since the iron and sulfur reduced in the Product Bin (collected in the Dense Bin) proportionally, it may be concluded that the reduction of iron and sulfur for the Product Bin also correlates to a reduced percentage of pyrite by mass in the Product Bin material in comparison to that of the initial sample. Conversely, the addition of sulfur and iron to the Dense Bin correlates to a higher percentage of pyrite by mass in the Dense Bin with respect to that of the initial sample. $2 \mathrm{~Hz}$ pulsations tests show similar results and are in Appendix C.

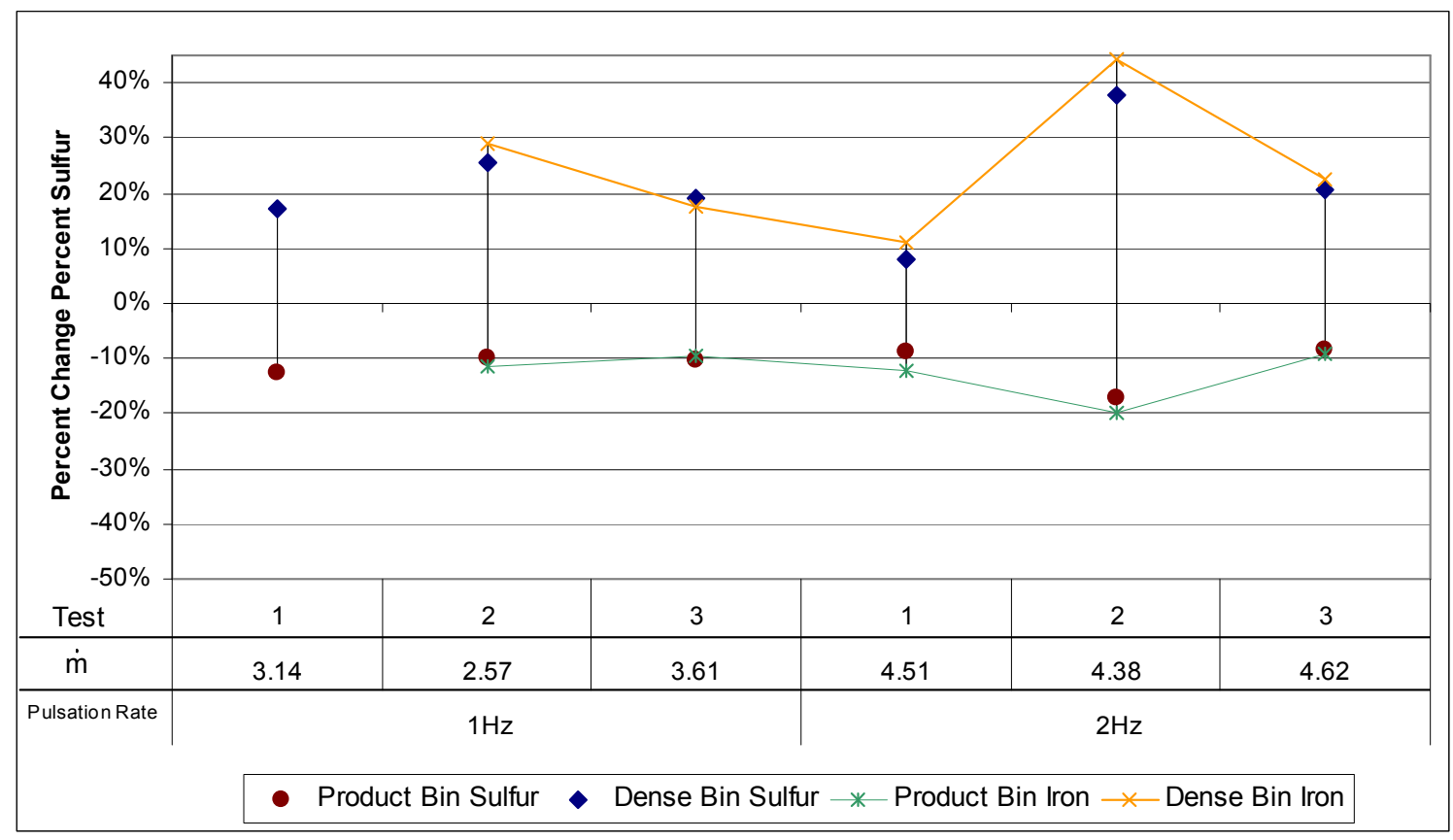

FIGURE 5-13: Results from tests with superficial gas velocity $u_{0}=0.9621 \mathrm{~ms}^{-1}$, coal particles $\left(105<d_{p}<210\right) \mu \mathrm{m}$, varying pulsation rates $(1 \mathrm{~Hz}$ and $2 \mathrm{~Hz})$, and grouped Product Bins. This figure compares the percent change of mass percent sulfur to the percent change of mass percent iron for tests with the given flow conditions.

Figure 5-13 shows the results from tests with a superficial gas velocity of $0.9621 \mathrm{~ms}^{-1}$ pulsation rates of either $1 \mathrm{~Hz}$ or $2 \mathrm{~Hz}$. The results show that the PCMPI varies almost identically to that of the PCMPS, suggesting, again, that the reduction of iron and sulfur in the Product Bin correlates to a reduced percentage of pyrite by mass in the Product Bin material 
with respect to the initial sample. Conversely, the addition of sulfur and iron to the Dense Bin correlates to a higher percentage of pyrite by mass in the Dense Bin with respect to that of the initial sample. Tests with superficial gas velocities of $0.9101 \mathrm{~ms}^{-1}, 0.8681 \mathrm{~ms}^{-1}$, and $0.8061 \mathrm{~ms}^{-1}$ show similar results and are in Appendix C. 


\section{CHAPTER 6: \\ CONCLUSIONS AND RECOMMENDATIONS}

\subsection{CONCLUSIONS}

The exploratory system, created to segregate coal with higher mass percent sulfur from coal with lower mass percent sulfur, has been designed and constructed. The tests show that it is possible to segregate coal with higher mass percent sulfur from coal with lower mass percent sulfur. The effects of the various flow conditions have also been analyzed to determine the best conditions for which maximum separation can occur.

The mass flow rate into the system was essentially held constant to simplify the analysis of the results. This is due to only small variations between the highest and lowest mass flow rates, with the difference between the lowest mass flow rate and highest mass flow rate being less than one gram per second.

The segregation of the product materials from the first and second cyclone show that separation of cleaner coal and dirtier coal does take place. However, the high efficiency of the primary cyclone only permitted a small amount of material to pass on to the secondary

cyclone. Since it would require a large initial volume of coal to provide a small volume of cleaner coal in the secondary cyclone's collection system, using the cyclone system as a cleaning mechanism would be inefficient.

Tests without flow pulsations $(0 \mathrm{~Hz}$ pulsations), for all superficial gas velocities, displayed on average a PCMPS of -9.20 with a standard deviation of $2.45 \%$ for the Product Bin. These tests were conducted without flow pulsations as a control for tests with pulsations and the same superficial gas velocities. Tests with $1 \mathrm{~Hz}$ flow pulsations, for all superficial gas velocities, showed an average PCMPS in the Product Bin of -14.12 with a standard deviation 
of $3.50 \%$. Finally, tests with $2 \mathrm{~Hz}$ flow pulsations, for all superficial gas velocities, showed an average PCMPS for the Product Bin of 11.82 with a standard deviation of $3.51 \%$.

Tests with $1 \mathrm{~Hz}$ pulsations, for all superficial gas velocities, showed the largest average PCMPS, which are almost 5\% higher than tests without flow pulsations and $2.3 \%$ higher than tests with $2 \mathrm{~Hz}$ pulsations. This suggests that $1 \mathrm{~Hz}$ flow pulsations create the conditions to best segregate cleaner coal from dirtier coal.

Tests with a superficial gas velocity of $0.9621 \mathrm{~ms}^{-1}$, for all flow pulsations, displayed on average a PCMPS of -10.87 with a standard deviation of $2.73 \%$ for the Product Bin. Tests with a superficial gas velocity of $0.9101 \mathrm{~ms}^{-1}$, for all flow pulsations, displayed on average a PCMPS of -10.31 with a standard deviation of $3.15 \%$ for the Product Bin. Tests with a superficial gas velocity of $0.8581 \mathrm{~ms}^{-1}$, for all flow pulsations, displayed on average a PCMPS of -13.34 with a standard deviation of $4.65 \%$ for the Product Bin. Finally, tests with a superficial gas velocity of $0.8061 \mathrm{~ms}^{-1}$, for all flow pulsations, displayed on average a PCMPS of -12.33 with a standard deviation of $3.87 \%$ for the Product Bin.

Tests with a superficial gas velocity of $0.8581 \mathrm{~ms}^{-1}$, for all flow pulsations, showed the largest average PCMPS for the Product Bin, which are almost 2.5\% higher than tests with a superficial gas velocity of $0.9621 \mathrm{~ms}^{-1}$ and more than $3 \%$ higher than tests with a superficial gas velocity of $0.9101 \mathrm{~ms}^{-1}$. Whiles tests with a superficial gas velocity of $0.8061 \mathrm{~ms}^{-1}$, for all flow pulsations, showed the second largest average PCMPS, which is almost $1.5 \%$ higher than tests with a superficial gas velocity of $0.9621 \mathrm{~ms}^{-1}$ and more than $2 \%$ higher than tests with a superficial gas velocity of $0.9101 \mathrm{~ms}^{-1}$. This suggests that a superficial gas velocity between $0.8581 \mathrm{~ms}^{-1}$ and $0.8061 \mathrm{~ms}^{-1}$ provides the best conditions for the segregation of cleaner coal from dirtier coal. 
From the analysis of the mass percent iron in conjunction with the mass percent sulfur tests, the segregation of cleaner coal from dirtier coal may be directly related to the segregation of coal with a lower mass percent pyrite from coal with a higher mass percent pyrite. This shows that CFB systems can be used to segregate clean from dirtier coal. Therefore, for the best conditions to segregate clean coal from dirtier coal, flow conditions should include a superficial gas velocity between $0.851 \mathrm{~ms}^{-1}$ and $0.8061 \mathrm{~ms}^{-1}$ with flow pulsations of $1 \mathrm{~Hz}$. The individual test data, shown in Appendix A, for tests with a superficial gas velocity of $0.8581 \mathrm{~ms}^{-}$

${ }^{1}$ and $1 \mathrm{~Hz}$ pulsations was able process coal with an initial mass percent sulfur of $1.66 \%$ and reduce the product stream's mass percent sulfur to $1.37 \%$ while increasing the mass percent sulfur of the waste stream to $1.99 \%$. Tests with a superficial gas velocity of $0.8061 \mathrm{~ms}^{-1}$ was able process coal with an initial mass percent sulfur of $1.37 \%$ and reduce the product stream's mass percent sulfur to $1.15 \%$ while increasing the mass percent sulfur of the waste stream to $1.53 \%$.

\subsection{RECOMMENDATIONS}

Due to the large amount of time required for chemical analysis, a new method for testing for the mass percent sulfur and mass percent iron should be utilized. The analysis method selected should be able to process material quick enough such that test conditions can be modified to avoid wasting time on flow conditions that provide no effect on segregation process. The analysis method should also include testing for the content of any other debris material to determine if the CFB system is also reducing the material that creates fly ash during the combustion process of coal.

More testing on the small scale CFB system should also be completed to determine the effect of various pulsation magnitudes. The time restrictions only allotted for the testing of a 
single pulsation magnitude and more consideration should be given larger pulsation magnitudes.

Further modifications should be made to the experimental system to allow for more material to be processed in a test. The dense particle collection bin is too small and quickly becomes full. If at all possible, consideration should be given to recycling the material captured in the Dense Bin to obtain a larger amount of cleaned material in the Product Bin.

Even though the mass flow rate into the system was rarely an issue, the addition of a mechanical feed screw should be considered. This would allow for tests to be conducted at specific flow rates. This would better control the variable mass flow rate into the system and prevent any large quantity of material to become injected into the riser system, influencing the results.

Finally, tests should be done in order to determine the velocity profile of the pulsating gas flow in the riser system. This information could be used to accurately calculate the Saffman Force on the particles; thus, the true effect of the gas pulsations could be determined. 


\section{BIBLIOGRAPHY}

42USC7651d. 1990. Phase II sulfur dioxide requirements. United States Code. 1990.

Akhtar, H. 2006. Development of a small separation riser for fine coal particles. s.I. : Masters Thesis, West Virginia University, 2006.

Almond, R. 2005. Small particle separation in a circulating fluidized bed riser system. s.I.: Masters Thesis, West Virginia University, 2005.

Bi, H.T. and Grace, J.R. 1995. Flow regime diagrams for gas-solid fluidization and upward transport. Vancouver : s.n., 1995. pp. 1229-1236. Vol. 26 No. 6.

Budge, D. and Brought, J. and Knight, J. 2000. Review of the worldwide status of coal preparation technology. 2000. Report No. CoalR199 DTI/Pub URN 00/1205.

Carvalho, J.A. Jr. 1995. Behavior of solid particles in pulsating flows. 1995. pp. 581-593. Vol. 185.

Cavallaro, J.A. and Johnosn, M.T. and Deurbrouck, A.W. 1976. Sulfur reduction potential of the coals of the united states - a revision of report of investigations 7633. s.I. : USBM Report of Intestigation, 1976.

Chen, Q. and Yang, Y. 2003. Development of dry beneficiation of coal in china. s.l. : Coal Preparation, 2003. pp. 3-12. Vol. 23.

Danielson, John A. 1967. Air pollution engineering manual. Los Angeles County (Calif) Air Pollution Control District. Cincinnati : U.S. Dept. of Health, Education, and Welfare, National Center for Air Pollution Control, 1967. pp. 91-94.

Donnelly, J. 1999. Potential revival of dry cleaning of coal. s.I. : The Australian Coal Review, 1999. pp. 26-30.

Ergun, S. 1981. Sulphur removal potential of american coals as a determinant of sulphur dioxide emmissions from coal-fired power plants. s.I. : Philosophical Transactions of the Royal Society of London, 1981. pp. 89-98. Vol. Series A.

Fan, L.S. and Zhu, C. 1998. Principles of gas-solid flows. Cambridge : The Press Syndicate of the University of Cambridge, 1998.

Gas velocities and gas boundary layers inside a riser of a circulating fluidized bed. Moran, J.C. and Glicksman, L.R. 2001. [ed.] D.W. Geiling. Reno: Proceedings of the 16th International Conference on Fluidized Bed, 2001. (FBC 01-0027).

Johnson, E.K. and Regester, J.L. and Kang, B.S. 2005. Fluidized fed riser as a dry particle separation system. s.I. : Society of Mining, Metallurgy, and Exploring, Inc, 2005. pp. 130-134. Vol. 22. 
Kawatra, K. and Eisele, T.C. 2001. Coal desulfurization - high efficiency preparation methods. New York : Taylor and Francis Inc., 2001.

Kim, S.W., et al. 2004. Flow structure and thickness of annular downflow layer in a circulating fluidized bed riser. Vancouver : Powder Technology, 2004. pp. 48-58. Vol. 142.

Leonard, J.W., Ed. 1991. Coal preparation. s.I. : Society of Mining, Metallurgy and Exploration, 1991.

Liu, X., et al. 2006. Effect of particle acceleration/deceleration on particle clustering behavior in dilute gas-solid flow. Beijing, China : Chemical Engineering Science, 2006. pp. 7087-7095. Vol. 61.

Lockhart, N.C. 1984. Dry beneficiation of coal. s.I. : Powder Technology, 1984. pp. 17-42. Vol. 40.

McCartney, J.T., O'Donnell, H.J. and Ergun, S. 1969. Pyrite size distribution and coal-pyrite particle association in steam coals. 1969. p. No. 7231.

Mei, R., 1992. An approximated expression for the shear lift force on a spherical particle at finite Reynolds number. International Journal of Multiphas Flow, 1992 pp.145-147. Vol. 18

Monazam, E.R., et al. 2005. Identification and characteristics of different flow regimes in a circulating fluidized bed. s.I. : Powder Technology, 2005. pp. 17-25. Vol. 155.

Monticello, D.J. and Finnerty, W.R. 1985. Microbial desulfurization of fossil fuels. s.I. : Annual Review of Microbiology, 1985. pp. 371-389. Vol. 39.

Pyrite liberation in coal - key to sulfur reduction during benefication. Richardson, D.L. and Lovell, H.L. 1979. Louisville : Coal Conference and Expo V., Coal Preparation and Utilization Symposium, 1979.

Regester, J.L. 2004. Separation of small particles due to density differences in a cfb riser system. s.l. : Masters Thesis, West Virginia University, 2004.

Regime transitions in gas-solid circulating fluidized beds. Bi, H.T. and L.S., Fan. 1991. Los Angeles : s.n., 1991. AiChE Annual Meeting. pp. 17-22.

Rhodes, M., Mineo, H. and Hirama, T. 1992. Particle motion at the wall of a circulating fluidized bed. Bradford (UK) : Powder Technology, 1992. pp. 207-214. Vol. 70.

Saffman, P.G. 1965. The lift on a small sphere in slow shear flow. Journal of Fluid Mechanics 1965. pp. 385-400. Vol. 22

Saffman, P.G. 1968. Corrigendum to the lift on a small sphere in slow shear flow. Journal of Fluid Mechanics 1968. pp. 624. Vol. 31 
Yousfi, Y. and Gau, G. 1974. Aerodynamique de l'ecoulement vertical de suspensions concentrees gaz-solides - I. regimes d'ecoulement et stabilite aerodynamique. Nancy, France: Chemical Engineering Scinece, 1974. Vol. 29 Issue 9.

Zhou, J., Grace, J.R. and Lim, C.J. and Brereton, C.M.H. 1995. Particle velocity profiles in a circulating fluidized bed riser of square cross-section. s.I. : Chemical Engineering Science, 1995. pp. 237-244. Vol. 50. 
APPENDIX A:

\section{INDIVIDUAL TESTS - FIGURES AND CHARTS}

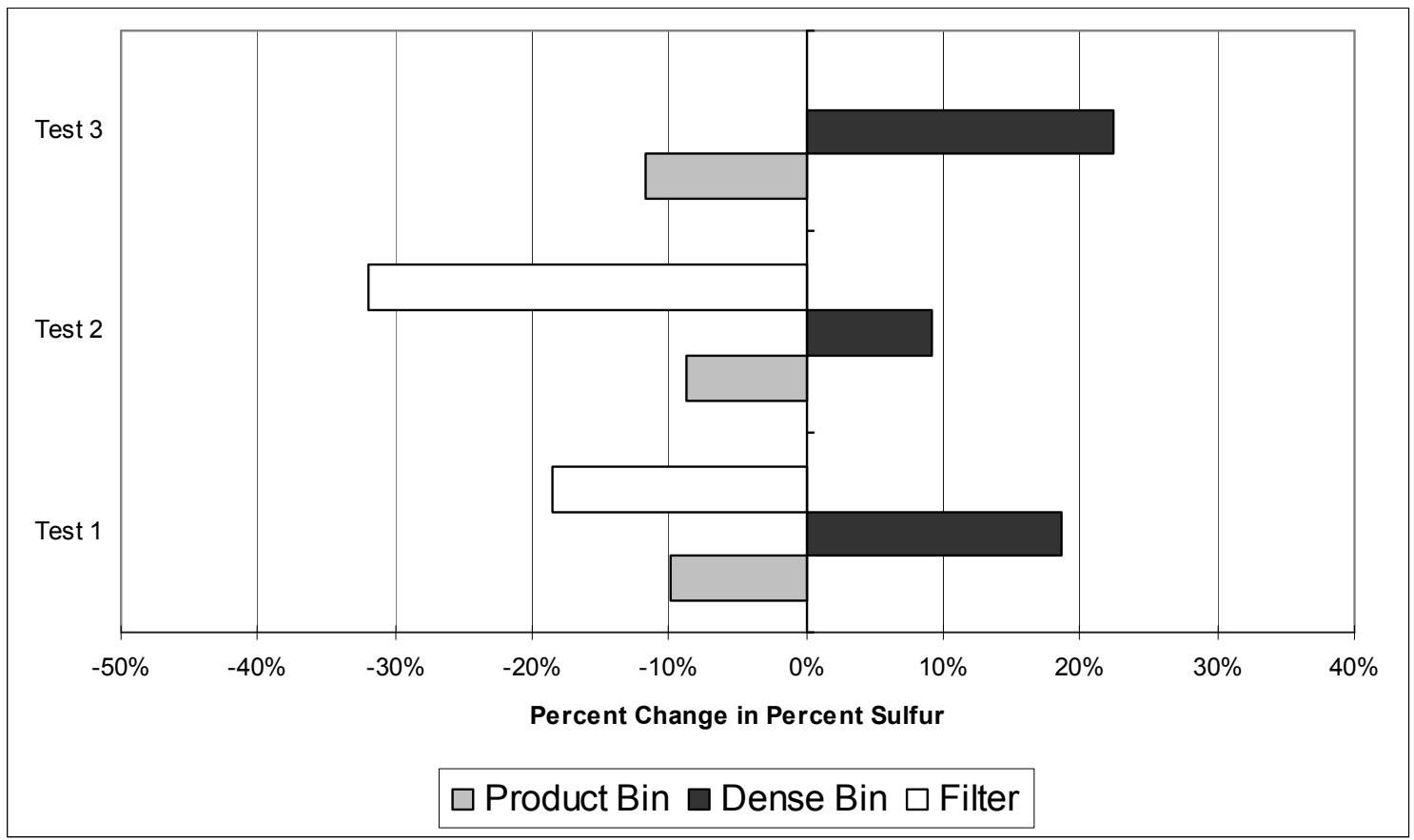

FIGURE A-1: Test Results for superficial gas velocity $\mathrm{u}_{0}=0.9621 \mathrm{~ms}^{-1}$, No pulsations $-0 \mathrm{~Hz}, \dot{m}=(4.62,3.71,1.72) \mathrm{kg}^{*} \mathrm{hr}^{-1}$, $\left(105<d_{p}<210\right) \mu \mathrm{m}$ coal particles, and grouped Product Bin results.

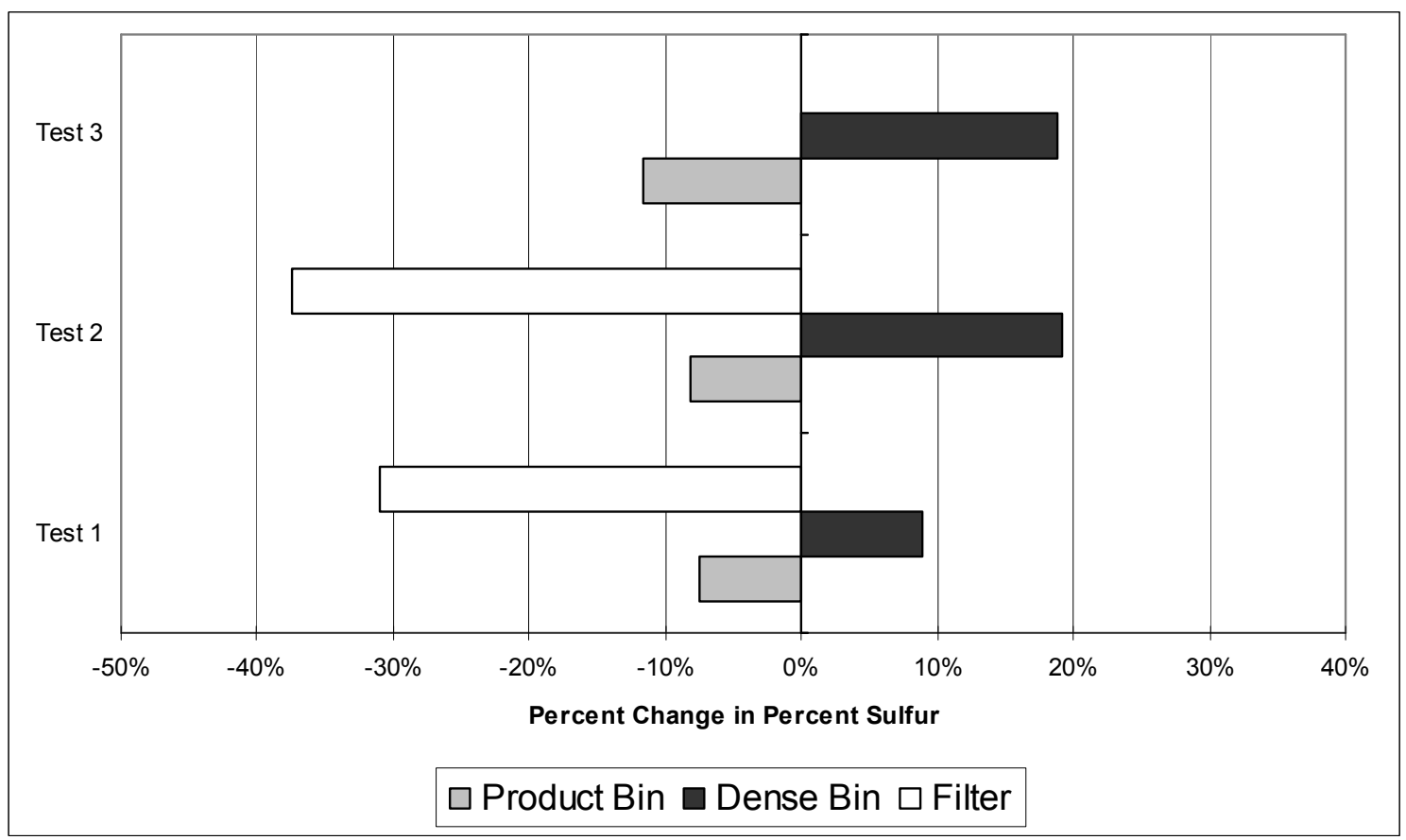

FIGURE A-2: Test Results for superficial gas velocity $\mathrm{u}_{0}=0.9101 \mathrm{~ms}^{-1}$, No pulsations $-\mathrm{OHz}, \dot{m}=(4.68,2.42,3.64) \mathrm{kg}^{*} \mathrm{hr}^{-1}$, $\left(105<d_{p}<210\right) \mu \mathrm{m}$ coal particles, and grouped Product Bin results. 


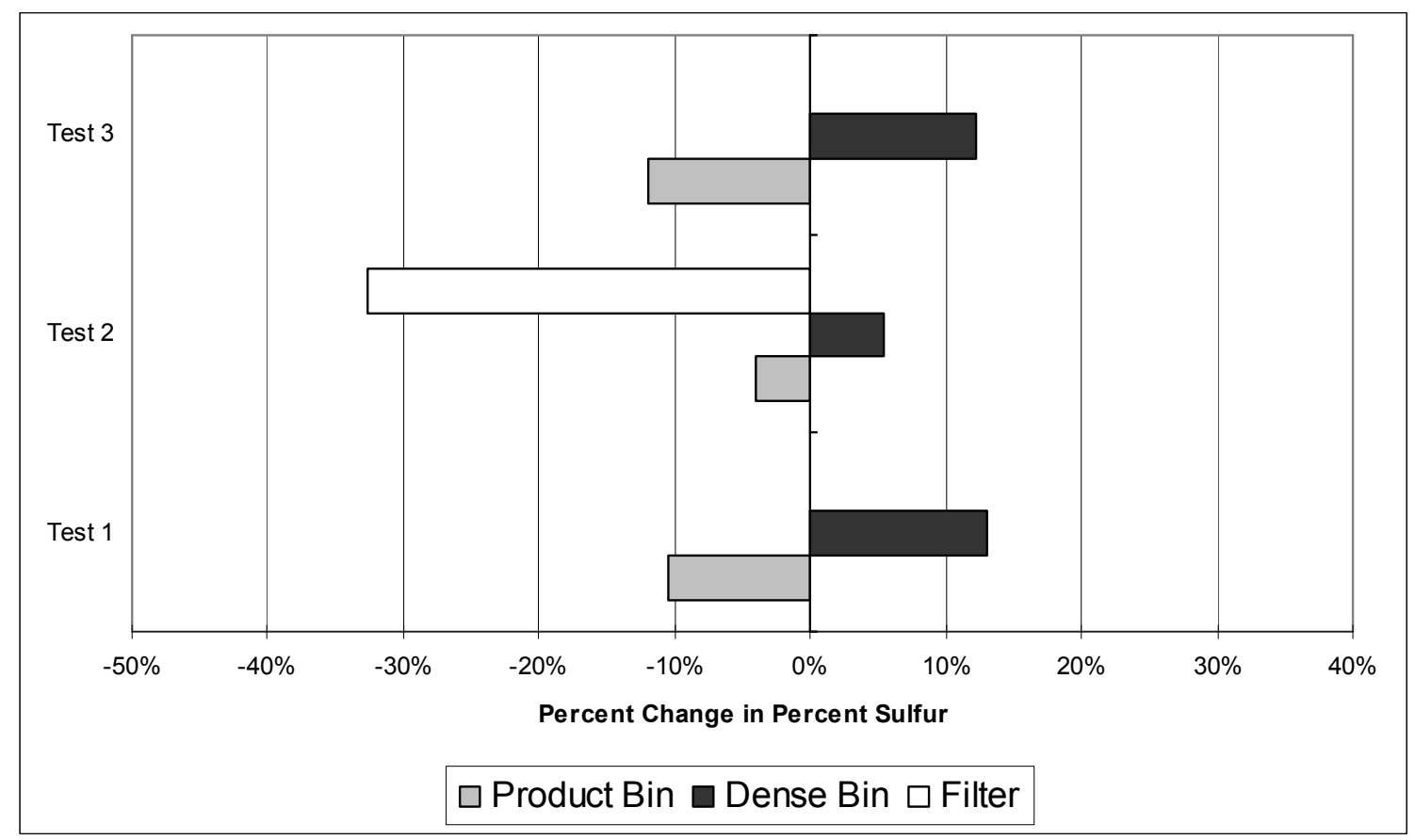

FIGURE A-3: Test Results for superficial gas velocity $\mathrm{u}_{0}=0.8581 \mathrm{~ms}^{-1}$, No pulsations $-0 \mathrm{~Hz}, \dot{m}=(1.19,2.62,1.64) \mathrm{kg}^{*} \mathrm{hr}^{-1}$, $\left(105<d_{p}<210\right) \mu \mathrm{m}$ coal particles, and grouped Product Bin results.

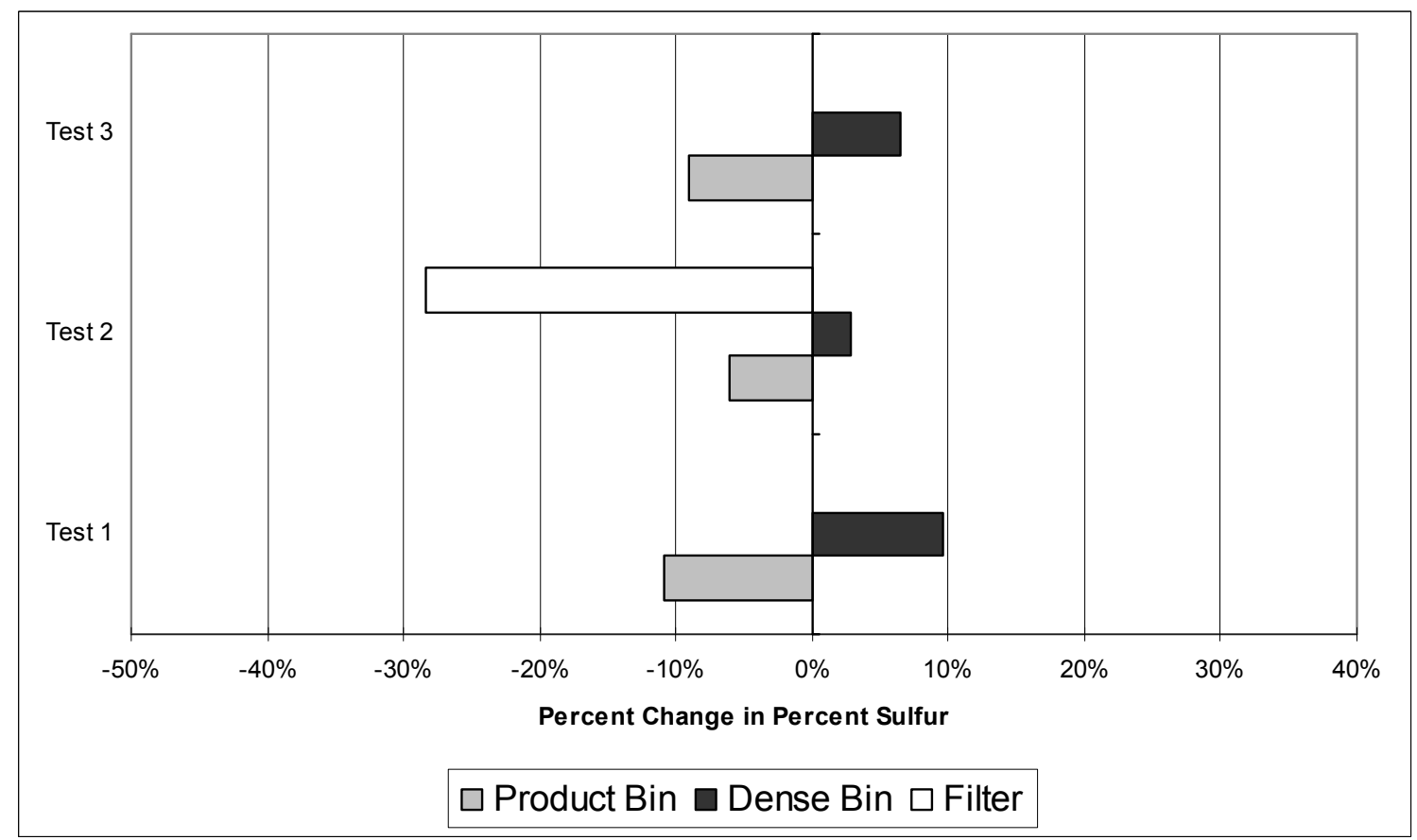

FIGURE A-4: Test Results for superficial gas velocity $\mathrm{u}_{0}=0.8061 \mathrm{~ms}^{-1}$, No pulsations $-\mathrm{OHz}, \dot{m}=(2.92,3.28,2.91) \mathrm{kg}^{*} \mathrm{hr}^{-1}$, $\left(105<d_{p}<210\right) \mu \mathrm{m}$ coal particles, and grouped Product Bin results. 


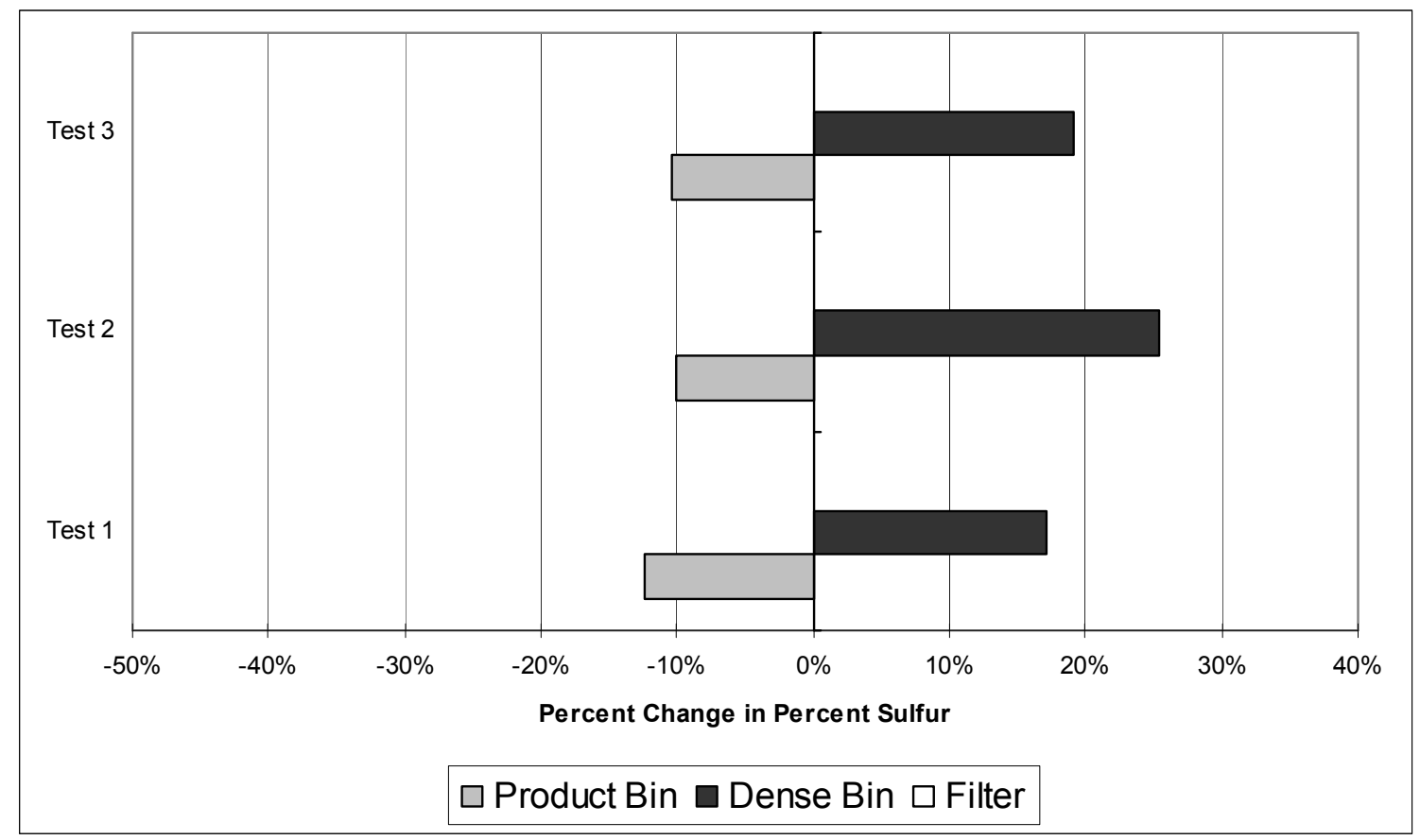

FIGURE A-5: Test Results for superficial gas velocity $u_{0}=0.9621 \mathrm{~ms}^{-1}$, Pulsations $-1 \mathrm{~Hz}, \dot{m}=(3.14,2.57,3.61) \mathrm{kg}^{*} \mathrm{hr}^{-1}$, $\left(105<d_{p}<210\right) \mu \mathrm{m}$ coal particles, and grouped Product Bin results.

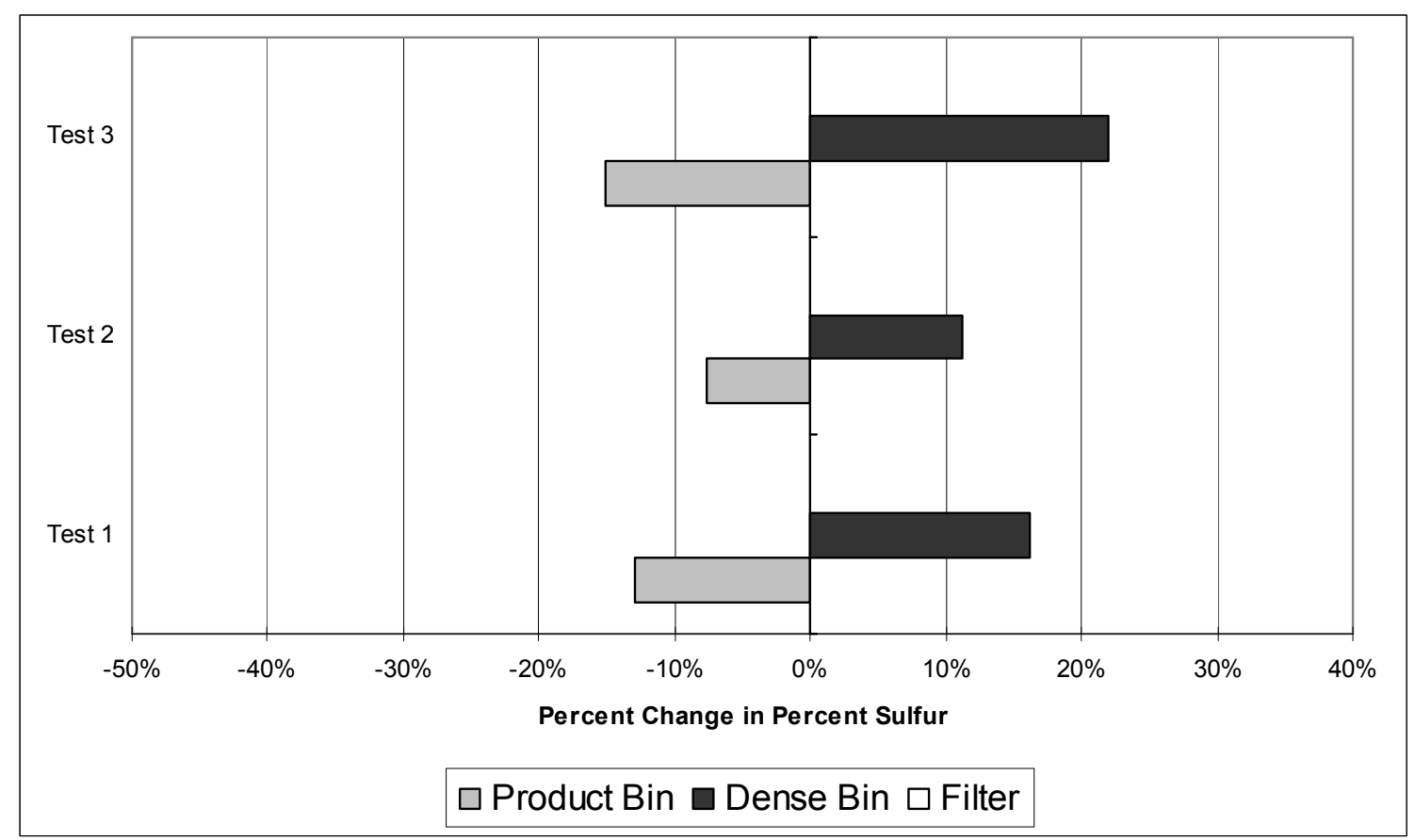

FIGURE A-6: Test Results for superficial gas velocity $\mathrm{u}_{0}=0.9101 \mathrm{~ms}^{-1}$, Pulsations $-1 \mathrm{~Hz}, \dot{m}=(4.17,3.53,4.31) \mathrm{kg}^{*} \mathrm{hr}^{-1}$, $\left(105<d_{p}<210\right) \mu \mathrm{m}$ coal particles, and grouped Product Bin results. 


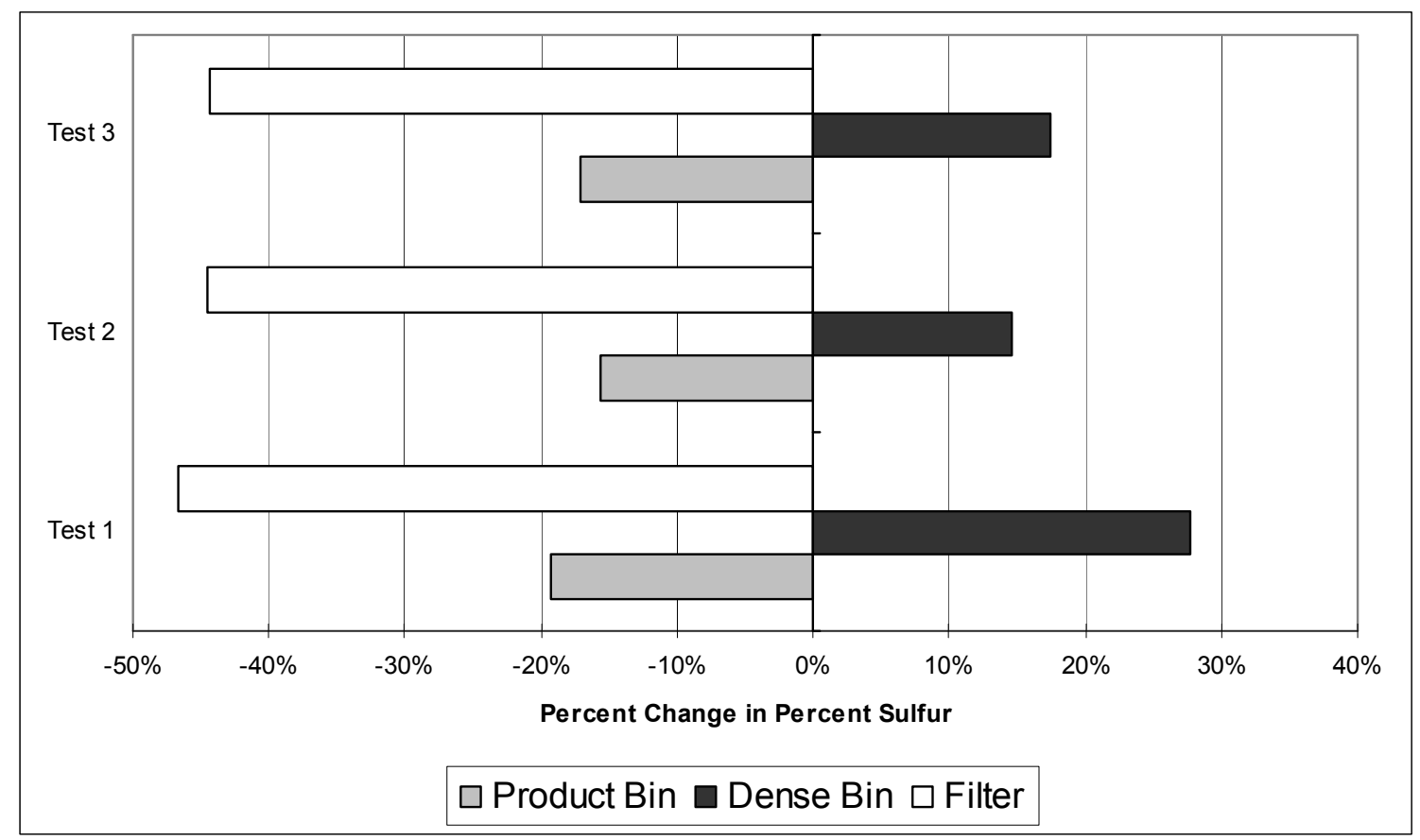

FIGURE A-7: Test Results for superficial gas velocity $u_{0}=0.8581 \mathrm{~ms}^{-1}$, Pulsations $-1 \mathrm{~Hz}, \dot{m}=(4.17,4.04,2.94) \mathrm{kg}^{*} \mathrm{hr}^{-1}$, $\left(\mathbf{1 0 5}<\mathrm{d}_{\mathrm{p}}<210\right) \mu \mathrm{m}$ coal particles, and grouped Product Bin results.

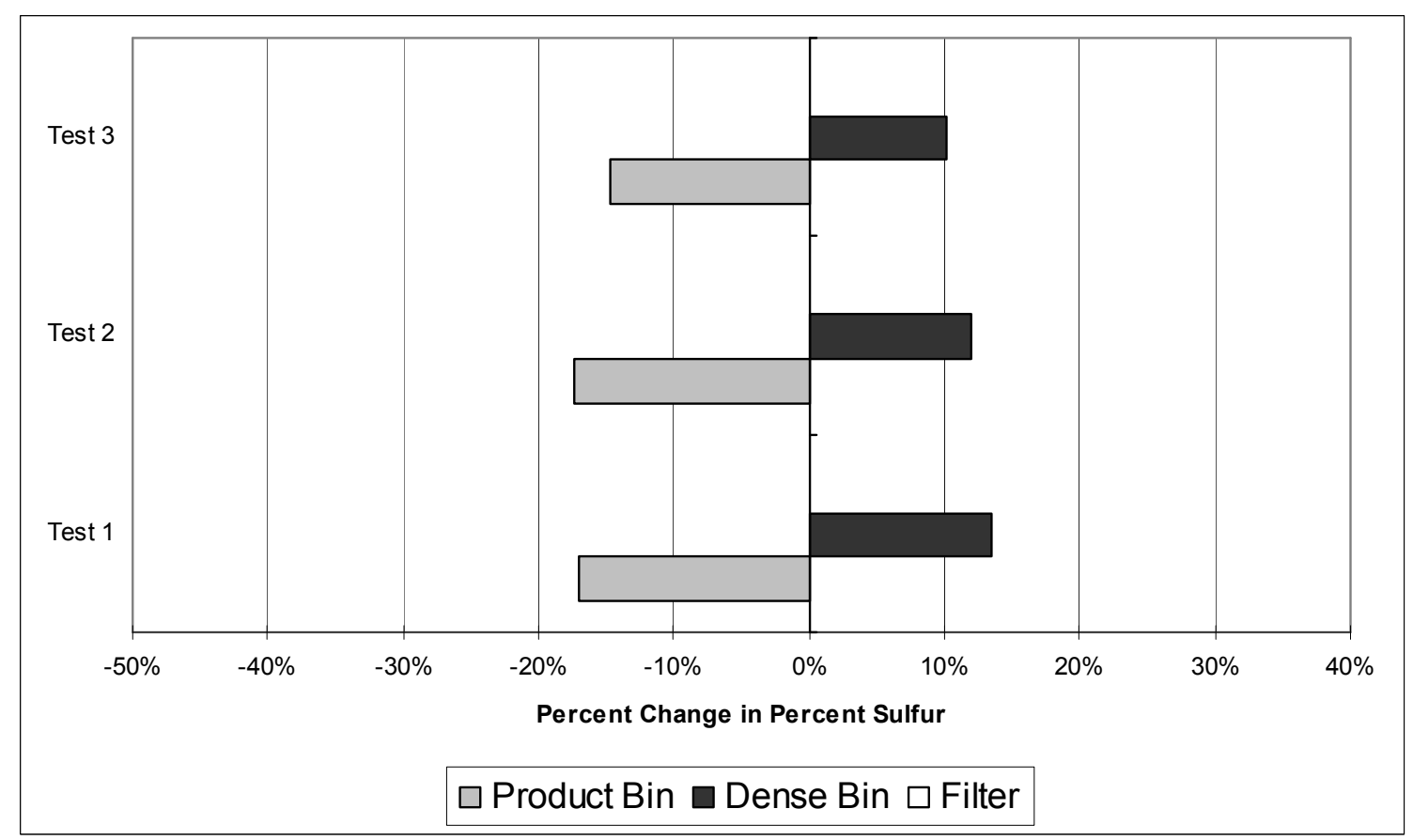

FIGURE A-8: Test Results for superficial gas velocity $\mathrm{u}_{0}=0.8061 \mathrm{~ms}^{-1}$, Pulsations $-1 \mathrm{~Hz}, \dot{m}=(4.69,3.43,2.61) \mathrm{kg}^{*} \mathrm{hr}^{-1}$, $\left(105<\mathrm{d}_{\mathrm{p}}<210\right) \mu \mathrm{m}$ coal particles, and grouped Product Bin results. 


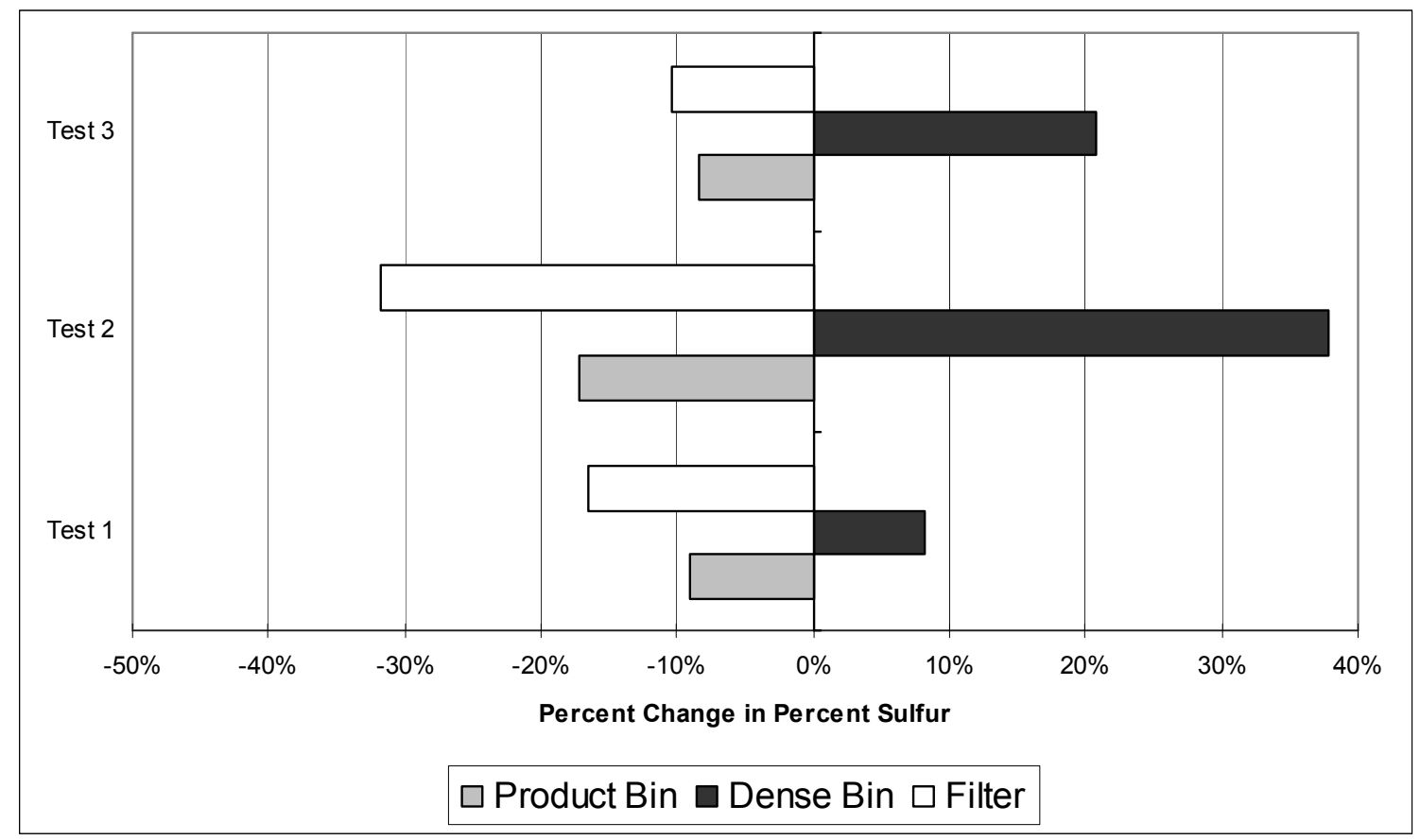

FIGURE A-9: Test Results for superficial gas velocity $\mathrm{u}_{0}=0.9621 \mathrm{~ms}^{-1}$, Pulsations $-2 \mathrm{~Hz}, \dot{m}=(4.51,4.38,4.62) \mathrm{kg}^{*} \mathrm{hr}^{-1}$, $\left(105<d_{p}<210\right) \mu \mathrm{m}$ coal particles, and grouped Product Bin results.

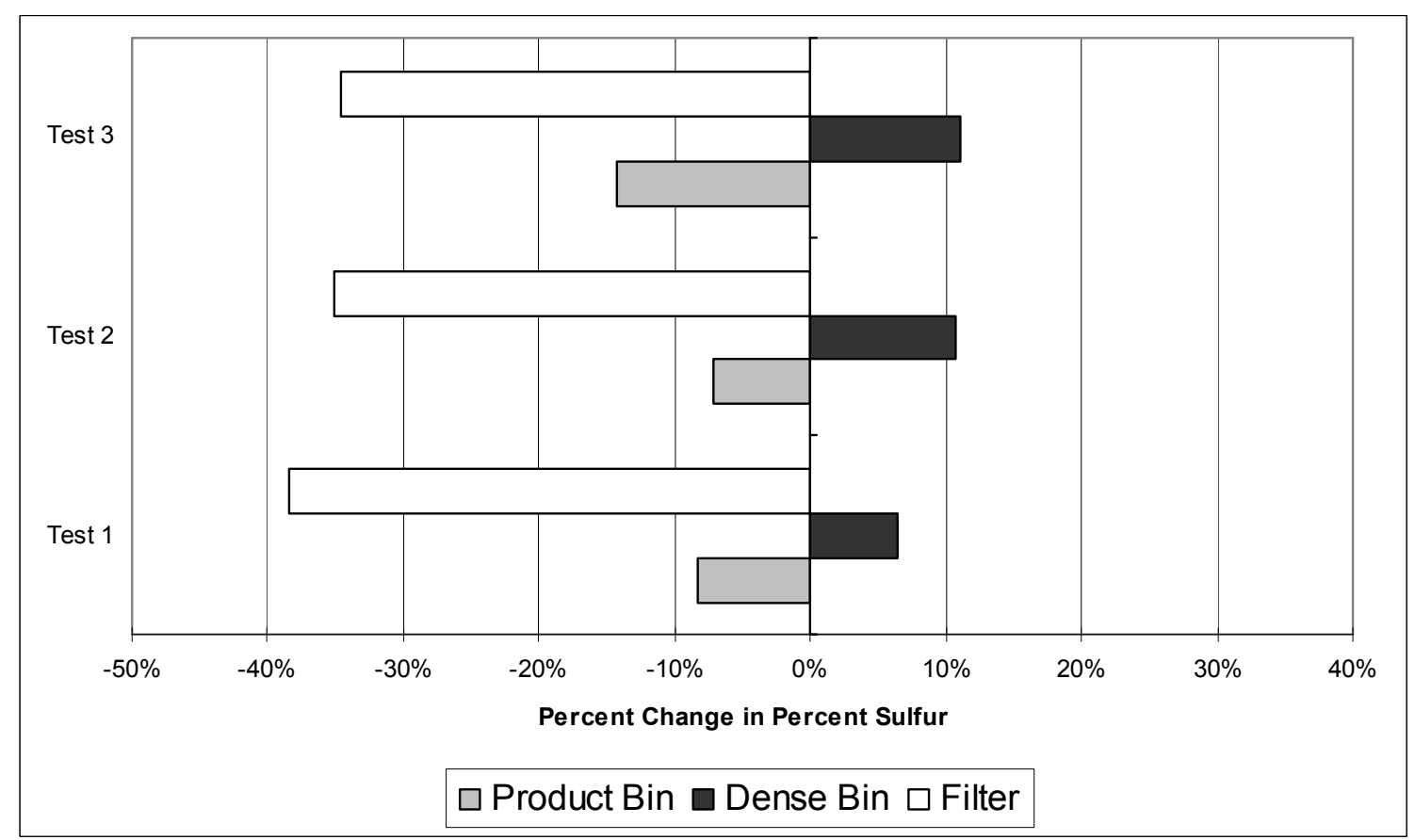

FIGURE A-10: Test Results for superficial gas velocity $\mathrm{u}_{0}=0.9101 \mathrm{~ms}^{-1}$, Pulsations $-2 \mathrm{~Hz}, \dot{m}=(4.56,4.85,3.46) \mathrm{kg}^{*} \mathrm{hr}^{-1}$, $\left(105<d_{p}<210\right) \mu \mathrm{m}$ coal particles, and grouped Product Bin results. 


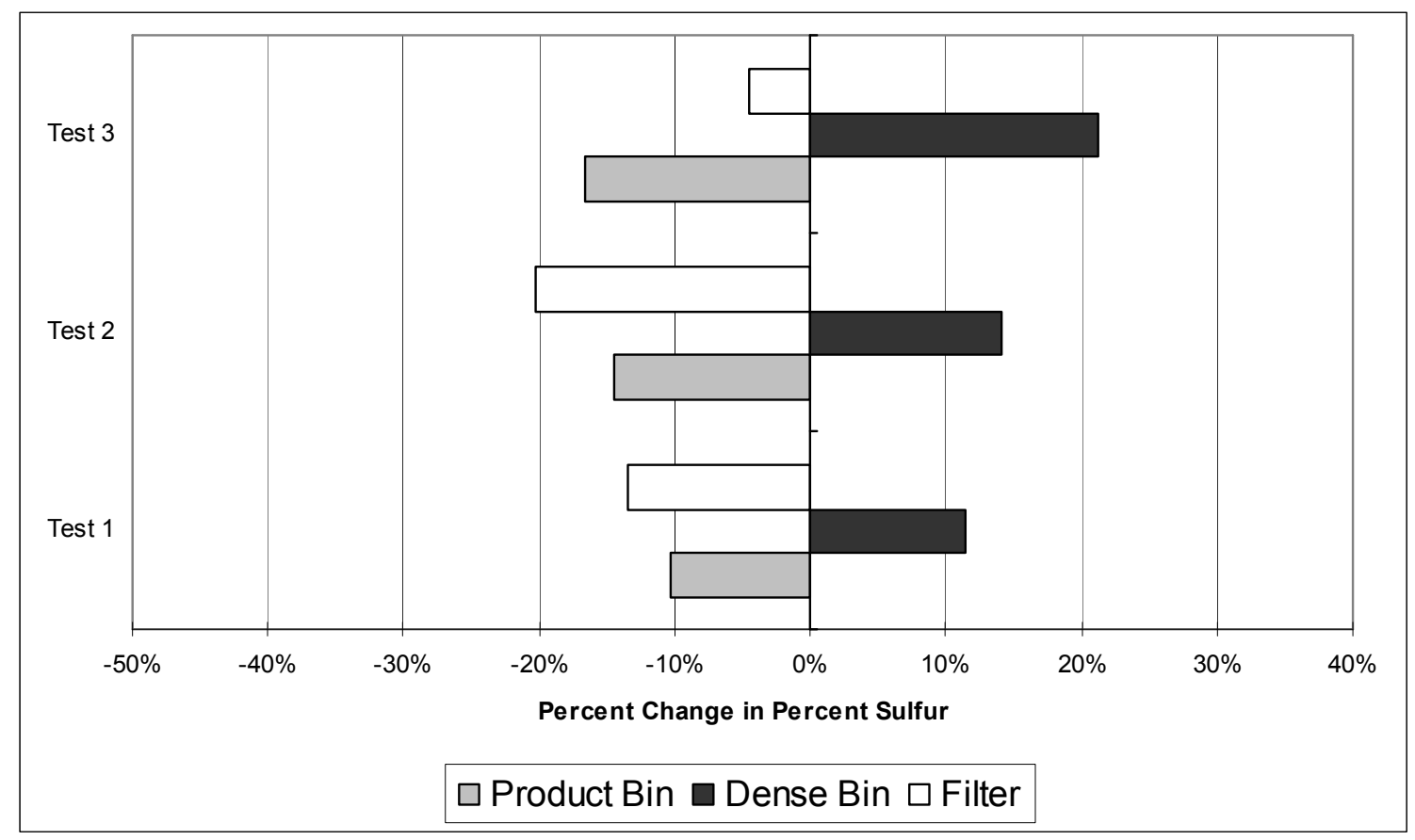

FIGURE A-11: Test Results for superficial gas velocity $u_{0}=0.8581 \mathrm{~ms}^{-1}$, Pulsations $-2 \mathrm{~Hz}, \dot{m}=(4.51,4.03,3.91) \mathrm{kg}^{*} \mathrm{hr}^{-1}$, $\left(105<d_{p}<210\right) \mu \mathrm{m}$ coal particles, and grouped Product Bin results.

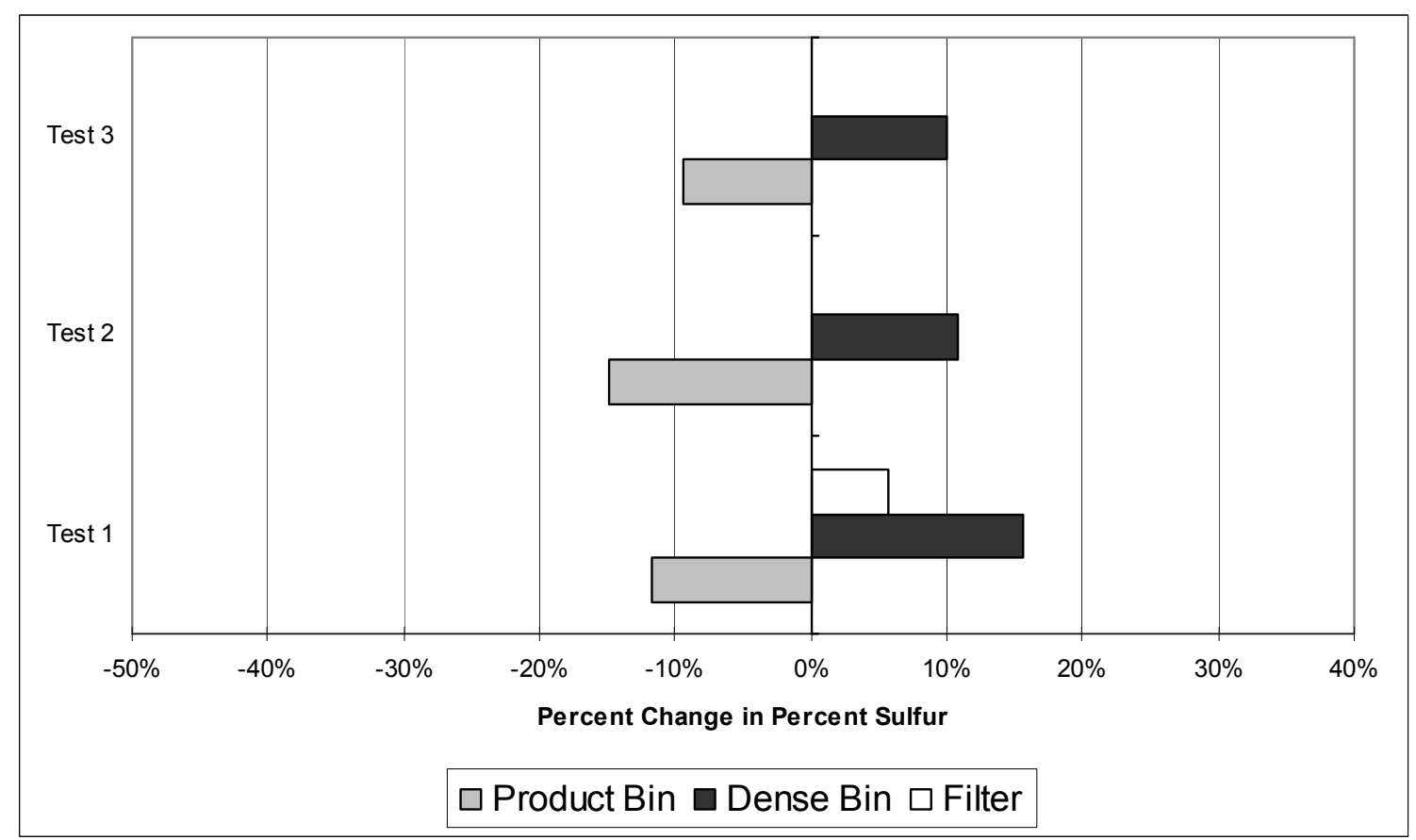

FIGURE A-12: Test Results for superficial gas velocity $\mathrm{u}_{0}=0.8061 \mathrm{~ms}^{-1}$, Pulsations $-2 \mathrm{~Hz}, \dot{m}=(3.07,2.41,3.67) \mathrm{KG}^{*} \mathrm{HR}^{-1}$, $\left(105<d_{p}<210\right) \mu \mathrm{m}$ coal particles, and grouped Product Bin results. 
TABLE A-1: Results for tests with $\mathrm{OHz}$ pulsations, $\mathrm{u}_{0}=0.9621 \mathrm{~ms}^{-1}$, and grouped Product Bins

\begin{tabular}{|c|c|c|c|c|}
\hline & & $\begin{array}{l}\text { Product } \\
\text { Bin }\end{array}$ & $\begin{array}{c}\text { Dense } \\
\text { Bin }\end{array}$ & $\begin{array}{l}\text { Initial } \\
\text { Sample }\end{array}$ \\
\hline \multirow{2}{*}{$\sum_{0}^{\infty}$} & Average & $-10.95 \%$ & $20.55 \%$ & \\
\hline & $\begin{array}{l}\text { Standard } \\
\text { Deviation }\end{array}$ & $1.32 \%$ & $4.29 \%$ & \\
\hline \multirow{2}{*}{$\stackrel{\infty}{\sum}$} & Average & $1.91 \%$ & $2.58 \%$ & $2.14 \%$ \\
\hline & $\begin{array}{l}\text { Standard } \\
\text { Deviation }\end{array}$ & $0.09 \%$ & $0.15 \%$ & $0.07 \%$ \\
\hline
\end{tabular}

TABLE A-2: Results for tests with $\mathrm{OHz}$ pulsations, $\mathrm{u}_{0}=0.9101 \mathrm{~ms}^{-1}$, and grouped Product Bins

\begin{tabular}{|c|c|c|c|c|}
\hline & & $\begin{array}{l}\text { Product } \\
\text { Bin }\end{array}$ & $\begin{array}{l}\text { Dense } \\
\text { Bin }\end{array}$ & $\begin{array}{l}\text { Initial } \\
\text { Sample }\end{array}$ \\
\hline \multirow{2}{*}{$\sum_{\substack{0 \\
\hdashline}}^{\infty}$} & Average & $-9.15 \%$ & $15.62 \%$ & \\
\hline & $\begin{array}{l}\text { Standard } \\
\text { Deviation }\end{array}$ & $2.22 \%$ & $5.77 \%$ & \\
\hline \multirow{2}{*}{$\stackrel{\infty}{\Sigma}$} & Average & $1.19 \%$ & $2.43 \%$ & $2.10 \%$ \\
\hline & $\begin{array}{l}\text { Standard } \\
\text { Deviation }\end{array}$ & $0.17 \%$ & $0.33 \%$ & $0.19 \%$ \\
\hline
\end{tabular}

TABLE A-3: Results for tests with $\mathrm{OHz}$ pulsations, $\mathrm{u}_{0}=0.8581 \mathrm{~ms}^{-1}$, and grouped Product Bins

\begin{tabular}{|c|c|c|c|c|}
\hline & & $\begin{array}{l}\text { Product } \\
\text { Bin }\end{array}$ & $\begin{array}{c}\text { Dense } \\
\text { Bin }\end{array}$ & $\begin{array}{c}\text { Initial } \\
\text { Sample }\end{array}$ \\
\hline \multirow{2}{*}{$\sum_{\substack{\infty \\
\infty}}^{\infty}$} & Average & $-8.84 \%$ & $10.17 \%$ & \\
\hline & $\begin{array}{l}\text { Standard } \\
\text { Deviation }\end{array}$ & $4.25 \%$ & $2.12 \%$ & \\
\hline \multirow{2}{*}{$\stackrel{\infty}{\sum}$} & Average & $1.74 \%$ & $2.12 \%$ & $1.92 \%$ \\
\hline & $\begin{array}{l}\text { Standard } \\
\text { Deviation }\end{array}$ & $0.17 \%$ & $0.34 \%$ & $0.26 \%$ \\
\hline
\end{tabular}


TABLE A-4: Results for tests with $\mathrm{OHz}$ pulsations, $\mathrm{u}_{0}=0.8061 \mathrm{~ms}^{-1}$, and grouped Product Bins

\begin{tabular}{|c|c|c|c|c|}
\hline & & $\begin{array}{l}\text { Product } \\
\text { Bin }\end{array}$ & $\begin{array}{c}\text { Dense } \\
\text { Bin }\end{array}$ & $\begin{array}{l}\text { Initial } \\
\text { Sample }\end{array}$ \\
\hline \multirow{2}{*}{$\sum_{0}^{\infty}$} & Average & $-8.67 \%$ & $6.32 \%$ & \\
\hline & $\begin{array}{l}\text { Standard } \\
\text { Deviation }\end{array}$ & $2.41 \%$ & $3.40 \%$ & \\
\hline \multirow{2}{*}{$\stackrel{\infty}{\sum}$} & Average & $01.55 \%$ & $1.80 \%$ & $1.70 \%$ \\
\hline & $\begin{array}{l}\text { Standard } \\
\text { Deviation }\end{array}$ & $0.12 \%$ & $0.18 \%$ & $0.14 \%$ \\
\hline
\end{tabular}

TABLE A-5: Results for tests with $1 \mathrm{~Hz}$ pulsations, $\mathrm{u}_{0}=0.9621 \mathrm{~ms}^{-1}$, and grouped Product Bins

\begin{tabular}{|c|c|c|c|c|}
\hline & & $\begin{array}{c}\text { Product } \\
\text { Bin }\end{array}$ & $\begin{array}{l}\text { Dense } \\
\text { Bin }\end{array}$ & $\begin{array}{l}\text { Initial } \\
\text { Sample }\end{array}$ \\
\hline \multirow{2}{*}{$\sum_{\substack{\infty \\
\infty}}^{\infty}$} & Average & $-10.95 \%$ & $20.55 \%$ & \\
\hline & $\begin{array}{l}\text { Standard } \\
\text { Deviation }\end{array}$ & $1.32 \%$ & $4.29 \%$ & \\
\hline \multirow{2}{*}{$\stackrel{\infty}{\Sigma}$} & Average & $1.91 \%$ & $2.58 \%$ & $2.14 \%$ \\
\hline & $\begin{array}{l}\text { Standard } \\
\text { Deviation }\end{array}$ & $0.09 \%$ & $0.15 \%$ & $0.07 \%$ \\
\hline
\end{tabular}

TABLE A-6: Results for tests with $1 \mathrm{~Hz}$ pulsations, $\mathrm{u}_{0}=0.9101 \mathrm{~ms}^{-1}$, and grouped Product Bins

\begin{tabular}{|c|c|c|c|c|}
\hline & & $\begin{array}{l}\text { Product } \\
\text { Bin }\end{array}$ & $\begin{array}{c}\text { Dense } \\
\text { Bin }\end{array}$ & $\begin{array}{c}\text { Initial } \\
\text { Sample }\end{array}$ \\
\hline \multirow{2}{*}{$\sum_{\substack{n\\
}}^{\infty}$} & Average & $-11.85 \%$ & $16.45 \%$ & \\
\hline & $\begin{array}{l}\text { Standard } \\
\text { Deviation }\end{array}$ & $3.81 \%$ & $5.34 \%$ & \\
\hline \multirow{2}{*}{$\stackrel{\mathscr{n}}{\Sigma}$} & Average & $1.77 \%$ & $2.34 \%$ & $2.01 \%$ \\
\hline & $\begin{array}{l}\text { Standard } \\
\text { Deviation }\end{array}$ & $0.15 \%$ & $0.08 \%$ & $0.08 \%$ \\
\hline
\end{tabular}


TABLE A-7: Results for tests with $1 \mathrm{~Hz}$ pulsations, $\mathrm{u}_{0}=0.8581 \mathrm{~ms}^{-1}$, and grouped Product Bins

\begin{tabular}{|c|c|c|c|c|}
\hline & & $\begin{array}{l}\text { Product } \\
\text { Bin }\end{array}$ & $\begin{array}{c}\text { Dense } \\
\text { Bin }\end{array}$ & $\begin{array}{l}\text { Initial } \\
\text { Sample }\end{array}$ \\
\hline \multirow{2}{*}{$\sum_{0}^{\infty}$} & Average & $-17.35 \%$ & $19.86 \%$ & \\
\hline & $\begin{array}{l}\text { Standard } \\
\text { Deviation }\end{array}$ & $1.82 \%$ & $6.92 \%$ & \\
\hline \multirow{2}{*}{$\stackrel{\infty}{\sum}$} & Average & $1.37 \%$ & $1.99 \%$ & $1.66 \%$ \\
\hline & $\begin{array}{l}\text { Standard } \\
\text { Deviation }\end{array}$ & $0.06 \%$ & $0.07 \%$ & $0.04 \%$ \\
\hline
\end{tabular}

TABLE A-8: Results for tests with $1 \mathrm{~Hz}$ pulsations, $\mathrm{u}_{0}=0.8061 \mathrm{~ms}^{-1}$, and grouped Product Bins

\begin{tabular}{|c|c|c|c|c|}
\hline & & $\begin{array}{l}\text { Product } \\
\text { Bin }\end{array}$ & $\begin{array}{l}\text { Dense } \\
\text { Bin }\end{array}$ & $\begin{array}{l}\text { Initial } \\
\text { Sample }\end{array}$ \\
\hline \multirow{2}{*}{$\sum_{\substack{\infty \\
\infty}}^{\infty}$} & Average & $-16.34 \%$ & $11.89 \%$ & \\
\hline & $\begin{array}{l}\text { Standard } \\
\text { Deviation }\end{array}$ & $1.40 \%$ & $1.70 \%$ & \\
\hline \multirow{2}{*}{$\stackrel{\infty}{\Sigma}$} & Average & $1.15 \%$ & $1.53 \%$ & $1.37 \%$ \\
\hline & $\begin{array}{l}\text { Standard } \\
\text { Deviation }\end{array}$ & $0.05 \%$ & $0.09 \%$ & $0.07 \%$ \\
\hline
\end{tabular}

TABLE A-9: Results for tests with $2 \mathrm{~Hz}$ pulsations, $\mathrm{u}_{0}=0.9621 \mathrm{~ms}^{-1}$, and grouped Product Bins

\begin{tabular}{|c|c|c|c|c|}
\hline & & $\begin{array}{l}\text { Product } \\
\text { Bin }\end{array}$ & $\begin{array}{c}\text { Dense } \\
\text { Bin }\end{array}$ & $\begin{array}{c}\text { Initial } \\
\text { Sample }\end{array}$ \\
\hline \multirow{2}{*}{ 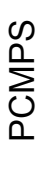 } & Average & $-11.55 \%$ & $22.26 \%$ & \\
\hline & $\begin{array}{l}\text { Standard } \\
\text { Deviation }\end{array}$ & $4.92 \%$ & $14.91 \%$ & \\
\hline \multirow{2}{*}{$\stackrel{n}{\Sigma}$} & Average & $1.53 \%$ & $2.08 \%$ & $1.72 \%$ \\
\hline & $\begin{array}{l}\text { Standard } \\
\text { Deviation }\end{array}$ & $0.29 \%$ & $0.15 \%$ & $0.25 \%$ \\
\hline
\end{tabular}


TABLE A-10: Results for tests with $2 \mathrm{~Hz}$ pulsations, $\mathrm{u}_{0}=0.9101 \mathrm{~ms}^{-1}$, and grouped Product Bins

\begin{tabular}{|c|c|c|c|c|}
\hline & & $\begin{array}{l}\text { Product } \\
\text { Bin }\end{array}$ & $\begin{array}{l}\text { Dense } \\
\text { Bin }\end{array}$ & $\begin{array}{c}\text { Initial } \\
\text { Sample }\end{array}$ \\
\hline \multirow{2}{*}{$\sum_{0}^{\infty}$} & Average & $-9.92 \%$ & $9.37 \%$ & \\
\hline & $\begin{array}{l}\text { Standard } \\
\text { Deviation }\end{array}$ & $3.79 \%$ & $2.60 \%$ & \\
\hline \multirow{2}{*}{$\stackrel{\infty}{\Sigma}$} & Average & $1.51 \%$ & $1.84 \%$ & $1.68 \%$ \\
\hline & $\begin{array}{l}\text { Standard } \\
\text { Deviation }\end{array}$ & $0.10 \%$ & $0.02 \%$ & $0.05 \%$ \\
\hline
\end{tabular}

TABLE A-11: Results for tests with $2 \mathrm{~Hz}$ pulsations, $\mathrm{u}_{0}=0.8581 \mathrm{~ms}^{-1}$, and grouped Product Bins

\begin{tabular}{|c|c|c|c|c|}
\hline & & $\begin{array}{c}\text { Product } \\
\text { Bin }\end{array}$ & $\begin{array}{l}\text { Dense } \\
\text { Bin }\end{array}$ & $\begin{array}{l}\text { Initial } \\
\text { Sample }\end{array}$ \\
\hline \multirow{2}{*}{ 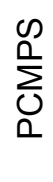 } & Average & $-13.82 \%$ & $15.62 \%$ & \\
\hline & $\begin{array}{l}\text { Standard } \\
\text { Deviation }\end{array}$ & $3.19 \%$ & $5.08 \%$ & \\
\hline \multirow{2}{*}{$\stackrel{\infty}{\Sigma}$} & Average & $1.29 \%$ & $1.73 \%$ & $1.50 \%$ \\
\hline & $\begin{array}{l}\text { Standard } \\
\text { Deviation }\end{array}$ & $0.11 \%$ & $0.06 \%$ & $0.09 \%$ \\
\hline
\end{tabular}

TABLE A-12: Results for tests with $2 \mathrm{~Hz}$ pulsations, $\mathrm{u}_{0}=0.8061 \mathrm{~ms}^{-1}$, and grouped Product Bins

\begin{tabular}{|c|c|c|c|c|}
\hline & & $\begin{array}{l}\text { Product } \\
\text { Bin }\end{array}$ & $\begin{array}{l}\text { Dense } \\
\text { Bin }\end{array}$ & $\begin{array}{c}\text { Initial } \\
\text { Sample }\end{array}$ \\
\hline \multirow{2}{*}{ 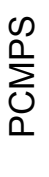 } & Average & $-11.99 \%$ & $12.19 \%$ & \\
\hline & $\begin{array}{l}\text { Standard } \\
\text { Deviation }\end{array}$ & $2.76 \%$ & $3.02 \%$ & \\
\hline \multirow{2}{*}{$\stackrel{\mathscr{n}}{\Sigma}$} & Average & $1.22 \%$ & $1.55 \%$ & $1.38 \%$ \\
\hline & $\begin{array}{l}\text { Standard } \\
\text { Deviation }\end{array}$ & $0.16 \%$ & $0.14 \%$ & $0.16 \%$ \\
\hline
\end{tabular}


APPENDIX B:

\section{AdDitionAL Figures - SEPARATE PRODUCT BinS}

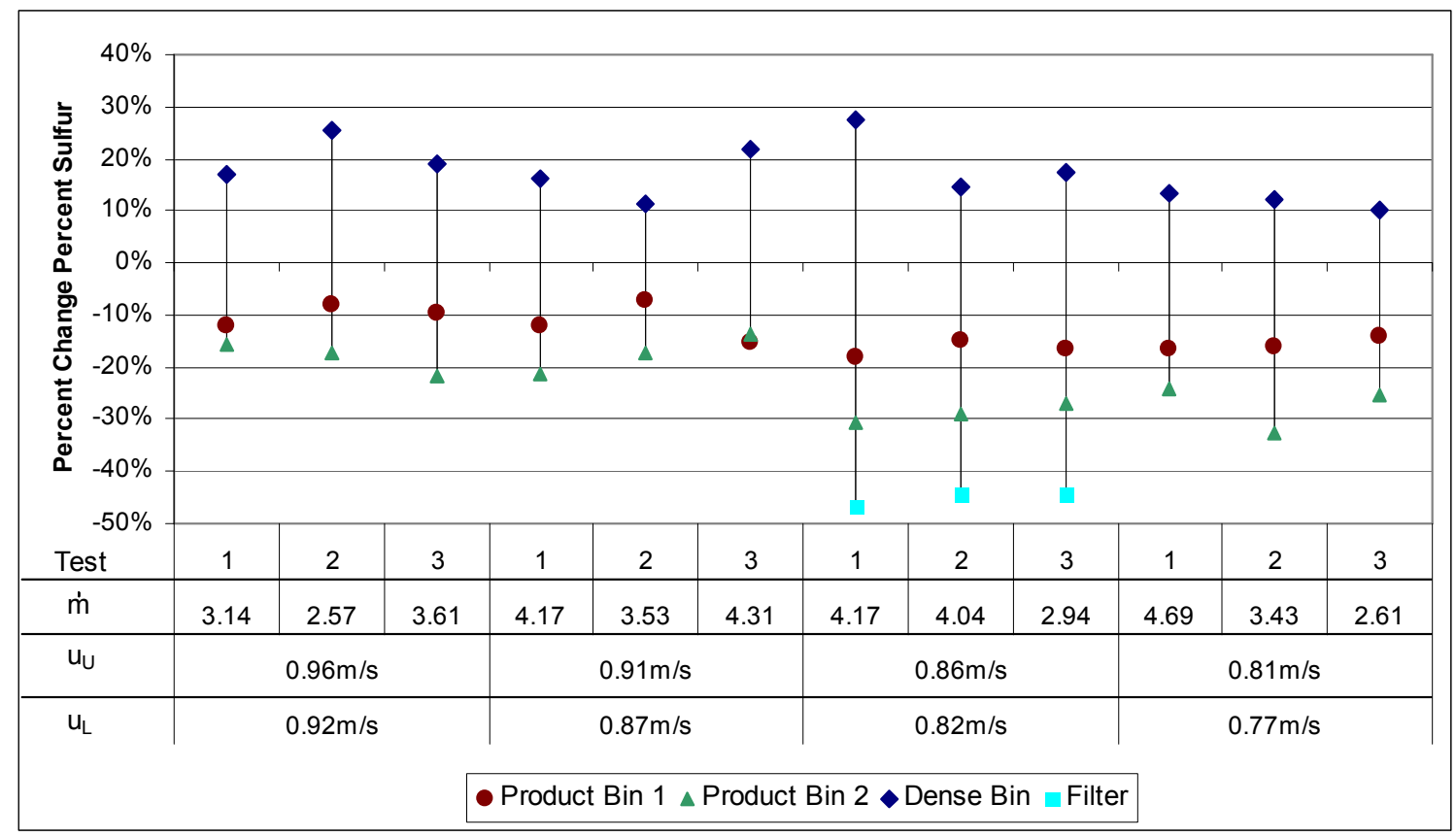

FIGURE B-1: Results from tests with $1 \mathrm{~Hz}$ pulsations, coal particles $\left(105<\mathrm{d}_{\mathrm{p}}<210\right) \mu \mathrm{m}$, decreasing superficial gas velocity with separated Product Bins.

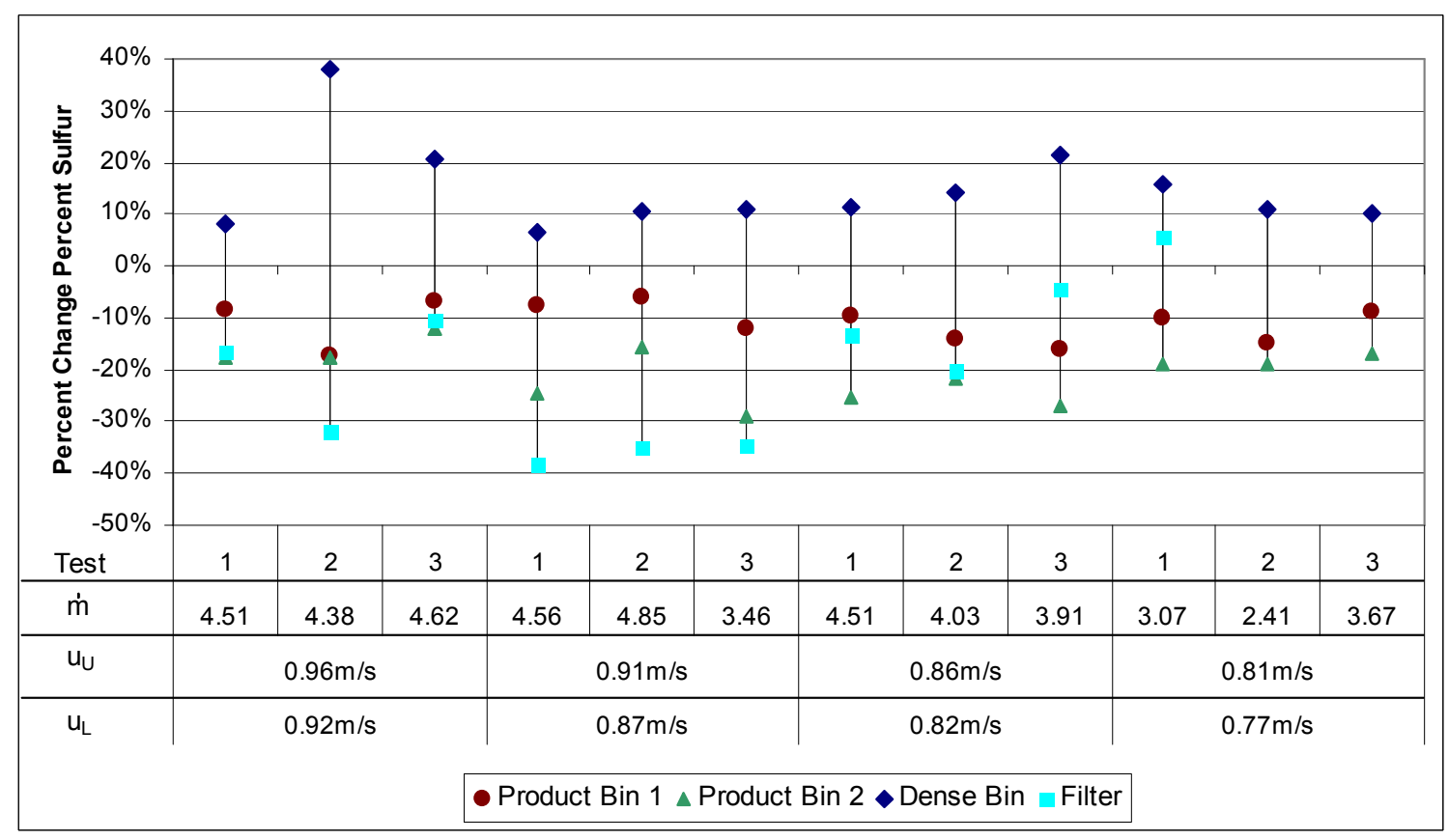

FIGURE B-2: Test Results from tests with $2 \mathrm{~Hz}$ pulsations, coal particles $\left(105<\mathrm{d}_{\mathrm{p}}<210\right) \mu \mathrm{m}$, decreasing superficial gas velocity with separated Product Bins. 


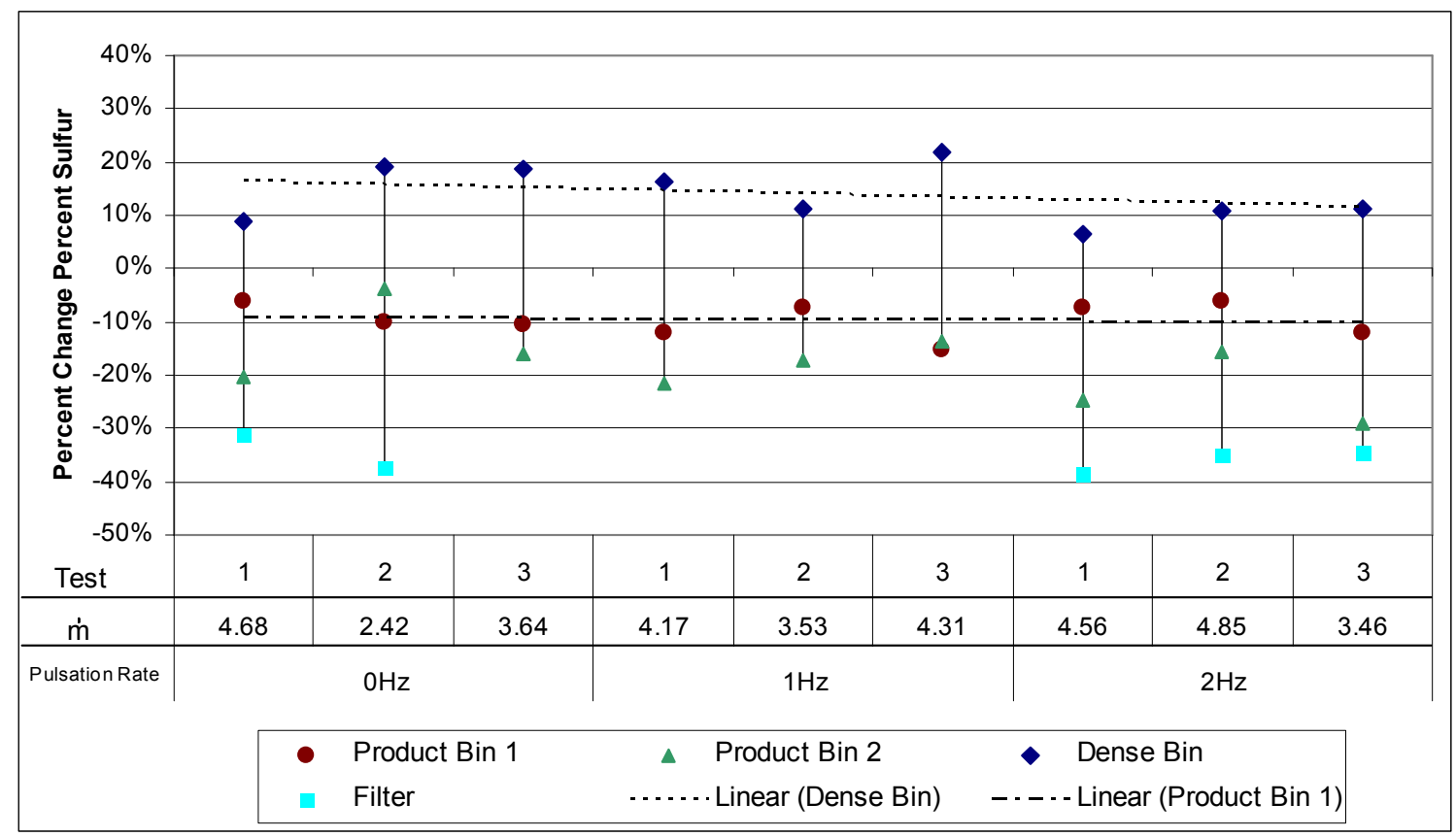

FIGURE B-3: Test Results for superficial gas velocity $u_{0}=0.9101 \mathrm{~ms}^{-1}$, coal particles $\left(105<d_{p}<210\right) \mu \mathrm{m}$, varying pulsation rates $(0 \mathrm{~Hz}$, $1 \mathrm{~Hz}$, and $2 \mathrm{~Hz}$ ), and separated Product Bins.

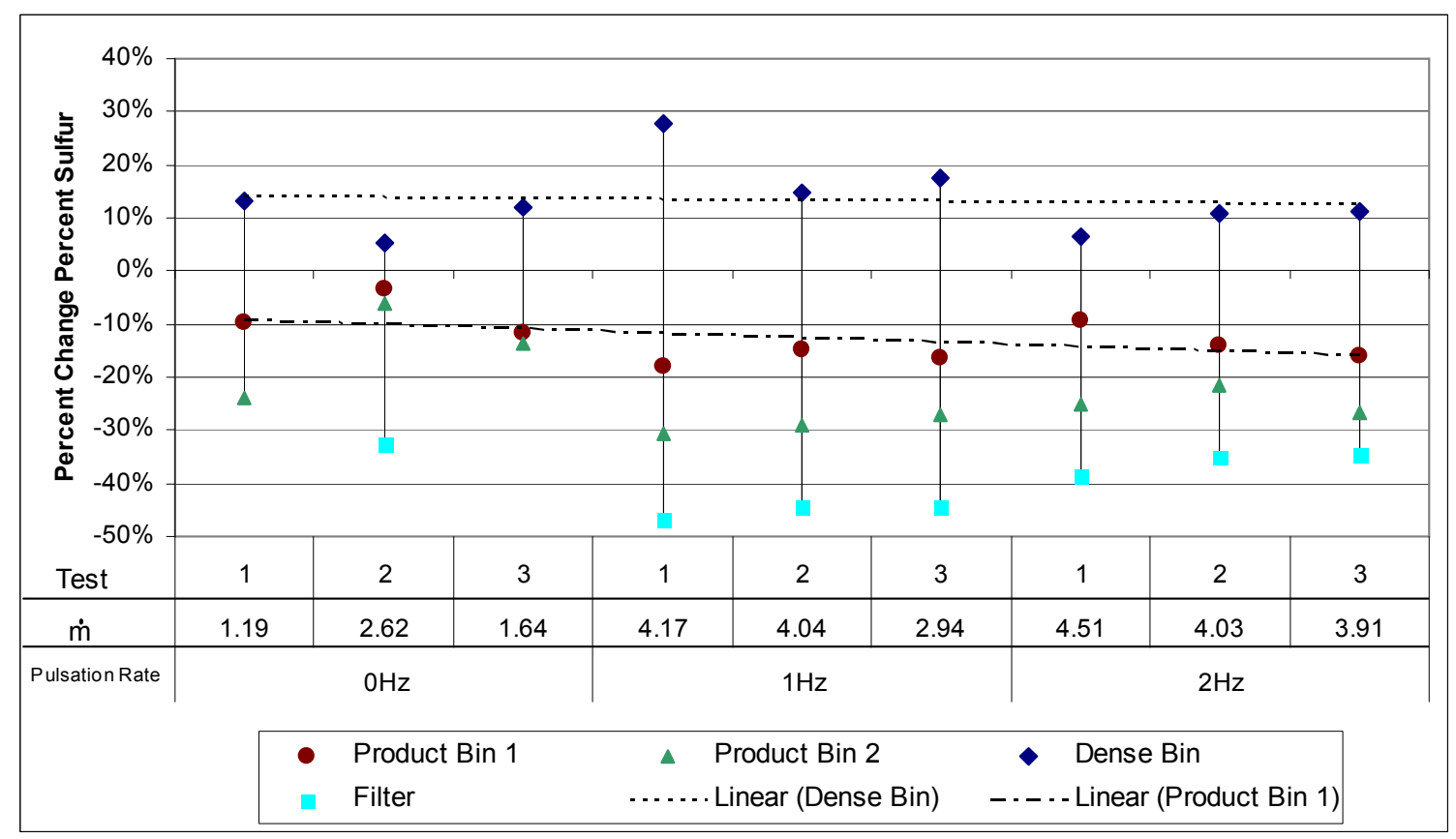

FIGURE B-4: Test Results for superficial gas velocity $u_{0}=0.8581 \mathrm{~ms}^{-1}$, coal particles $\left(105<d_{p}<210\right) \mu \mathrm{m}$, varying pulsation rates $(0 \mathrm{~Hz}$, $1 \mathrm{~Hz}$, and $2 \mathrm{~Hz}$ ), and separated Product Bins. 


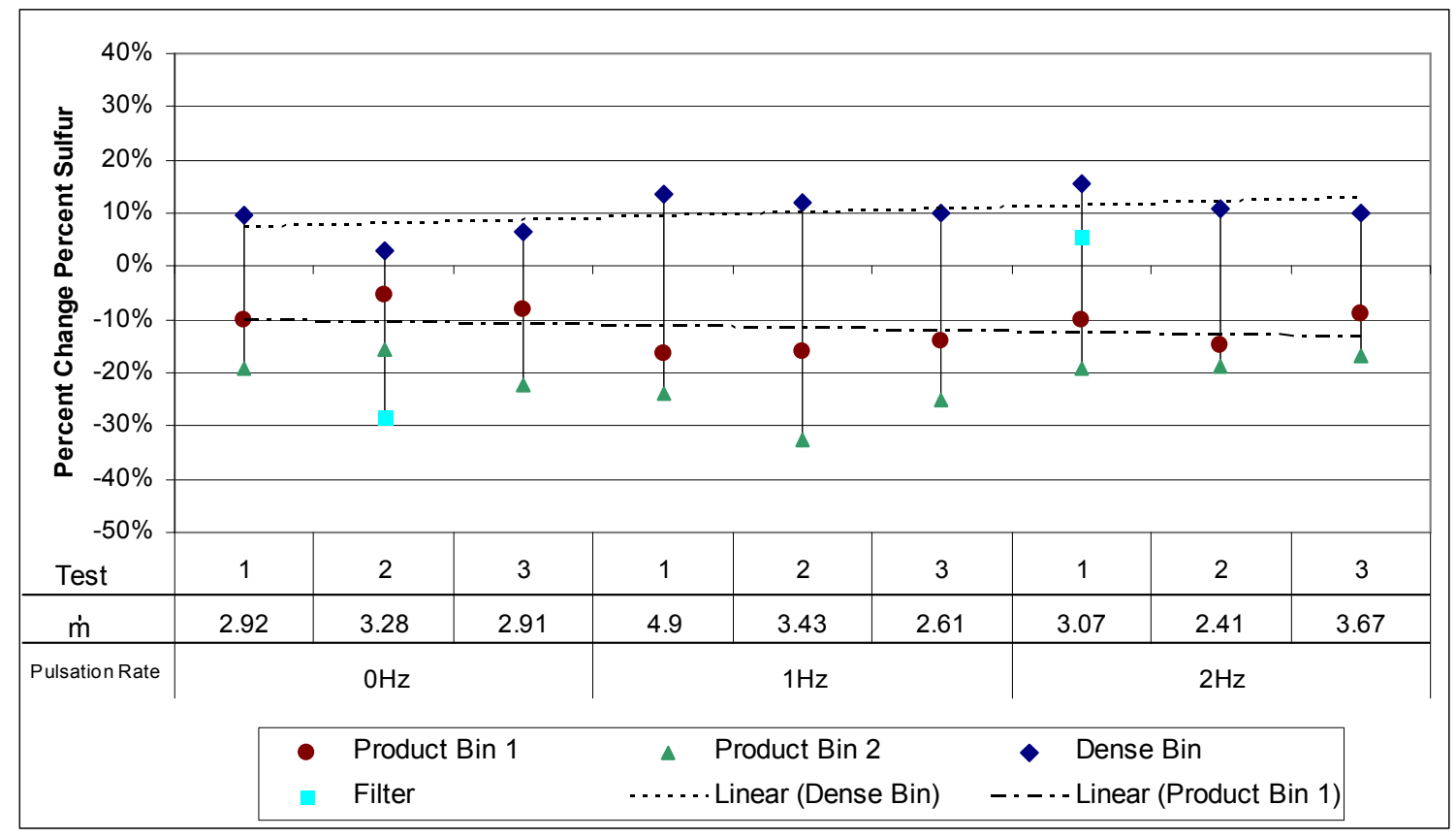

FIGURE B-5: Test Results for superficial gas velocity $u_{0}=0.8061 \mathrm{~ms}^{-1}$, coal particles $\left(105<d_{p}<210\right) \mu \mathrm{m}$, varying pulsation rates $(0 \mathrm{~Hz}$, $1 \mathrm{~Hz}$, and $2 \mathrm{~Hz}$ ), and separated Product Bins.

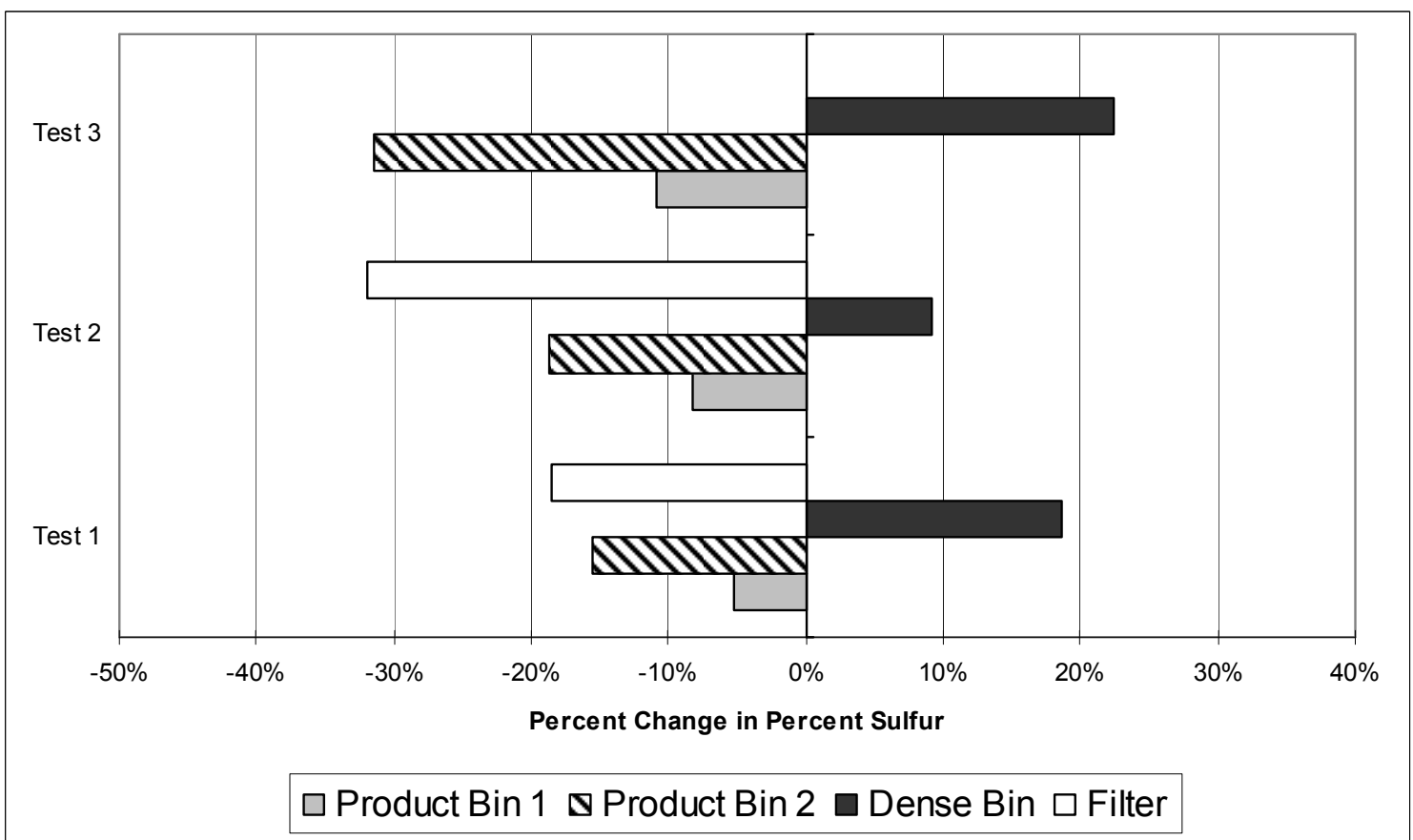

FIGURE B-6: Test Results for superficial gas velocity $\mathrm{u}_{0}=0.9621 \mathrm{~ms}^{-1}$, No pulsations $-\mathrm{OHz}, \dot{m}=(4.62,3.71,1.72) \mathrm{kg}^{*} \mathrm{hr}^{-1}$, $\left(105<d_{p}<210\right) \mu \mathrm{m}$ coal particles, and separated Product Bin results. 


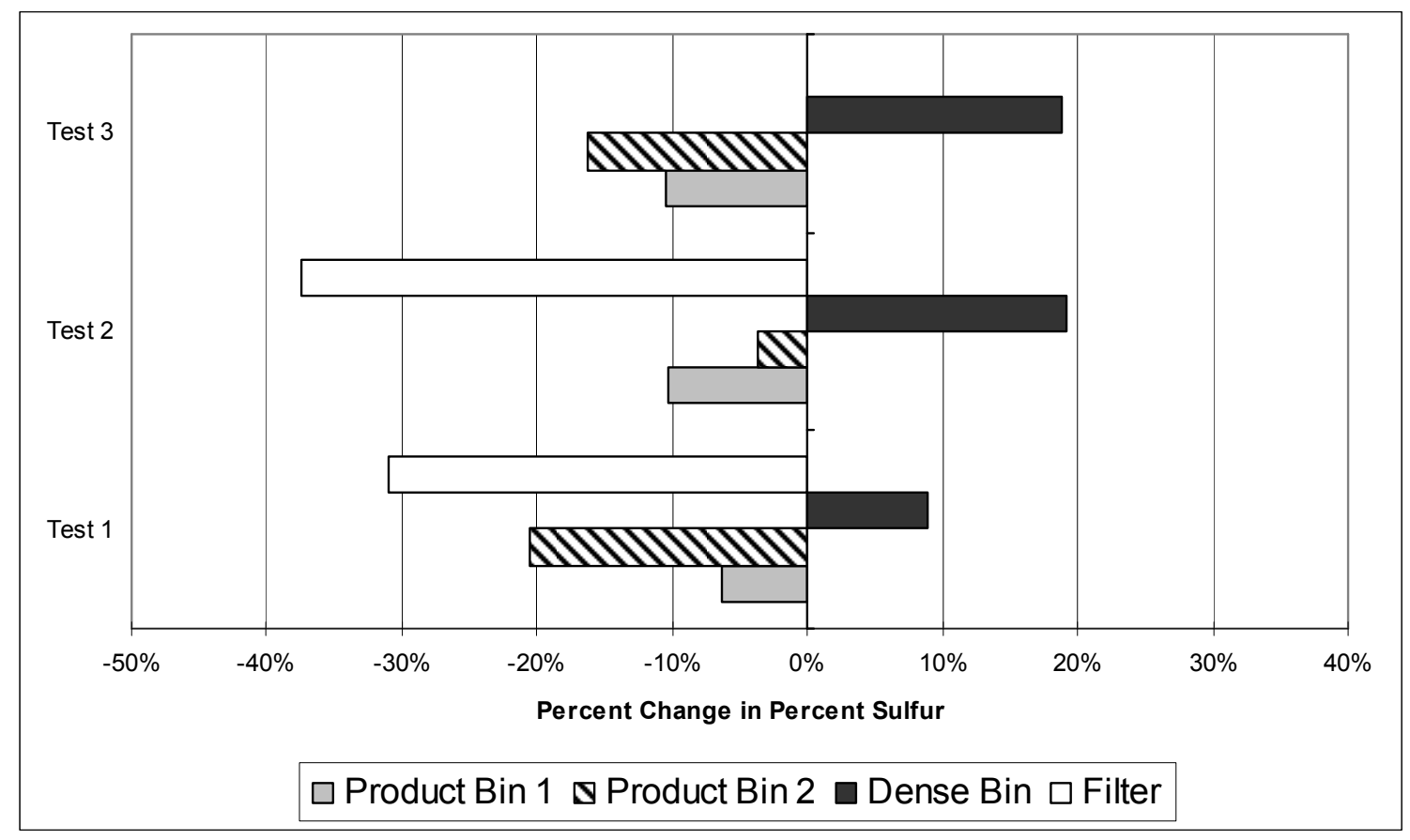

FIGURE B-7: Test Results for superficial gas velocity $\mathrm{u}_{0}=0.9101 \mathrm{~ms}^{-1}$, No pulsations $-\mathrm{OHz}, \dot{m}=(4.68,2.42,3.64) \mathrm{kg}^{*} \mathrm{hr}^{-1}$, $\left(105<d_{p}<210\right) \mu \mathrm{m}$ coal particles, and separated Product Bin results.

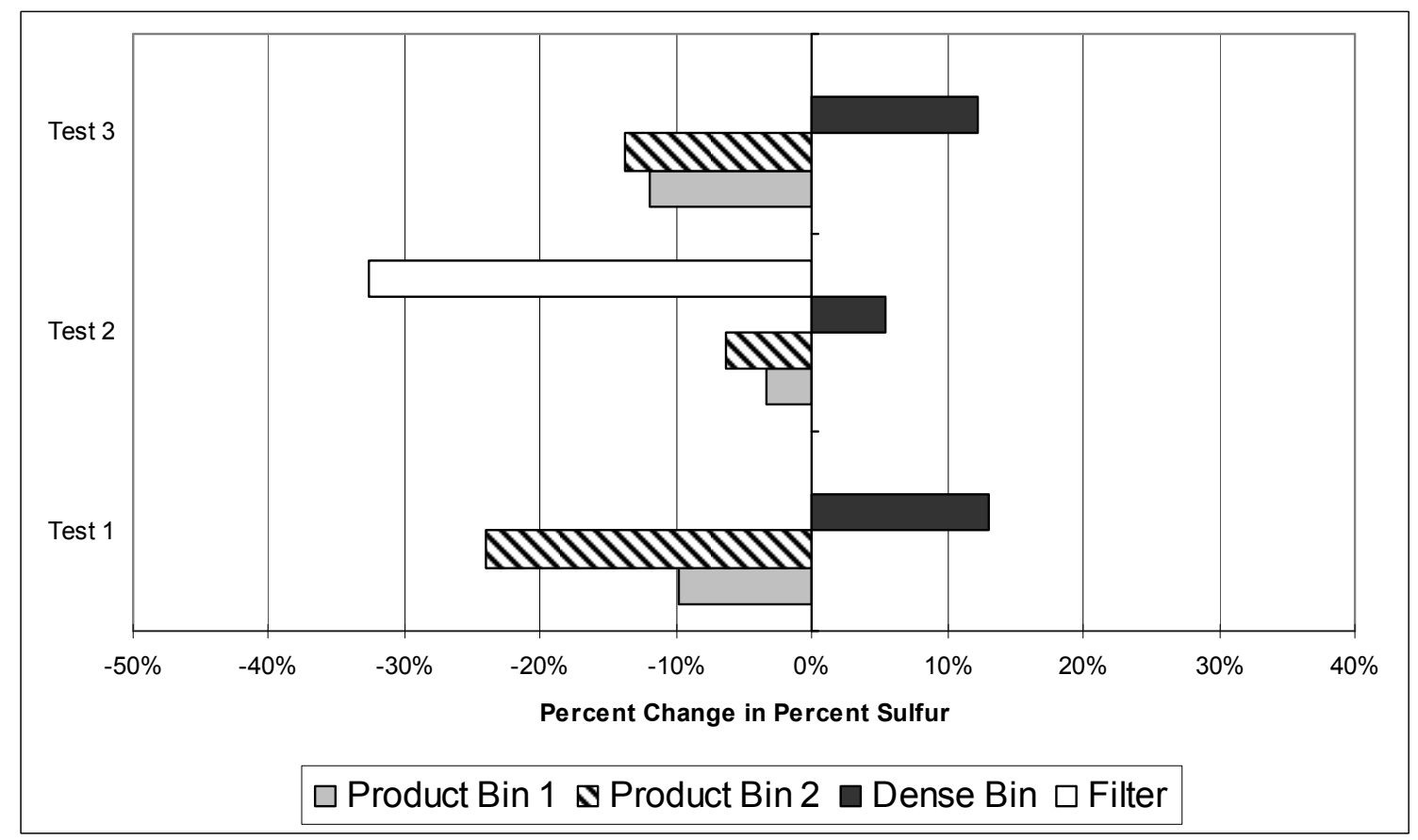

FIGURE B-8: Test Results for superficial gas velocity $\mathrm{u}_{0}=0.8581 \mathrm{~ms}^{-1}$, No pulsations $-\mathrm{OHz}, \dot{m}=(1.19,2.62,1.64) \mathrm{kg}^{*} \mathrm{hr}^{-1}$, $\left(105<d_{p}<210\right) \mu \mathrm{m}$ coal particles, and grouped Product Bin results. 


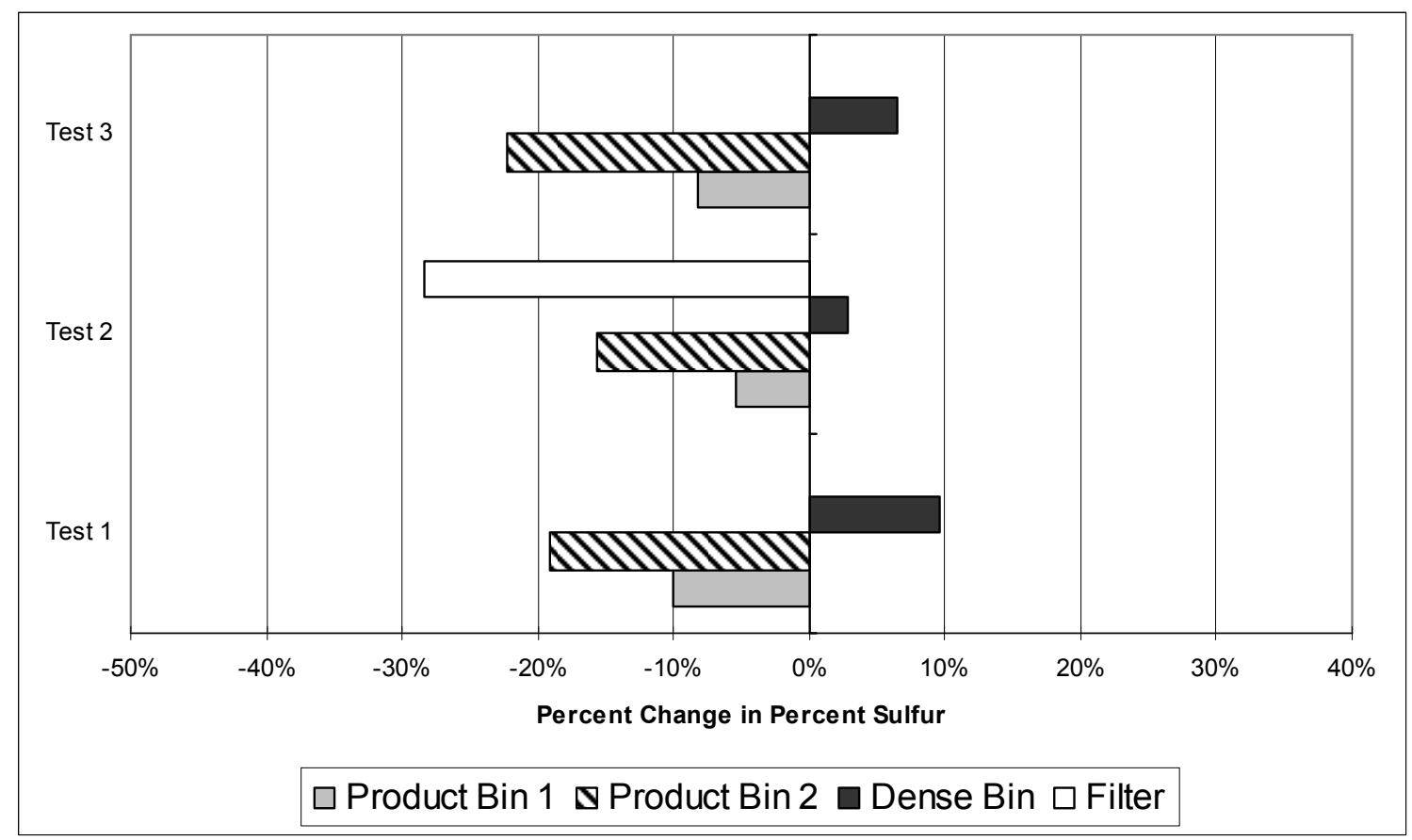

FIGURE B-9: Test Results for superficial gas velocity $\mathrm{u}_{0}=0.8061 \mathrm{~ms}^{-1}$, No pulsations $-\mathrm{OHz}, \dot{m}=(2.92,3.28,2.91) \mathrm{kg}^{*} \mathrm{hr}^{-1}$, $\left(105<d_{p}<210\right) \mu m$ coal particles, and separated Product Bin results.

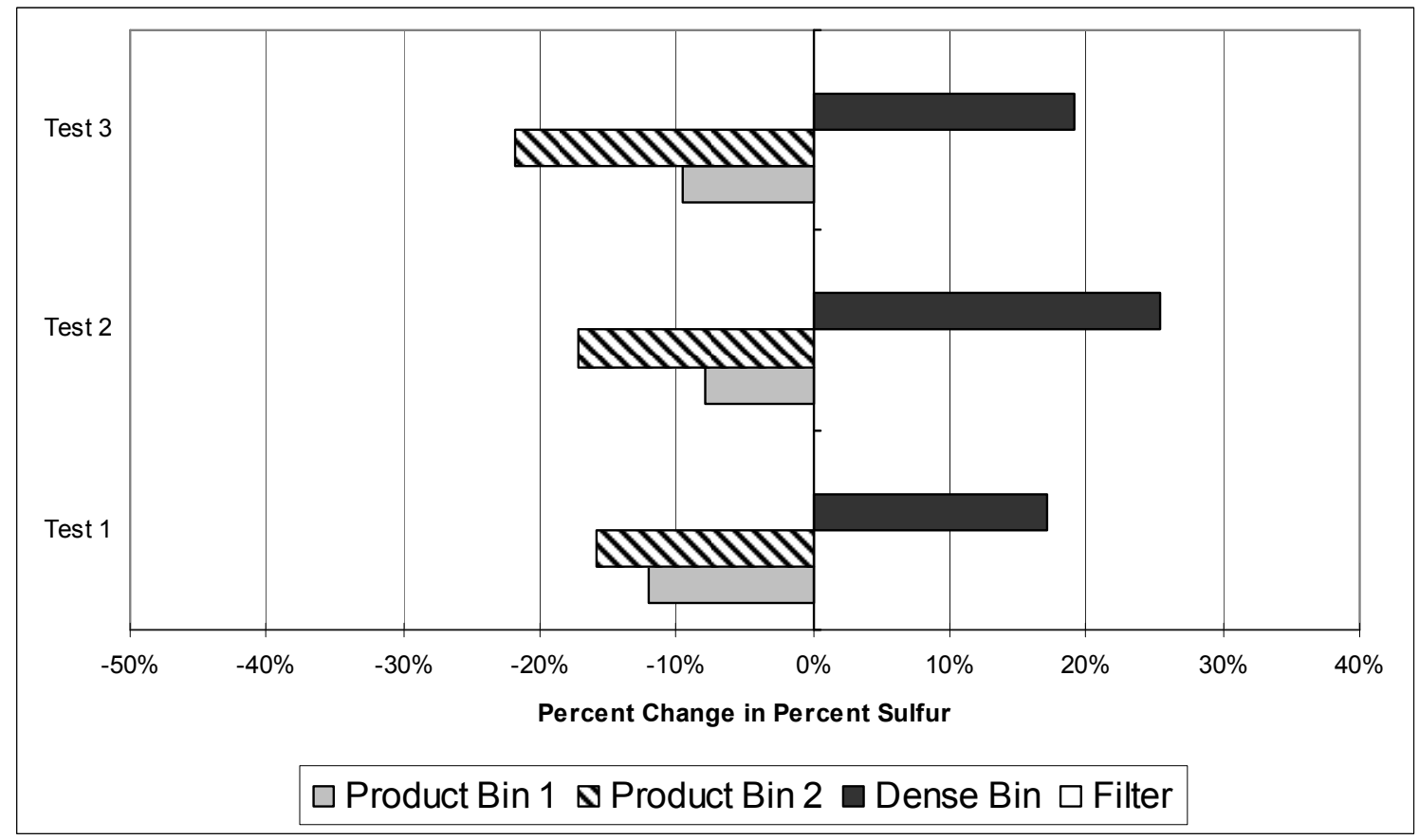

FIGURE B-10: Test Results for superficial gas velocity $\mathrm{u}_{0}=0.9621 \mathrm{~ms}^{-1}$, Pulsations $-1 \mathrm{~Hz}, \dot{m}=(3.14,2.57,3.61) \mathrm{kg}^{*} \mathrm{hr}^{-1}$, $\left(105<d_{p}<210\right) \mu \mathrm{m}$ coal particles, and separated Product Bin results. 


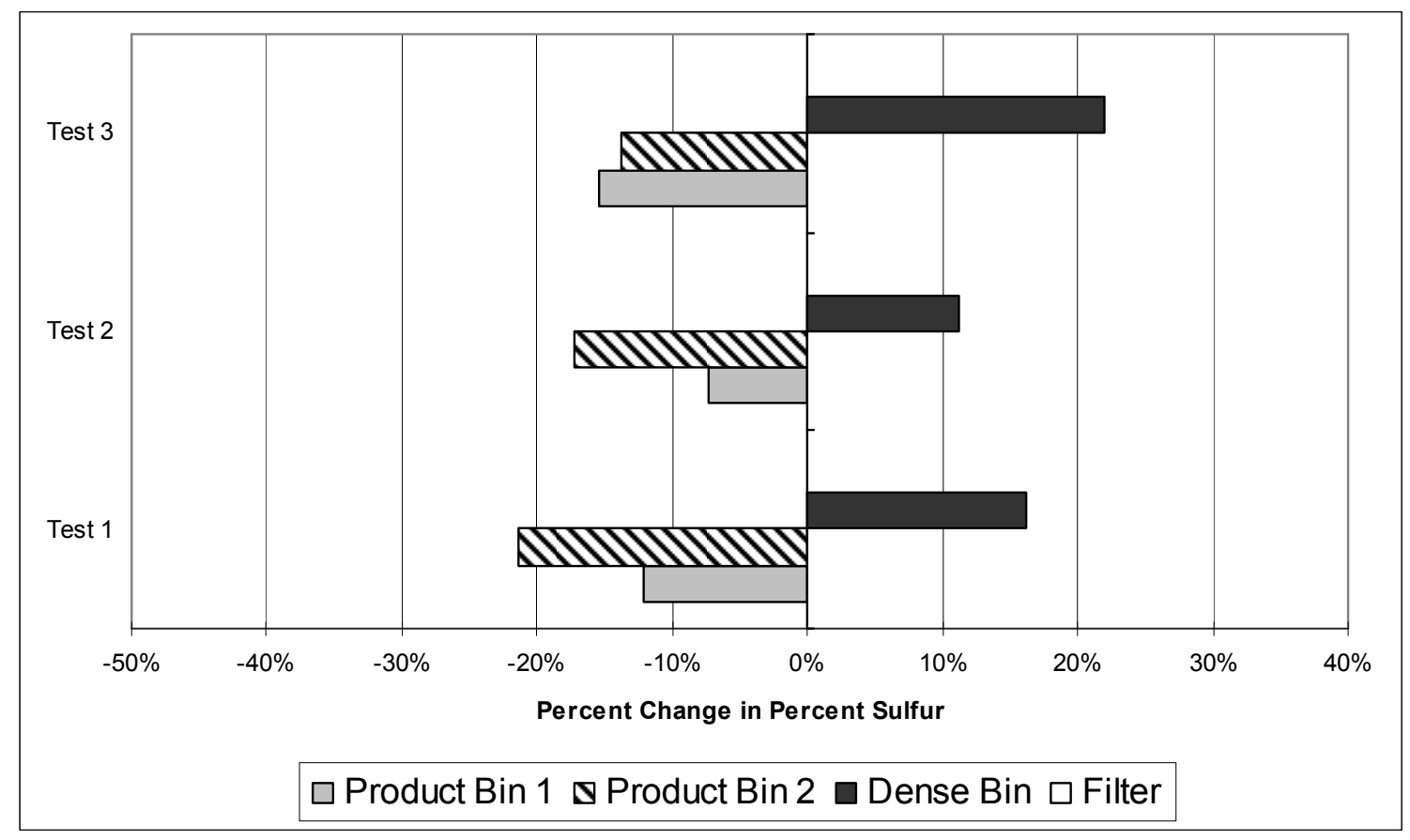

FIGURE B-11: Test Results for superficial gas velocity $\mathrm{u}_{0}=0.9101 \mathrm{~ms}^{-1}$, Pulsations $-1 \mathrm{~Hz}, \dot{m}=(4.17,3.53,4.31) \mathrm{kg}^{*} \mathrm{hr}^{-1}$, $\left(105<d_{p}<210\right) \mu m$ coal particles, and separated Product Bin results.

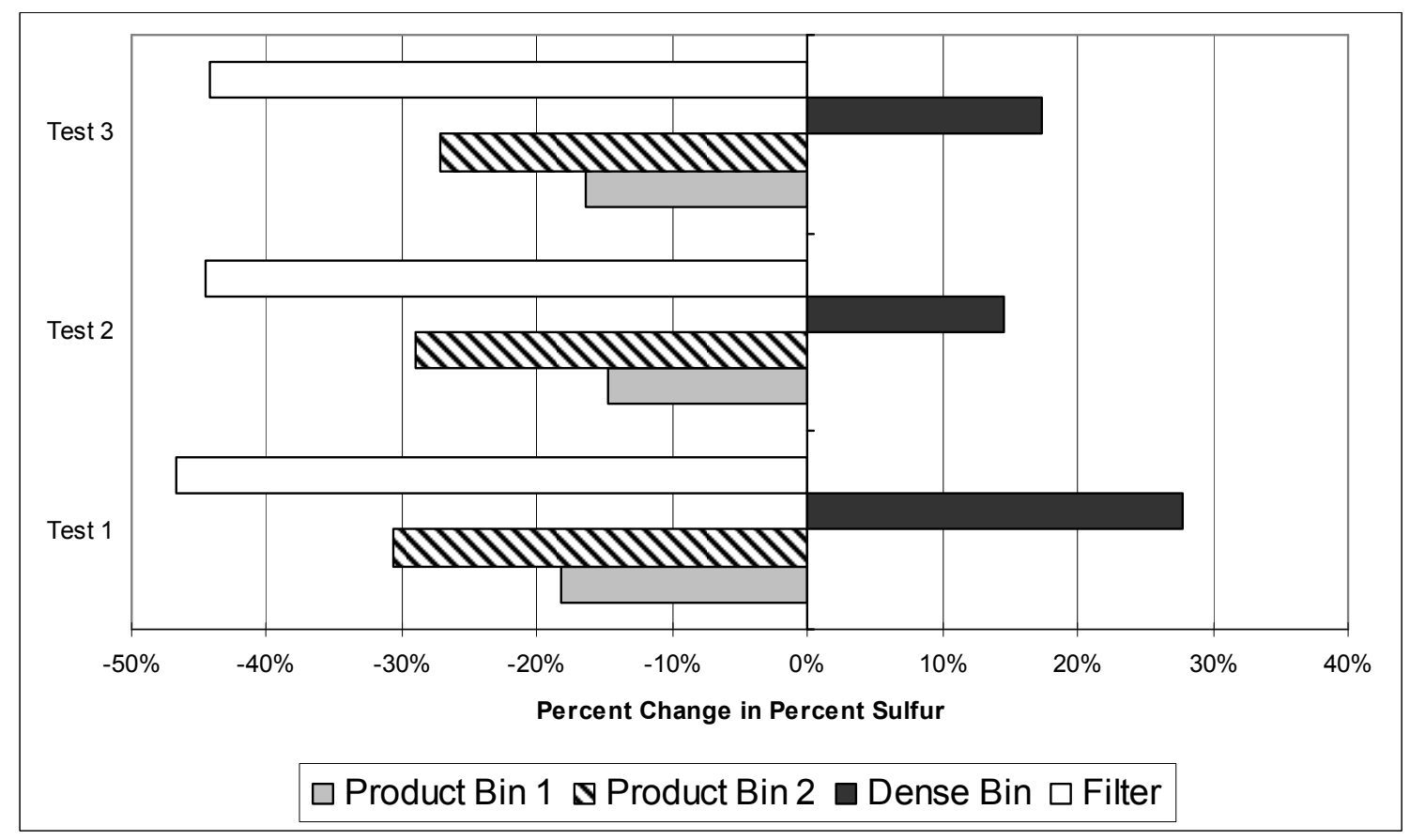

FIGURE B-12: Test Results for superficial gas velocity $u_{0}=0.8581 \mathrm{~ms}^{-1}$, Pulsations $-1 \mathrm{~Hz}, \dot{m}=(4.17,4.04,2.94) \mathrm{kg}^{*} \mathrm{hr}^{-1}$, $\left(105<d_{p}<210\right) \mu m$ coal particles, and separated Product Bin results. 


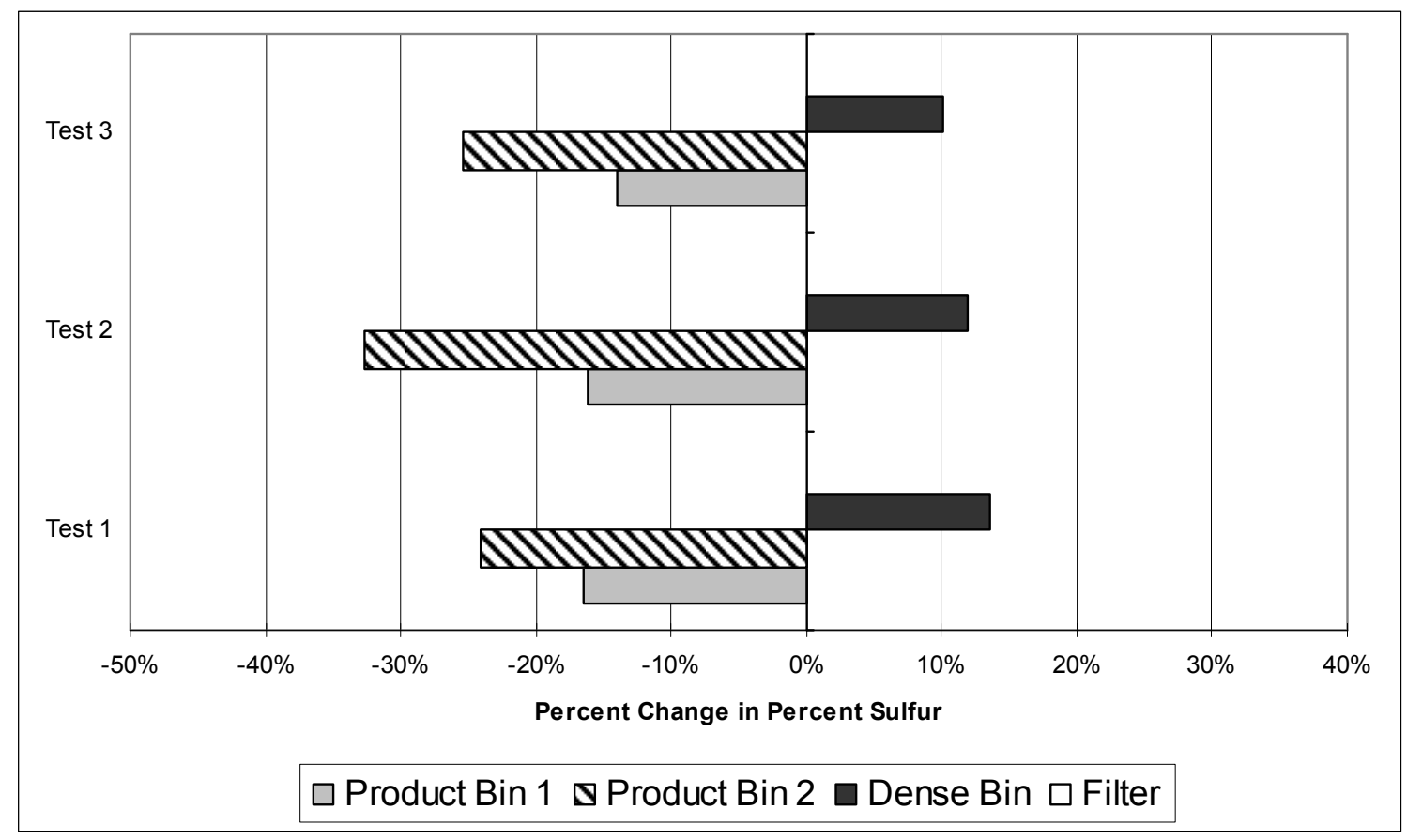

FIGURE B-13: Test Results for superficial gas velocity $\mathrm{u}_{0}=0.8061 \mathrm{~ms}^{-1}$, Pulsations $-1 \mathrm{~Hz}, \dot{m}=(4.69,3.43,2.61) \mathrm{kg}^{*} \mathrm{hr}^{-1}$, $\left(105<d_{p}<210\right) \mu m$ coal particles, and separated Product Bin results.

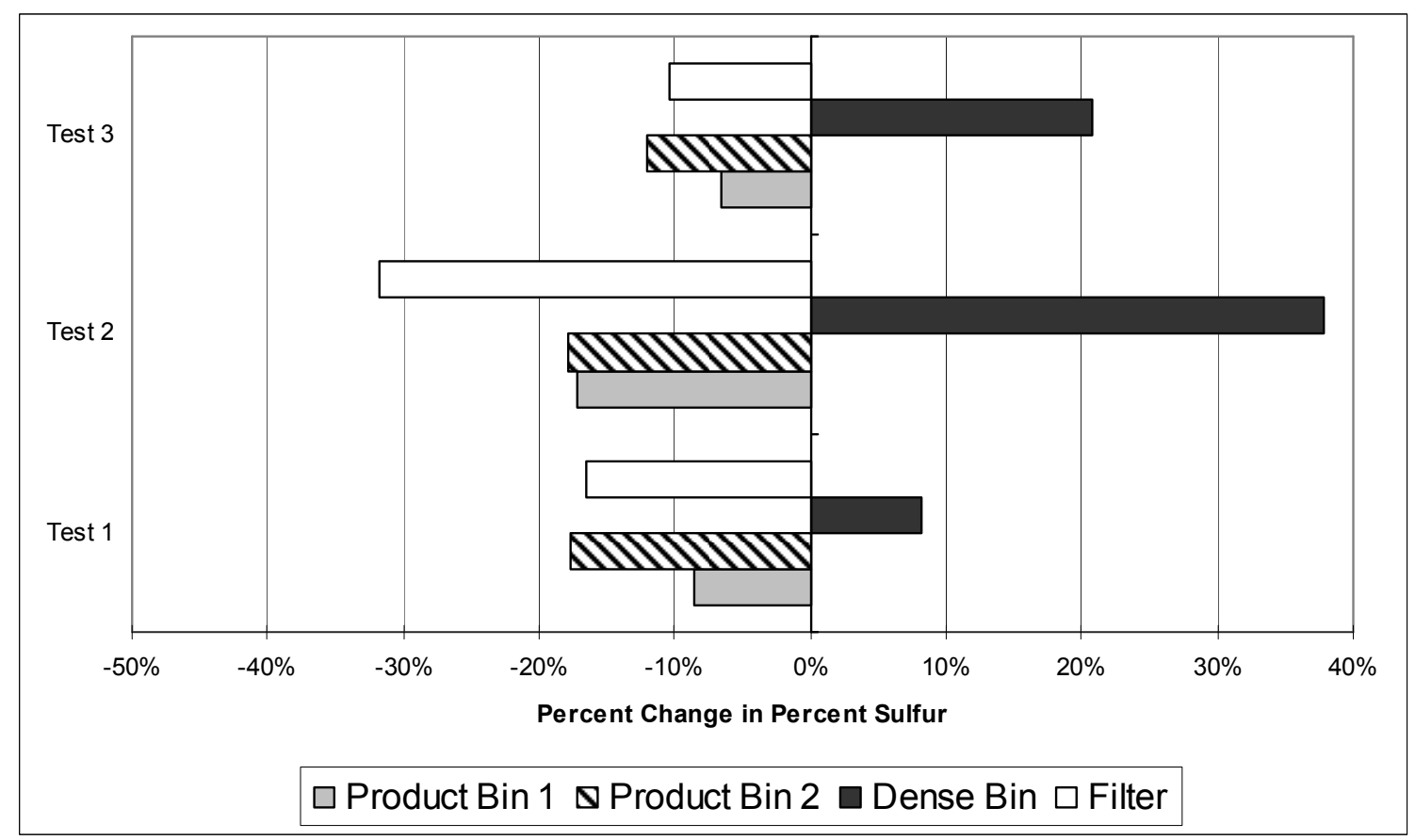

FIGURE B-14: Test Results for superficial gas velocity $\mathrm{u}_{0}=0.9621 \mathrm{~ms}^{-1}$, Pulsations $-2 \mathrm{~Hz}, \dot{m}=(4.51,4.38,4.62) \mathrm{kg}^{*} \mathrm{hr}^{-1}$, $\left(105<d_{p}<210\right) \mu \mathrm{m}$ coal particles, and separated Product Bin results. 


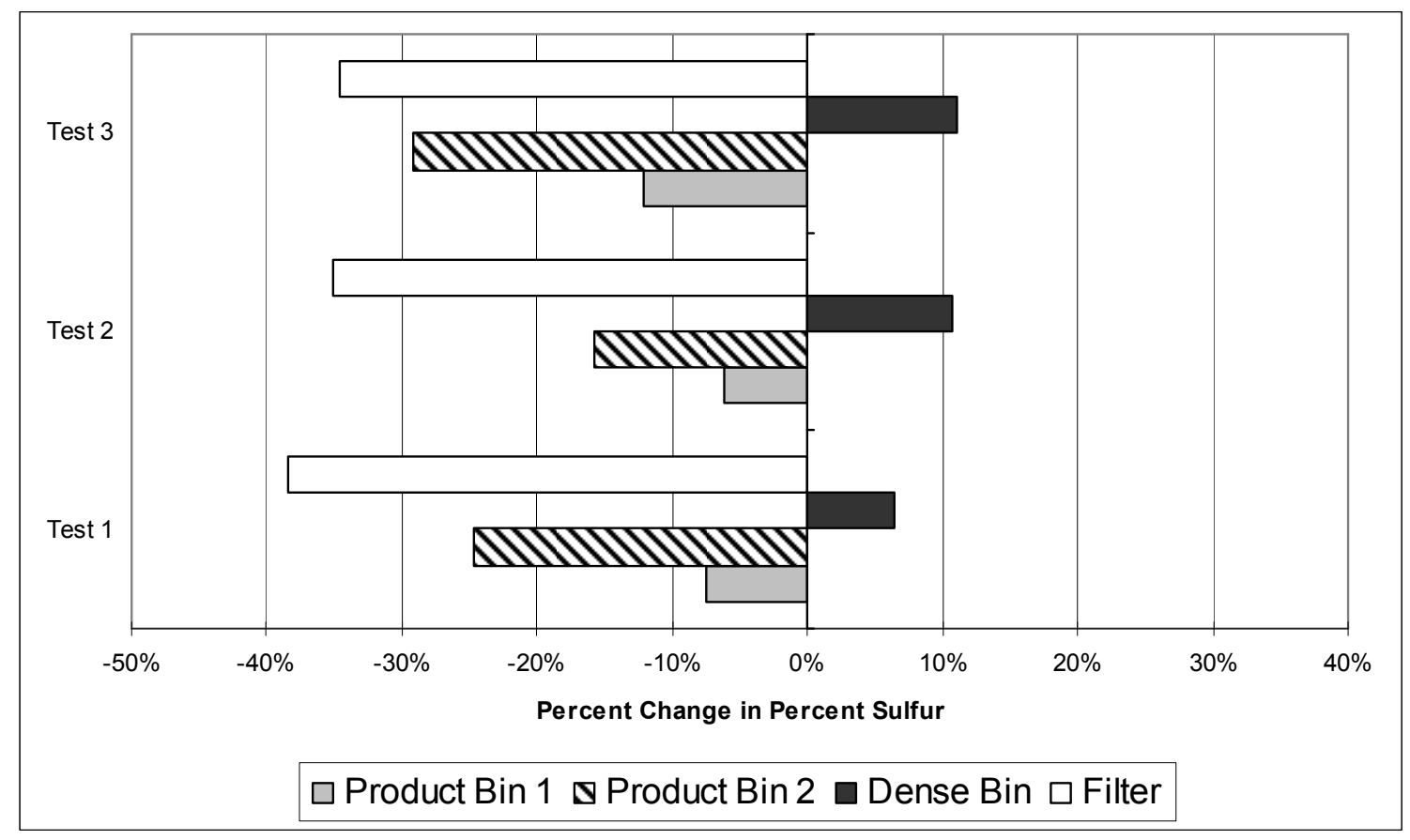

FIGURE B-15: Test Results for superficial gas velocity $\mathrm{u}_{0}=0.9101 \mathrm{~ms}^{-1}$, Pulsations $-2 \mathrm{~Hz}, \dot{m}=(4.56,4.85,3.46) \mathrm{kg}^{*} \mathrm{hr}^{-1}$, $\left(105<d_{p}<210\right) \mu m$ coal particles, and separated Product Bin results.

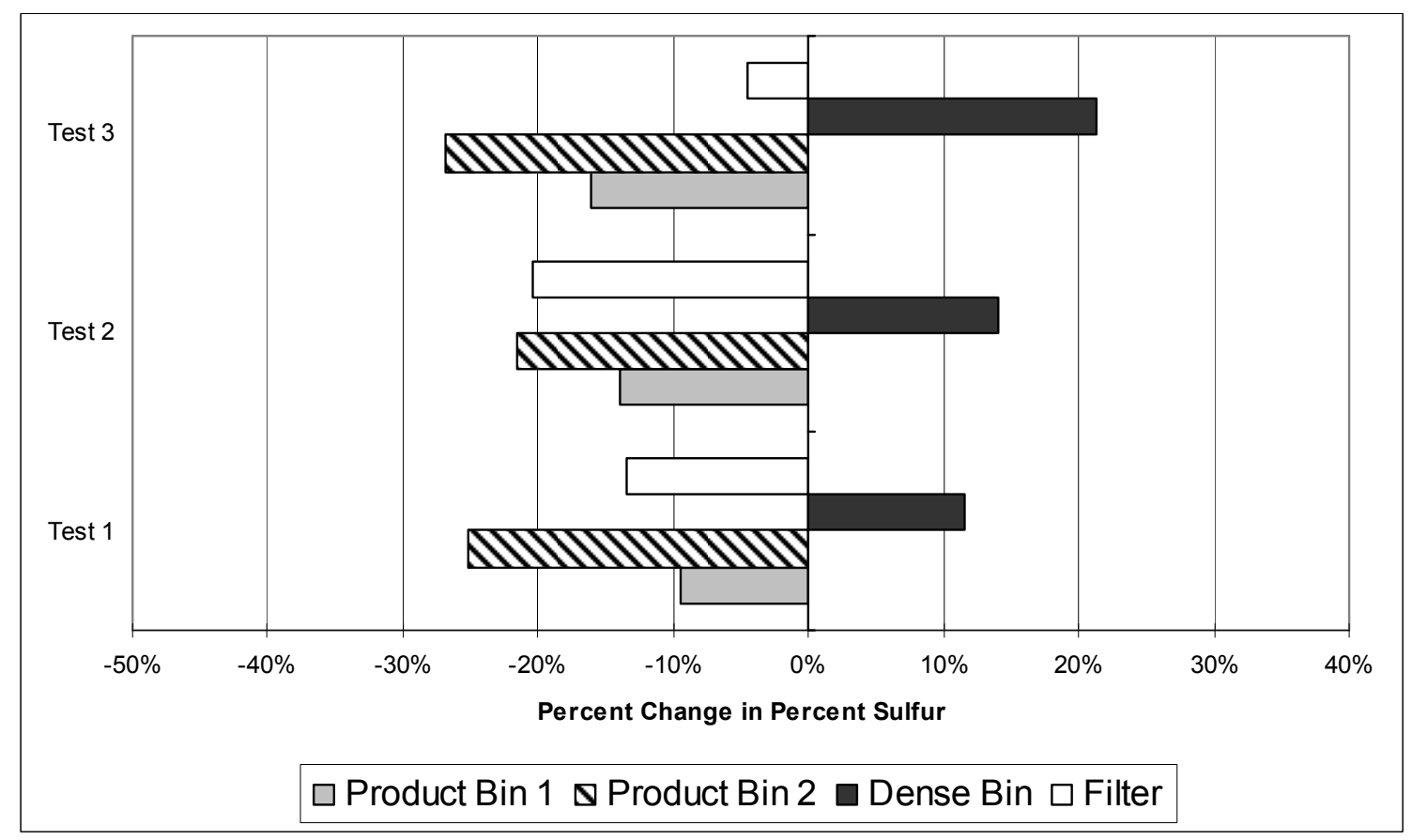

FIGURE B-16: Test Results for superficial gas velocity $\mathrm{u}_{0}=0.8581 \mathrm{~ms}^{-1}$, Pulsations $-2 \mathrm{~Hz}, \dot{m}=(4.51,4.03,3.91) \mathrm{kg}^{*} \mathrm{hr}^{-1}$, $\left(105<d_{p}<210\right) \mu m$ coal particles, and separated Product Bin results. 


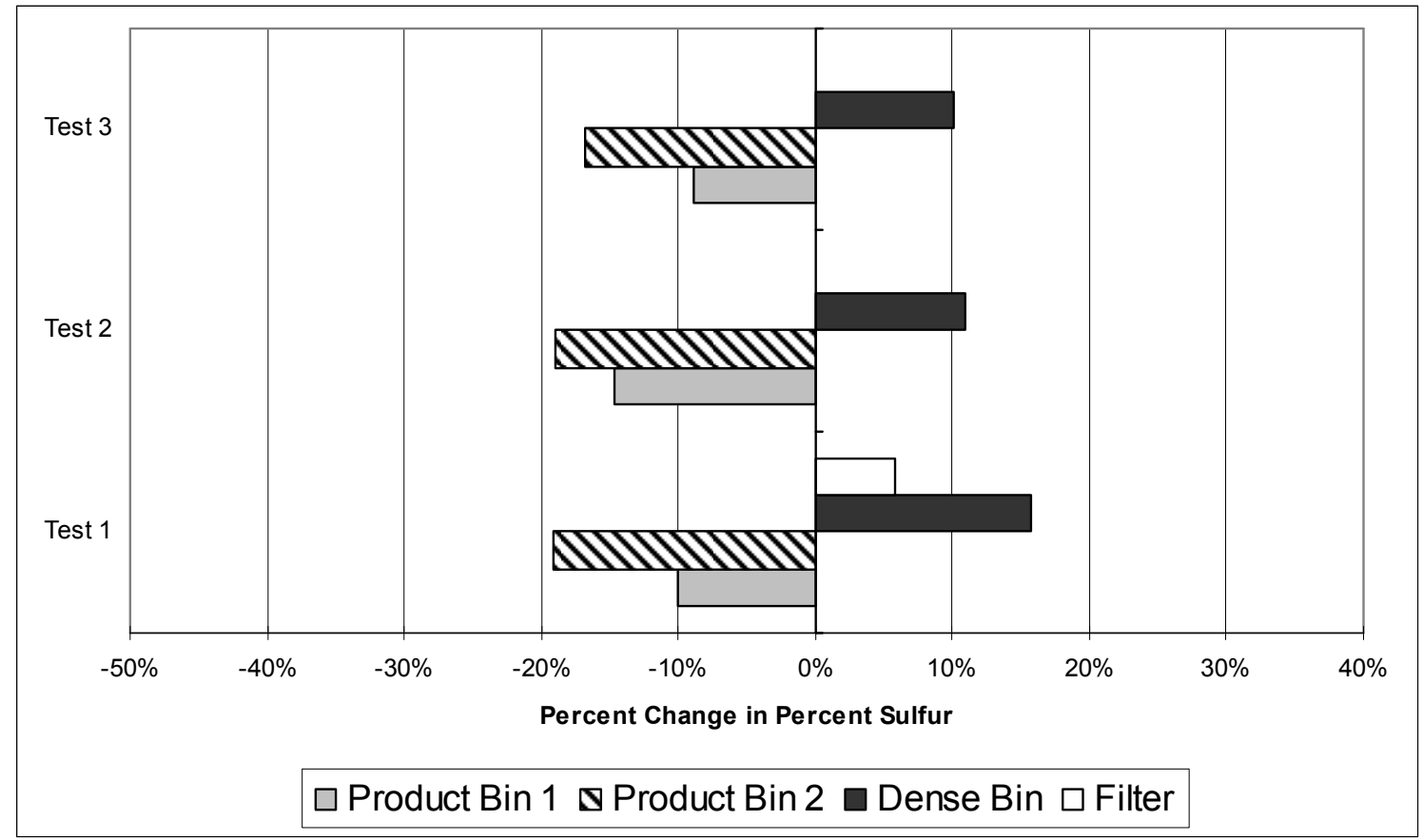

FIGURE B-17: Test Results for superficial gas velocity $\mathrm{u}_{0}=0.8061 \mathrm{~ms}^{-1}$, Pulsations $-2 \mathrm{~Hz}, \dot{m}=(3.07,2.41,3.67) \mathrm{kg}^{*} \mathrm{hr}^{-1}$, $\left(\mathbf{1 0 5}<\mathrm{d}_{\mathrm{p}}<210\right) \mu \mathrm{m}$ coal particles, and separated Product Bin results. 


\section{APPENDIX C:}

\section{AdDitionAL Figures - IRON REMOVAL ANALYSIS}

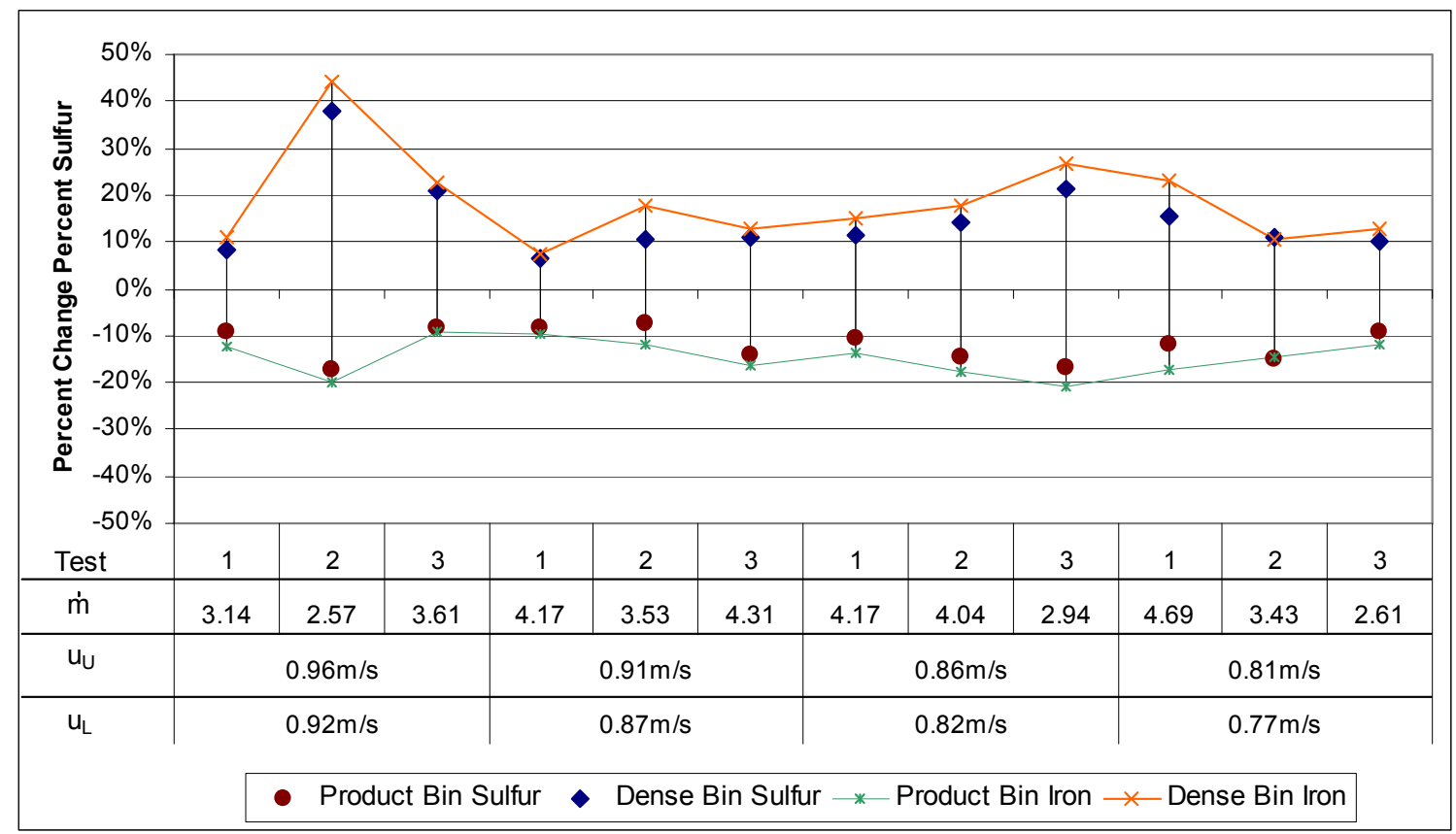

FIGURE C-1: Results from tests with $2 \mathrm{~Hz}$ pulsations, coal particles $\left(105<\mathrm{d}_{\mathrm{p}}<210\right) \mu \mathrm{m}$, and decreasing superficial gas velocity with grouped Product Bins. This figure compares the percent change of mass percent sulfur to the percent change of mass percent iron for tests with the given flow conditions.

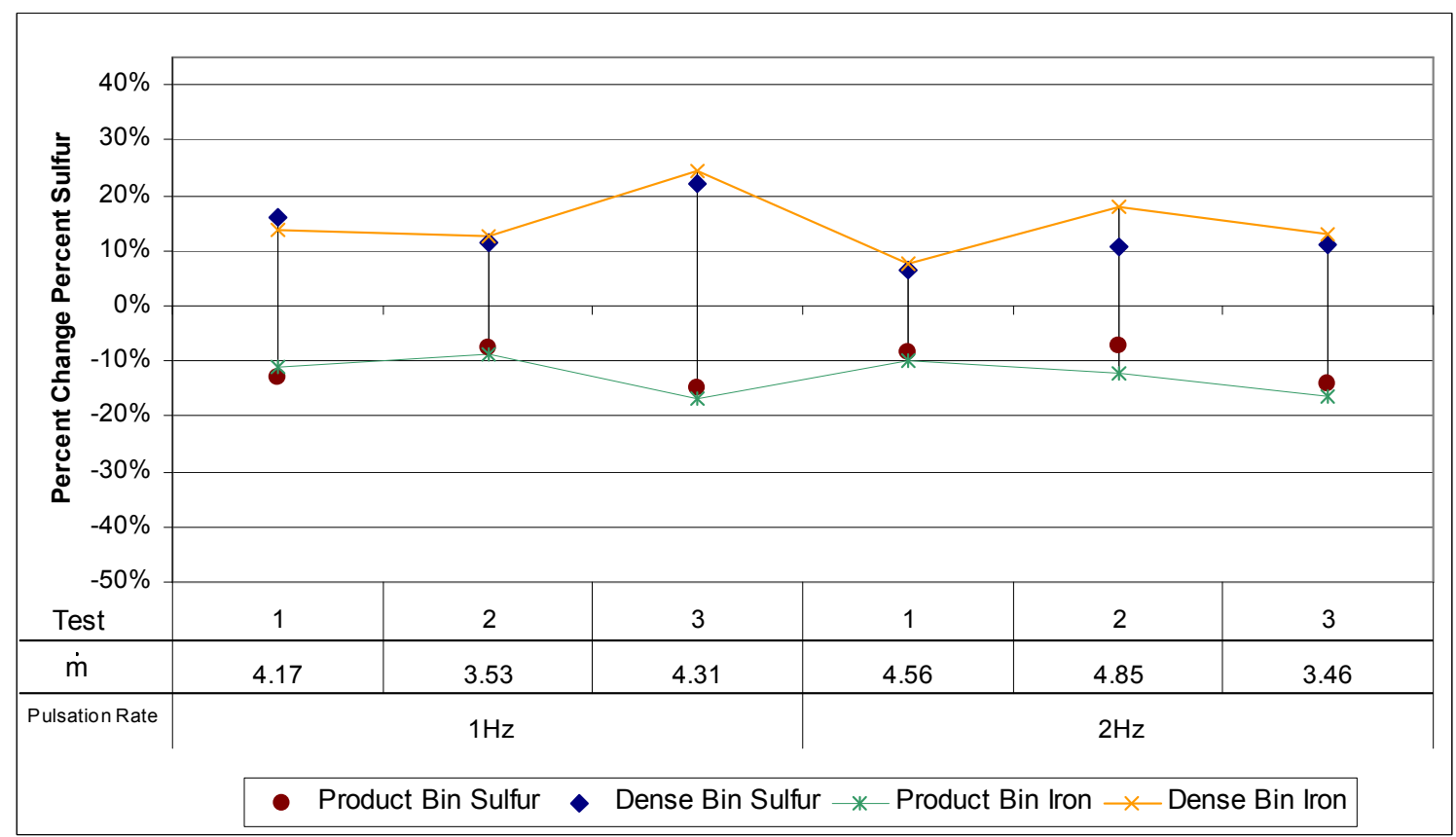

FIGURE C-2: Results from tests with superficial gas velocity $u_{0}=0.9101 \mathrm{~ms}^{-1}$, coal particles $\left(105<d_{p}<210\right) \mu \mathrm{m}$, varying pulsation rates $(1 \mathrm{~Hz}$ and $2 \mathrm{~Hz})$, and grouped Product Bins. This figure compares the percent change of mass percent sulfur to the percent change of mass percent iron for tests with the given flow conditions. 


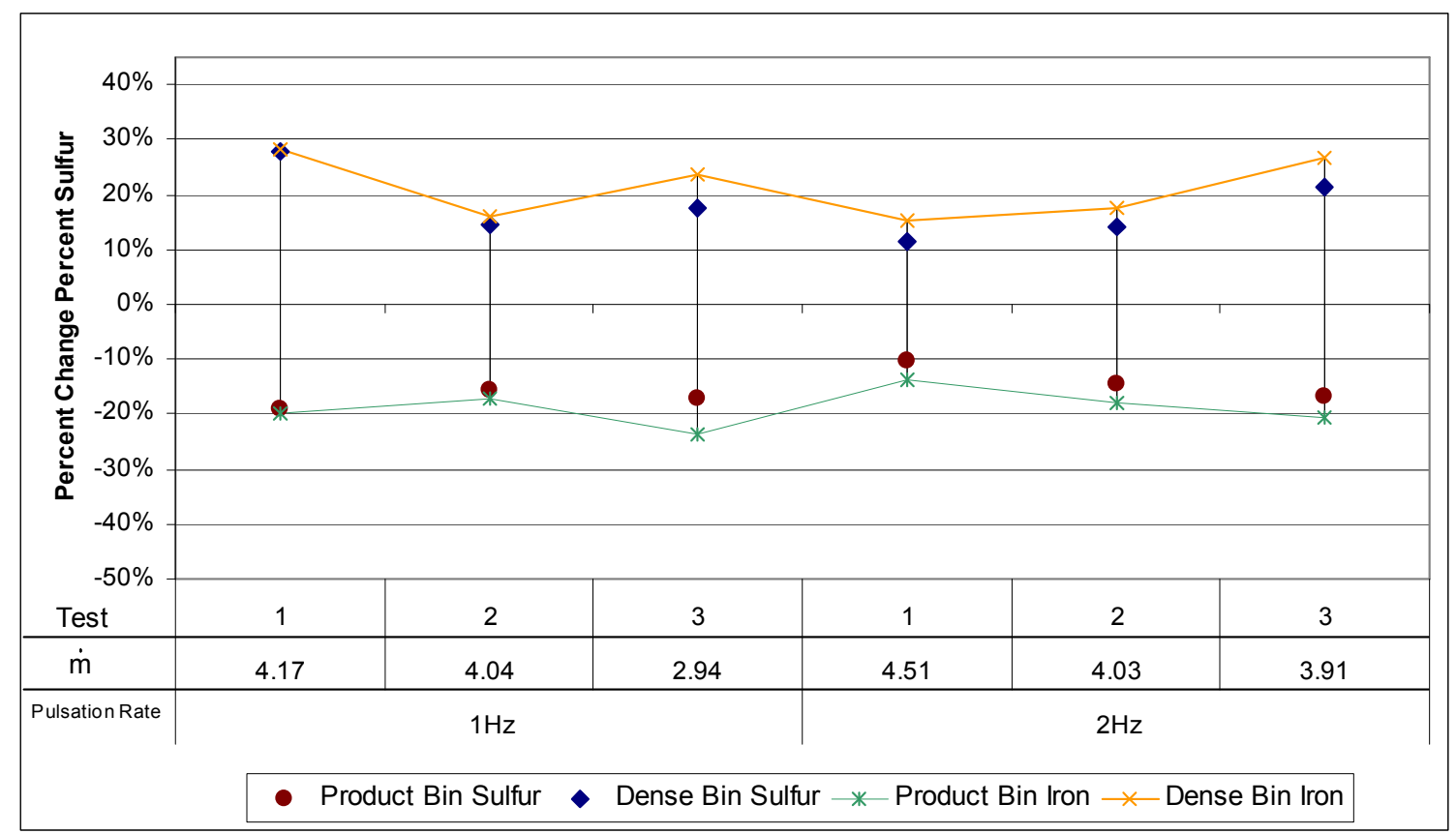

FIGURE C-3: Results from tests with superficial gas velocity $u_{0}=0.8581 \mathrm{~ms}^{-1}$, coal particles $\left(105<d_{p}<210\right) \mu \mathrm{m}$, varying pulsation rates $(1 \mathrm{~Hz}$ and $2 \mathrm{~Hz})$, and grouped Product Bins. This figure compares the percent change of mass percent sulfur to the percent change of mass percent iron for tests with the given flow conditions.

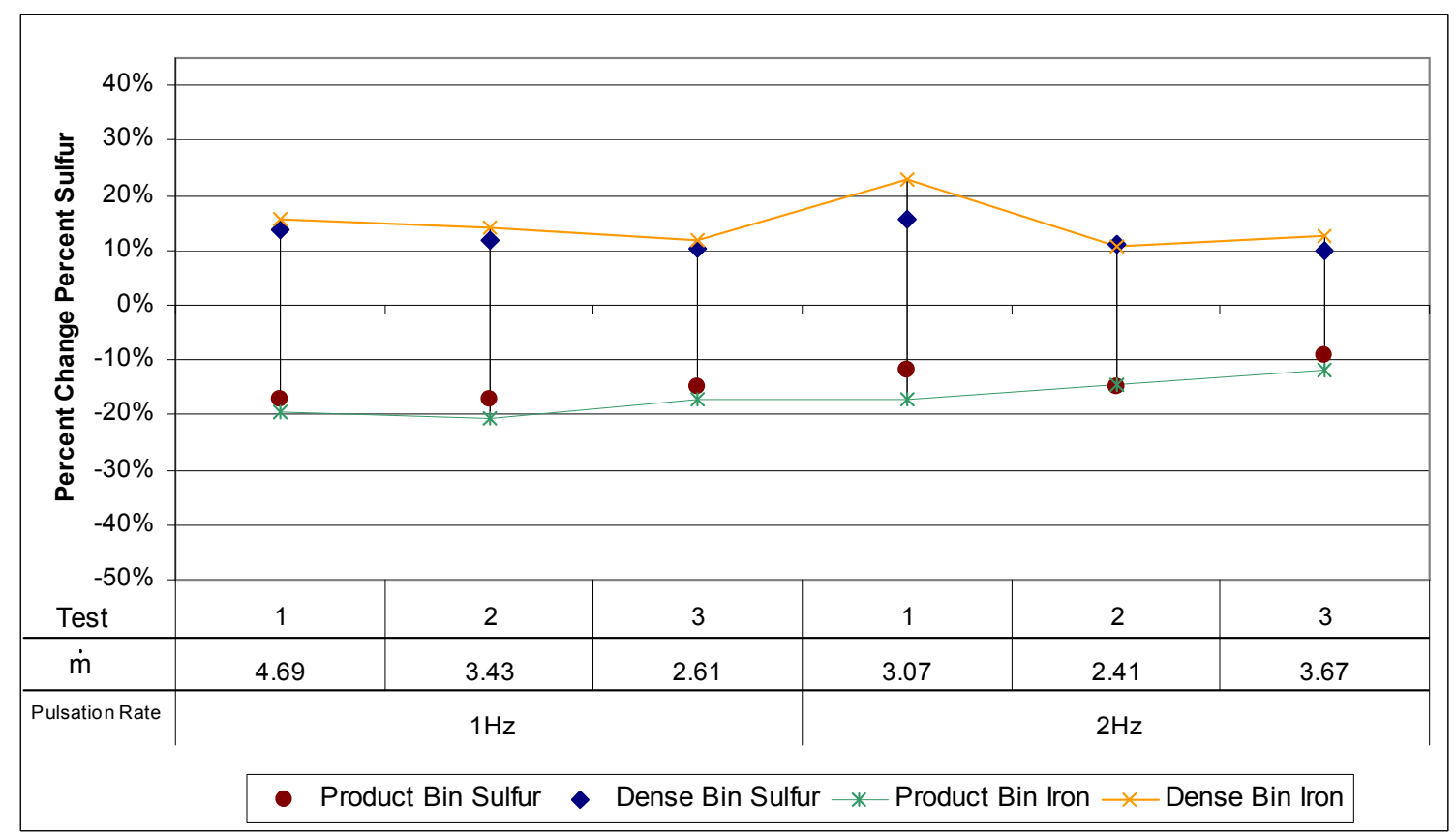

FIGURE C-4: Results from tests with superficial gas velocity $u_{0}=0.8061 \mathrm{~ms}^{-1}$, coal particles $\left(105<d_{p}<210\right) \mu \mathrm{m}$, varying pulsation rates $(1 \mathrm{~Hz}$ and $2 \mathrm{~Hz})$, and grouped Product Bins. This figure compares the percent change of mass percent sulfur to the percent change of mass percent iron for tests with the given flow conditions. 


\section{APPENDIX D: VARIOUS MATLAB CODES}

Code to calculate the terminal velocity of a particle and corresponding particle Reynolds Number.

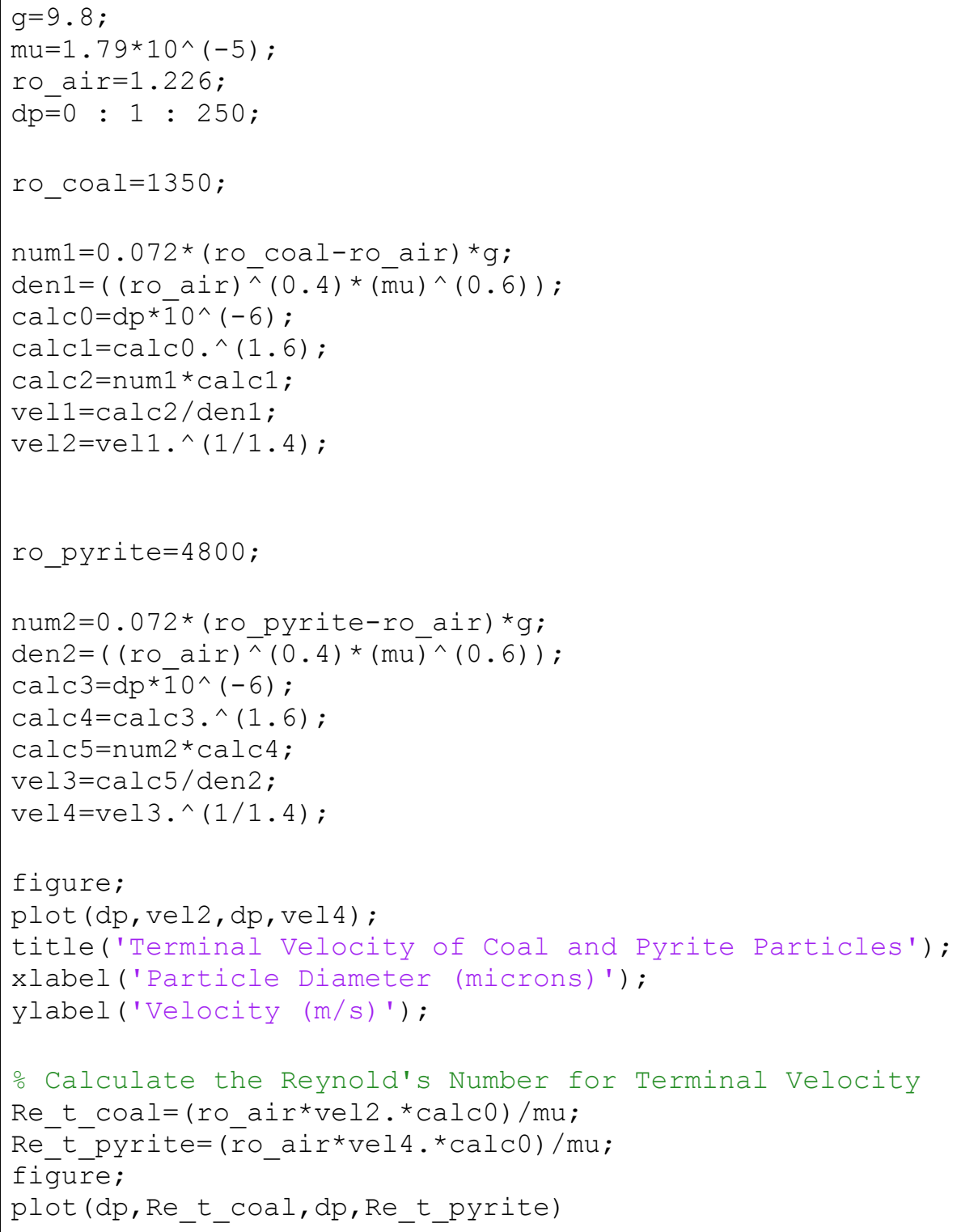


Code to calculate the effect of a particle's percentage of pyrite on the terminal velocity of the particle.

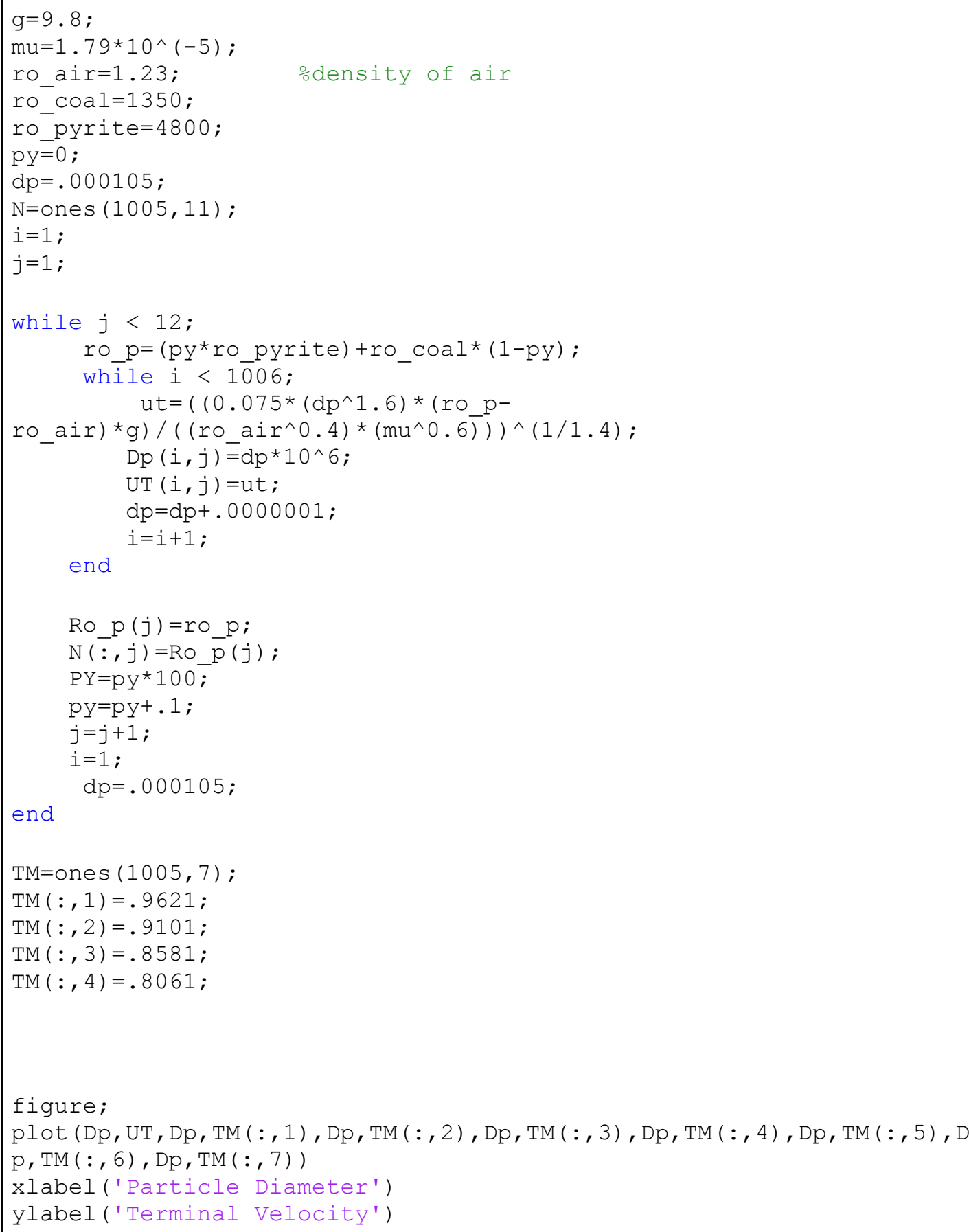


Code used to calculate the flow regime of the riser.

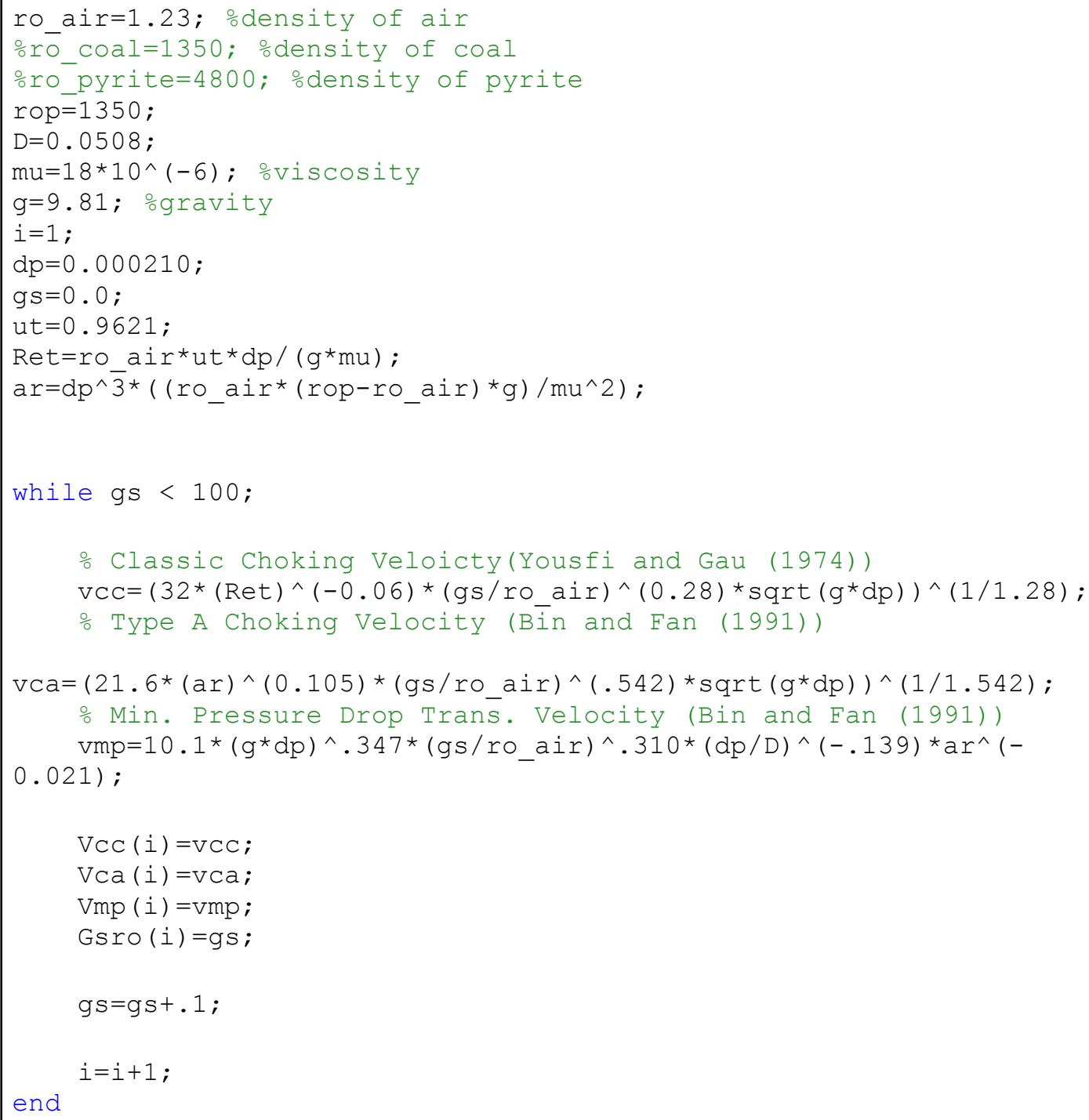


APPENDIX E:

VARIOUS PHOTOGRAPHS

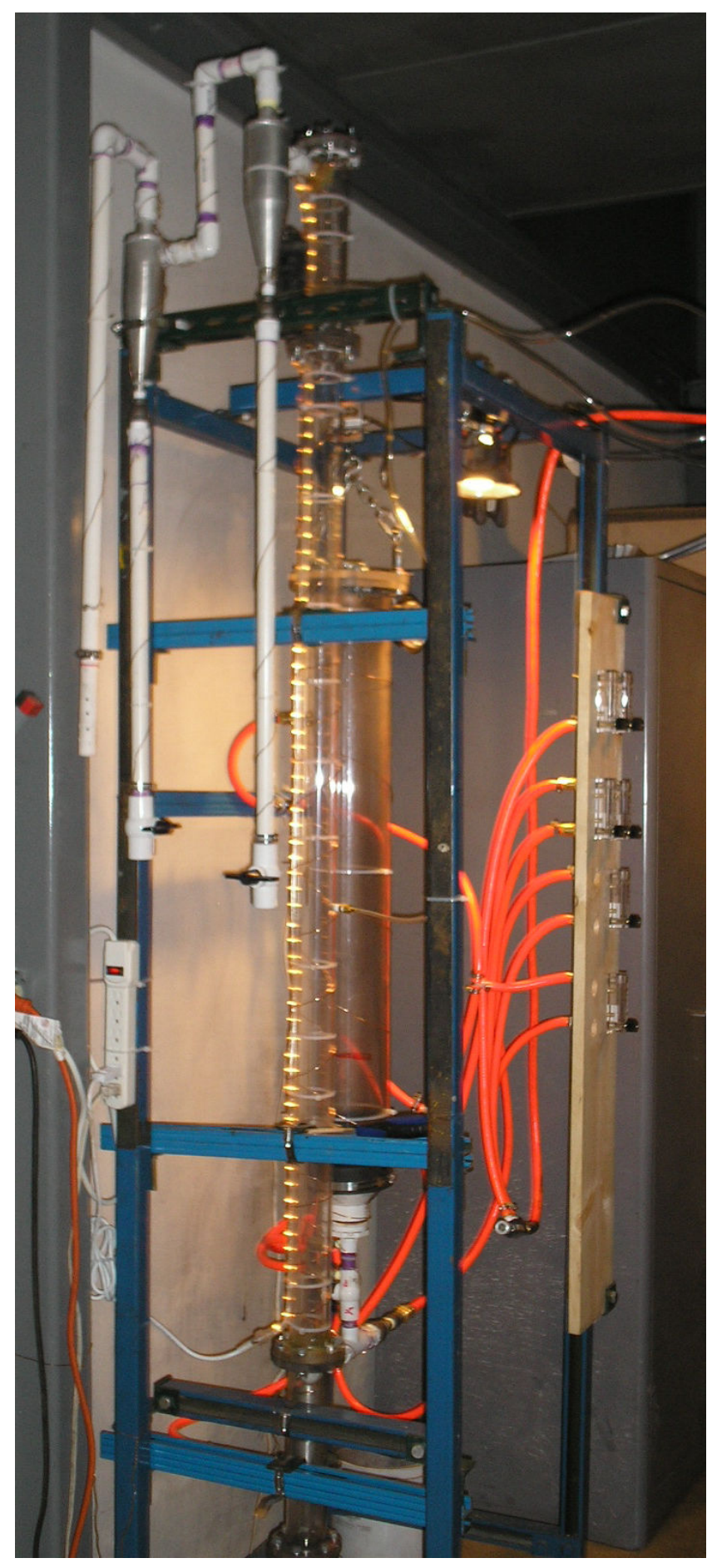

FIGURE E-1: Experimental system 


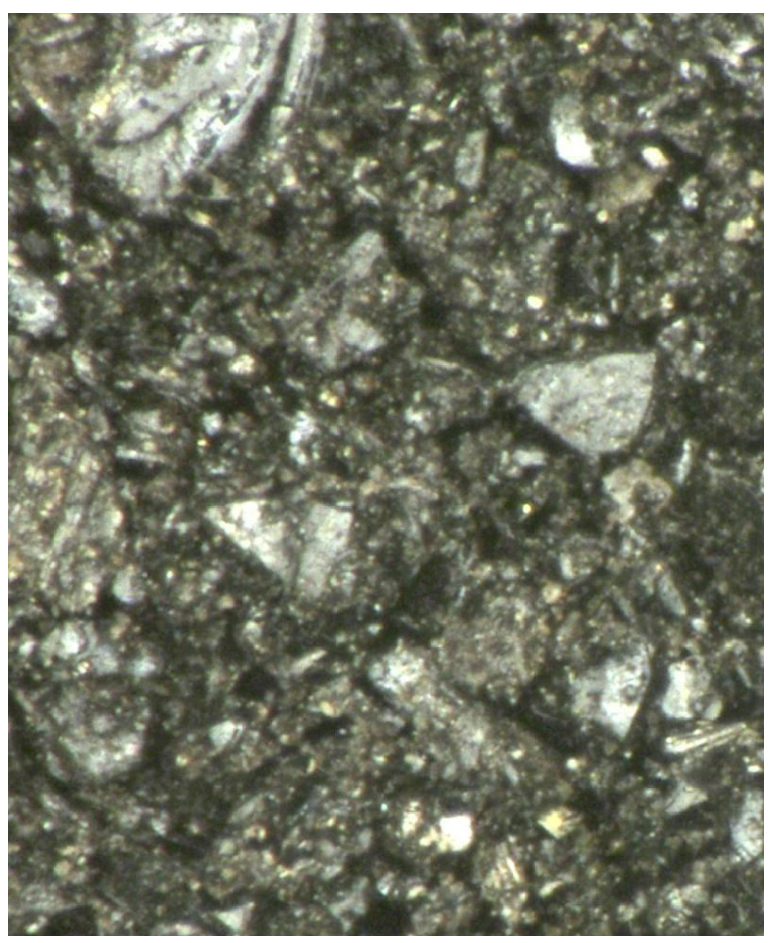

FIGURE E-2: INITIAL MIXTURE SAMPLE (200X) Particle diameter $(105<\mathrm{dp}<210) \mu \mathrm{m}$

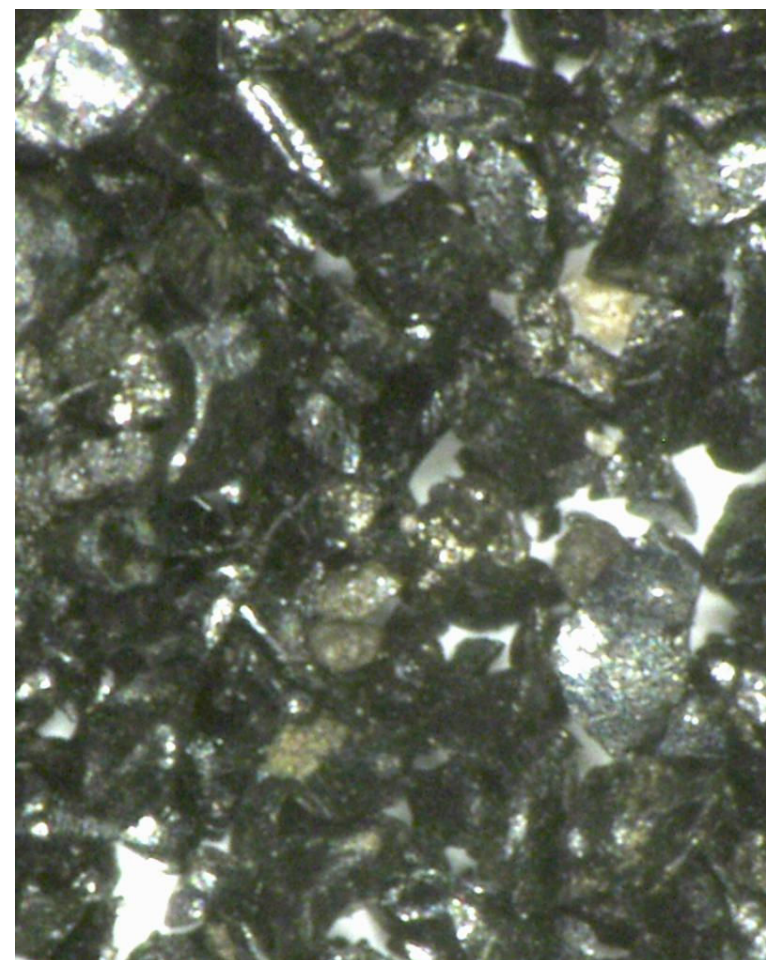

FIGURE E-3: Dense bin sample (200x)

OHz pulsations, $\mathrm{u}_{0}=0.9621 \mathrm{~ms}^{-1}$, Particle diameter $(105<\mathrm{dp}<210) \mu \mathrm{m}$ 


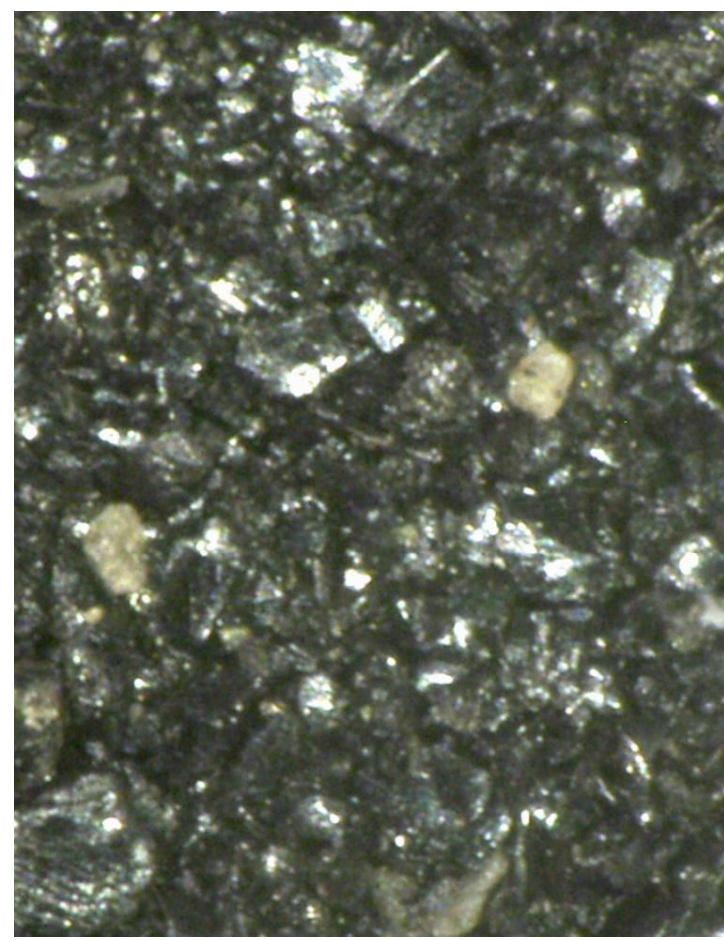

FIGURE E-4: Product bin 1 sample (200x)

OHz pulsations, $u_{0}=0.9621 \mathrm{~ms}^{-1}$, Particle diameter $(105<\mathrm{dp}<210) \mu \mathrm{m}$

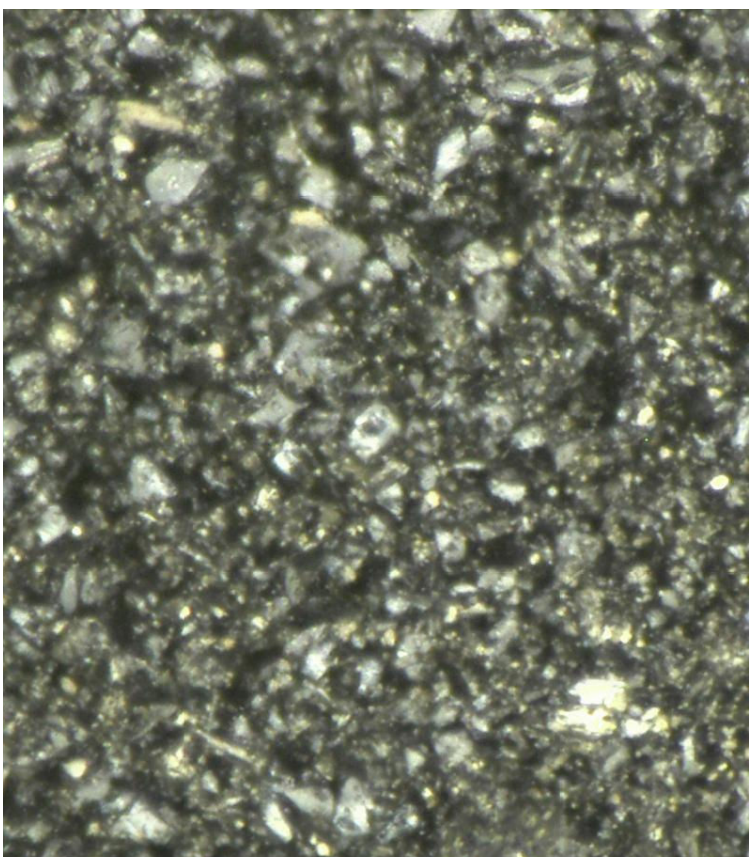

FIGURE E-5: Product bin 2 sample (200x)

$\mathrm{OHz}$ pulsations, $\mathrm{u}_{0}=0.9621 \mathrm{~ms}^{-1}$, Particle diameter $(105<\mathrm{dp}<210) \mu \mathrm{m}$ 